\title{
A RACE AND GENDER GROUP ANALYSIS OF PARTICIPANT EXPERIENCES IN A LEADERSHIP DEVELOPMENT PROGRAMME IN A SOUTH AFRICAN RETAIL ENVIRONMENT
}

by

Clifford Pierre Lewis

Submitted in partial fulfilment of the requirements for the degree Magister Commercii (Industrial Psychology)

in the

FACULTY OF ECONOMIC AND MANAGEMENT SCIENCES

at the

UNIVERSITY OF PRETORIA

September 2011 


\section{FACULTY OF ECONOMIC AND \\ MANAGEMENT SCIENCES}

\section{Declaration Regarding Plagiarism}

\begin{tabular}{|l|l|}
\hline I (full names \& surname): & Clifford Pierre Lewis \\
\hline Student number: & 10336584 \\
\hline
\end{tabular}

\section{Declare the following:}

1. I understand what plagiarism entails and am aware of the University's policy in this regard.

2. I declare that this assignment is my own, original work. Where someone else's work was used (whether from a printed source, the Internet or any other source) due acknowledgement was given and reference was made according to departmental requirements.

3. I did not copy and paste any information directly from an electronic source (e.g., a web page, electronic journal article or CD ROM) into this document.

4. I did not make use of another student's previous work and submitted it as my own.

5. I did not allow and will not allow anyone to copy my work with the intention of presenting it as his/her own work.

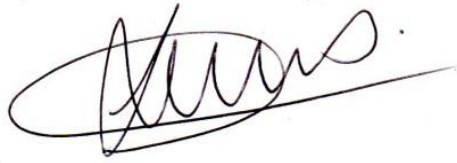

Signature 


\section{Acknowledgements}

To all my classmates - past and present - thank you for all the notes, exchange of ideas and long nights together.

Thank you to my friends and family for your unwavering support. Your faith in my abilities gave me the strength to continue when work and studies at the same time seemed to be too big a challenge.

To my employer, your support and encouragement goes beyond what anyone could expect from someone in your position. While remaining firm and fair, you allowed me access to data and approved time off when I needed it, which is greatly appreciated. Your wisdom and insight into the world of work has been invaluable in my development as a person and as a professional. Thank you for sharing it with me.

My "research assistant" also deserves a great deal of thanks. I use the term loosely, since she was not paid for her assistance but I am grateful for her help with the focus groups. Your help made it so much easier for me to complete this project. Thank you my friend!

Lastly to my research supervisor; you took the concept of constructive criticism to a whole new level. Your thorough work ethic, insight and approachable nature made it an absolute pleasure to complete this work. 


\section{Contents}

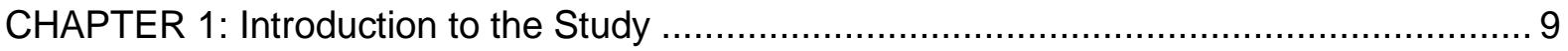

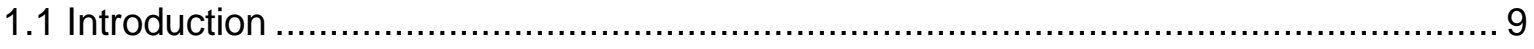

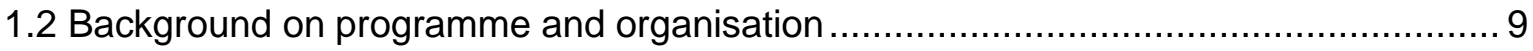

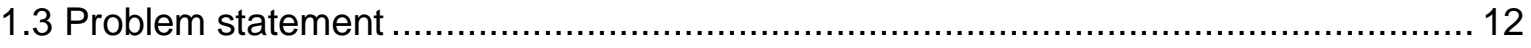

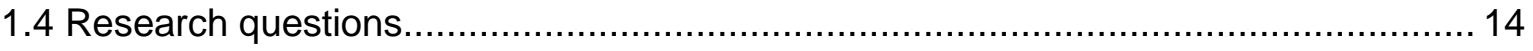

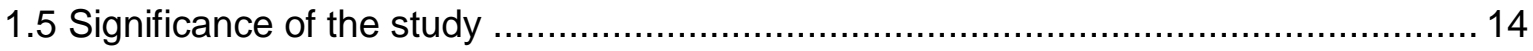

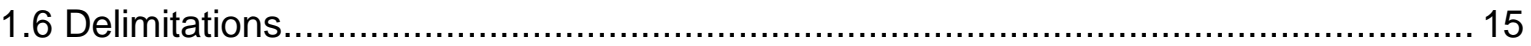

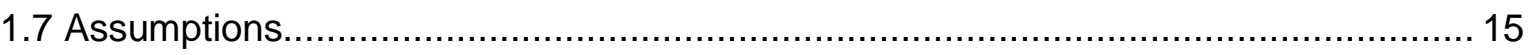

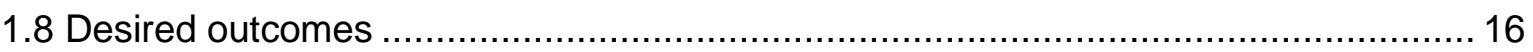

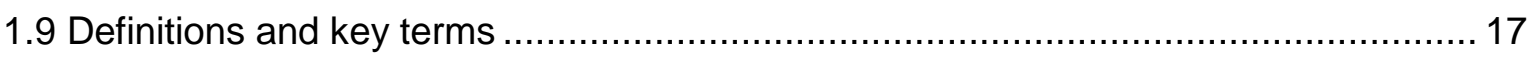

1.10 Chapter overview ............................................................................... 19

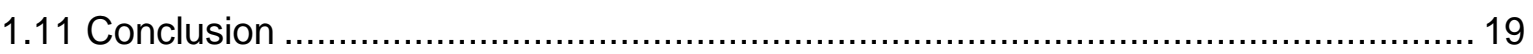

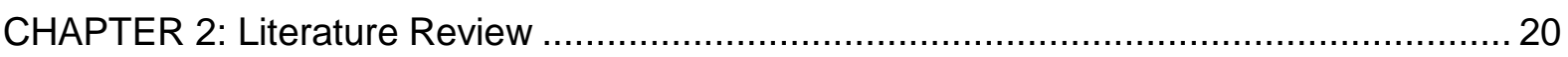

2.1 Organisational leadership development theory .................................................... 20

2.2 Race and gender in leadership development................................................... 24

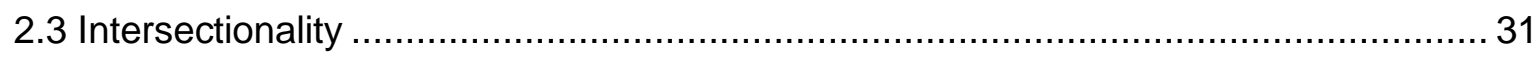

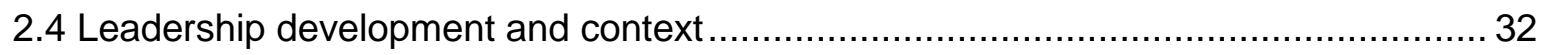

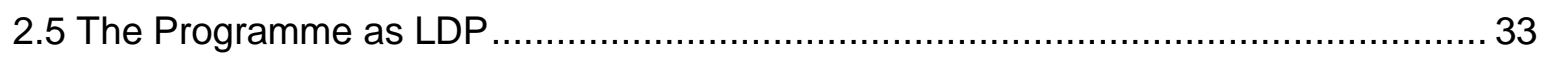

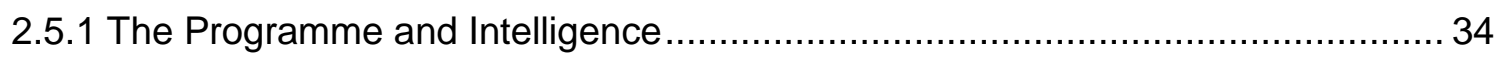

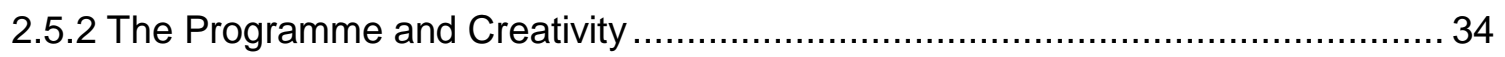

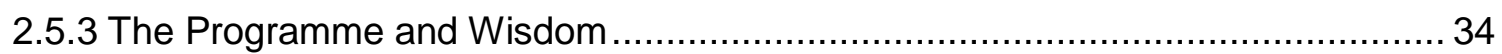

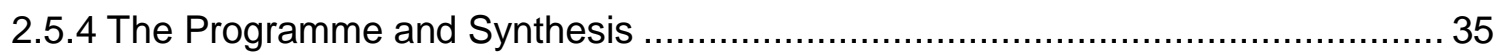

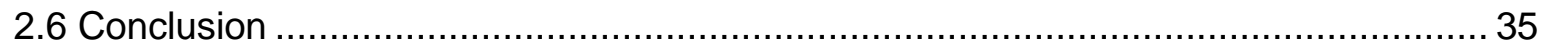

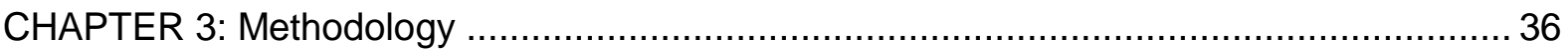

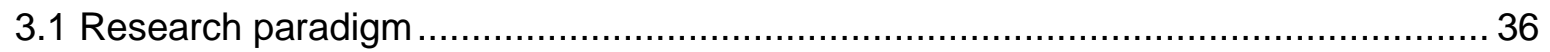

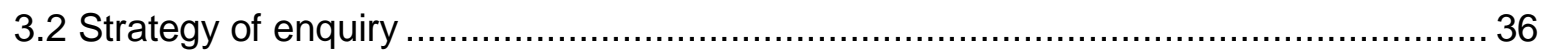

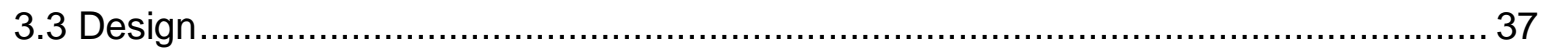

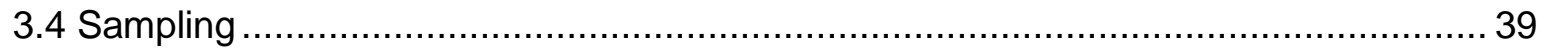

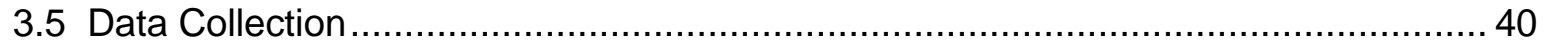

3.5.1 Basic considerations for data collection ........................................................ 40

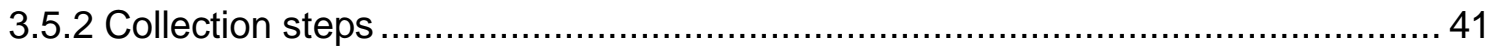

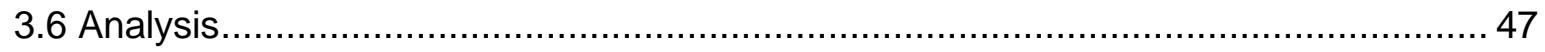

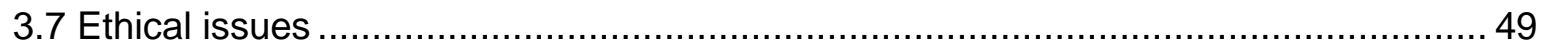

3.7.1 Ethical Issues in the Research Problem ........................................................ 49 
3.7.2 Ethical Issues in the Purpose and Questions ................................................... 49

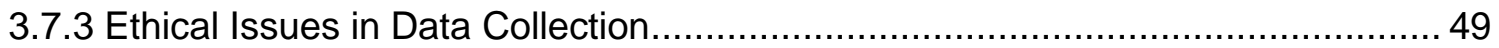

3.7.4 Ethical Issues in Data Analysis and Interpretation ........................................... 49

3.7.5 Ethical Issues in the Writing of Research Results ........................................... 50

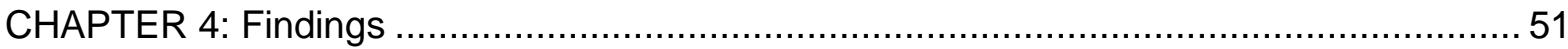

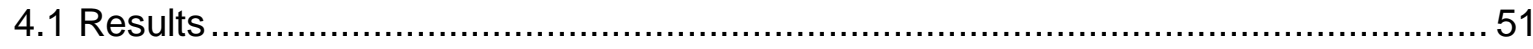

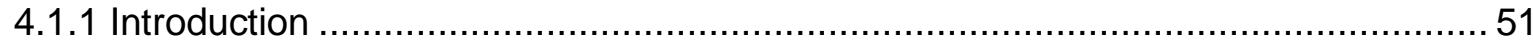

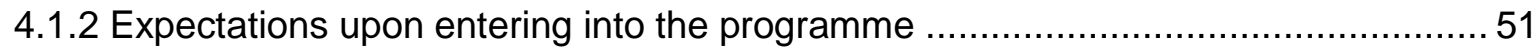

4.1.2 a) Expectation for coaching and mentoring during the programme ................... 51

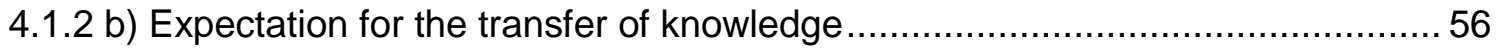

4.1.2 c) Expectation for a more structured approach to learning interventions ..............58

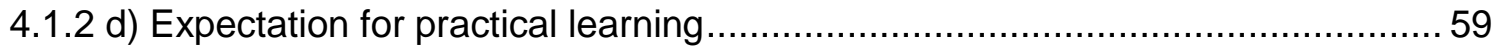

4.1.2 e) Expectation to develop people management skills ......................................61

4.1.2 f) Expectation for a short training period before appointment as manager ...........62

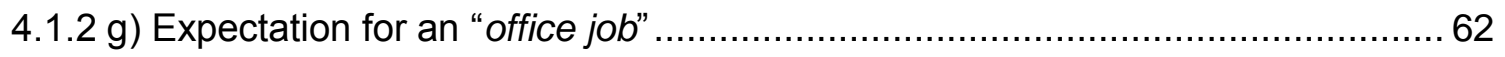

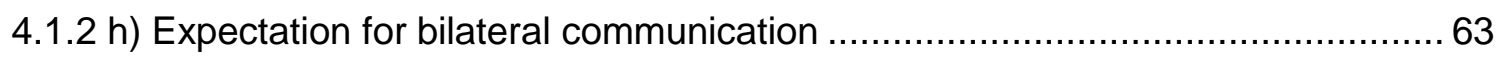

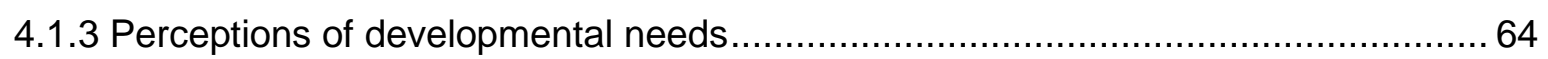

4.1.3 a) Developmental needs not met by the programme ...................................... 64

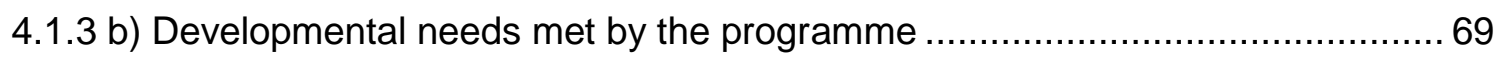

4.1.4 Treatment during the programme .............................................................. 72

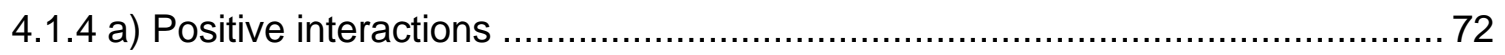

4.1.4 b) Perceived level of influence of own behaviour on situational outcomes .......... 74

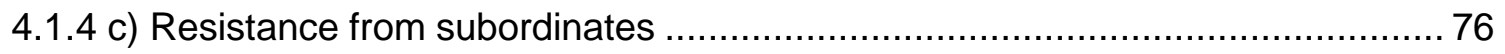

4.1 .4 d) Perceptions of professional jealousy ........................................................ 78

4.1.4 e) Perceptions of differential or equal treatment ............................................ 79

4.1.4 f) Positive interaction with members of a different gender............................... 81

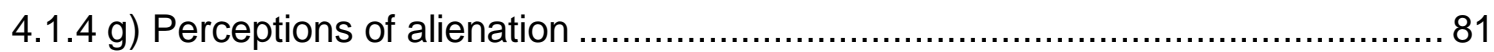

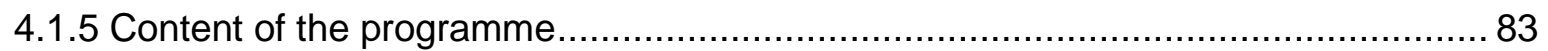

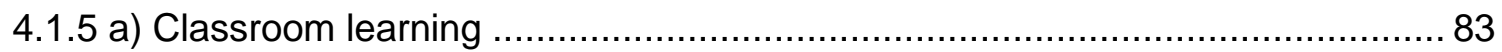

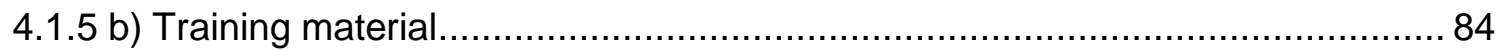

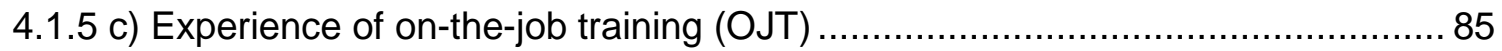

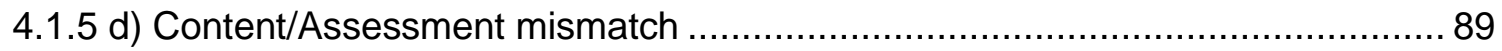

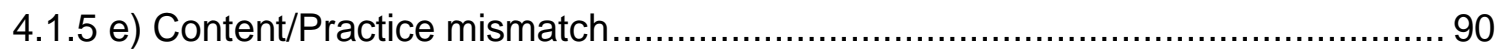

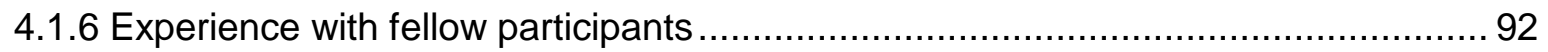

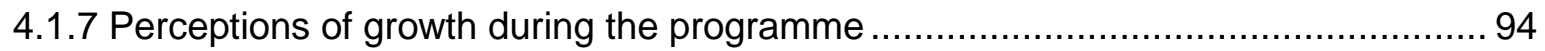

4.1 .7 a) Personal and professional growth ........................................................... 94 


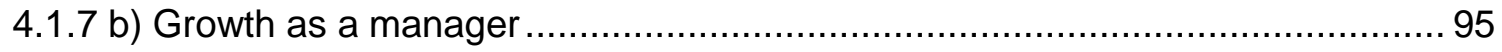

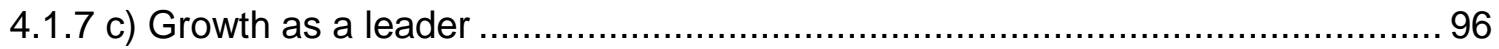

4.1.8 Results from data sampled from exit documentation ....................................... 97

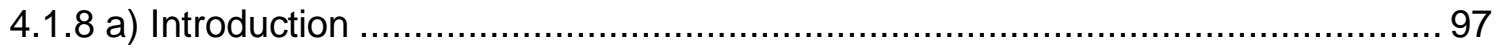

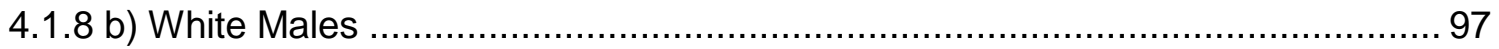

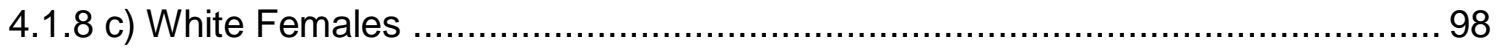

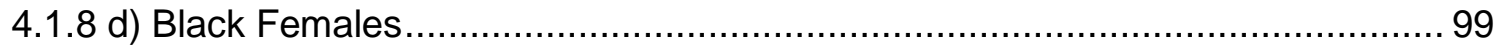

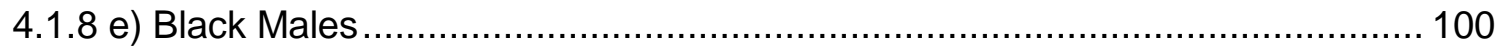

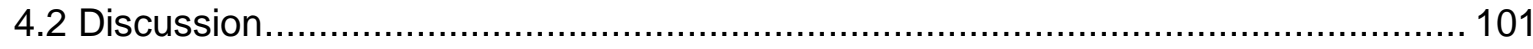

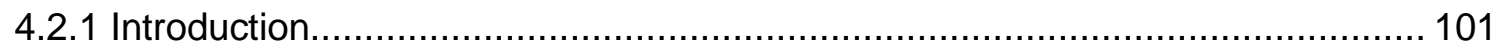

4.2.2 Existing Theoretical Models of Leadership .................................................. 101

4.2.2 Identity as a possible determinant of differential experiences .......................... 124

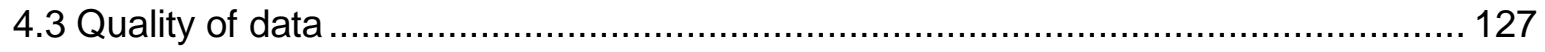

4.3.1 Trustworthiness and Credibility ...................................................... 127

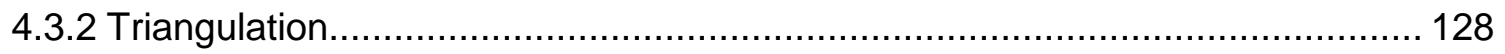

4.3.3 Transparency of methods and Confirmability ....................................... 130

CHAPTER 5: Conclusion and recommendations ..................................................... 131

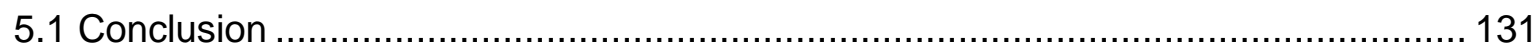

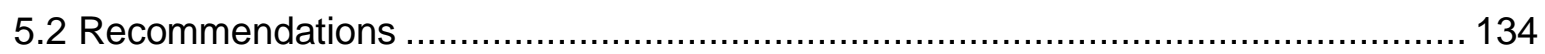

5.2.1 Recommendations for further research................................................. 134

5.2.2 Recommendations for programme improvement .......................................... 135

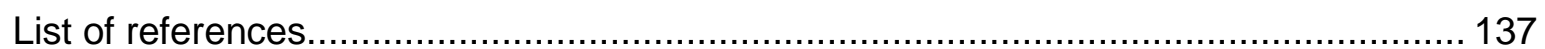

Annexure

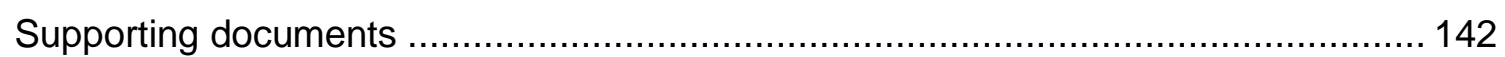

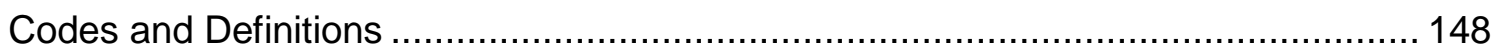

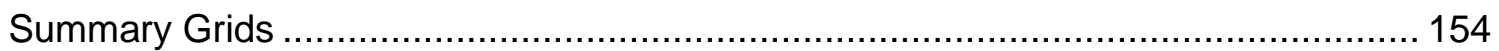




\section{List of Figures and Tables}

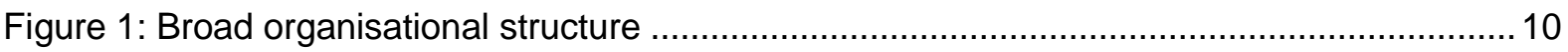

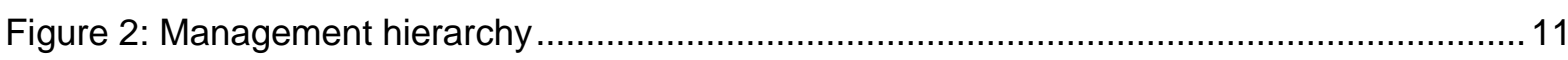

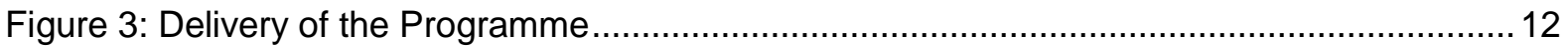

Figure 4: Intersectional gender and race composition of coaches and mentors ..........................26

Figure 5: Programme participant intersectional composition ............................................. 27

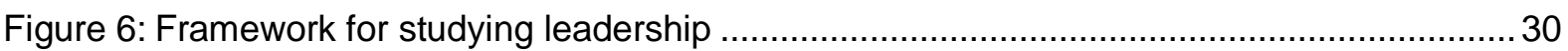

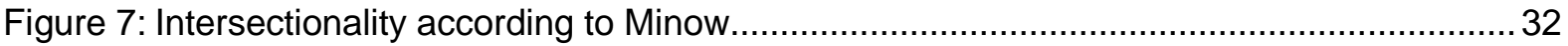

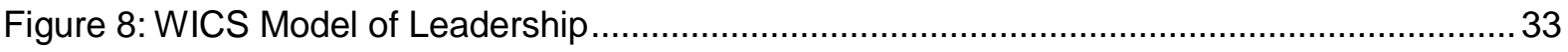

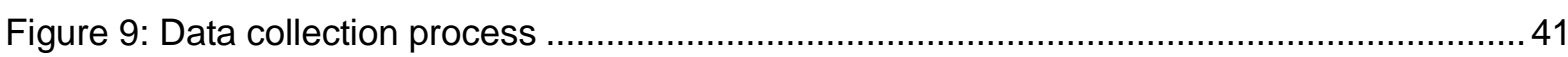

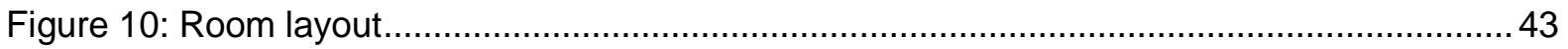

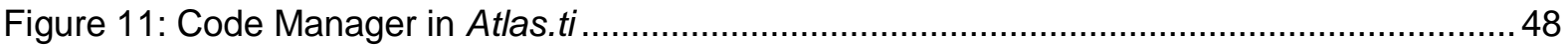

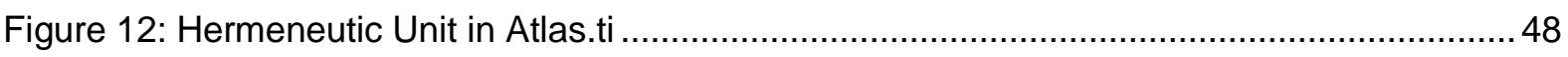

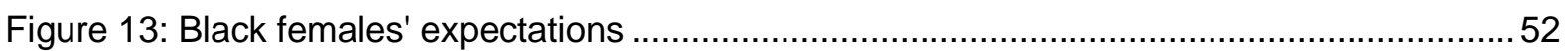

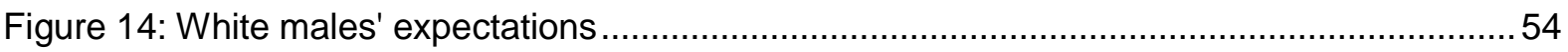

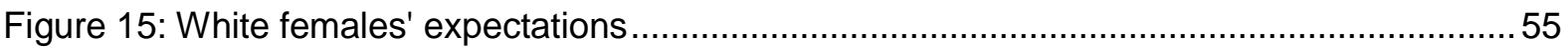

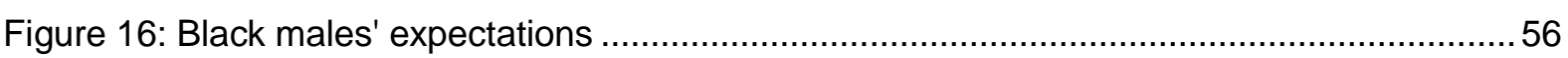

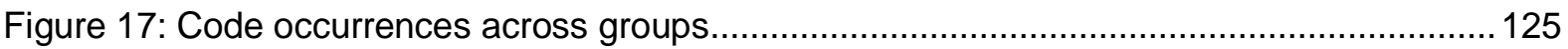

Table 1: Summary of differential outcomes over the last four years preceding this study ........... 13

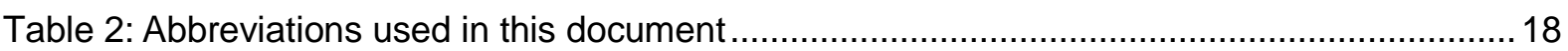

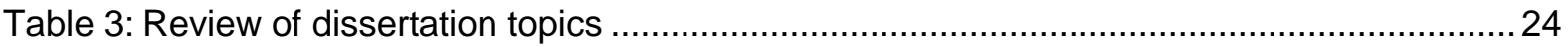

Table 4: Advantages and disadvantages of focus group as data collection method .....................38

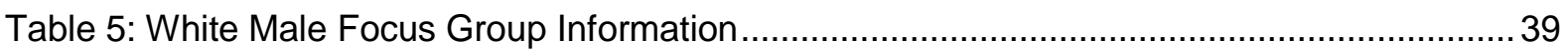

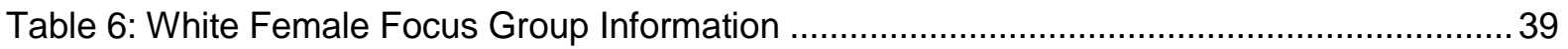

Table 7: Black Female Focus Group Information ................................................................ 40

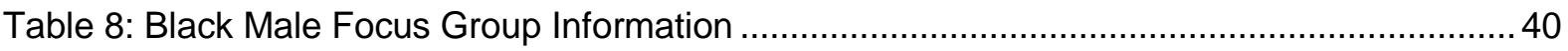

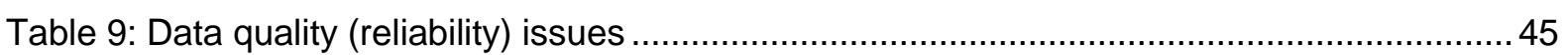

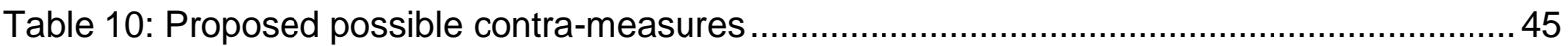

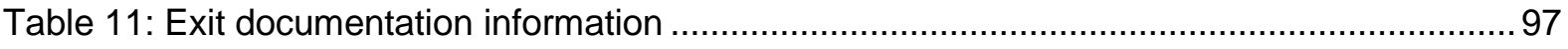

Table 12: Summary of exit documentation data for white males ............................................... 97

Table 13: Summary of exit documentation data for white females .............................................98

Table 14: Summary of exit documentation data for black females ............................................99

Table 15: Summary of exit documentation data for black males .............................................100

Table 16: Summary of development on Wisdom dimension of WICS Model .............................108

Table 17: Diverging factors of identity influencing experience ............................................... 124 


\section{Abstract}

In recent years, much has been written about leadership development as a tool to ensure organisations an adequate supply of leaders. It is generally accepted that said leadership is a set of skills which can be developed by means of a sequence of planned interventions.

To date, however, leadership development theory has failed to recognise the possibility of the differential experiences of individuals from diverse backgrounds. This study examines the possibility of differential experiences in a Retail Group's leadership development programme by examining the perceptions of four race and gender groups who participated in the same development programme.

Data was collected means of series of sequential intersectional focus groups. Responses were gathered with a semi-structured discussion guide, which were recorded by using digital voice recorder and written notes. All recordings and notes were transcribed and imported into Atlas.ti for analysis. Thematic coding was used to identify themes within group responses, as well as across the different groups.

The results indicate support for existing literature. In particular, that of black females possibly being at a "double disadvantage" when included in leadership development programmes, that gender and race shapes how experiences are perceived, and that intersectionality is an appropriate approach when investigating possible differential experiences across groups within a development programme. Group differences, however, were not of such a significant degree that it explained large group differences in success rates on the programme. Nor do the findings justify single identity development programmes. The research did, however, lay the foundation for further inquiry. 


\section{CHAPTER 1: Introduction to the Study}

\subsection{Introduction}

According to Yukl (2010), the fascination with the concept of leadership has only transcended into scientific study in the twentieth century. Since the dawn of 'leadership' as a legitimate scientific field of study, there have been many proposals as to what makes an effective leader, who might be considered as an effective leader, and more importantly what assumptions can be made regarding the development of leadership.

One of the most significant contributing factors to myriad of approaches to leadership, is the fact that a concise, agreed upon, definition of the phenomenon is still not forthcoming. Many scholars have tried to pin down the meaning and implication of the concept of leadership, but because of the close association with terms such as power, authority, management and control, a true and sufficient definition still eludes us (Yukl, 2010). For the purpose of this study, the concept of leadership will be considered as the ability to influence thoughts and direct behaviour in an attempt to reach organisational goals.

One way of attaining organisational goals is to pursue them via the influence of organisational leadership; and further, one way of ensuring that the organisation is supplied with effective leadership is by the development of organisational leadership. Attempts to develop leadership skills are expected to be a key factor in achieving competitive advantage, and organisations should thus have a clear focus on what makes for effective leadership development (Harris \& Cole, 2007).

\subsection{Background on programme and organisation}

The study was conducted in a division of a large retail group in South Africa. The group trades both locally and internationally. Due to its sheer size, the group is divided into many divisions. Divisions may be operational- or support (non-operational), and operational divisions also include some decentralised support functions. Figure 1 shows a basic depiction of the subject Retail Group's structure: 


\section{RETAIL GROUP}

\section{CENTRALISED SUPPORT FUNCTIONS}
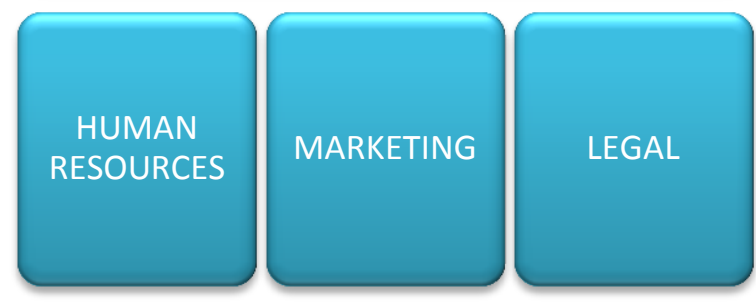

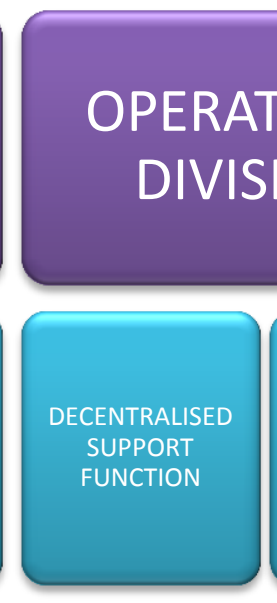

NON-

OPERATIONAL

DIVISIONS

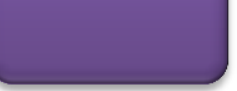

OPERATION

SPECIFIC

SUPPORT

(SUPPLY,

OPERATIONS

Figure 1: Broad organisational structure

In order to manage its massive staff complement, this retail group needs a considerable and competent supply of management. Both micro- and macro influences create the situation where a member of the management team needs to be trained on various technical competencies as well as behavioural competencies. As a result, the company needs to maintain a steady management talent supply line. In an effort to have a standardised framework to develop said managers for its retail outlets, the Retail Group has designed and developed, amongst others, an entry level programme for the systematic enrolment and development of leadership talent. A participant enrols into this programme for a 12-month period in any one of the operational divisions, which prepares participants for their role as assistant managers (all managers reporting to the branch manager) in a retail store. Figure 2 is a graphic depiction of the management hierarchy and indicates where the participant in the programme (trainee manager) fits in and will be appointed after successful completion of the program. 


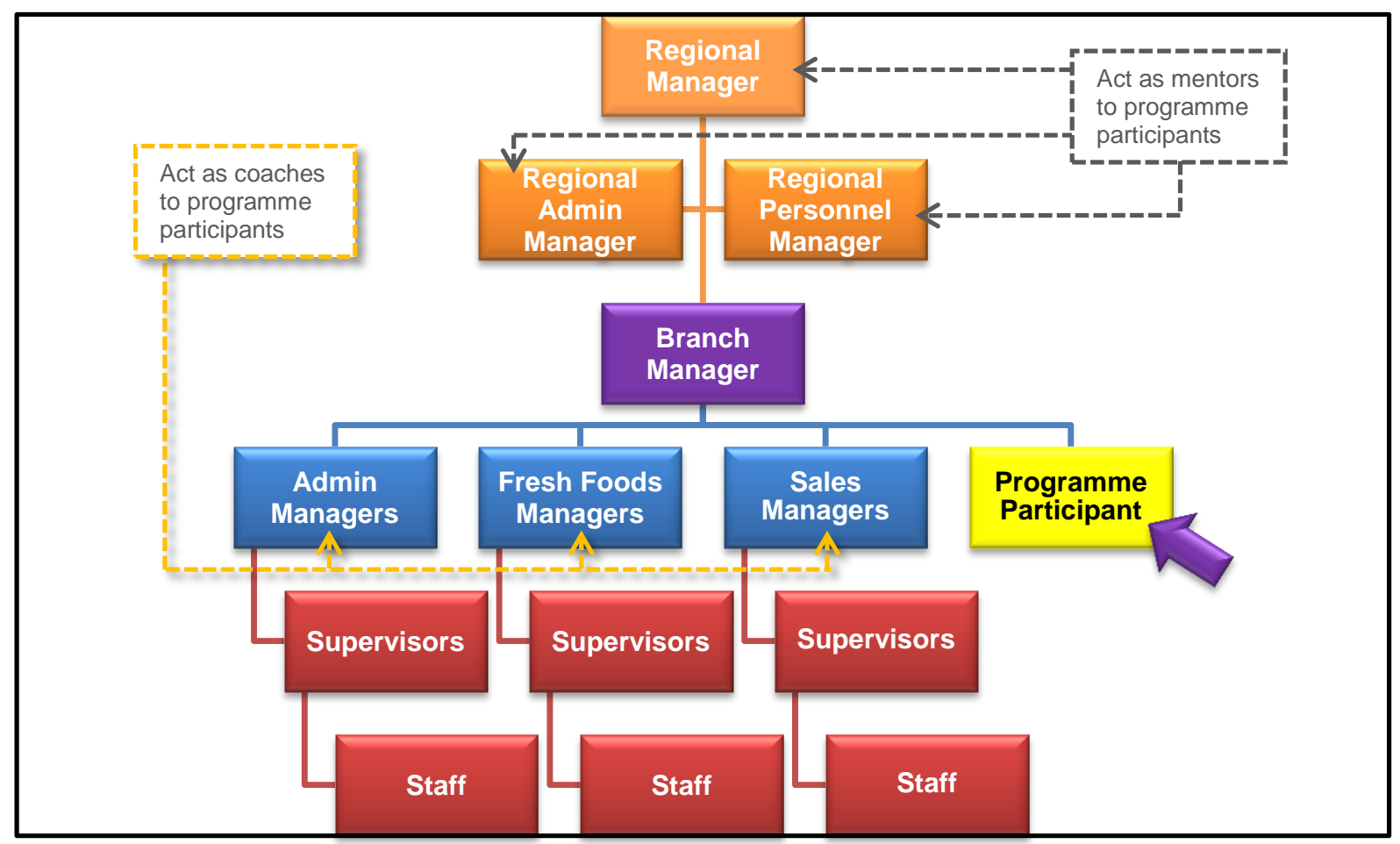

Figure 2: Management hierarchy

The programme is aimed at equipping the participant with the necessary foundational retail knowledge, Retail Group -specific knowledge, practical skills, as well as leadership skills. No one walks into the organisation and immediately becomes a branch manager. One enrols in the programme and after successful completion is appointed as assistant manager, specialising in one department (e.g., administration, groceries, fresh foods, etc.). From assistant manager one will get the opportunity to be promoted to branch manager, from branch manager to regional manager and so forth. This process implies an emphasis on development of skills in an effort to feed the talent pipeline. Entry into this programme has two options. Firstly, one can be promoted from supervisor level into the training programme, or candidates can be sourced from outside the organisation, of which the latter is used more frequently. Candidates respond to an advertisement in print media, write proficiency tests and undergo a competency based panel interview. Success on the test and interview grants the candidate access to the programme.

This programme has various benefits. It provides a standardised guideline for development and assessment activities and therefore minimises the chances of unfair discrimination. It supplies the business with a constant stream of leadership talent, as well as providing competitive advantage as the course is accredited as a (NQF 4) qualification with the W\&R SETA. 


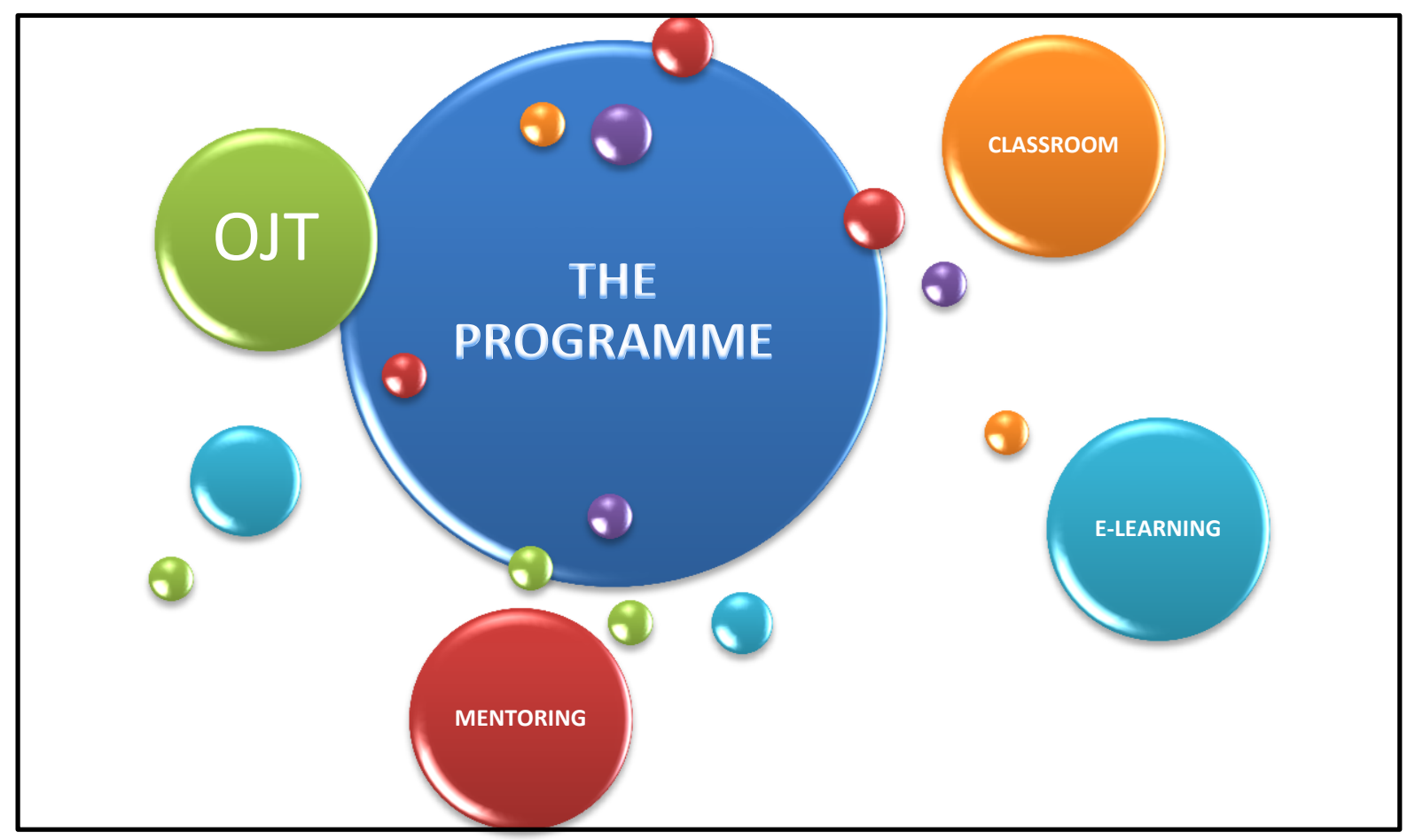

Figure 3: Delivery of the Programme

The programme comprises five main modules which are delivered by means of mentoring, classroom learning, on-the-job training, and e-learning, as indicated by Figure 3. These modules are operationally divided up into: Groceries, Non-food, Fresh-food, Administration and Management. Once a module has been completed (within a predetermined time period) the trainee manager is assessed by a member of the regional team against pre-determined performance criteria.

\subsection{Problem statement}

According to Neely (2009), it is important to recognise that participant perceptions influence the design of a development program. However, to date not much research has been done on the intersectional experience of participants from different race and gender groups enrolled in the same leadership development program. There is a significant amount of literature on women in leadership and previously disadvantaged race groups in leadership (see literature review section), but there is a gap in the body of knowledge regarding participant experiences viewed from a perspective of membership in both race and gender groups (i.e. white females, black females, white males, and black males).

The need to investigate these experiences is supported by the simple fact that even though a development programme is the same for everyone (i.e. standardised), this does not mean that everyone experiences it in the same way, ergo, will not achieve the same 
outcomes. According to Bell and Nkomo (2001), as well as Booysen and Nkomo (2010), gender and race are interdependent and interactive and plays a significant role in giving meaning to social experiences. Research has demonstrated that some race and gender groups face different challenges in management positions compared to those from dominant groups. These differential experiences may influence how different groups experience the development programme as well as the outcomes they receive from participating in it.

The Retail Group invests a lot of resources (monetary and non-monetary) into the development of their future leaders. As the existing literature does not provide sufficient information to use as a foundation for the investigation of differential outcomes on the leadership development programme, this study will serve as a starting point in investigating experiences across gender and race groups. Table 1 is a summary (of the last four years preceding this study) of terminations from the programme, i.e., participants that exited the programme before successful completion, as well as the average duration in the programme (take into account that the prescribed period for successful completion is 12 months). This information was taken from the organisation's central data, stored on SAP. The purpose of this study will be to gather rich intersectional data on the differential experiences of participants enrolled in this specific leadership development programme. This data will illuminate how the different groups experience the programme and their perceptions of its effectiveness in addressing their developmental needs.

Table 1: Summary of differential outcomes over the last four years preceding this study

\begin{tabular}{|c|c|c|c|c|c|c|c|c|c|c|}
\hline STRATA & \multicolumn{2}{|c|}{ BLACK MALES } & \multicolumn{2}{|c|}{ WHITE MALES } & \multicolumn{2}{|c|}{ BLACK FEMALES } & \multicolumn{2}{|c|}{ WHITE FEMALES } & \multicolumn{2}{|c|}{$\overline{\text { TOTAL }}$} \\
\hline $\begin{array}{c}\text { NUMBER OF } \\
\text { ENROLMENTS* }\end{array}$ & 137 & $38.59 \%{ }^{\dagger}$ & 55 & $15.49 \%^{\dagger}$ & 137 & $38.59 \%{ }^{\dagger}$ & 26 & $7.32 \%{ }^{\dagger}$ & 355 & $100 \%$ \\
\hline TERMINATIONS ** & 26 & $18.97 \%^{\mp}$ & 32 & $58.18 \%^{\mp}$ & 21 & $15.32 \%^{\ddagger}$ & 16 & $61.53 \%^{\ddagger}$ & 95 & $26.76 \%$ \\
\hline $\begin{array}{c}\text { AVERAGE } \\
\text { DURATION } \\
\text { (months) }^{*}\end{array}$ & & .99 & & 2.54 & & 5.62 & & .70 & & 21 \\
\hline
\end{tabular}

$\dagger$ Expressed as a percentage of total number of enrolments.

$\ddagger$ Expressed as a percentage of stratum enrolments.

* All these figures exclude trainee managers who are currently still active in the program.

** Terminations exclude terminations due to death. 


\subsection{Research questions}

1. How do participants belonging to different race and gender groups experience the Retail Group's leadership development programme (LDP)?

2. Do participants from different gender and race backgrounds feel that their race and gender affect their experiences in a retail group's LDP?

3. Are there differences in how different race and gender groups evaluate the content of the programme?

4. Do participants from different gender and race backgrounds feel that the programme addresses their developmental needs?

5. Are there differences in how different race and gender groups experience peer interactions within the LDP?

6. Are there differences in how different race and gender groups experience developmental support within the LDP?

\subsection{Significance of the study}

According to Ospina and Foldy (2009), without a proper conceptualisation and understanding of contextual influences (and more relevant to this study, the experience of this context) leadership theory remains essentially incomplete. They also state that leadership and race has not yet influenced mainstream leadership theory, while Valentine (2007) notes that previous attempts at interlocking experiences of various diversity groups have led to practices of "adding" one form of oppression to another, inherently assuming one designated group as base identity, namely white males. This train of thought would then imply that, for example, if a black female is enrolled in a standardised leadership development program, she would be at a "double disadvantage".

However, Anthias and Yuval-Davis (as cited in Valentine, 2007), state that one cannot understand the experiences of an individual belonging to two groups by merely adding theory of the two groups together. Currently, little theory is available on how the intersection of race and gender influences the experience of participants involved in a leadership development programme. Such an understanding is paramount for the development of practical guidelines on how to develop leadership skills in diverse settings. Understanding how race and gender influences participant experiences and outcomes in a LDP are critical in the South African context given the legal mandates for transformation of the managerial workforce. This study focuses on one specific leadership development context and attempts to describe how this context is experienced by members from different race and gender groups. 


\subsection{Delimitations}

One of the main delimitations of this study is the fact that the research was only done in one division of a single organisation. Thus, findings are not generalizable to other organisations. There is, however, the expectation that the findings will be generalizable to the rest of the organisation, as the programme is the same across divisions and the composition of participants are relatively similar. However, by focusing on a single organisation, the researcher was able to control for other factors that could impact the findings. That is, if the programme and contexts participants are enrolled in are not the same, experiences cannot be compared to each other.

Another delimitation was the availability of time to gather data. To gather data for the purpose of this study, the researcher had to engage in focus groups. Participants and the researcher also have challenging workloads which had to be accommodated in the data collection.

Lastly, the researcher's involvement in the leadership programme at hand, may have influenced participants willingness to share their experiences openly. One of the researcher's job requirements is to act as custodian of the programme in the division. There exists a possibility that participants may have felt if they give negative feedback it might impact negative on their own position in the organisation. However, the data do suggest participants were willing to share their experiences openly.

\subsection{Assumptions}

According to Leedy and Ormrod (2005) all research studies are based on some implicit assumptions that are considered as truth without outright investigation. This specific study is based on the following assumptions:

1. Leadership ability is a skill and not an inherent personality trait.

2. Leadership skills can be developed by means of training and development interventions.

3. The Retail Group's LDP programme can be considered as a leadership development programme.

4. Examining participant experience from an intersectional perspective will provide more valuable information than examining experience from a single-identity perspective (i.e., only from a race or only from a gender perspective).

5. Leadership in organisations directs the behaviour of the workforce. 


\subsection{Desired outcomes}

Individuals enrolled in this programme will have to display competence on certain measurable components of leadership in a retail environment. These may include certain theoretical and knowledge based competencies. For instance knowing how to analyse business reports, more soft skills like managing customer service, or more exclusively leadership skills like leading and motivating your team's activities.

Tests and assessments have been standardised for the use of assessors of the candidates. Assessments include written knowledge tests, workplace assignments, workplace observations (conducted by an in-store coach), monthly presentations (presented by the candidate) to the mentor, and a summative assessment by a third party who was not involved in the development process.

Standardising assessment tools and processes may seem enough, and having a concrete structure to work from, but this does not eliminate prejudices that some assessors may hold, or bias that may occur towards certain groups, due to the way assessments are designed. It is also difficult to determine such biases and prejudices from the viewpoint of the assessor or assessment designer. This study suggests that in order to identify and eliminate possible unfair treatment, one must examine individual experiences of the candidates involved in this LDP.

Compensation and Benefits for Law Offices published a news brief in 2007 in which they quote an unknown author in saying that gender stereotypes has as a result the systematic underestimating and underutilization of female leadership talent. As the Retail Group's LDP has assessments that are mostly based on subjective expert opinions, the risk of this type of bias occurring definitely exists. However, if individual experiences are not examined, and then compared cross-group, one will not be able to make informed decisions on how and what to do to avoid such biased behaviour during assessments in this programme.

Ospina and Foldy (2009), however, state that even though there may be differences in gender and race between candidate and assessor, some shared or collective identities may cause individuals to transcend personal interests and perform beyond expectations. Another interesting consideration is that this may not only apply to the candidate. The candidate may very well also have preconceived notions about the mentor and/or assessor they have been assigned to - which in turn will then affect how they behave around the mentor or assessor which will then have an effect on the outcome of the assessment and finally the outcome of the candidate's performance on the programme. But this cannot be said with certainty without examining unique personal experiences. Hence the imperative for this study. 
Lord et al. (as cited in Ospina \& Foldy, 2009), also mention that leaders have the ability to elicit certain behaviours in followers that include:

- change in follower's self-perception

- degree of identification with the leader

- willingness to commit to group initiatives rather than personal ideals

This statement is important for this specific study because all mentors, coaches and individuals conducting assessments also act as some sort of a leader within the organisation, whether it is a branch manager, regional manager. Examining individual experiences and investigating whether or not the leader was able to elicit these kind of behavioural changes in the candidate may offer valuable information on what the impact or the impact of certain parts of the programme had on the candidate.

This study aimed to investigate the idea of universality in leadership development. Data collected and analysed tried to work towards providing insight into how individuals from different gender and racial backgrounds experience a leadership development programme. This proved valuable for both the organisation and individuals since the existing programme has been designed several times over without taking into account different needs and perceptions of various race and gender groups. As the literature demonstrates, if race and gender influence the status and barriers of non-dominant groups in management positions then should organisations use a one-size-fits-all approach to leadership development?

The literature indicates strong deficiencies that exist in leadership development theory pertaining to intersectionality between gender and race, as well as the contextual influences on leadership practice and development. It is proposed that diversity and context should be studied together as the context may (just like the LDP) be experienced differently by individuals from different backgrounds and therefore give different meanings to the LDP. The starting point should therefore be with the individual and their unique experiences.

\subsection{Definitions and key terms}

This paper contains some terms that may need to be defined. Some terms may mean something else in other contexts and some terms may be unfamiliar. What follows are brief descriptions of such terms.

Coaching: The practice of inspiring, energizing, and facilitating the performance, learning, and development of a coachee (Taie, 2011). 
Gender: Gender is a social concept referring to the social construction of biological- and sexual differences between men and women. It is assumed that gender is a social concept and sex is a biological concept (Ratele \& Duncan, 2003, p.179).

Intersectionality: An approach to human experience research that rejects the concept of the separation of different identity categories (McCall, 2005, p.1771).

Leadership: Leadership, in an organisational context, is the ability to influence, motivate and enable others to contribute to the effectiveness of an organisation (House, as cited in Yukl, 2010, p.21).

Leadership development: The act of developing specific leadership competencies by means of a sequence of intentional and structured interventions (Yukl, 2010, p.423).

Mentor: In a vocational learning environment, the mentor is a role model who opens doors, provides insights, guidance, and emotional support, and otherwise brings benefits to the mentee (Lunsford, 2011).

Race: A social construct referring to differences in human beings, based on skin colour, hair type and physiognomy (Henze, 2004, p.312).

Single Identity Leadership Development Programmes: A development programme that caters for a specific group of people, e.g., women, black people etc. (Ohlott, 2002).

Table 2: Abbreviations used in this document

\begin{tabular}{|l|l|}
\hline \multicolumn{1}{|c|}{ Abbreviation } & \multicolumn{1}{c|}{ Meaning } \\
\hline LDP & Leadership Development Program \\
\hline HRIS & Human Resources Information System \\
\hline
\end{tabular}




\subsection{Chapter overview}

In this first chapter an introduction was given regarding the organisation and the programme under scrutiny. The chapter explains the problem that prompted this research project, as well as the desired outcomes this project aims to achieve. Lastly, the first chapter also outlines delimitations, assumptions, the significance of the research and some key term definitions.

Chapter two contains relevant existing literature on this subject. The literature study starts with basic concepts associated with leadership development in an organisational context and then expands into concepts more specifically pertaining to this study. These concepts include race- and gender in leadership development, intersectionality, leadership development and -context, and finally a theoretical model which supports the Retail Group's programme as a LDP.

Chapter three contains an explanation of the methodology used in this research project. The methodology section includes the research design, sampling procedures, data collection methods, the procedure used in analysis as well as ethical issues.

Chapter four shows a representation of the findings as well as a discussion of those findings. This section will discuss the findings in relation to existing literature as contained in the literature review as well as how the research addresses the desired outcomes as stated in the beginning. This chapter will also discuss the limitations of the research and make recommendations for further study into this subject as well as practical recommendations.

\subsection{Conclusion}

This research is exploratory in nature as it aimed to shed light on a phenomenon from a perspective different from ways the phenomenon of leadership development has been researched in the past. This study addressed a current business problem, while at the same time, adding to the body of knowledge by illuminating how participants from diverse backgrounds experience the same LDP. The results should enable the organisation to adapt existing practices in such a way that in takes into account group experiences and to enhance the eventual outcomes of the programme. The existing literature call for more attention to the influence of race and gender in organisations is supported from the results of this study as it provides knowledge about leadership development from a intersectional group experience perspective. 


\section{CHAPTER 2: Literature Review}

\subsection{Organisational leadership development theory}

Modern organisations do not only look quite different from those of even a few years back, but they are also being managed-, and more importantly lead, differently (Schreuder \& Coetzee, 2006). New legislation that promotes 'population representivity' has seen the inclusion of far more diverse participants into organisational leadership development programs. LDP's tend to be standardised for one organisation, business unit or leadership position. If, however, participants in the programme come from a diverse background, should one not ask the following question: How do individuals from a diverse population experience an organisational leadership development program? To understand the theoretical and empirical underpinnings of this question, it is necessary to review the literature on leadership development, particularly literature examining race and gender and leadership development.

There is a wide consensus that leadership, like any other skill, can be developed. Sinclair (2009) states that there has been a great deal of research done on the development of organisational leadership skills, but with most of this research the focus has been on the content and delivery of the intervention itself. There are, however, strong indications that differing personal characteristics and individual traits have an impact on the successful outcome of such a leadership development intervention (Gibson, Ivancevich, Donnely \& Konopaske, 2006; Baldwin \& Ford, 1988). If different personal characteristics have an impact on the successful development of a leader, then it can be argued that diversity, like race and gender, may also have an impact (April \& Shockley, 2007).

Day (2001), in a comprehensive review, examined the state-of-the-art of leadership development. Included in his list of tools to be used are $360^{\circ}$ feedback, mentoring, coaching, job assignments, action learning (which is also referred to in this paper as "experiential learning"), all of which are used in this programme. Day (2001) also adds to this by stating that there is a distinct difference between leader development and leadership development. The programme under scrutiny is focussed on the individual and the assumption that leadership can only realise through efforts of the individual. The programme, according to Day (2001), and therefore be categorised as leader development and not necessarily leadership development. This position strengthens the needs for a study based on individual experiences. If one is to engage in effective development interventions based on the individual, understanding the individual's personal experience during the development process, may yield valuable information.

Focus not only should be given to effectivity during the programme (i.e., individual experience) but also to the outputs of the programme (i.e. return on investment). Avolio, 
Avey and Quisenberry (2010) explored how to estimate the return on leadership development investment and state that estimations on the behaviour and its related outputs should be seen as any other business estimation. The assumption is that organisations invest into leadership development with a desired outcome in mind. It therefore stands to reason that the desired outcome should be measured in relation to what level of investment it took to realise that outcome. Of key importance in the study by Avolio et al (2010) is the concept of effectivity, i.e. are resources being spent effectively to reach organisational goals. This study validates research such as this one, since much like this study did, their model involves having correct assumptions about impacting factors and then probing into the mechanics of the development intervention(s). Ineffective application of resources then imply certain changes be made to the leadership development programme(s). Practitioners sometimes have to come up with creative ways of developing leadership, to gain effective results for their investments. One such an "alternative" means of development is single identity development.

Ohlott (2002) investigated some myths associated with single identity development programs. The results from this paper clearly indicated that there are unique barriers to leadership development associated with specific designated groups, some of which may be overcome by utilising single identity development. One main issue that was identified in Ohlott's (2002) paper is that of self- preservation. Participants explained that if they were in a single identity development intervention they did not feel pressurised to positively represent their race or gender, nor did they feel that their minority status was a negative contribution. According to Locander and Luechauer (2005), these types of fears cause people to protect what they have rather than share resources. Bush (2005) also states that, apart from the self-preservation theme, women also learn differently, and will therefore not experience a standardised development programme in the same way as their male counterparts. Bush (2005) also mentions that the vast difference in professional backgrounds between men and women will impact on how and how fast women develop the necessary leadership skills. The utilisation of single identity development, therefore suggests a focus shift, from self-preservation and other protection mechanisms, to the actual development. 
In a cross-cultural analysis of cultural beliefs and values pertaining to leadership, the GLOBE Project found that some attributes like technical skills rank highly across cultures (in terms of the perception of important skills a leader should possess). However, some personal attributes showed much variation in ranking in terms of importance (Yukl, as cited in Swanepoel, Erasmus, Van-Wyk \& Schenk, 2007). Some of these attributes include:

- Ambition

- Caution

- Compassion

- Dominance

- Formality

- Independence

This prompts the following question: If these personal attributes are considered as differentially important across cultural groups, how does the LDP (that is delivered to various cultural groups) incorporate it into or exclude it from the developmental process, in order to achieve the developmental goal?

Race and ethnicity influences behaviour and experiences because it shapes the way in which the individual, belonging to a specific racial group, perceives the world (Ospina \& Foldy, 2009). According to Andersen, Collins and Holvino (as cited in Booysen \& Nkomo, 2010), however, the influence of race and gender converge and exert a joint effect on the individual in a professional situation. Because of this, the effects of these concepts should not be viewed in isolation, but rather from an intersectional perspective which is discussed more fully later in this review. If gender and race have a combined effect on world view and behaviour, it might be necessary to investigate the need for different approaches in development as well. Ohlott (2002) states that focussing development initiatives individually per group (i.e., black males, white males, black females, white females) may create an environment that is more conducive to learning and development as opposed to a mixed group. These groups, however, should not exclude the opportunity for intersectional investigation.

Now consider these barriers and compare them to some of the preferred attributes of leaders identified by GLOBE as important for some cultural groups in the following (hypothetical) example: A young female is enrolled in an organizational leadership development program. She values caution and compassion in someone in a leadership position and acts accordingly. Her colleagues, however, see this behaviour as "typically female" from their perspective (because they are of the opinion that leaders should be dominant and ambitious) and stereotype her as "weak". As a result, they exclude her from informal communication networks as they do not think she has anything of value to add. 
This comparison of the attributes identified by GLOBE, and the common barriers to organizational advancement prompts the following question: Do these barriers directly hinder organisational advancement, or do they indirectly hinder development by infringing on values and beliefs through unique experience, which then in turn affect the individual's possibilities for advancement? The relevance of this question is supported by Zhang and Bartol's (2010) statement that individuals use role identities to create cognitive schemas that gives meaning to events and subsequently channels behaviour. This position is also shared by Ospina and Foldy (2009), who said that one's concept of race (one's own and others) affects how you structure and represent your experiences to give meaning to the world. They add that, in the past, when studying leadership, race has always been treated as a special case, instead of a source for theorizing about the experience of a phenomenon. In addition to this, current social policies advocating equal and representative "inclusion", tend to overlook what exactly it is that these excluded individuals should now be included into. These approaches then ignore or essentially "wash out" key attributes of the designated group (Burman, 2004). One such attribute would be the individual's unique experience in a LDP.

It is not enough to merely "legitimise" individual experiences from a diverse background, based on limited ideas about race, culture and ethnicity. Riviere (2005) suggests that in a learning environment, these experiences must be realised in the sense that they must be made real through understanding of that individual's experience. This understanding can only occur if individual experiences are investigated as phenomena to build a body of knowledge from which new theory can be developed. Consider Table 3. Rusch (2004) conducted a study regarding gender and race in leadership development. The table indicates available research (in dissertation form) on various issues surrounding leadership and leadership development. More recently Ospina and Foldy (2009) echoes the same sentiment in their review of existing leadership literature. The low volumes on leadership, gender and race is a definite indication of the knowledge gap pertaining to this phenomenon. 
Table 3: Review of dissertation topics

\begin{tabular}{|l|c|}
\hline \multicolumn{1}{|c|}{ Topic } & Number of dissertations \\
\hline Leadership & 11268 \\
\hline Leadership and education & 3513 \\
\hline Leadership and schools & 2559 \\
\hline Leadership on gender or race or diversity & 1764 \\
\hline Leadership and principals & 1608 \\
\hline Leadership and superintendents & 557 \\
\hline Leadership and gender & 650 \\
\hline Leadership, schools, and gender & 255 \\
\hline Leadership, principals, and gender & 245 \\
\hline Leadership, superintendents and women & 94 \\
\hline Leadership, superintendents and gender & 93 \\
\hline Leadership, schools and diversity & 73 \\
\hline Leadership, superintendents and race & 9 \\
\hline Leadership, superintendents and minority & 12 \\
\hline Leadership, race women and schools & 9 \\
\hline Leadership preparation and gender & 4 \\
\hline Leadership preparation and race & 0 \\
\hline
\end{tabular}

Adapted from Rusch (2004)

\subsection{Race and gender in leadership development}

According to Bush (2005), the past few decades have seen a significant increase in women entering the workplace, however, there is still a significant under-representation of women in senior leadership positions. At the same time, there has been a slow increase in previously (and currently) under-represented groups in the workplace. For example in South Africa, the 2008-2009 report of the Employment Equity Commission showed that whites males and females held $72.8 \%$ while Blacks, Coloureds and Indians held $24.2 \%$ (the remaining $3 \%$ were held by foreign nationals) of top management positions. The $2010-2011$ report indicated a similar situation, where $73.1 \%$ of top management positions are held by white individuals and $81.1 \%$ of top management positions being held by males.

Gender equality progression has also been relatively slow in South Africa. The continued slow progress of women advancing into management has been documented annually in the Business Women's Association of South Africa Corporate Census (BWASA Census, 2010). Research is consistent in demonstrating that both women and the 'historically disadvantaged' (Blacks, Coloureds and Indians) in management positions continue to experience some barriers that affect their careers and advancement (e.g. April \& Torun, 2006; Heilman, 2001; Fauconnier \& Mathur-Helm, 2008; Eagly \& Carli, 2007). 
Research by Catalyst and CLC (as cited in Killian, Hukai \& McCarty, 2005) identified five primary barriers to advancement in organisations experienced by leaders from 'historically disadvantaged' group:

- Lack of role models

- Exclusion from informal communication networks

- Stereotyping

- Lack of challenging assignments

- Commitment to family responsibility

A possible consideration when faced with differences in terms of how groups perceive leadership in an organisational context, and what styles may be more desirable, is that of norms. Norms are defined (in this context) as a code of conduct by which groups gauge what is considered as acceptable behaviour (Marckwardt, Cassidy \& McMillan, 1998). According to Chatman (2010), these societal norms can be descriptive, in the sense that the merely describe and explain group behaviour, or be prescriptive, where they are used as strong influences of group behaviour. Chatman (2011) cites various existing literature (Bell, 2007; Chatman \& O’Reilly, 2004; Kearney, Gebert, \& Voelpel, 2009; Van Knippenberg \& Schippers, 2007) and continues to explain that diverse backgrounds (in this case different gender and race groups) may bring with them differing norms which could negatively impact on the intra-group trust, motivation to work together as well as lead to distractions.

At the same time, the literature on gender has also demarcated the challenges women in leadership- and management confront. For example; a number of studies (April \& Torun, 2006; Fauconnier \& Mathur-Helm, 2008; Eagly, \& Carli, 2007; Heilman, 2001) report gender stereotyping, exclusion from networks, challenges to authority, and over- placement in staff positions. Clearly, both race and gender create differential experiences and outcomes in organizations. Because of the continued presence of these barriers, Bush's (2005) sentiments are reminiscent of those of Ohlott (2002), in advocating single identity development. Ohlott (2002) is also of the opinion that development programs that are standardised and presented to a mixed group put certain individuals at a disadvantage as their main priority becomes self-preservation (i.e. protection from stereotyping and ridicule) rather than the development of their leadership skills. Debebe (2011) also advocates for this assertion when citing various authors (Edmondson, 1991; Mezirow, 1991; Kolb \& Kolb, 2005) in saying that development interventions may fall prey to internalised stereotypes and (gender) roles, if they do not take into account whether or not the programme participant perceives the learning environment to be "safe" or not. Further aggravation to this situation comes when assessing developed skills. One should also consider that being white and male hardly ever gets taken into account when conducting a leadership development program. It might be taken into account with recruiting and selecting candidates based on 
affirmative action, but not during the development process. Why is it then that gender and race only become an issue during movement towards individuals that are not white middle class males? Is it perception-based? Are organisational policies at play? Could it possibly be a deficit in the theory?

Valentine (2007) proposes a skew in how theory on gender (specifically referring to feminist theory) has been constructed over the years, but according to Lyons, McArthur and DeVries (2007) not even HR policies advocating and attempting to regulate fair and equal treatment, when it comes to leadership evaluations have an impact. The perceptions of stakeholders regarding gender are the most significant influence on performance evaluations. Lyons et al. (2007) note that the literature reveals leadership to be predominantly viewed as a masculine role. The implication of this is that "good leadership" is then associated with stereotypical male behaviour, to which females may be expected to adapt. Their (females) performance may also be evaluated according to gender expectations - they are therefore seen to need to "overcome" their gender in order to perform effectively as a leader. Taking this into account, one should also consider existing literature of the dynamics between coach/mentor and student, especially dynamics in these relationships where there may be gender and racial differences.

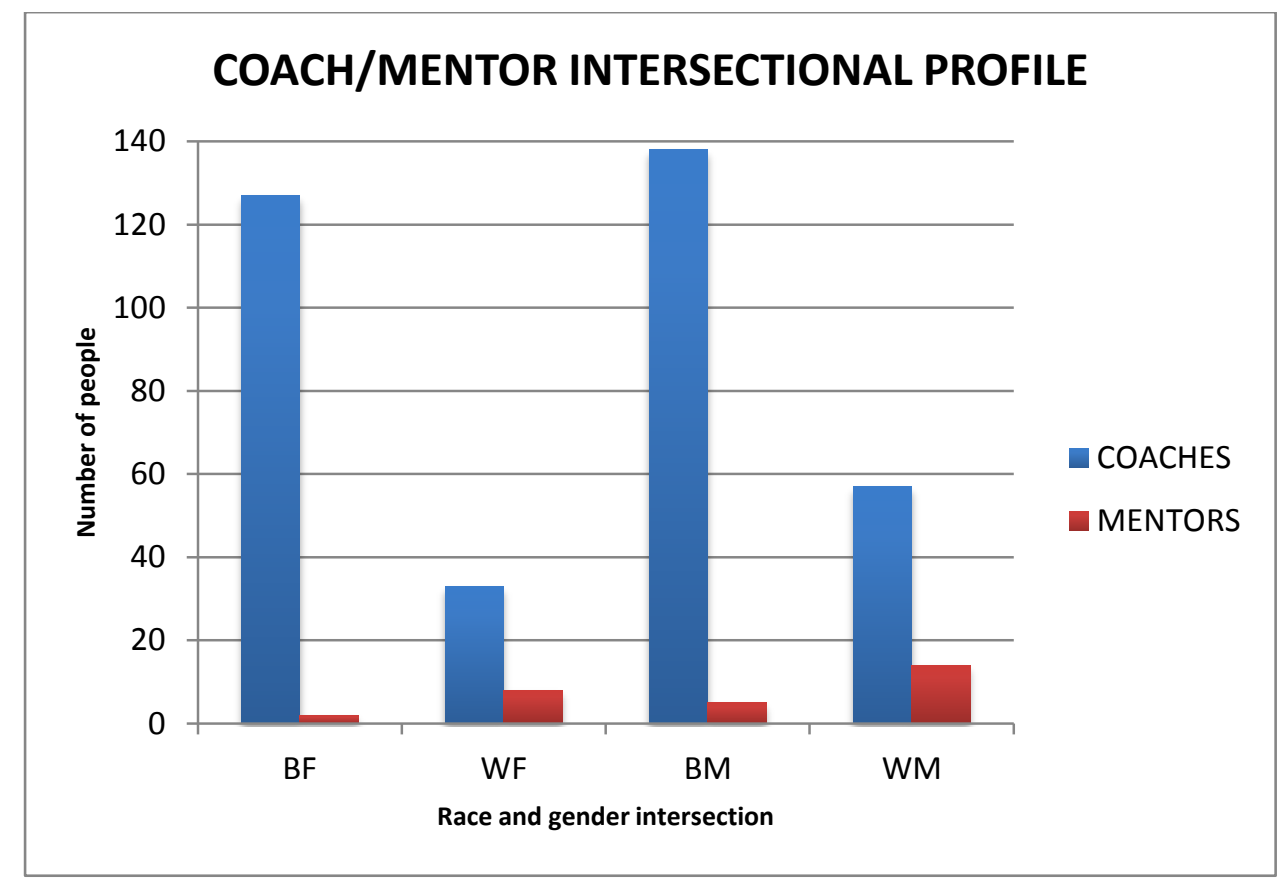

Figure 4: Intersectional gender and race composition of coaches and mentors

Figure 4 is a graphic depiction of the intersectional gender and race composition of individuals assigned to act as coaches and mentors to programme participants. At coach level, whites seem to be underrepresented and at mentor level blacks, especially black 
females seem to be underrepresented. However, when considering representivity in terms of coaching and mentoring, one must also take into account the composition of participants. Figure 5 is a graphic depiction of the intersectional (gender and race) composition of programme participants enrolled into the programme over a period of the last four years. This composition, compared to the coach/mentor composition indicates that the current coach complement is in line with the composition of programme participants in terms of representivity, but that mentor composition (profile) is not in line with the programme participant profile. The literature (Thomas, 1989; Blake, 1999) indicates that differences in gender and race may lead to problematic mentoring relationships. This is especially the case for women as the mentee, being assigned to a male mentor. The data was therefore also scrutinised for possible evidence of this occurrence.

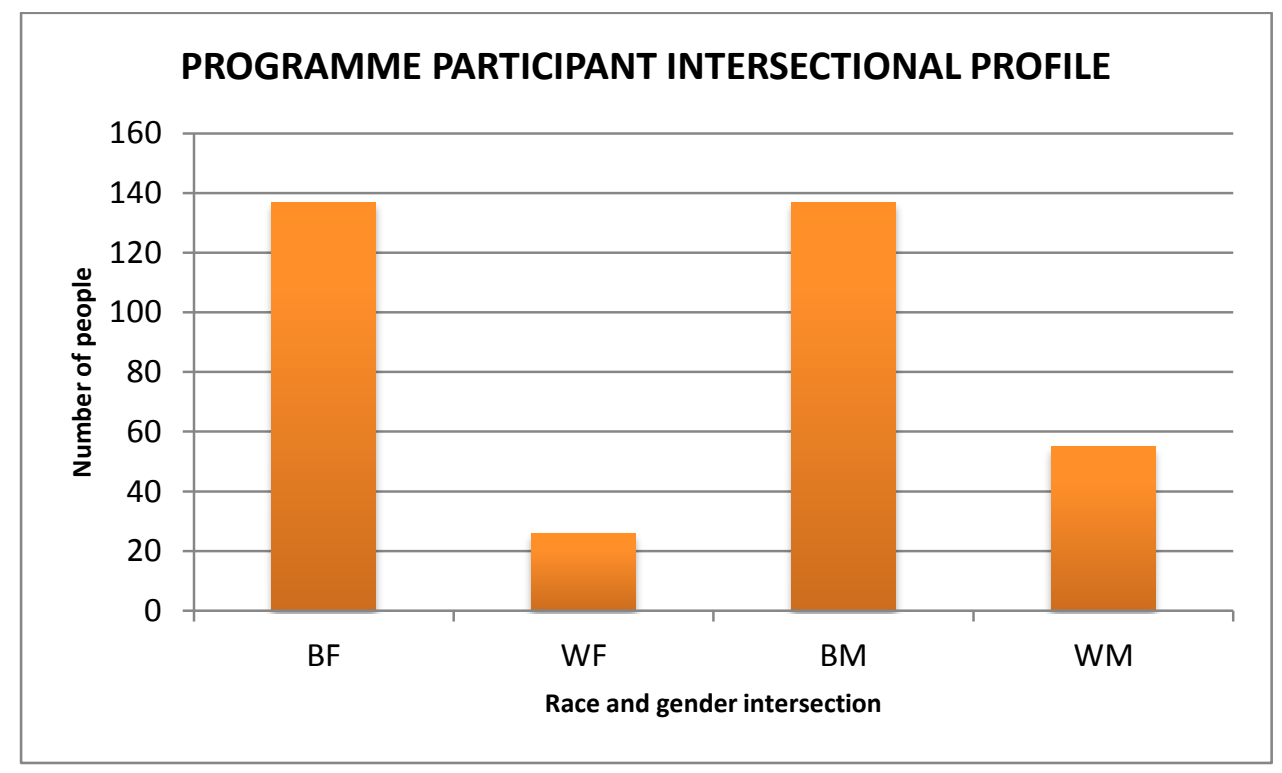

Figure 5: Programme participant intersectional composition

From a positive perspective, Debebe (2011) suggests that making use of all-women training and development groups and gender-sensitive learning practices are conducive to bringing about leadership transformation. From a more negative perspective, Chatman (2010) proposes possible distrust between participants as well as participants and coaches/mentors. Chatman (2010) suggests that differing psychological conditions, coupled with the minority group factor, questions regarding authenticity in feedback may arise. Simply ignoring all forms of diversity and presenting and assessing a LDP irrespective of unique attributes, however, is not the answer. If one considers race, Davis, Galinsky and Schopler (1995) state that if a diverse group converges for a common purpose (in this case to complete a leadership development program) and the approach is "colour-blind", it denies the significance of race and that groups may have different developmental needs. Davis et 
al. (1995) also proposed a framework for leadership within a multiracial context. The framework proposes that a successful leader must be able to recognise the critical importance of racial differences and the effect thereof on the group, anticipate possible causes of racial tension and mitigate the effects thereof, as well as solve problems that might arise from issues of racial tension. The framework in short is therefore also called the "RAP" framework. I suggest, however, that the "RAP" framework is not only applicable to racial differences when it comes to leadership development, but that a LDP should (a) recognise, anticipate and problem solve all kinds of diversity issues (especially in a South African context), as well as (b) enable the leader who is being developed to be able to recognise, anticipate and problem solve issues of diversity.

As mentioned earlier, one's diverse background provides a framework from which to make sense of social interactions (Ospina \& Foldy, 2009). Therefore, who you are, dictates what you are experiencing, to a relative extent. Davis et al. (1995) also mentions that allocating less attention to racial differences in groups is not due to motivations discriminatory in nature, but rather due to the fear of increasing racial tensions. A kind of a "let sleeping dogs lie" mentality. This may explain why South African organisations appear to make little use of single-identity training and development programmes. However, ignoring race differences may do more harm than good. As Davis et al. (1995) points out, ignoring racial issues have an ever higher probability of increasing racial tensions. In additional to possible tensions related to racial differences, Debebe (2011) also explains that gender is a socialization process that starts at birth and forms feminine and masculine identities, of which most organisations favour the latter in leadership positions. This is a cause for great concern when having to develop organisational leadership in line with employment equity targets. Another important factor is that Debebe (2011) places relationships at the core of what would in all probability be considered a "safe" training environment, but referring back to Ospina and Foldy (2009) who postulate that identity shapes perception of experiences, how these relationships are built and maintained may differ across groups of individuals.

Employers (and in this case mentors and managers of a LDP) cannot simply choose to ignore differences and then assume that individuals form different racial groups have the same experience in their organisation and that everyone's perception of their experience is the same (Igbaria \& Wormley, 1992). According to Davis et al. (1995), the purpose and goals of the group may very well be a great source of tensions, especially when these goals are in conflict with some norms and beliefs of individual members. All of this culminates in a need to better understand the intersectional experiences of individuals in an LDP.

Keeping a participant engaged in the programme under such circumstances may prove difficult if one considers the three categories of engagement, namely affective, behavioural and cognitive (Conner, 2009). But to understand more deeply how this type of environment 
or context impact on each dimension, one must first consider individual experiences. Conner (2009) refers to "cohort culture", where the opinions of a group engaged in a developmental process are shared. This cohort culture does not, however, limit itself to a certain race or gender, but is rather associated with a group of people that are geographically close to each other. This prompts another need for investigating individual experience, especially when it influences the participant's engagement in the program. Some experiences originating from the individual's race or gender, may cause the participant to feel removed from the group, but other group experiences may be shared. What the participant experiences as "cohort culture" may give very positive insight into why some individuals succeed on an LDP and why some do not.

Further evidence of the knowledge gap is illustrated in the graphical depiction of the framework for studying leadership in Figure 6. This figure incorporates individual traits, individual behaviours and situational factors as a precursor for desired leadership outcomes, but it fails to take into account what differences might occur during the leadership experience. The model suggests that organisations will select leaders from similar backgrounds which my leads to practices of self-bias ${ }^{1}$, and that leaders have limited control over situational variables (Gibson et al, 2006). Practices of leaders exhibiting self-selection bias are unfair and unethical in itself, but are also problematic when considering the diverse workforce of most South African organisations. Limited control over situational variables also poses a significant hurdle when one considers that the perceived nature of the situation may differ between individuals. The literature indicates that leader behaviour will not only be influenced by individual traits like personality aptitude and personality, but that a person's diverse background (e.g. gender and race) will also directly affect how the leader makes sense of what is happening around him/her (Bell \& Nkomo, 2001; Booysen \& Nkomo, 2010; Ohlott, 2002; Ospina \& Foldy, 2009).

This study attempted to fill the gaps regarding what the leader is experiencing and how they experience it. How and what the individual experiences might then also illuminate why certain behaviours are exhibited. In order for this to be done in a systematic and structured way, existing literature and models on leadership and leadership development was used to anchor the process. One of these models is the model for studying leadership as proposed by Gibson et al (2006), as well as complementary theories on motivation.

\footnotetext{
${ }^{1}$ Self-selection bias is the practice of surrounding oneself with individuals similar to oneself (Gibson et al, 2006)
} 


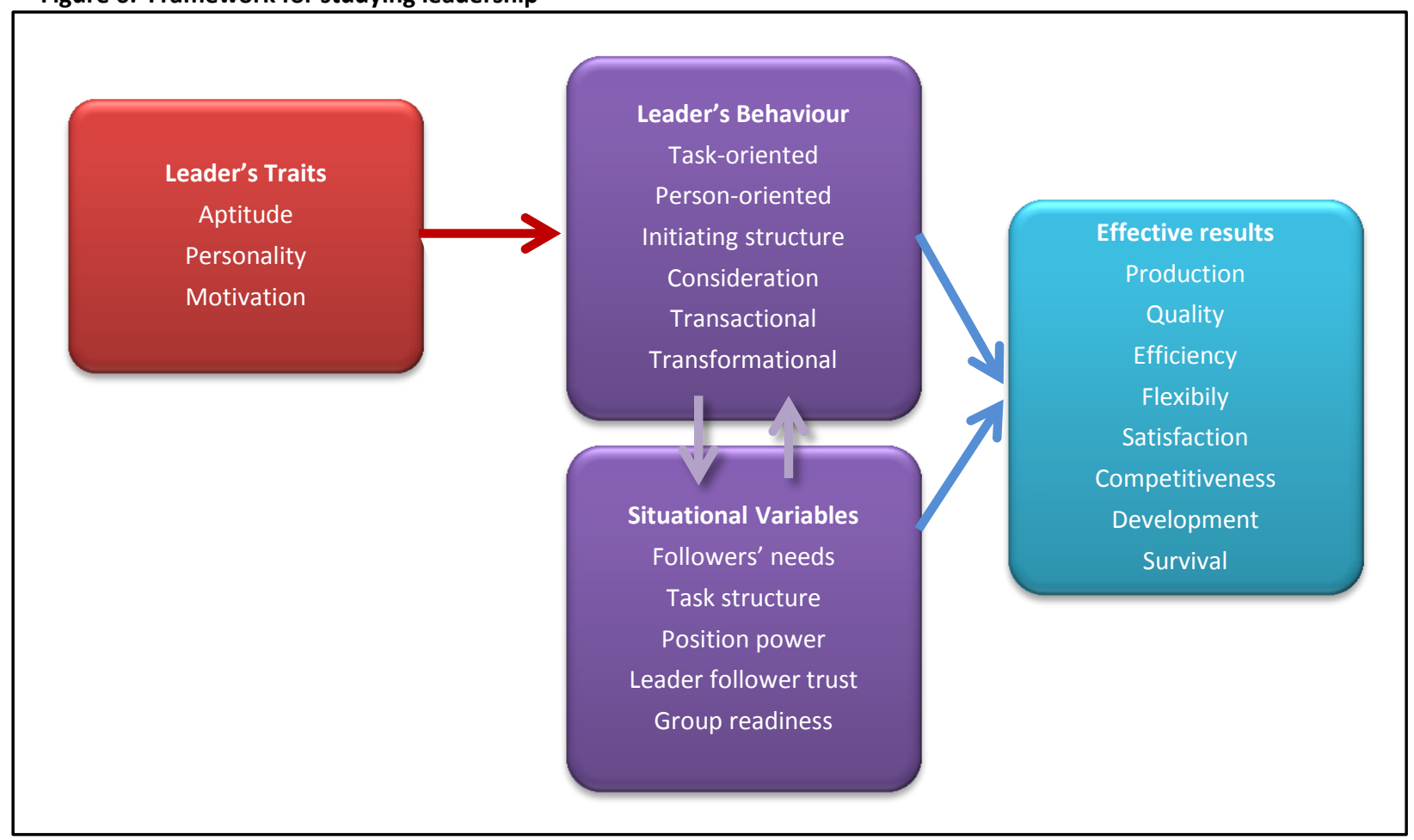

Adapted from Gibson et al. (2006)

Hollyforde and Whiddett (2003) compiled several contemporary theories on motivation from various authors. Three of these most commonly known theories are applicable within the context of the programme as well as the aforementioned model by Gibson et al. (2006). These are the Achievement Theory, Expectancy Theory and Goal-Setting Theory. Each of these are briefly outlined in terms of their relevance to this study. The first, Achievement Theory, relates to an individual feeling responsible for a specific outcome of an event/project, i.e., success or failure. Achievement Theory closely relates to locus of control theory in the sense that, if a person feels that he or she has control over outcomes (the achievement) and in so doing be motivated by that knowledge, that the person may be considered one with an internal locus of control (Sterbin \& Rakow, 1996). According to Achievement Theory, the individual must be desirous of the undertaking, must receive unambiguous feedback and the undertaking must be of value to the individual for motivation towards the achievement to occur. One can then assume that a belief that there is little control over whether or not something is achieved, the individual will not be motivated to work towards it. Expectancy Theory is related more to the nature of the outcome of the individual's efforts, than that of the ability (control) to achieve the specific outcome. Expectancy Theory holds that the individual expects an outcome to hold certain benefits and will therefore be motivated to strive towards it. Finally, Goal-Setting Theory relates to an individual's level of motivation based on the perception of a goal's level of challenge to the individual. Goal-Setting Theory postulates 
that an individual will be more highly motivated to work towards a goal if it is perceived to be suitably challenging, specific (instead of general) and if behaviour on the individual's part is perceived to have influence of goal attainment.

\subsection{Intersectionality}

Intersectionality (the main approach for this study) refers in essence to researching a phenomenon from more than one perspective. Scholars in the field of intersectionality view social identity categorisation as misleading constructs which do not take into account the heterogeneity of experience within a group (McCall, 2005). According to Burman (2004), only focussing on a single dimension of a difference regarding an intervention is essentially inadequate. This is because the various dimensions (like a person's race and gender) impact on each other and have a combined influence on the individual (Booysen \& Nkomo, 2010). Intersectionality, therefore, has the potential to offer more valuable information about the phenomenon.

Consider the following example: A prospective student phones a university with an inquiry about a law degree. A consultant transfers the prospective student to the legal faculty. The question, however, is about being a corporate legal advisor, so the legal faculty transfers the call to the faculty of commerce. The faculty of commerce do not have a department on legal studies and the call gets transferred once again.

If there was one person with intersectional knowledge about both law and commerce, this prospective student's inquiry would have been able to be settled with one transfer. What must also be considered are the effects of collecting many different segments into one group (as opposed to intersectionality that looks at individual experience from more than one perspective) like for instance grouping Black, Indian and Coloured into one "non-white group". This may have some valuable perspective to add, but according to Jones, Ni and Wilson (2009), these types of practices overlooks valuable information specific to a distinct group.

Given South Africa's political past, certain established racial- and gender hierarchies may still influence peoples' experiences and material outcomes (Booysen \& Nkomo, 2010). If an individual has a specific view of their role in society and the organisation, based on their gender or race, this will influence how they perceive a development programme (Ospina \& Foldy, 2009).

Minow (as cited in Valentine, 2007) defines intersectionality as the study of an individual at a crossroads of multiple groups. This is depicted graphically in Figure 7. This type of research is also able to illuminate hidden acts of multiple discrimination and how they 
conceal damaging and uneven power relations. It also provides the researcher with the ability to determine how identities of self are constructed within this specific context.

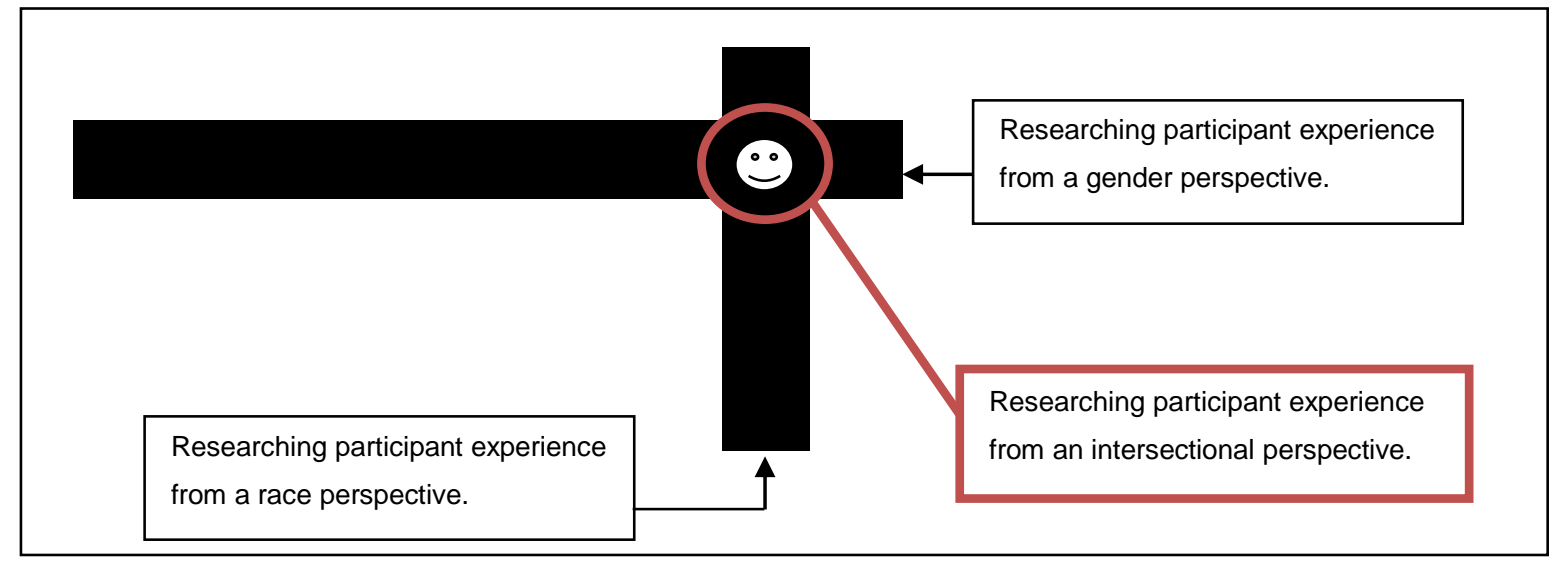

Figure 7: Intersectionality according to Minow

According to Nkomo (1992) researchers commit a "sin of omission" in their theoretical frameworks when examining race from this perspective. Jones et al. (2009) state that it is important to consider attachment processes for different race groups and how they affect outcome. Moreover, intersectionality will consider more than just the "sin of omission" pertaining to various race groups. It will also take into account how different subgroups of the specific race group experience the LDP.

The focus of an intersectional study of experience is not to discredit or ignore the relevance of social categorisation, but rather to gain insight into how these categories are experienced within a leadership development context (Fernandes \& Glenn, as cited in McCall, 2005). Such an analysis will provide the researcher richer data regarding the specific phenomenon.

\subsection{Leadership development and context}

Taking into account that leadership development is a learning-, or skills development intervention like any other, one should also consider contextual factors and more specifically how they influence the development of leadership skills. According to Conner (2009), most studies on context when researching learning are focussed on what happens in the classroom. Not many studies have examined the effect of the cohort. In other words, what is the effect of specific group members, engaged in a learning programme, on each other? Conner (2009) goes on to state that one must also take into account life circumstances, commitment to the programme and degree of engagement to the programme.

Ospina and Foldy (2009) echoes the sentiment of Conner (2009), by saying that leadership studies have focused everything but the context in which the leadership is 
practiced. They mention that, not only should influence of the context on the leader be examined, but also how leadership manifests in a given context. According to Ospina and Foldy (2009), focussing on the context will provide insight on how the influence of leadership unfolds among the actors engaged in these activities.

If one considers the richness that race, gender and other diversity issues bring to the working context, it makes sense to have insight into how context and leadership mutually interact. Especially if one believes that leadership in organisations directs the behaviour of the workforce (one of the assumptions of this research study).

\subsection{The Programme as LDP}

There are many different perspectives and approaches to leadership development in organisations. Before one can embark on an exploration of experiences during a leadership programme, one should first ascertain if the programme at hand is actually a LDP in some form. Based on the literature, the Programme is, in fact a LDP. The "WICS Model for Organisational Leadership" (Sternberg, 2003) will be used to justify this statement.

Figure 8: WICS Model of Leadership

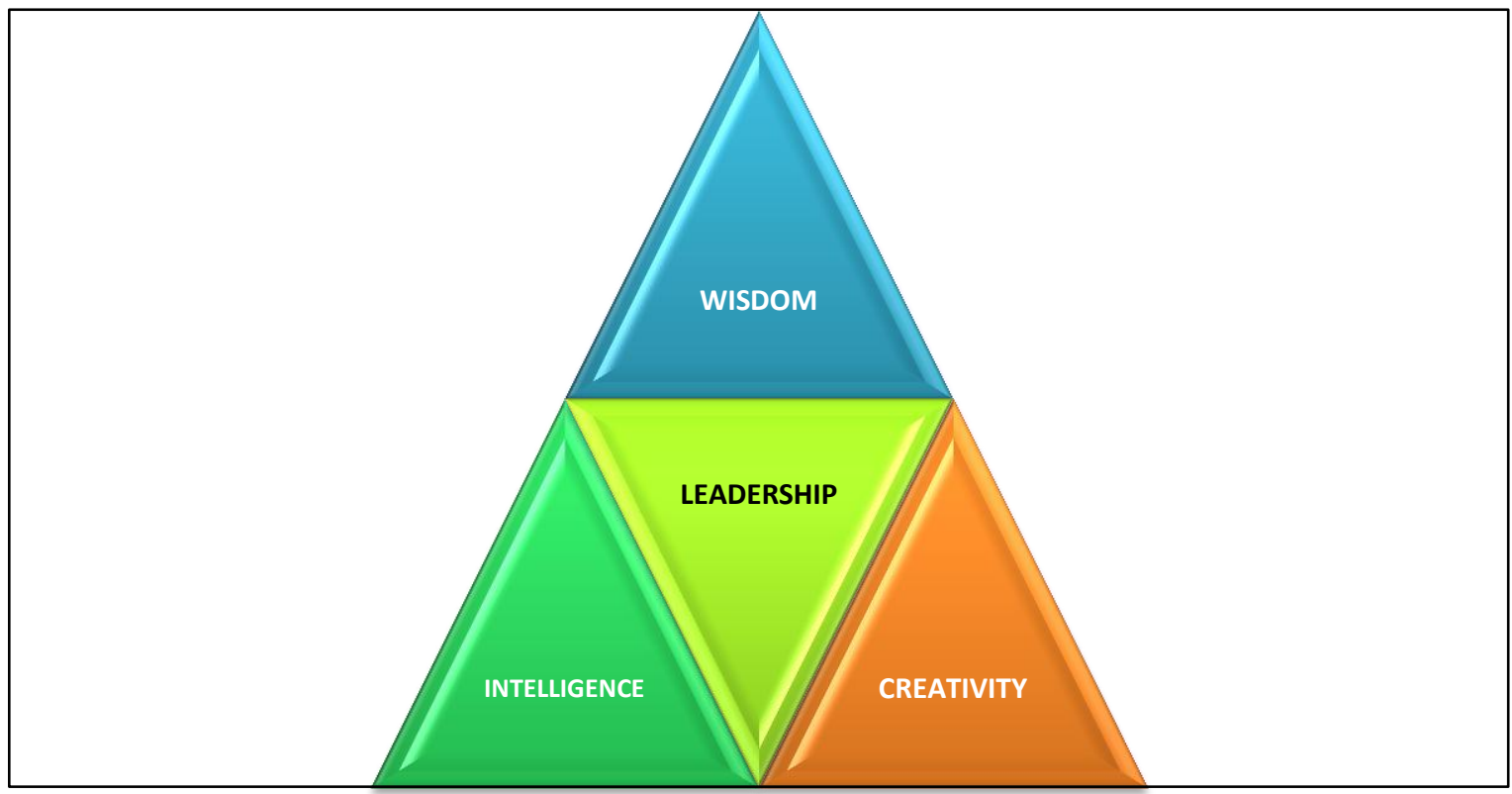

Adapted from Sternberg (2003)

Figure 8 graphically depicts the relationship wisdom, creativity and intelligence has with organisational leadership. The researcher will briefly analyse this and draw a parallel to the LDP this study wishes to examine. 


\subsubsection{The Programme and Intelligence}

Academic intelligence refers to memory, and analytical ability pertaining to that memory. One cannot be considered as having intelligence (rather than being intelligent) if one cannot recognise, recall, evaluate and judge information. Practical intelligence, however, refers to a person's ability to solve everyday problems with available knowledge.

The Programme as a LDP aims to provide participants with the necessary foundational knowledge (or academic intelligence) and put it into practice by means of experiential learning. This practice, however, does not eliminate the need for a basic level of cognitive ability. According to Schmidt and Hunter (1998), cognitive ability is the best single predictor of future job performance. The programme also takes this into account by setting entry requirements that include cognitive ability testing. Success on the theoretical component is determined by means of knowledge tests and presentations. Practical competence is assessed by means of simulations and practical tasks.

\subsubsection{The Programme and Creativity}

Sternberg (2003) considers creativity as important for leadership because it is the skill used to generate new ideas which others will follow. Sternberg (2003) goes on to say that creativity is a learnt skill and a choice. One chooses to think and act creatively. Due to the nature of the organisation, even if business processes, marketing strategy and even the leadership development programme is standardised, each branch and region comes with a unique set of requirements and challenges. This is why creative thinking is fostered by means of mentoring during the Programme. Senior management coach participants in the programme in order to help them develop a mind-set of thinking that is conducive to creativity.

\subsubsection{The Programme and Wisdom}

Holliday and Chandler (as cited in Sternberg, 2003) state that wisdom can be divided into five sub-parts. These are exceptional understanding, judgement and communication, competence, interpersonal skills, and social modesty. These components are mentored during and even after permanent appointment, as well as thought in a safe classroom environment by field specialists. For example, communication skills and interpersonal skills interventions are outsourced to subject experts to ensure credibility of the program. 


\subsubsection{The Programme and Synthesis}

According to Sternberg (2003), the last component: synthesis, involves combining all the various component into a set of leadership behaviours. In the Programme, synthesis of the preceding components are promoted as well as assessed by placing the participant in a "relief" role for a period of time and observing performance. The participant will still receive coaching, but to a far lesser extent than before. The trainee manager must now synthesise all newly acquired intelligence, creativity and wisdom, to be able to function in a leadership role.

\subsection{Conclusion}

The literature review supports the assumption that the programme under scrutiny is indeed a leadership development programme and can be studied as such. The literature also points towards utility in the investigation of the possibility of differential experiences in a leadership development programme. The literature also suggests possible value in examining experiences, at group level, from an intersectional approach as opposed to an individual level. Finally, the current knowledge gap (on group experiences) in existing literature validates the merit of this study and it's intended outputs. 


\section{CHAPTER 3: Methodology}

\subsection{Research paradigm}

The research paradigm that guided this study is that of social constructivism. According to Creswell (2009), this paradigm holds the assumption that individuals seek to find understanding and meaning in social experience. Constructivism suggests that this meaning is subjective and that one individual does not necessarily experience the same event in the same way as another. The position of the researcher is that the leadership development programme under question was designed from a positivistic approach that ascribes to determinism in the sense that it assumes selection criteria is sufficient to predict successful completion of the programme and that successful completion of the programme will lead to the practicing of desirable leadership skills. Ad hoc observations and data from the HRIS (SAP), however, have suggested differential performance on the programme and differential outcomes post-completion.

The goal of research rooted in constructivism is to understand differential experiences and to inductively construct theory based on this understanding of experience. Conducting research on a leadership development programme from a constructivist perspective provides valuable understanding about how the leadership development programme is experienced by different race and gender groups, and in turn places the organisation in a position to improve the programme.

\subsection{Strategy of enquiry}

The study followed a qualitative research design, in that it attempted to interpret and understand differing subjective perspectives of the participants of the study (Creswell, 2009). The philosophical approach was that of social constructivism. The assumption was that participants in the leadership development programme develop subjective meanings to their experience of the programme and that these meanings shape their behaviour and their subsequent achievements in the programme (Creswell, 2009). The strategy of enquiry was phenomenological. As the researcher, it was attempted to understand the lived experiences of participants in the Programme, in an effort to be able to understand the phenomenon of differential success rates between members of different race and gender groups (Saunders, Lewis \& Thornhill, 2009).

All data collected was therefore empirical primary data as any analysis or interpretations made from this study was based on newly acquired information (Saunders et al., 2009). Primary data was then triangulated with secondary data. The study was also exploratory in nature as the research aimed to explore the specific phenomena of leadership development 
programme experiences in a new light, namely intersectionally between gender and race (Saunders et al., 2009).

\subsection{Design}

According to the Husserlian perspective (Bradbury-Jones, Sambrook \& Irvine, 2009) focus groups are an inappropriate mode of data collection when dealing with phenomena that may occur at a group level. The reason is that the Husserlian perspective proposes the researcher has to completely detach from the phenomena and strictly describe without interpreting or explaining. However, Heidegger (as cited in Bradbury-Jones, et al., 2009), challenges the Husserlian theory and states that truth is not something that is constructed from distancing oneself from the phenomena. From a Heideggerian perspective, therefore, understanding will only be gained from interacting with- and interpreting a phenomena. This perspective is supported by Jasper (as cited in Bradbury-Jones, et al., 2009) who states that focus groups add to understanding by allowing for participants to elaborate on their shared experiences.

The strategy for collection in this research was therefore focus groups. This strategy produced data rich in detail, which is difficult to gain from other research methods (Maree, 2010). This strategy is also useful to gain insight into a phenomenon on group level, as participants do not only engage with the researcher, but also with each other by reflecting on each other's responses, which also in turn enhances methodological rigour (Thomas, 2008; Bradbury-Jones, et al., 2009). Bobby (as cited in Thomas, 2008) proposes the following definition for a focus group:

"A group of people that has been brought together to participate in a discussion of interest (p.78)."

The extended definition also mentions that an environment must be created so that all participants are able to discuss the phenomena under investigation. The eventual success of the focus group will depend on the extent to which participants can engage in the session and interact with each other. Maree (2010), however, indicates that some participants in such a focus group may find the experience threatening, and as a result withdraw from participating. For this reason, a 'single identity focus group' strategy (Ohlott, 2002) approach was considered, as it may significantly reduce this anxiety as the participants will be surrounded by individuals of similar identity.

The moderator conducted four group discussion sessions with between six and eleven participants in each session, eliciting information regarding their experience in the 
programme. Maree (2010) suggests a 'funnel structure' where the discussion starts with more broad questions which are then narrowed down as the discussion progresses (see Annexure - DOC.04). An agenda for the focus group sessions was also developed and utilised. Audio aids as well as the assistance of a note taker were used in the recording of data to ensure that non-verbal reactions are also noted and recorded.

The researcher only fulfilled the role of 'moderator'. According to Thomas (2008), the moderator is a 'first among equals' who should only intervene during a discussion to ensure that the discussion stays on topic, then add new elements to the discussion and also probe for deeper meaning of experience. Thomas (2008) continues to say that if the researcher does not adhere to this role of 'moderator' and dominates the focus group session, it may result in participants being less likely to interact with each other and especially the researcher, leading to narrow and shallow discussions.

According to Thomas (2008), the literature also indicates various advantages and disadvantages associated with focus groups. Table 4 provides a brief summary of this. All of these factors were taken into account during data collection.

Table 4: Advantages and disadvantages of focus group as data collection method

\begin{tabular}{|l|l|}
\hline \multicolumn{1}{|c|}{ ADVANTAGES } & \multicolumn{1}{|c|}{ DISADVANTAGES } \\
\hline Opportunity to observe participant interactions. & $\begin{array}{l}\text { Guidance from the moderator may disrupt crucial } \\
\text { participant interactions. }\end{array}$ \\
\hline $\begin{array}{l}\text { Insight into sources of complex behaviour. } \\
\text { for meaning from these comparisons. }\end{array}$ & They provide depth, but not breadth. \\
\hline $\begin{array}{l}\text { May possibly provide into cultural and subcultural } \\
\text { contexts and variables. }\end{array}$ & $\begin{array}{l}\text { Views may tend to "consensus" instead of "true" } \\
\text { individual viewpoints, i.e., groupthink. }\end{array}$ \\
\hline Allow for depth of discussions. & \\
\hline $\begin{array}{l}\text { Participants may be encouraged to speak, who } \\
\text { would in other situations not be. }\end{array}$ & \\
\hline
\end{tabular}

Source: Thomas (2008). 


\subsection{Sampling}

For the purpose of this study, trainee managers currently enrolled in the programme, during the 2010/2011 financial year, were sampled from only one "operational division" of the Retail Group (refer to background for broad organisational structure). The sampling technique used was stratified random sampling, where the population is divided into several defined strata and random sampling is then done from each stratum (Saunders et al., 2009). The division's population was divided into the following four strata underlying this phenomenological study:

- Black males

- White males

- Black females

- White females

Based on the organisation's demographics, whites and blacks are the two most prominent racial groups. For this reason, and the fact that other races would have been difficult to sample, coloureds and Indians were not included in this study. Participants from each of the selected four strata were then randomly selected. To provide sufficient opportunity for each stratum to be equally represented, a sample size of 37 respondents were used (distributed as indicated by tables 5-8). This meant that the focus groups would have between six and eleven respondents from each stratum. The small nature of this sample size is a result of the sort of rich data that was collected but it is deemed appropriate for a focus group design. In-depth qualitative data were gathered regarding each race and gender group's subjective experience. Using a sample too large may have impeded the researcher's ability to adequately analyse data as well as allowing air time for all participants in the focus group to be heard (Creswell, 2009).

WHITE MALE FOCUS GROUP INFORMATION
DATE AND TIME
PARTICIPANTS' DURATION IN THE PROGRAMME
\begin{tabular}{|l|c|}
\hline 0-3 Months & 1 \\
\hline 3-6 Months & 3 \\
\hline 6-9 Months & 3 \\
\hline 9-12 Months & 2 \\
\hline >12 Months & 2 \\
\hline TOTAL & 11 \\
\hline
\end{tabular}

Table 5: White Male Focus Group Information

\begin{tabular}{|c|c|}
\hline \multicolumn{2}{|c|}{ WHITE FEMALE FOCUS GROUP INFORMATION } \\
\hline DATE AND TIME & $11 / 02 / 2011 ; 10: 25-12: 15$ \\
\hline \multicolumn{2}{|c|}{ PARTICIPANTS' DURATION IN THE PROGRAMME } \\
\hline $0-3$ Months & 1 \\
\hline 3-6 Months & 0 \\
\hline 6-9 Months & 0 \\
\hline 9-12 Months & 2 \\
\hline$>12$ Months & 3 \\
\hline TOTAL & 6 \\
\hline
\end{tabular}

Table 6: White Female Focus Group Information 


\begin{tabular}{|c|c|}
\hline \multicolumn{2}{|c|}{ BLACK FEMALE FOCUS GROUP INFORMATION } \\
\hline DATE AND TIME & $11 / 02 / 2011 ; 12: 20-14: 15$ \\
\hline \multicolumn{2}{|c|}{ PARTICIPANTS' DURATION IN THE PROGRAMME } \\
\hline $0-3$ Months & 1 \\
\hline 3-6 Months & 1 \\
\hline 6-9 Months & 0 \\
\hline 9-12 Months & 3 \\
\hline$>12$ Months & 4 \\
\hline TOTAL & 9 \\
\hline
\end{tabular}

Table 7: Black Female Focus Group Information

\section{BLACK MALE FOCUS GROUP INFORMATION}

DATE AND TIME $\quad 11 / 02 / 2011 ; 14: 45-16: 30$ PARTICIPANTS' DURATION IN THE PROGRAMME

\begin{tabular}{|l|c|}
\hline $0-3$ Months & 2 \\
\hline 3-6 Months & 3 \\
\hline 6-9 Months & 4 \\
\hline 9-12 Months & 2 \\
\hline$>12$ Months & 0 \\
\hline TOTAL & 11 \\
\hline
\end{tabular}

Table 8: Black Male Focus Group Information

\subsection{Data Collection}

\subsubsection{Basic considerations for data collection}

Limitation to access of information for the proposed study was minimal as a result of the researcher's employment by the Retail Group. The researcher was granted physical access to premises and participants during office hours. There were two primary gatekeepers in this regard, pertaining to the access of information and accessing it during office hours. They are the Divisional Manager and the Divisional Personnel Manager. However, taking into account the possibly valuable and useful information this study may yield, there were no objections to the access of information. The results from this study put them in a better position to manage the differential success rates of participants in the Programme, by taking into account individual experience.

The main concern regarding access was that of cognitive access to the actual data needed to explore the phenomena. The researcher's position in the organisation has created a difficult situation: Access to participants and premises was not a concern, but due to top level management involvement, there was concern that participants may not share information willingly. To try and overcome this, the purpose of the study was clearly explained as being primarily academic, but as also value adding to development and in no way corrective or disciplinary in nature. The researcher also stressed the importance of anonymity and confidentiality during the opening of the focus group sessions. A consent form was distributed to each participant explaining what their participation entails as well as the ethical guidelines in conducting the study (see annexure). Participants were also assured that they will be free to leave should they feel uncomfortable or exposed in any way. The data are reported out in aggregate form in terms of summative conclusions in respect to the major research questions in the study.

This section (graphically depicted in Figure 9) describes the steps followed before, during and after the data collection process. 


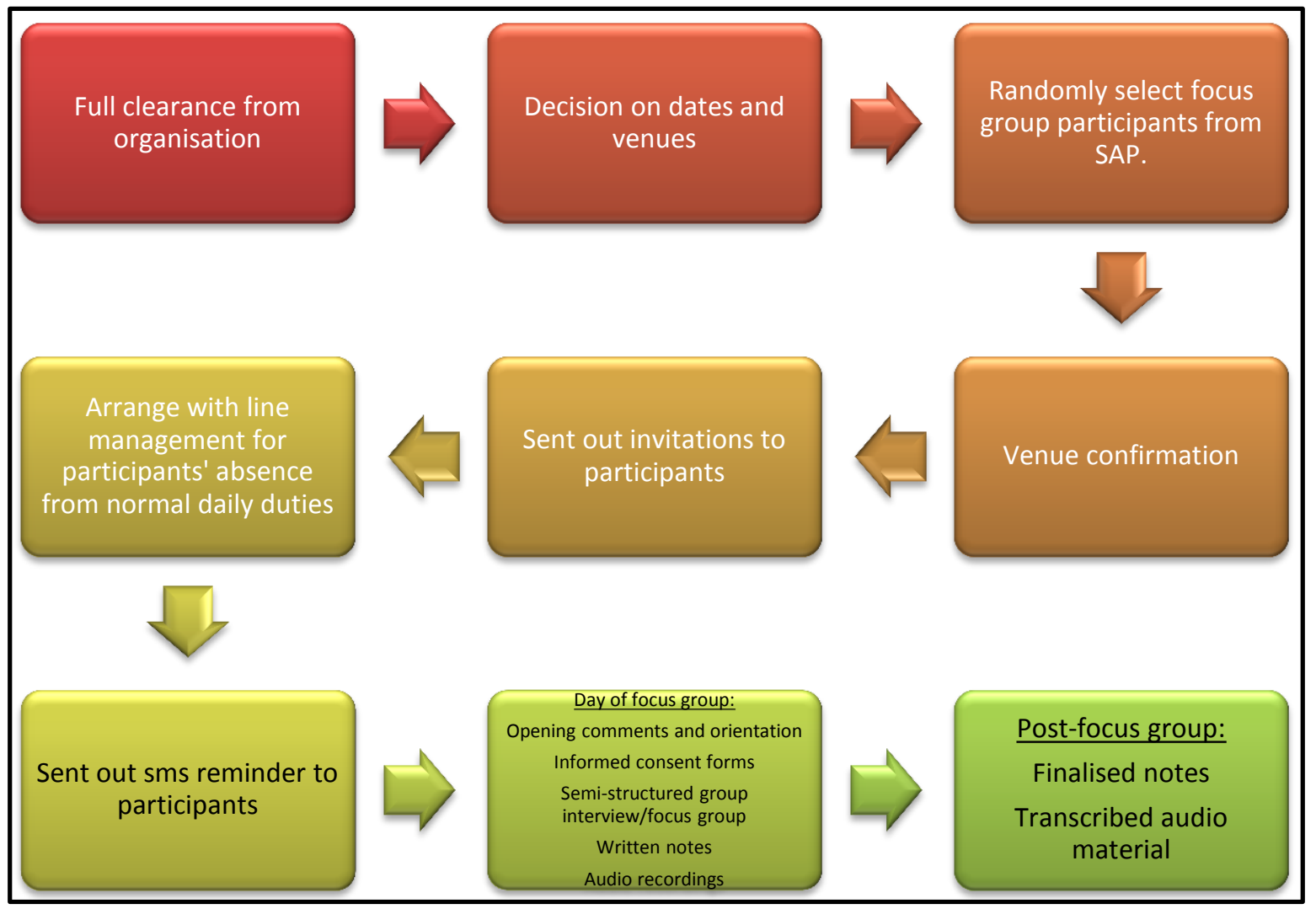

Figure 9: Data collection process

\subsubsection{Collection steps}

\subsection{2 a) Full clearance from the organisation}

The organisation was fully informed of the nature of the research project. Authorisation was obtained from two sources. Both the Divisional Manager (of the division in which the research was conducted) and Group Training Manager received an executive summary (DOC.01) of the proposed research and were asked to sign a research authorisation form (DOC.02). Authorisation for access to exit interviews was also requested from the specific division's Divisional Personnel Manager.

\subsection{2 b) Decision on dates and venues}

After the Division provided the researcher with clearance to conduct the research, the most appropriate dates and convenient venues was determined. The chosen date was on a day where business operations can most afford the absence of the participants. The date also aimed to cause minimal disruption to their planned training programme in which they are enrolled. The chosen venue(s) was at one of the Division's training centres, and was selected based on venue availability and convenience for participants. 


\subsection{2 c) Selecting participants}

A complete list of possible participants was drawn from SAP. This list consisted of all Trainee Managers who are active in the development programme under investigation. The list was then sorted and candidates who are conveniently located close to the Division's training centres were identified. This list of Trainee Managers was then sorted according to race and gender. The following candidates were then selected to participate in the study (see stratified random sampling section in research proposal):

- 6 white females

- 9 black females

- 11 white males

- 11 black males

\subsection{2 d) Venue Confirmation}

Conveniently located training venues were confirmed for use on the confirmed dates. Correspondence was sent out to ensure that there are no clashes with other training sessions, and to ensure that the venue is well prepared for participants' arrival.

\subsection{2 e) Send out invitations to participants}

A formal of letter of invitation (DOC.03) was sent out to participants as identified in previous steps. This letter was on an official University letterhead and indicated dates, time, duration and purpose of the study. It also stressed anonymity and the participants' right not to take part as well as the right to exit at any time during the session. Mention was also made that no remuneration will be given for participation in this study, as it goes against the ethical guidelines of the University.

\subsection{2 f) Arrangement with line management}

After the invitation was accepted, the researcher sent out correspondence about the Trainee Manager's required presence at a meeting. Due to the nature of the study, and the importance of anonymity, no information regarding the research was given to line, only that the participant will be absent from his/her normal duties for the given time period. Due to the researcher's currently held position in the organisation, this practice is entirely legitimate and allowable, and insured the protection of the participants' anonymity.

\subsection{2 g) Send out SMS reminder}

Two days before the specific focus group, a SMS reminder was sent out specifying dates and times of the focus group. 


\subsection{2 h) Day of the focus group}

On the day of the focus group, the candidates were welcomed with refreshments and showed to the room that had already been prepared. Tables and chairs were arranged in a "conference room" format as indicated by Figure 10.

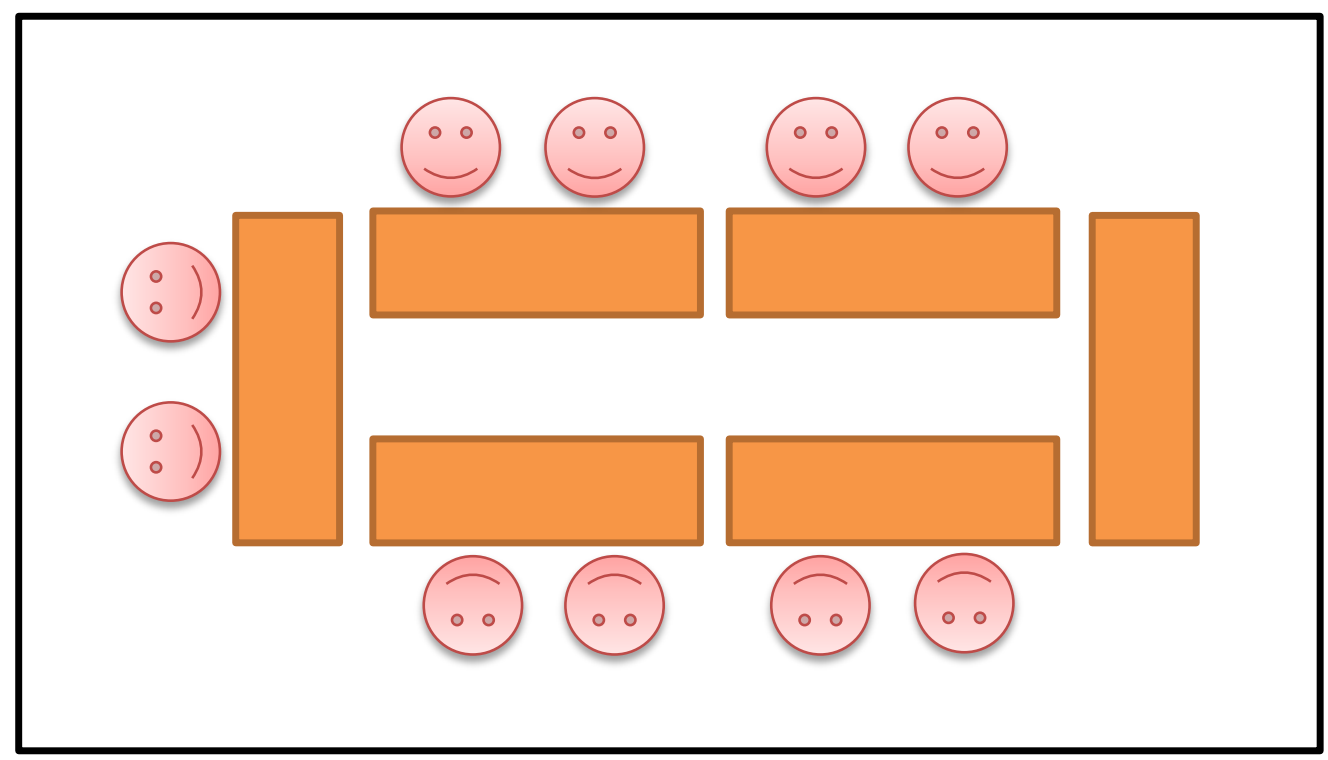

Figure 10: Room layout

Opening comments and orientation were conducted at the start of every session. The candidates were reminded about what the purpose of the session is and opportunity was given for questions. Thereafter, the facilitator explained the format of the day, how questions (DOC.04) were structured and how data would be collected. Further opportunity for questions was given. Any participants who felt uncomfortable or unwilling to participate further were given the opportunity to leave at that point. The remaining participants were required to complete and sign an informed consent form (DOC.05). At this point it should be noted that none of the participants, from any of the groups, felt that they needed to leave.

After the informed consent forms were collected, the audio recording device was switched on and the focus group commenced. With this research approach, some data quality issues may have impacted negatively on the process and on the eventual findings. Table 9 is a summary of possible negative influences associated with this process. Next to each issue, the number of possible contra-measures are indicated that may mitigate negative influences on the research process. Possible contra-measures are contained in Table 10. Trustworthiness of data was ensured by making sure to also present negative findings as well as triangulating focus group findings with the content analysis of exit interviews. 


\subsection{2 i) Data recording}

As outlined in the design and methodology sections, the data were collected by means of semi-structured focus groups. Notes were, however, also kept on events that led up to the actual collection of the data, events that fall outside of the boundaries of the planning and set structure as well as events that may have occurred post-collection (Hofstee, 2006). The information from these notes was also included in the analysis of the data as a means of maintaining reliability of data. Notes were kept (and reported on) during the data analysis process (in the form of Atlas.ti memos). This provides the reader with a clear understanding and indication of the researcher's thought processes and reasons for presented findings. This is presented in the discussion section.

Quality concerns in a qualitative research study relates to concepts such as transparency, confirmability, trustworthiness and credibility. This is because qualitative research do not normally yield statistical indicators from which one may determine reliability and validity. This will be discussed more at the end of chapter 4. At this point, however, it can be noted that the need for proper and systematic recording of data was increased by the fact that data were collected from more than one source. Multiple focus groups, comprising of participants with varying demographics, was conducted. The evidence from these focus groups were then triangulated with evidence gathered from exit interviews. All of this data were then analysed using content analysis.

The data collected from the focus groups were recorded in two ways. Firstly, group discussions, as facilitated by the researcher, were recorded on a voice recorder. These recorded discussions were then transcribed verbatim for content analysis. Secondly, participants were assigned a nominal label. This label aided in recording non-verbal reactions to discussions, as well as distribution and frequency of comments. Hand written notes were made in pre-determined short-hand, to note non-verbal reactions as well as to give direction to the voice recording in terms of who made specific comments, while at the same time protecting anonymity by disguising real names. For example, if one person keeps making the same comment, or leads the discussion into a certain direction, or even reacts in a particular way, this may have been difficult to determine from voice recording alone. In a focus group, it is not just the words that are of importance, but also the tone in which they are said. Hand written notes also serve as backup in case the technology failed (Saunders, Lewis \& Thornhill, 2009). According to Trochim (2001), it is important to check data for errors. When transcribing voice recordings, hand written notes served as a means of checking if transcription was done correctly.

According to Saunders et al. (2007), contextual data should also be recorded. Contextual data were mainly gathered from the HRIS contained on SAP. This included age, gender race, education level and position in the organisation. Predetermined factors like the date, 
time and venue was also be recorded by means of an agenda and notes on deviation from the set agenda.

The secondary data did not have to be transcribed or recorded, as it has already been committed to paper. Authorisation for access to a sample of existing exit interviews were obtained and copies of the completed interview guides were made, and included into the data set. A summary of these are included in the findings section.

Table 9: Data quality (reliability) issues

\section{DATA QUALITY ISSUES}

\begin{tabular}{|l|l|}
\hline Issues & $\begin{array}{l}\text { Contra- } \\
\text { measure }\end{array}$ \\
\hline $\begin{array}{l}\text { Interviewer bias, which may result, directly or indirectly of the imposition of the } \\
\text { interviewers beliefs and frame of reference onto participants, by means of tone } \\
\text { and non-verbal behaviour during interviewing. }\end{array}$ & 1,7 \\
\hline $\begin{array}{l}\text { Interviewee bias, which is a result of perceptions about the interviewer and may } \\
\text { affect responses given during the focus group. }\end{array}$ & $2,3,4,5,7$ \\
\hline $\begin{array}{l}\text { Self- preservation, which is any behaviour exhibited by the interviewee in order to } \\
\text { protect themselves from what they perceive to be a threat, e.g. exposure resulting } \\
\text { from the discussion of a sensitive or personal issue. }\end{array}$ & $2,3,4,5,6$ \\
\hline $\begin{array}{l}\text { The time consuming nature of in-depth discussions may restrict the depth of } \\
\text { certain responses. }\end{array}$ & $1,6,8$ \\
\hline
\end{tabular}

Table 10: Proposed possible contra-measures

\begin{tabular}{|l|l|}
\hline \multicolumn{2}{|c|}{ DATA QUALITY CONTRA-MEASURES } \\
\hline NR & DESCRIPTION \\
\hline 1 & $\begin{array}{l}\text { The researcher need to be knowledgeable about the research topic and the setting in which the } \\
\text { phenomenon is occurring. For this research project, the researcher did a thorough literature } \\
\text { study and was familiar with the organisational context and the specific context of the } \\
\text { programme under investigation. }\end{array}$ \\
\hline 2 & $\begin{array}{l}\text { Supplying the interviewee with information about the research process and its aims may } \\
\text { increase credibility of responses. Understandable and logical questions during the focus group } \\
\text { also added to this credibility. }\end{array}$ \\
\hline 3 & $\begin{array}{l}\text { The researcher's appearance may influence the perception of the interviewee. The researcher } \\
\text { dressed in a presentable manner during the focus groups, but did not wear a company uniform. } \\
\text { The researcher stressed the research is primarily for academic purposes. }\end{array}$ \\
\hline 4 & $\begin{array}{l}\text { The opening comments and first few comments by the interviewer have a significant impact on } \\
\text { the outcome of the focus group. The interviewer established rapport before ensuring that there } \\
\text { is informed consent and that any uncertainty is cleared up. }\end{array}$ \\
\hline
\end{tabular}




\begin{tabular}{|l|l|}
\hline 5 & $\begin{array}{l}\text { The questioning approach must reduce the scope for bias during the focus group. The } \\
\text { researcher asked the questions in a neutral tone of voice, and made evert effort to phrase the } \\
\text { questions clearly, without being ambiguous or vague. All questions were grounded in real life } \\
\text { experiences, rather than abstract concepts. }\end{array}$ \\
\hline 6 & $\begin{array}{l}\text { Interviewer behaviour during the focus group may also impact on the outcome and results. The } \\
\text { interviewer took care not to speak in a negative tone of voice, make comments that are not } \\
\text { related to the questions, display non-verbal behaviour or gesture in a manner that may signal } \\
\text { some form of bias. }\end{array}$ \\
\hline 7 & $\begin{array}{l}\text { Some forms or cases of bias may be difficult to control due to cultural differences. The } \\
\text { researcher was attentive to this possibility and also mentions the possibility of this during the } \\
\text { opening comments. In an effort to minimise the chances of cultural bias influencing responses } \\
\text { and the recording thereof, the researcher repeated and paraphrased responses to determine } \\
\text { understanding as the participant intended responses to be understood. }\end{array}$ \\
\hline 8 & $\begin{array}{l}\text { To maximise data collection and avoid any information being lost as well as optimise time } \\
\text { available, both written notes and audio recordings were used to collect responses during the } \\
\text { focus group. During the opening comments, part of the informed consent will include knowledge } \\
\text { and consent to be recorded. Audio material will then be transcribed post-focus group. }\end{array}$ \\
\hline
\end{tabular}

\subsection{2 j) Post-focus group}

After all the items in the questioning schedule were discussed, opportunity was given to participants to make general comments. Thereafter, participants were thanked for their contributions and given permission to leave. Notes were finalised and any final mental notes will be recorded on the audio recording device. After all the different strata were put through the focus group, the audio materials were transcribed. 


\subsection{Analysis}

The use of focus groups as method of data collection produced a large amount of qualitative data. This qualitative data originated from discussion notes and transcribed audio recordings. Data were analysed by using a content analysis approach. Traditionally, content analyses have been used as a quantitative tool to give qualitative data an assigned numerical value and then using statistics to analyse the data (Klenke, 2008). However, for the purpose of this study, and because the goal is the understanding of meaning in experiences, techniques as suggested by Trochim (2001) were used:

- Coding, which is the methodical processing of categorising qualitative data, and defining of the nature and content of each category.

- Memo-ing, which is the process of recording the researcher's ideas and thoughts as they evolve throughout the process of interacting with the data.

- Integrative diagrams (as produced by Atlas.ti "network" function), which are graphic depictions of information that come to light when analysing the content and interactions between categories. These diagrams illustrate where there are similarities and differences on group level experience.

These techniques were utilised in the qualitative data analysis steps as prescribes by Creswell (2009), p.183. These steps are as follows:

STEP 1: Organise and prepare data for analysis by transcribing notes and audio material, and optically scanning through recorded information.

STEP 2: Reading through all the data collected.

STEP 3: Coding of data, by looking at the most descriptive responses and segmenting the data into 'chunks' of information. Both open and axial coding was used. Open coding to establish codes, and axial coding for grouping and analysis.

STEP 4: Consider all the data as a whole and give meaning to the various themes and categories that were identified during coding.

STEP 5: Interrelate the various categories and identify similarities and differences between them, by means of interrelated diagrams.

STEP 6: Give meaning to differences and similarities among categories.

According to Klenke (2008) the researcher has the option of using computer-aided coding or human coding. This data analysis has been done by using the computer-aided coding of the software package Atlas.ti.

Because the study aimed to ascertain whether or not differences exist in participant experiences in a leadership development programme, thematic coding was used in data analysis. Thematic coding was chosen because it lends itself to the establishment of 
patterns that may exist within text (Klenke, 2008). These thematic codes must contain certain elements which will all be included with the aid of Atlas.ti. These elements are as follows:

- A label

- A definition

- A description of how the theme occurs

- A description of any qualification or exclusion to the identification as a theme

- Positive and negative examples of the theme to eliminate confusion

Figures 11 and 12 indicate how these elements are included by using Atlas.ti.

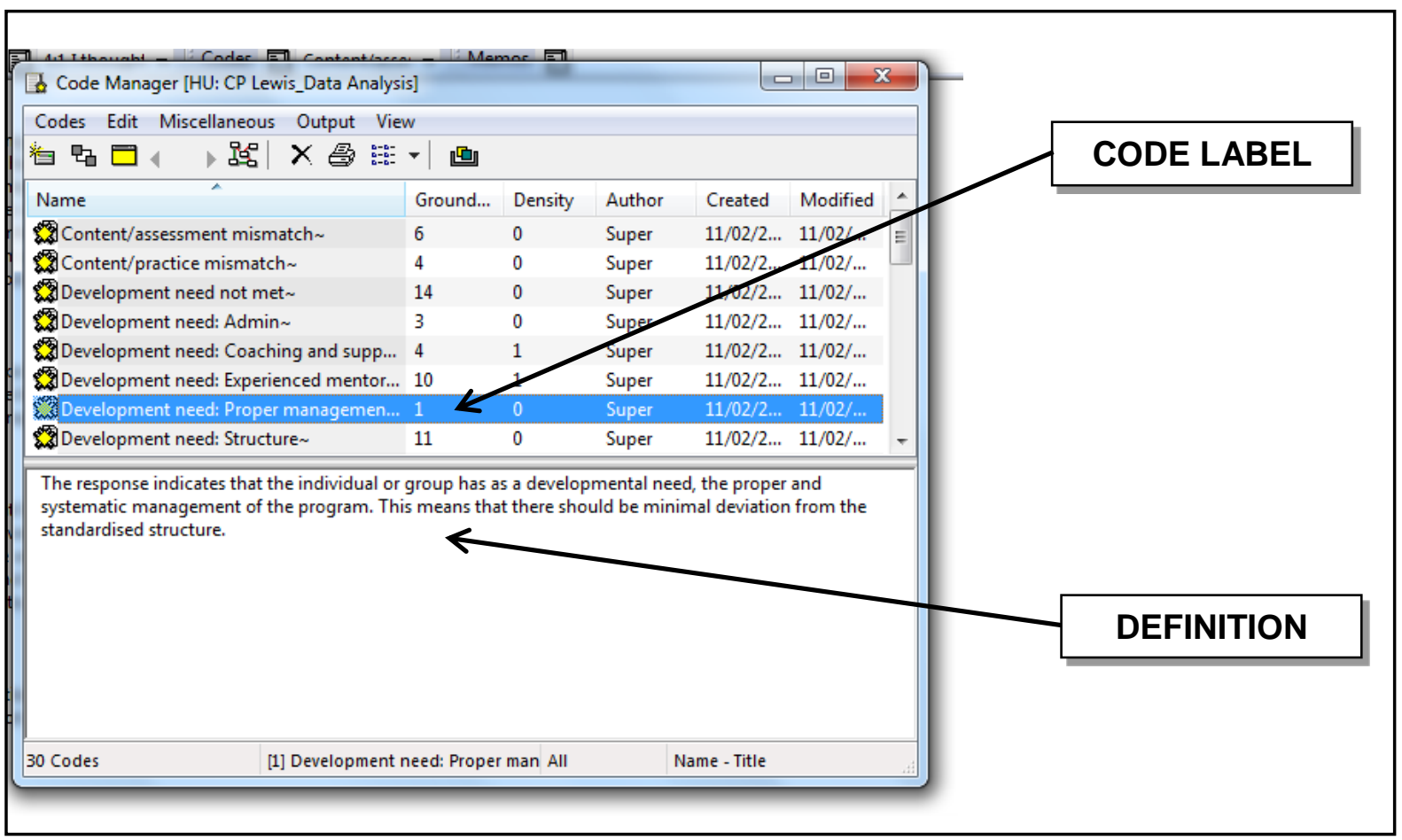

Figure 11: Code Manager in Atlas.ti

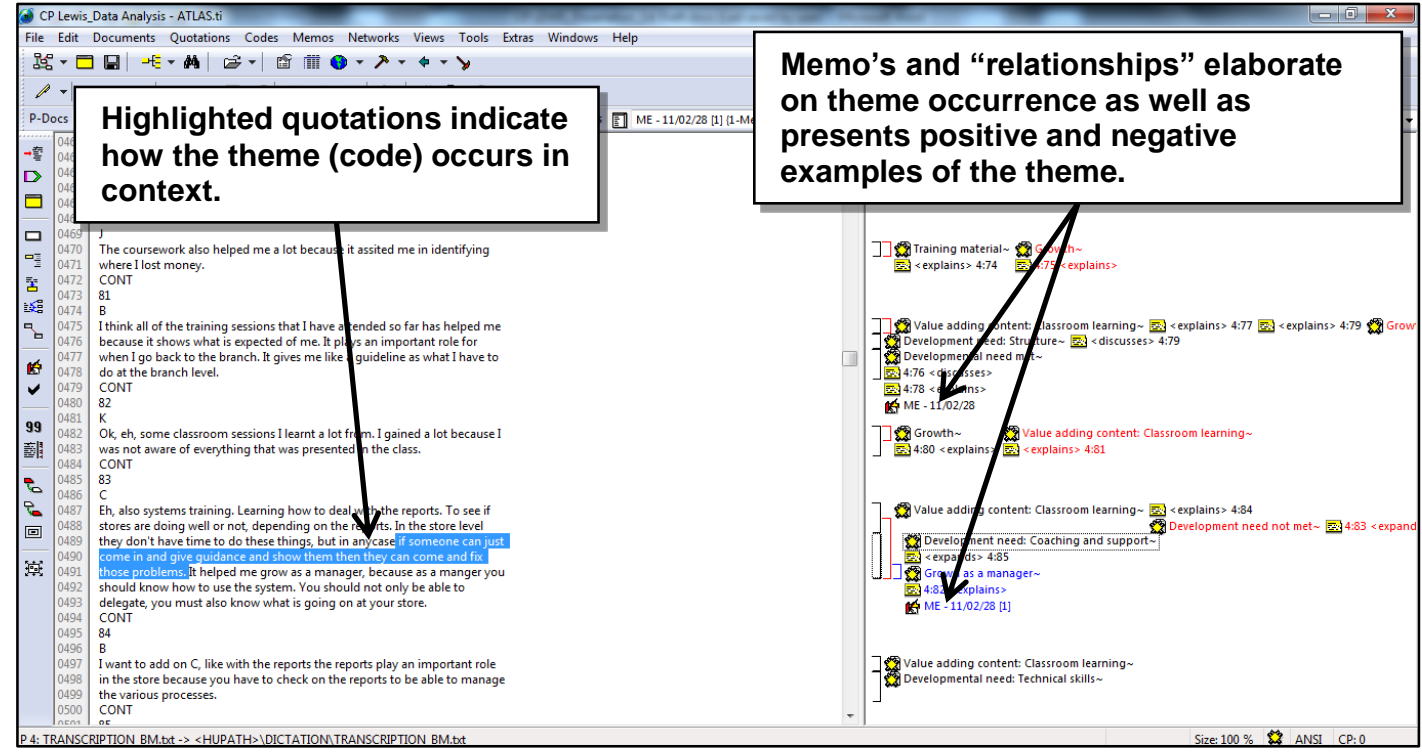

Figure 12: Hermeneutic Unit in Atlas.ti 


\subsection{Ethical issues}

As with any activity involving business processes and the inclusion of people, ethical issues must be considered. For the purpose of this paper, they are addressed separately as set out by Creswell (2009) as follows:

\subsubsection{Ethical Issues in the Research Problem}

In identifying a research problem it was important to identify a problem that will be beneficial to individuals other than the researcher. This study sheds light on the diversity issues that impact on leadership development; specifically, how race and gender affects the experience of a group in an organisational leadership development program. Organisations can benefit from this study by being able to better understand how their diverse workforce is experience a leadership development intervention. Participants can benefit from being able to voice concerns and perceptions of the programme and encourage practices that work for a specific group.

\subsubsection{Ethical Issues in the Purpose and Questions}

The purpose of the study was clearly stated and was not deceptive to any of the participants. This included the unit of the organisation from which the participants are taken. The intended, and expected outcome of the study was clearly an unambiguously communicated.

\subsubsection{Ethical Issues in Data Collection}

During the collection of data, at no point was any organizational property intentionally put at risk. No participant in the study was put at risk in terms of physical or psychological harm. Possible harmful effects of the study, like undue anxiety caused by participating in a focus group, was mitigated by ensuring that participants are fully informed and engaged in a single identity focus group. A representative from the organisational unit (for example the regional operations manager, or the regional personnel manager) from which participants were taken, as well as the participants were all be requested to read and sign an informed consent form before being included in the study. This informed consent form stressed anonymity and the right to exit from the project, should the participant feel uncomfortable or exposed.

\subsubsection{Ethical Issues in Data Analysis and Interpretation}

In analysing the data gathered from the study the following took place: 
- Participant names and specific job titles were excluded from final write-up to protect anonymity.

- Data and analyses will be kept in a locked area, and properly discarded after a reasonable period of time (5-10 years).

- The supervising institution will remain the owner of the data, which in this case is the Department of Human Resource Management at the University of Pretoria.

- Audio recordings, their transcripts and notes from the focus group were also considered during data analysis to ensure that all responses (including non-verbal responses) from the group are taken into account.

\subsubsection{Ethical Issues in the Writing of Research Results}

During the writing of the research paper, the following were considered:

- Careful attention was paid to ensure that language is not used that may be biased or offensive to specific groups included in the study.

- In writing up the results the researcher kept to the ethos of grounded theory by basing all interpretations in the data and not imposing one's own expectations.

- The labour of others was not exploited in the writing of the research paper. Excluding the time used of participants during interviews and focus groups, individuals were not remunerated for their work.

- Credibility will be assured by releasing the research paper for peer review. 


\section{CHAPTER 4: Findings}

\subsection{Results}

\subsubsection{Introduction}

This chapter contains the findings from the focus groups. In order to assist with the reporting of findings, selected memos, as well as selected quotes, have been arranged per code in a code summary table and inserted into the Annexure. The tables are arranged so that each race and gender group has its own column, within that specific code. In each table, the column for the group(s) in which the code did not occur was blacked out.

Within each column, a " $Q$ " represents a quote from the transcribed discussions and an "M" represents an extract from memos that was made during coding and linked to sections of the text. For each code, the level of groundedness as the code density was also indicated. The groundedness was used as the measure to arrange the codes' summary tables from "most occurring" to "least occurring".

In some instances codes were taken out of this sequence and collapsed with another code in the sequence if the findings of the two codes were closely related. What should also be noted is that some memos or quotes may appear as having been repeated in each summary grid. This is not an error, but does so to indicate that a specific quote or memo relate to more than one code. Lastly, for reporting purposes, axial coding was then used to group these various codes together into groups. In order to anchor these groups, findings are reported according to topics of interest as per the semi-structured focus group interviews. Responses not contributing to a specific theme or trend in a group or groups are excluded from the reported findings.

\subsubsection{Expectations upon entering into the programme}

\subsection{2 a) Expectation for coaching and mentoring during the programme}

The expectation for receiving coaching and/or mentoring during the programme occurred in all four groups, although it was not discussed from exactly the same point of concern and was also not discussed at the same frequency across groups. Of the four groups, the white females discussed and expectation for coaching and/or mentoring the most and the black males discussed it the least.

The black females mentioned quite a few expectations which may be inferred to be related to an expectation for coaching and/or mentoring. They discussed communication about expectations (of them, from superiors) and structure during this programme. This may be an indication that they expected some form of coaching and support. Figure 13 is a 
graphic depiction (from Atlas.ti), indicating the network of expectations expressed by the black female group.

Figure 13: Black females' expectations

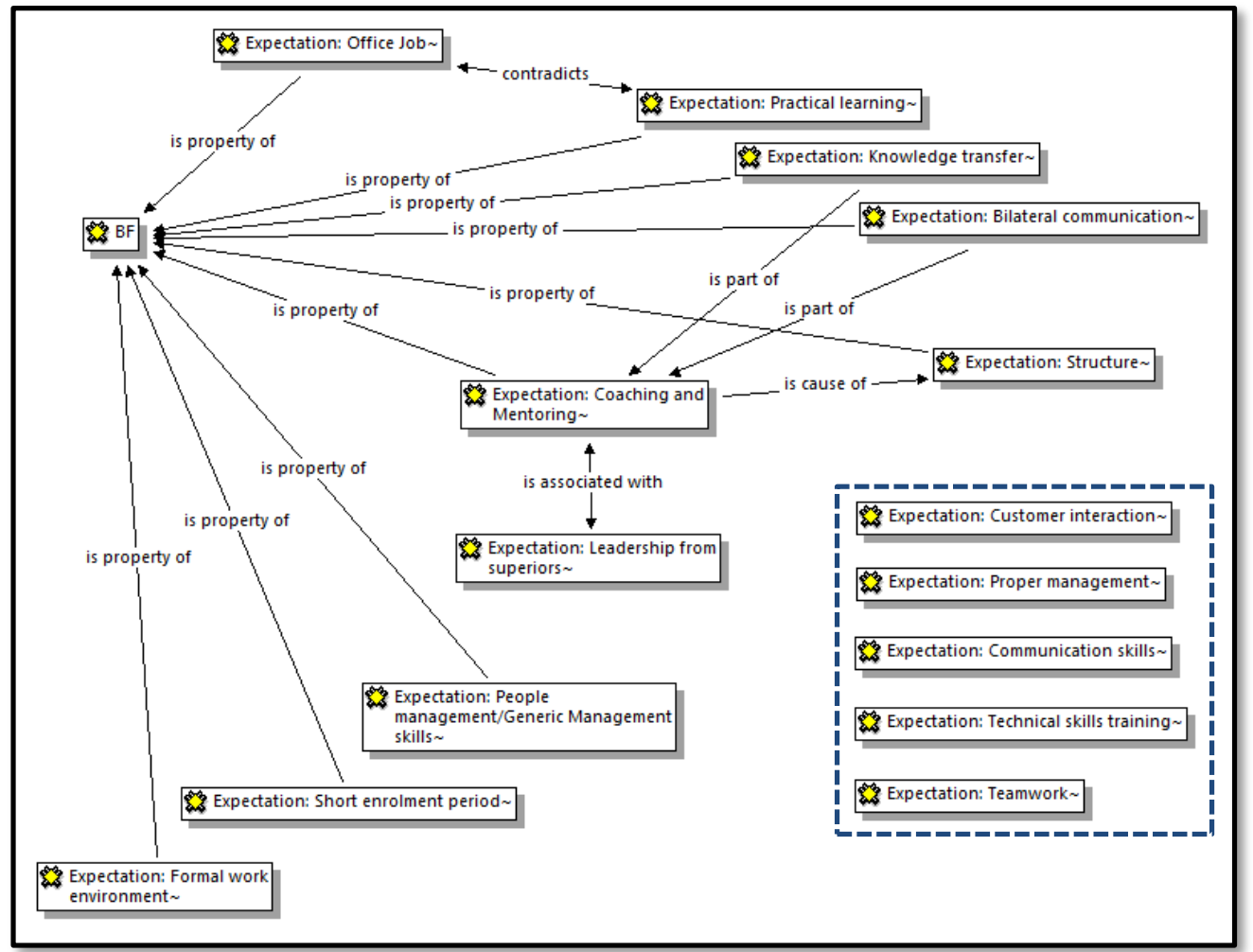

Atlas.ti mindmap of code occurrence relating to black females' expectations (pre-axial coding for the purpose of reporting findings)

The black female group also explained that they expected high competence from the individuals assigned to them for their development as well as a transfer of that knowledge. This, in turn, could be an indication that the black females expected a certain level of experienced mentoring. The notion of assigned coaches not having time to provide guidance came up throughout the discussion. The group also agreed with an opinion that reluctance from line to provide coaching support is usually due to operational pressures. Some distinctive quotes pertaining to this theme where as follows:

[BF] "If I ask for info, she must answer me now. I know that they are busy. I can help her achieve her task whatever she is doing. But now they are too busy..."

[BF] "Ya, if I have info that I want from them, they have to give me."

[BF] "We were not trained as person. We had to take information. We had to train ourselves." 
[WM] "Where I made the biggest mistake is that I thought I was going to be spoon-fed. By that though my training was delayed by some time and then I just changed my mindset whereby I basically just excluded them from my training and just kept on doing my own thing."

[WM] "I expected like, in the department, there should be a dedicated training manager"

The two preceding statements encapsulate the general opinion of the white male group regarding coaching and mentoring. The white male group mentioned an expectation of structure, guidance, support and "attention from superiors", which is indicative of an expectation of some form of coaching. The group also discussed what they refer to as " $a$ high level of competence" which also indicates that they expected mentors with experience to assist with their development. Figure 14 is a graphic depiction of all the expectations the white males expressed of the programme. 


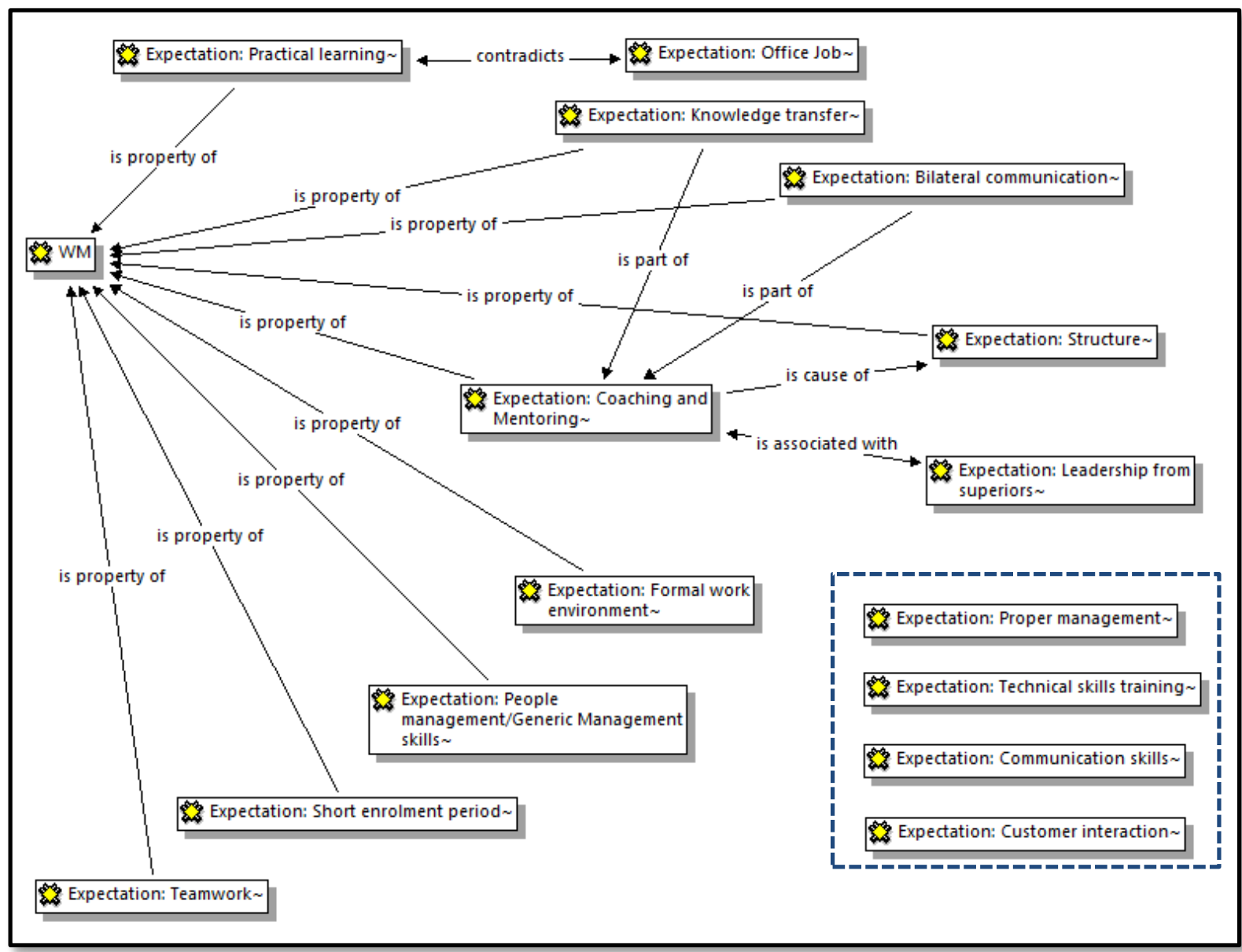

Atlas.ti mindmap of code occurrence relating to white males' expectations (pre-axial coding for the purpose of reporting findings)

The white females' main concern in terms of this theme was that of support, as is evident from the selected quotes below. The group agreed that support during their programme was one of their biggest expectations. Part of this support, they say, is expecting their coaches to monitor their progress closely. They expected to be continuously informed of the progress they are making (or not so).

When asked if an expectation of support was created, the white females agreed that most of them assumed that it will be the case. This expectation was not necessarily created by line management, but an assumption on their part. There is not much mention about experienced mentoring in the white female group. Their focus was more on coaching; specifically the support and guidance component thereof. Figure 15 is a graphic depiction of expectations of the programme discussed by the white females. 


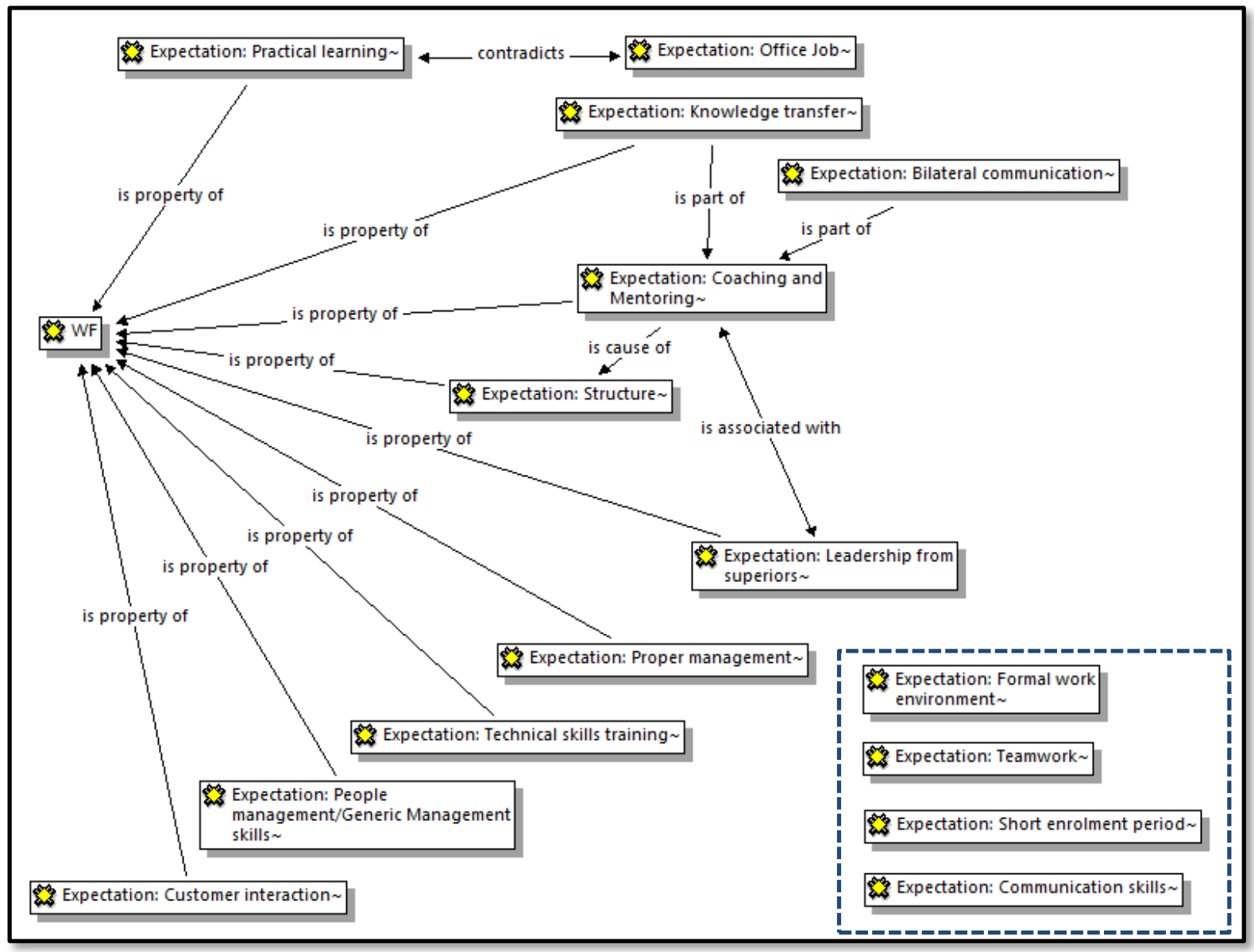

Atlas.ti mindmap of code occurrence relating to white females' expectations (pre-axial coding for the purpose of reporting findings)

[WF] "And I think exactly what she (A) said, like we trained in the departments ourselves which is fine we know how to bake a bread, mould the dough, but there was never a specific time when you worked with the specific manager of that department to show me what management skills are supposed to go with that."

[WF] "No, I just thought that a coach would be more actively involved than what there was."

[BM] "Basically I thought it was going to be a 6 months training, we will be getting experience from people who has that previous experience in terms of the FMCG, and then the others they don't have the experience on that. And then secondly I thought there was going to be an execution of on the job training. Same as like the mentors. Maybe they will be coming into the stores and then see you when you are doing the job." 
[BM] "...there must be someone who sits down with you and corrects you on that issue..."

The two preceding statements summarise the brief discussion the black males had on the topic of coaching and/or mentoring. The black males only briefly mentioned that they did expect some sort of one-on-one interaction as well as receive guidance and knowledge from experienced individuals, but did not discuss this specific expectation at length. Figure 16 is a graphic depiction of all the expectations of the programme the black males expressed.

Figure 16: Black males' expectations

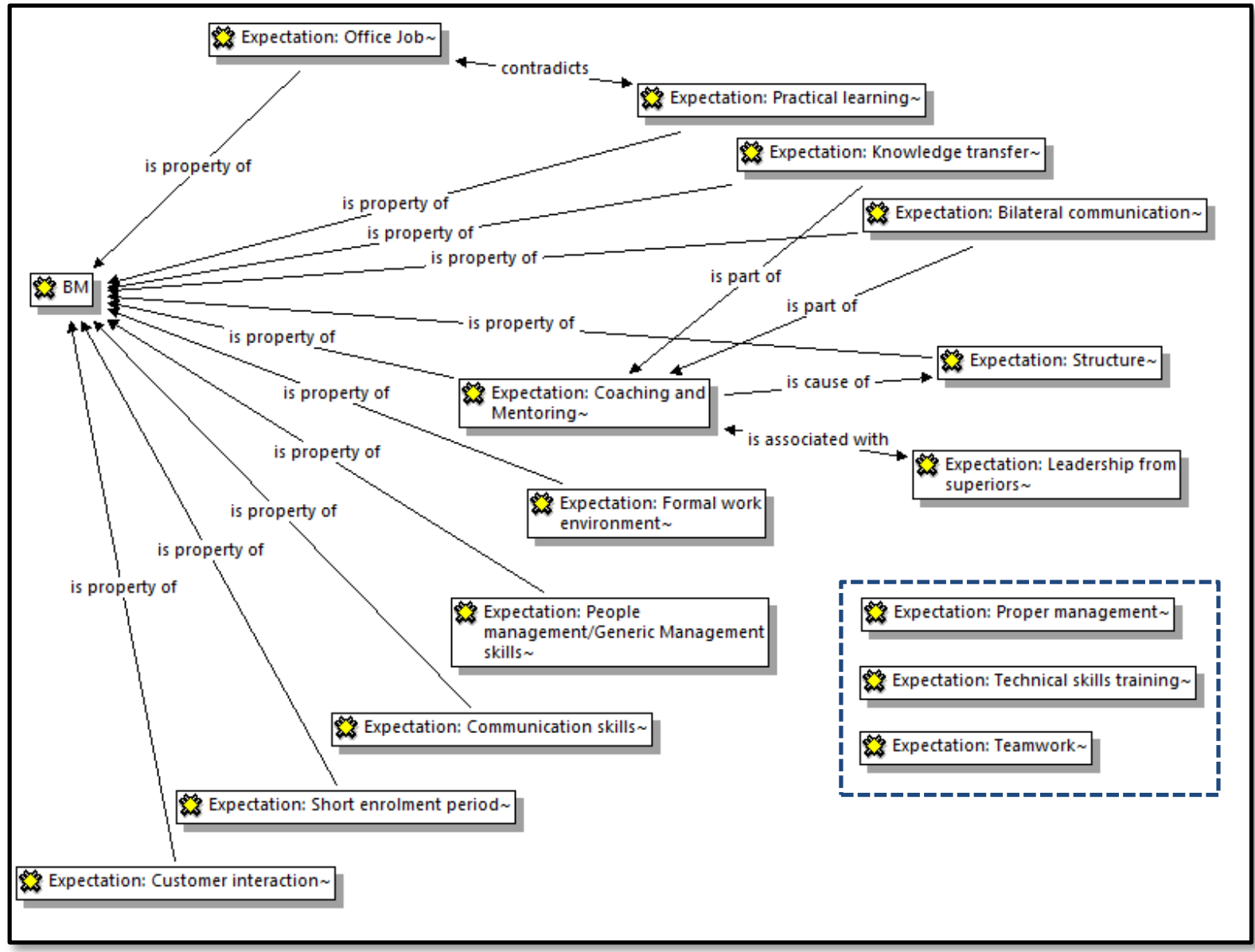

Atlas.ti mindmap of code occurrence relating to black males' expectations (pre-axial coding for the purpose of reporting findings)

\subsection{2 b) Expectation for the transfer of knowledge}

Closely related to the expectation for coaching and mentoring was an expectation for knowledge transfer. All four groups discussed an expectation for the transfer of knowledge from coach or mentor, to participant. 
The general consensus regarding the actual occurrence of knowledge transfer among the black females was negative. They state that there was an expectation in the beginning of their programme that their senior colleagues would be able to "show them the ropes" by manner of speaking. This expectation was however not fully met for some who have already successfully completed the programme. A possible reason proposed by the group is that of poor communications from the coach of what is expected of them with regards to their development. This inference was made based on the following and other similar quotes:

[BF] "I expected to get more knowledge, more competence, more info from the manager..."

[BF] "Always we have to find out information from them, but then, at the end of the day, there are certain things that you don't even know about..."

The black males also indicated an expectation of knowledge transfer when they discussed the level of competence expected from line managers, however, responses were not quite as negative. It seems as if the black males eventually obtained the required information and knowledge, just not as soon as they would have preferred. Some statements regarding their expectation of knowledge transfer include:

[BM] "Yes, ya ok, its different for because my eh, I'm getting like the right information if I ask a branch manager but when you ask the next level or maybe different manager you are not getting, it's like you are not on the same page."

[BM] “...I used to have a mentor, and whenever I would ask him to give me the information he would keep me busy with tasks instead of giving me the info."

Some of the white male participants indicate that knowledge transfer would have been enhanced if they were better oriented in the beginning of their programme. Like the other groups, the white males also had an expectation to engage in knowledge transfer activities with experienced senior personnel, but what they mentioned that was not noted by the other groups, was that positive interactions may actually have a negative impact on knowledge transfer. The notion was that if the relationship becomes too "friendly" in nature, it may lead to incorrect knowledge being transferred, and because of the nature of the relationship, not be challenged (in terms of the correctness of the information). The group agreed with this opinion and some indicated that they have indeed experienced it. 
The white females had a definite expectation of in-depth knowledge of each department being transferred to them in the beginning of the programme. The white female group also expressed frustration about the rate at which knowledge transfer takes place. Their frustration was indicative of an expectation of a consistent stream of skill and knowledge to come their way. What they experienced, however, was too much repetition, and not enough consistent and on-going learning. Some related statements in this regard included:

[WF] "That's what I have got a problem with. I'm supposed to train in receiving but I've heard enough of people telling me I'm supposed to be taught by the back admin manager."

[WF] "Well I thought there would be a lot more information about the department itself..."

When discussing coaching and mentoring as well as knowledge transfer, all the groups raised various opinions about the structure of the programme. Experience of the programme structure was also included in the semi-structured focus group questions. The next section summarises specific responses about programme structure.

\subsection{2 c) Expectation for a more structured approach to learning interventions}

All the groups expressed an expectation for a structured approach to the learning programme. In this regard structure is used as an umbrella term in reference to sequence of interventions, planning of activities, and the formal and/or informal nature of activities.

The white male group expressed the highest expectation for structure and their general sentiment is captured in the following statement:

[WM] "You see because see now you start with a department and it has certain steps, a - z, but now you with stupidity instead of starting with a, you are starting with $j$. The whole picture is not coming together so it takes you longer to get the whole picture."

Responses indicated that the white males expected most of this sense of structure to their programme to come from personal interactions with their superiors. There were numerous mention of "guidance" from line management and other senior members of management. The perception among white males were that they would have progressed faster through the programme, had they received the necessary structure they expected. It was mentioned that in cases where this expectation of structure to the programme was not 
met, it was due to operational pressures. The focus among white females, in terms of an expectation of structure, was the structure gained from interactions with their specifically assigned coach. They mention that proper management of their programme, on the coach's part, would have addressed this expectation, as is evident from the following quote:

[WF] “...ya, I mean if I do waste three times, for three different departments, I think I know how to do waste..."

[BF] "I expected us to get lessons each and every week."

The preceding statement is indicative of the high level of interaction the black females expected from their coaches. The group also indicate that they expected a sense of structure to originate from these interactions with their respective coaches. They mention that they wanted to know, from the beginning, what areas to focus on, at what time, for how long. At times, when this expectation was not met, standard training material offered some form of structure.

The black males indicate confusion in terms of progression through programme components. This indicated an expectation of structure, but not necessarily in what form. The black males, unlike the other groups, did not express exactly what kind of structure they expected, or how it should have been communicated to them. They also expressed confusion (which is captured in the quote which follows) regarding business standards, since not all branches are exactly the same. This may indicate that they were not only expecting structure from the programme, but structure in the organisation in general.

[BM] "When I started my training, they didn't tell me that you are going to start somewhere and then go somewhere else."

\subsection{2 d) Expectation for practical learning}

In terms of the specific skills that were expected to be developed, one included the expectation of exposure to practical learning activities. All four groups indicated this expectation.

The black female group expressed concern about the balance between practical learning (which is mainly an application of technical skills) and the more "soft" management skills. It was evident from the group's discussions that they realised the importance of practicing technical skills, but they also feel that that is where the programme stops. Data suggest that the black females were of the opinion that learning is too heavily focussed on the technical 
component of the programme. Their expectation for the development of technical skills through practical learning and their concern for the balance between practical learning and soft skill development are captured in the following two statements:

[BF] "When I started, I expected to learn, you know, I knew I was not going to be a manager at the get-go, you know, I expected to learn first and then become a manager."

[BF] "I expected to know the technical skills first, you know, then after that, you know, you have to learn the management skills. But I didn't expect to be on the technical part all the time."

These responses could be indicating that the biggest concern for the black males was their expectation of a more structured approach to on the job training. The impression given was that tasks are being done by programme participants, but not from a training and development approach and instead from an operational approach, as is indicated in this statement:

[BM] "I thought there was going to be an execution of on the job training"

[WM] "...when you start to go out and start with your department at least you have a background of that department already."

The white males shared the concern of the black males when briefly discussing this topic. They expected practical learning to be preceded by technical skills training, and accompanied with some form of mentoring.

The white female group expressed the expectation of learning the specific management skills which is associated with a set of technical skills. They mentioned observation (on their part) and inclusion in management activities quite frequently. For example, in the following statement, the white females are of the opinion that they (as trainees) should not only be developed on the technical component of a department, but also on the management component which is unique to that department:

[WF] "...I think exactly what she said, like we trained in the departments ourselves which is fine we know how to bake a bread, mould the dough, but there was never a specific time when you worked with the specific manager of that department to show me what management skills are supposed to go with that..." 


\subsection{2 e) Expectation to develop people management skills}

In addition to the expectation of the programme to make participants technically competent through exposure to practical learning activities, another specific skill that was expected to be developed was the ability to manage people. The expectation to develop people management and/or generic management skills was discussed by all four groups, but from selected quotes it was evident that the conceptualisation of what "people management skills" are and how it should be taught differed across the groups.

Discussions in the black female group indicated an expectation of becoming competent on all technical aspects of the business, followed by a focus on general people management skills. They did, however, mention that they expected the different skills sets to complement each other. The group expressed their perception of this expectation not being met as the technical skills development far overshadows that of general management skills development. Their expectation of the specific "people management" component emerges in, amongst others, the following statements:

[BF] "How to be a manager, how to control people"

[BF] "Ok, for me it was, if I had to manage people, then I had to know how this works."

The black male group indicated an expectation to be developed as leaders. This was evident by their mentioning of the word leadership as well as discussing concepts such as problem-solving and supporting subordinates with problems. The participants from the black male group also expressed the opinion that this type of skill should be developed, and not merely technical competence. This sentiment is shared by the white males.

[BM] "What I expected to learn, I think I'm getting it. Leadership skills like communicating with staff and being assertive."

Discussions among the white female participants seem to point towards an expectation of more management training and less technical skills training. Although the group acknowledged the necessity and their anticipation of technical skills training, they expected the skill of managing people to take up the bulk of their development. Some of the white females mention that insufficient management skills training and significant cultural differences resulted in difficulty to interact with fellow employees. These opinions are captured in the following two statements:

[WF] "I expected to learn about how to handle the people" 
[WF] "I expected to learn more about managing instead of doing the job itself."

\subsection{2 f) Expectation for a short training period before appointment as manager}

Responses pertaining to expectations about the programme were not limited to content. Participants also expressed opinions on the nature of the programme, one of which was the duration. Of the four groups, only the white female group did not express an expectation of a short programme enrolment period.

Among the black females, there was not much discussion on the topic, they only stated that they knew they were not going to be managers from the beginning, but they did, however, expect their appointment to happen sooner (than the prescribed 12 month training period).

The black males expressed variable expectations in terms of how long the training period would be, but all of those expectations were shorter than the standard training period of 12 months. There was also an expectation that, after successful completion of the programme, that the candidate would be immediately appointed. One thing mentioned in the black male group which was not noted by the other groups, is that the way in which their positions was advertised may have led to certain unrealistic expectations. This opinion was supported by the rest of the group and is captured in the following statement:

[BM] "Due to the advertisement that they are using, probably it's what makes us to expect more. When they advertise, they don't say we are looking for trainee manager, they say we are looking for branch managers, admin managers, sales managers and service department managers..."

What stood out from the discussions, the white males had on this topic, was not necessarily an expectation of a training period shorter than the standard 12 months, but rather that the standard period would be strictly enforced throughout. They mentioned that the training period was discussed with them, but that some of them are over the prescribed time and are still on the programme.

\subsection{2 g) Expectation for an "office job"}

Another expectation pertaining to the nature of the programme (as described by participants), was that of the training programme, as well as the management position subsequent to the successful completion of the programme, to be an "office job". The expectation of being in a position which involves mostly office-based activities and the 
related typical "office hours" was only discussed among the black female and black male groups. The central idea regarding this theme emerged from the following statements:

[BF] "When I started here, I expected to be, like, a manager. Doing the job like a manager, not being used to do the job like a staff member."

[BF] "I was expecting myself sitting in the office the whole day."

[BM] “I wasn't expecting working like long hours..."

[BM] "I had never realised that when you come into the company that I would be on the floor most like an operational manager..."

The black female group agreed that they had an expectation of working out of an office setup. The content of the training programme was therefore contrary to what they expected since the programme involves "hands-on" activities, and also since you do not act as a manager, before you have proven your competence on the work at hand.

The black males also indicated that they did not expect the amount of involvement in dayto-day activities. The black male's discussions also indicate that they expected to work out of an office and through others, instead of doing a lot of the work themselves. The black males also indicated that they did not expect the long hours involved, not only in their training, but in the organisation in general.

\subsection{2 h) Expectation for bilateral communication}

Some responses also indicated that the individual or group expected an open two-way channel of communication between participant and superiors. This communication is related to all stakeholders involved in the development of the candidate and also includes a desire on the candidate's part for self-expression. This trend did not occur in the white female group.

[BF] "Some of them, when you wanted information, they did not have the information they are supposed to have. I was expecting them to know at least a little bit, because of the experience that they have, I expected them to have a little bit more information..."

[BF] "Then you ask, can you help me with this then they say, no I'm busy..."

As indicated from the preceding quotes, candidates in the black female group indicated the opinion that if there was better communication between the participants and line 
management, there would be better coaching and trainee managers will also be able to assist management with their own management duties.

[BM] "I was expecting open communication with superiors."

The black males indicated some frustration with the communication channels they experienced with their managers. This implied an expectation on their part to be able to communicate with the individuals who have been assigned to them for their development. The black males also indicate an expectation of being involved and being able to provide input into their own development (which would have been facilitated through communication with coaches). The group seem to have expected an environment that is conducive to communication and the expression of ideas and opinions.

In the white male group there was not an in-depth discussion about communication, but they did suggest that problems in the retail store (not limited to problems associated with the training programme) are partially due to poor communication as inferred from this statement:

[WM] "It's an eye-opener to realise that behind the scene it's actually not going that well. It's a matter of communication..."

\subsubsection{Perceptions of developmental needs}

In terms of the different groups' perceptions of developmental needs, there were needs raised with a subsequent indication that the need was met and some were indicated as not have been met. There were, however, developmental needs identified without an indication of whether or not it has been met by the programme. The latter did not seem to indicate a dominant theme and will therefore not be reported on.

\subsection{3 a) Developmental needs not met by the programme}

Of all the developmental needs mentioned as not being met, the proper management of individual programmes, coaching and support during the programme, and developing people management skills were mentioned by all four groups as not being met by the programme. Some quotes in this regard are as follows:

[BF] "Honestly speaking I do love the system a lot. I don't think that there is a problem with the program, I do believe that there are problems individually in our branches..." 
[WM] "Yes, absolutely, but it depends on what you do. So the application of you in the revamp. You are not playing a manager's role if you are doing the work and the merchandiser is sitting"

[BM] "I disagree. The timing is correct. It's just a matter of like, in the branch level, the managers the style that they are using..."

[WF] "Um, for our region, I would say that our files weren't used in our region, and it doesn't really help. No-one even thinks about it. We would do it, but it doesn't actually help. It's time wasting. Even when you write a test, nothing is even in the test or in general there."

In respect to proper management of the individual programme, the data suggests that all groups felt that their development in the programme was not being properly managed. The opinions in this regard seem to be that available resources are being underutilised and that participant development is not being managed properly by custodians of the programme at branch level.

From these similarities across groups, it was interesting to note that the white males indicated the highest need for the proper management of their programme, based on code frequency during discussions in the focus group. The white male group felt that their development is not being managed properly in terms of the sequence of learning activities, time spent on different activities and access to learning aids. Some of the participants in the white male group mentioned that they move from department to department based on what seems like operational needs of the various branches, instead of their developmental needs. They feel that the transition between departments and the change from one learning intervention to the next is not managed in a way that aids learning or development, but rather supports operational needs. Some also feel that there is too much of an emphasis on practical learning, instead of mentoring on how to manage properly.

In general, the black females expressed a need for more development that would help them with self-confidence. During the focus group discussions, they made statements like "I don't know how to handle a difficult situation" and "I am too soff". Some also indicate that it is their current level of knowledge regarding disciplinary procedures and skills on how to handle insubordinate staff which might be hampering their ability to manage people.

The developmental need for more structure during the programme emerged in all the groups, except for the white females. The males (black and white) indicated the highest need for structure, based on the frequency of the code in their discussions. From the two male groups, the code "Developmental need: Structure" occurred the most in the black 
males. Most of the black males' responses seem to indicate that the need for structure is not an inherent development need. Instead, the need for structured activities and transition between them seemed to be the result of the need for proper management of the programme not being met. They mentioned an increased need for structure when there are deviations from their original development plan, and when they discussed structure they mention an expectation for "standards" and "standard practice" across business units.

The sequence of learning interventions also seemed to be problematic for the white male group. The group indicated that although they had not yet fully reached a level of competence which they feel comfortable with, they were often moved to the next department. The white males' discussion also point to the lack of consistency in the manner in which candidates are assigned various activities and moved between departments. This sentiment was also shared by the black males who mention that they were often moved to a new department without feeling confident enough on the content of their current department.

[BM] "The manager will decide you are going to another module without fully completing one of the modules"

[BM] "I just need someone to tell me what is expected of me."

[WM] "(Facilitator) So in terms of structure, you experienced many disruptions? (Majority of participants) Yes."

[WM] "I'm not happy with the sequence of the departments, because one day they need you in a stocktake and one day they need you in the deli and you can't finish something..."

[BF] "I've been training for a long time and it still feels like I don't know what I'm doing."

Curiously therefore, all but the white females indicated a need for some form of structure as being necessary to successfully complete the programme. Among the black females there seemed to be a general confusion around expectations. Participants therefore feel that they do not know when they will be moving or what criteria are used for the decision to move them to another department. The need for structure and consistency came out as a developmental need which was not met for white males as well. However, in this group it was said that this situation cannot be generalised to all branches. As trainee managers move around different departments and branches, it was noted that making a statement like "there's no structure" would be inaccurate and unfair to some branches. There were only some situations with a lack of structure and consistency. 
The two male groups indicated that standardised training material did not address their perceived developmental needs. Some statements in this regard were as follows:

[WM] "That is my biggest concern. It takes you hours and hours to finish the assignments, but its duplication that you are doing."

[WM] "(Facilitator) How has the content of the programme assisted you with dealing with these challenges? - (Respondent) Nothing"

[BM] "...most of the stuff that I was given to instruct or to delegate the staff or to motivate the staff, when the manuals arrived, when I read it, it was very easy for me."

The black males mention specifically that they expected the training material to assist with them developing their people management skills, which it did not. The main concern among the white males was the perception that the work (written assignments, report analysis, etc.) is a lot of duplication and did not seem to link with them developing their skills as a manager or leader.

The developmental need for experienced mentoring was not met during the programme according to the black males and the black females. The main concern among the black females was that they did not have someone to put all the information into perspective. The group mentions that they receive very good classroom training as well as on-the-job training, but would then like a mentoring session with their senior line managers to contextualise and put all the information into perspective. They mentioned that this would be very beneficial, especially for those who are new to the retail industry since they receive very large quantities of new information at a time. The black males indicate that in some instances they are assigned to a mentor who has a lot of experience, and who can do the job, but they cannot explain the process to the trainee manager.

[BM] “...but now the person doesn't know the information. Then in anycase it becomes more difficult for you..."

[BM] “...if you go with a question to ask that person, they don't know how to answer the question, but they know how to do it practically..."

[BF] "There is also the case that some of our managers do not know what elearning is."

[BF] "With me, um, the OJT is there the classroom training is marvellous, the mentoring is lacking..." 
There was a significant gender difference in the developmental needs indicated as not being met. Both white and black females indicated that the programme did not help them with their developmental need to be more assertive. The discussion from one participant in the black female group captures the general feeling of those in the focus group. She indicated that while she knows she has to develop her assertiveness as it is part of the requirements of the job, but she doesn't know how. She said: "I am too soft". Likewise participants in the white female group expressed similar sentiments. The white females indicated their preferred management style to be pleasant and friendly, but they do not know where to draw the line between being someone's friend and being their manager. The white females also agreed that they find it hard to be "strict" in the most direct sense of the word.

The white male group was the only group that did not indicate more time to develop skills as a developmental need. The black females and black males indicated that the expectation of the amount of work which needs to be covered, and the desired level of management skill to be developed, is not in line with the time allocated to complete the programme; whereas the concern with the white females was that the time which their coaches have available for them is not in line with the amount of coaching the programme dictates. Both black groups (males and females) indicated that they would need more time to complete the programme successfully. A participant from the black male group mentions that receiving additional management responsibility is a contradiction in terms. Consensus among participants pointed to a contradiction in the way the programme is implemented. Increased responsibility assists with the development of management skills, since trainees are expected to manage a section of the operation and deal with consequences of not meeting targets, but at the same time, this then requires additional time for the overall programme as it is not included in the normal planned sequence of development events. Some quotes illustrate this finding:

[WF] "I like went to my service department manager and told her that I wanted to do the recon and she just told me that she was busy..."

[WF] "A lot of times I've gone to my managers and said, this is what I've noticed, please explain it to me or help me, only to hear that they don't have time..."

[BF] “I feel like I need more time..."

The black male and black female groups also indicated that the development of administration skills was not addressed sufficiently. The black females mention that this is 
as a result of inadequate exposure to learning activities relating to administration in the business. Some of their quotes on the development of administration skills were as follows:

[BF] "Um, for some of the ladies who has not went to admin yet, do not understand me when I say, the Admin file does not cover everything."

[BM] "Me as well. I need development on admin. Because I am not used to the admin exposure in store level."

\subsection{3 b) Developmental needs met by the programme}

The most interesting trend which came out among all four groups, was the dual opinion of the level of coaching and support participants felt they received during the programme. All four groups agreed that coaching and support is necessary for the successful completion of the programme and in the previous section it was stated that the majority of participants felt their developmental need for coaching and support was not addressed. However, this was only with regards to in-store coaching and mentoring. According to participants, this lack of coaching and support was due to time constraints, as well as the competence levels of certain line managers who were required to act as coaches (with varying focus on these perceived causes across the different groups). At the same time, participants from all groups indicate that they did receive some form of satisfactory coaching and support, but not in the same way. The two white groups (male and female) seemed to be of the opinion that more senior individuals (refer to Figure 2: Management Hierarchy in Chapter 1) are more interested in spending time on their development than the coaches they interact with daily. The two black groups (male and female) discussed more frequently receiving support from fellow participants. The following quotes from the different race and gender focus groups illustrate the differences that were found:

[WM] “That's because mangers don't always help as they should but I don't think it's because they don't want to, I just don't think they have the time..."

[WM] "Our regional manager is very strict with the trainees. He wants to know how you are doing, what's your progress and stuff like that."

[WF] "There just isn't enough time. Not even to get to your own work, other than help the trainee." 
[WF] "In my training, I've done all of that. With the mentors that I had, if something needed to be done, she doesn't send somebody else, she sends her trainee, because I needed to know how the specific task had to be done. She always said "it's the trainee's job". She knew how to do it, but I needed to learn it."

[BF] 'We have to help each other. It doesn't matter whether you are a trainee or if you are an assistant manager, or if you are the branch manager, sometimes you need help."

[BF] "I don't want to say I'm slow, but some of the other trainees know things more than I do. They pick up information better than I do, so sometimes I just feel like I don't know. I do get support from the other trainee..."

[BM] "I need assistance, someone who can coach me."

[BM] "If we see like someone is not coping, we try to help that person to build to the same level as the rest of us. So that why you won't see a difference because we are always helping each other to build the same level."

Apart from the white female group, all the groups felt their need to develop technical skills was addressed during the programme. The white females did not mention that it was not addressed per se, but simply did not mention it while discussing skills which were developed. All participants realise that in order to be a good manager, one must be technically competent. This is why most of them mentioned, or agreed that, developing technical competence is an important component of the programme. The data suggests that there was no lack in exposure to technical skills development for most of the participants.

[BM] "Ya I think the both go hand and hand whereby, let's say he has produced those good, you can't manage him if you don't even know the recipe..."

[BF] "I never had a computer at home, but right now, I'm a computer wizz..."

[WM] "(Facilitator)... which component would you say is the most beneficial or most value adding? (Respondent) I would say it's the reports on the system..."

Unexpectedly, the black females also discussed the fact that the technical skills they learnt while on the programme have also benefited their personal lives. Skills they mentioned was cooking, baking (as part of Service Department training) and being able to 
work on a computer. The black males, however, did not necessarily feel that the ratio of technical training and other component of the programme were appropriate. They feel that technical training make up the bulk of their development and from that they feel they have become "glorified staff members", instead of competent managers. The white males did not elaborate much on their opinions regarding technical skills training, but they did mention a few examples, and that it has been beneficial to them. 


\subsubsection{Treatment during the programme}

\subsection{4 a) Positive interactions}

Positive interactions were mentioned by all four groups and involve positive interaction between programme participant and other stakeholders in the organisation. Positive interactions mentioned included interactions between participant and management, participant and staff, or between fellow participants. The white females discussed this topic the most and the black males the least. Some illustrative quotes pertaining to the white females' experience of positive interactions were as follows:

[WF] "(Facilitator) What do you think will happen if you were more included in the management team? Would you still interact like that with your fellow participants? (Respondent) Yes I think so, because we still learn from each other."

[WF] "The most of the knowledge I got when I started, was from my fellow trainees when I started who already worked in the department for 2 or 3 or 4 months before I started."

[WF] "I have been respected by some of the staff members; others won't really listen to you because they think you are just one of those who just comes and go."

The majority of the group agreed that mutual learning had taken place through positive interactions with fellow participants. Some participants in the white female group even suggested that these kinds of interactions with fellow participants are a requirement for successful completion, even if coaching and mentoring is optimal. The data suggested that positive interactions with fellow participants provide guidance and support during the programme.

For some participants in the white male group, interactions with subordinates were only positive after appointment as an assistant manager. The reason proposed for this was that subordinates only comply after the participant formally received management authority (as a result of appointment as assistant manager). There was a consensus among the white males that interactions amongst each other and interactions with superiors were of a positive nature. One could tell from the discussion that the positive interactions between fellow participants are reminiscent of camaraderie and support. One participant mentions that interactions with superiors were not always positive, but continues to say that he does not want to make a generalisation (the rest of the group agreed with this statement in the sense that some interactions with senior individuals are less than positive, but that it is not the 
norm). What stood out from this discussion, however, was that the white males felt they had better and more positive interactions with participants from a different race group. The proposed reason for this was the possibility of professional jealousy that may be present among participants of the same race and gender group. Quotes illustrating the white males' stance on interactions with various stakeholders are as follows:

[WM] "In the beginning the black trainees were more helpful than the white ones."

[WM] "It comes from different sides, from two different sides. Sometime you get some of the managers who will be like that and then some who are not. So I don't want to make a generalization. You don't feel like that because it doesn't come from all sides."

The black males, similar to the white males, mention that they get along better with participants from a different gender group. They did not, however, elaborate on interactions with individuals from different race groups. No real reason for this was proposed. One participant in the black male group mentions that they treat each other like brothers and sisters. It was mentioned that they "eat together and treat each other like friends", so one would assume then that the black males and females also got to know each other on a more personal level during the programme, like it was mentioned by the white females. This finding emerged from statements like:

[BM] "Even in our store, we are treated like brothers and sisters."

[BM] "My experience with ladies is no problem because as I would say like almost always I was surrounded by trainee ladies, because like I was the only guy in the store of the trainees."

[BF] “...I don't want to say I'm slow, but some of the other trainees know things more than I do. They pick up information better than I do, so sometimes I just feel like I don't know. I do get support from the other trainee..."

The truly positive and supportive nature of the interactions between participants is illustrated by the preceding statements. One of the black females mention that she feels that she sometimes pick up information slower than her fellow participants. In those cases, she said, her fellow participants are always willing to help her. The group agrees that this positive interaction among participants addressed their need for support. 


\subsection{4 b) Perceived level of influence of own behaviour on situational outcomes}

With regards to treatment during the programme, it was also discussed that one's own behaviour may influence treatment and situation outcomes in general. These responses indicate a realisation of, or a reference made to, the participant's own behaviour influencing the behaviour of others. Own behaviour influencing outcomes was discussed in all but the black female group, and was perceived differently by each group.

Among the black males, the data on this theme had a distinct focus on cultural norms and practices. They mentioned having to manage staff members that are older than them (programme participant) and explain that the way in which you approach the situation is very important. One participant proposed the following example to illustrate the point: If you as a younger manager give an instruction in a rude or domineering manner to an older staff member, the staff member would more often than not tell you that they will not recognize your authority since you are much younger than them. However, if you give the same instruction to the same person in a friendly, polite and respectful manner, there would hardly ever be any resistance. Mutual respect was mentioned several times in this regard. The black male group acknowledged that one's own attitude has a significant impact on how others treat you. Some statements that led to this finding include:

[BM] "To be on my experience somebody to give you respect, actually we don't just demand respect form the staff, we earn the respect from the staff, by respecting them."

[BM] "I think it's the manner of giving instruction. Each person has their own way of giving instruction, so the language that they are using, that is where the problem comes. Sometimes, maybe the way they approach those old ladies, that is the problem."

Within the white male group there was some debate about how and whether your own behaviour affects the outcome of a situation and how others treat you. Half of the group agreed that your own behaviour and attitude has an impact on the outcome of a situation. They explain by saying that they have worked with fellow participants in the programme who had a poor attitude and (according to them) a false sense of entitlement. One participant referred to such an attitude as being "career suicide". This led to poor cooperation from management as well as subordinates. On the other hand, it was also mentioned that developing in this programme cannot happen if you sit passively and merely behave like a "yes-man". Carrying on in this vein it was said that you also need to assert yourself and "stamp down your authority" in order to gain access to the knowledge and skills necessary to successfully complete the programme. One participant within the white male group also 
mentioned that outcome and behaviour is not absolutely and directly linked. According to him, sometimes a positive and inquisitive attitude is met with resistance and poor cooperation from both line management and subordinates. Additional illustrative points are as follows:

[WM] "It also depends on how you stamp down your authority because you don't really have that big authority. Also, I agree it will depend from different people if how you, um, approach the people or get information. Tell them listen what's your problem?"

[WM] "We did experience with some of the trainees we worked with is that attitude was a big problem. The trainees' attitudes towards other trainees. You make difficult for yourself, because that is the people who is going to help you in the future, so that can be like career suicide also."

The white females, on the other hand, viewed this topic from more of an "outsider's perspective", as opposed to the other groups who discussed it from a "personal experience perspective". One participant briefly mentions that a poor attitude will in all probability be met with resistance, but then the group discussed the idea based on observations of line management. They mention that in many cases, the way in which line management communicate with staff does not facilitate proper working relationships. They also acknowledge that poor behaviour has a negative impact on the situation and outcome thereof.

[WF] "What I learnt in my program, is respect. If you don't respect your colleagues, they will not respect you. But as a management, respect can go that far."

[WF] "In general, in our company we have a really bad way of speaking to our staff. You won't get co-operation that way, you will lose all your staff that way." 


\subsection{4 c) Resistance from subordinates}

Another theme which emerged as part of the experience of treatment during the programme was resistance from subordinates. The data suggest that in some cases resistance from subordinates may be linked to own behaviour as discussed in the previous section. It is important to note here that programme participants do not have formal authority and therefore do not have any staff members officially reporting to them, but they are however required to act on behalf of a manager as part of on-the-job training. Some responses indicated that the participant experienced difficulty with staff members following instructions and accepting authority, while the participant was still enrolled in the programme. This theme emerged from all four of the group discussions.

[WM] 'Um, I can also add to that, um, I don't think it's just authority, I think it's also a problem with race, because I've witnessed in my store there's been some black trainee managers and some white trainee managers. Then there are staff members who have been working for many years and they don't like sharing knowledge with a young white boy or young white girl."

[WM] "I feel that when you are in the programme the staff does not respect you."

The preceding statements illustrate the white males' stance on the possible causes of resistance from subordinates. In addition to resistance from subordinates being attributed to the theme previously discussed, namely perceptions of trainee managers not having legitimate authority, the white male group were the only group indicating that resistance from subordinates may be as a result of racial tension. Supporting the findings from the previous section, one participant also mentioned that from personal experience, resistance has also been the result of a poor attitude on the part of the (trainee) manager. The majority of the group agreed with this statement.

The white females also made mention of one's own attitude possibly leading to resistance from subordinates - specifically the way in which one communicates instructions to subordinates. The white females agreed that cooperation from staff is varied. In some instances they would receive cooperation, and in some instances not. A concern among the white females, however, is that they do not always feel empowered to control subordinates when they are faced with resistance. They seem to be uncertain about the legitimacy of their authority, and the scope thereof. Some distinctive remarks in this regard were:

[WF] "I have been respected by some of the staff members, others won't really listen to you because they think you are just one of those who just comes and go." 
[WF] "Well ya, at the time, because it was still really early in my program. But for instance now, that lady will greet me, she will do something if I ask her to, but that's now."

The main theme that emerged in the black females' discussion on the topic of resistance from staff is that they suspect staff to have a perception that black females should not be seen as an authority figure. Illustrating this finding are the following statements:

[BF] "Sometimes when a customer comes to you and explains a problem then they say they want to talk to a manager, and I say I am the manager and when the white trainee manager walks past, then they will explain to them. Even the staff."

[BF] "(Facilitator) Do you feel that there is a perception among some people that black females do not have authority? (Majority of respondents) Yes."

There is also mention of resistance due to age differences. The data suggest that black female participants have positive interactions with fellow participants and most line managers, but however struggle with cooperation from subordinates. As with the black females, in the black male group the main theme within resistance from subordinates was that of the age gap. The back males mention recurrently that instructions are met with either a statement of superior experience (as opposed to that of the trainee manager), or an expression of insubordination based on an age difference (with the subordinate being much older than the manager in training). This finding was inferred from statements such as the following:

[BM] 'If you've got five trainees in the store, they won't like all of us. If they don't like you from the beginning, they will say 'you are not even the age of my first born so why are you telling me what to do."

[BM] "I've been told some things and when coming to staff that are like the same age as me, when I give instructions then they say oh well you are just a trainee." 


\subsection{4 d) Perceptions of professional jealousy}

In some of the preceding sections, participants cite professional jealousy as a possible source of negative interactions. Professional jealousy in this instance refers to a perception that feelings of contempt exist towards another person, based on the other person's level of success, relative to your own. This theme emerged from all four groups.

The black female group suggested that poor management of their programme by certain members of line management might be the result of their fear that the programme participant may become direct competition. The group also agrees that they experience more occurrences of the so-called professional jealousy from members of the same gender group. This finding correlates with data pointing towards better interactions between groups of a different gender. The black males share the opinion of the black females that poor management (specifically the quality of mentoring received) is a result of the fear of possible competition. The following statements capture the groups' stance on the possible occurrence and impact of professional jealousy:

[BF] "I just feel than men, they can open up to me. I can ask questions and you know we can communicate better, but now with women I don't know we have this thing where we are looking at each other like no, she thinks she is better."

[BM] "...he would keep me busy with tasks instead of giving me the info."

The white females share the same opinion as the black females, in that they perceived participants from the same gender group to be more jealous than their male counterparts. One participant in the white female group also mentioned that there seems to be jealousy between participants from different branches (irrespective of gender or race). The reason she proposes for this is because of perceived preferential treatment on the part of the "jealous party".

[WF] "The guys will also come to you and assist you. The ladies it's not like they won't help you, if you ask them, but they won't come to you. They guys will come out of their own."

The white male group indicated a perception that professional jealousy might be present in the beginning of a relationship between fellow participants, but then later would diminish as the participants get to know each other. This finding is illustrated by the following statement: 
[WM] "I think it's professional jealousy or something like that. It's like I told you, after a while, you start to know them and you are more accepted."

\subsection{4 e) Perceptions of differential or equal treatment}

As part of investigating perceptions of the nature of treatment during the programme, responses were elicited to ascertain perceived differential treatment, relative to fellow participants. In this instance "treatment" includes treatment from management, staff and or fellow participants.

[BF] "When we do inspections, the branch manager says if you see any problem on the sales floor, please say it. But when I do say something, another manager at the back will say 'C, shut up'..."

[BF] "But then when the other guy came, the white guy, and said the same thing to the lady, she did not say anything about that. It's things like that we experience. They never listen. When you talk to them they don't listen because you have a problem with them apparently."

The black females expressed concerns of perceived differential treatment due to possible nepotism, and racial- and gender discrimination. The group agreed that differential treatment does take place, as is evident from the preceding quotes, however, it was also mentioned that differential treatment is not always the case, and that in some instances the group does feel that they are being treated fairly.

One concern mentioned by the black males was that of possible favouritism from line management, but in terms of differential treatment the black males refer to differential treatment from staff members, where some do not want to accept their authority. Data seemed to indicate a perception that archaic form forms address influence the extent to which black males is able to exert their authority. These findings are illustrated in the following quotes:

[BM] "You see with treatment from staff, especially in our age group. If it is a white trainee, they will call him 'meneer', but if you give them an instruction, they will call you by your first name. Some of them when you give them an instruction they won't listen to the instruction, but when a white trainee comes and gives an instruction, they will do it immediately."

[BM] "Yes, I have experienced that, but in different manner, not necessarily when I give an instruction. In a way of that they have that mentality that if I 
should say, white people are still superior to black people, but when you give an instruction they know they are in a work environment and they have to do it and they just do it. The only thing is that the white person is 'meneer' and you they call you by the name."

When probing about whether or not the groups experience fair and equal treatment, as opposed to differential treatment, the responses among the black females were mixed. No dominant themes emerged in this regard. It could be said, however, that the responses indicating some kind of significance when probing about "equal treatment" was the expression that some experiences of treatment during the programme was not always pleasant, but not necessarily perceived as being "unequal".

Among the black males, the overwhelming response was that treatment from line management was fair and equal across all subgroups (race was mentioned specifically). It was mentioned, however, that when placed on special assignment in some instances the treatment in other branches was not so equitable.

[BM] "I think treatment of the managers is fair to me because if you are a manager, if you are going to teach either person you must know exactly how to pack a shelf."

[WM] "I think overall we've been treated good..."

[WM] "Sometimes you are the only one from a certain race group and then you might get excluded from the group."

[WM] "I don't think it's just authority, I think it's also a problem with race, because l've witnessed in my store there's been some black trainee managers and some white trainee managers. Then there are staff members who have been working for many years and they don't like sharing knowledge with a young white boy or young white girl."

Curiously, the white males cite the same issues as the black males. They also mention that treatment from management can generally be considered as fair and equal, but that staff sometimes resists their authority. Racial differences are cited as the most probable cause. Data therefore indicate that the black males experience differential treatment based on their race (which is predominantly the same as the staff members) and the white males also experience differential treatment from staff based on their race. Whereas the black females indicate differential treatment from management, and white females do not mention any occurrences of differential treatment. 


\subsection{4 f) Positive interaction with members of a different gender}

Some responses regarding treatment during the programme yielded evidence of more preferable interactions between groups of different genders. All but the white male group discussed these experiences.

The black females, without proposing a reason for it other than "men being more relaxed", indicated that working with fellow participants of the opposite gender was better than working with participants of the same gender. Other emerging themes provide possible explanations for this occurrence. Exactly the same sentiment was shared by the black male participants and the white female participants. The white female participants also mention that their male counterparts have been more supportive than participants from their same demographic. Some quotes illustrate this finding:

[BF] "I feel like I get along with men, better than with women. Men of all races."

[BM] "My experience with ladies is no problem because as I would say like almost always I was surrounded by trainee ladies."

[WF] "Yes, I also get along with the guys way better than with the girls."

\subsection{4 g) Perceptions of alienation}

The white male and white female groups expressed experiences of exclusion and alienation. This alienation refers to exclusions from groups of participants, social work groups, or the management team in general.

There was mention in the white male group that alienation or exclusion only occurred in the beginning of the programme but then diminished over time. The proposed reason for this was that the exclusion was a result of racial differences, as is indicated from the following statement:

[WM] "Sometimes you are the only one from a certain race group and then you might get excluded from the group."

[WF] "Yes, this week is already going better than last week. But I still think that skin colour does have an effect."

From the preceding quote, it is evident that the white females share the sentiments of the white males. The general perception in the white female group is that alienation or exclusion 
also occurred as a result of racial differences. The impression, however, was not that this exclusion was intentional, but rather due to "racial cliques" that formed. Like with the white males, it was mentioned that the state of racial cliques among fellow participants dissipated as time went on. 


\subsubsection{Content of the programme}

\subsection{5 a) Classroom learning}

Response data on classroom learning returned mixed responses across the four groups. Responses ranged from quite negative to very positive. Of the four groups, the white males were the only group in which the theme of "value adding classroom learning did not occur". On the contrary, the white males felt that in many cases classroom learning was essentially a waste of time.

[WM] "(Facilitator) How has the content of the programme assisted you with dealing with these challenges? (Respondent) Nothing."

Among the white females, there was a general consensus that classroom learning was beneficial to their development in the programme as well as providing structure in the absence of coaching. Some participants, however, mention that they are not always able to put the new learning into practice due to time and other operational constraints. In cases where they do apply knowledge and skills from classroom learning, it has assisted with problem solving and decision-making. The white females therefore felt that classroom learning is a necessary basic foundation. This inference was made from the following statements amongst others:

[WF] "They always say, if you want to know ask, but how are you supposed to ask something you don't know about? So it's good to go to the class to get guides and stuff so you can know what to ask."

[WF] "Ya, but when we go back we remember all of stuff especially if the class was interesting. We remember a lot of stuff so when you go to the problem you remember, ah, that's how you do it."

The black females shared the opinion of the white females in the sense that classroom learning was beneficial and that they found it more structured than OJT because of the paceand in some cases, the absence of coaching. The black females also mentioned that it addressed their need for support, but that classroom learning was difficult to apply.

The black males agreed that classroom learning has contributed to their growth during the programme. The group agreed that of their classroom learning sessions attended so far, their systems training sessions was the most valuable to them. Like the other two groups, the black males also stated that, although classroom learning was beneficial to their 
development, applying and practicing new skills in their stores was not always possible. Some illustrative quotes include:

[BF] "For me personally, you know, sitting and listing to that person guiding me, teaching me. For me personally it's where I can grasp anything."

[BM] "Classroom training they helped me to grow much, so we getting information."

\subsection{5 b) Training material}

During discussions on the content of the programme, all four groups proposed opinions on the standard training material. One should note here that training material refers to training manuals, training DVD's, workplace assignments and programme modules.

The black females agreed that the standardised training material assisted with their development. Data suggests that material assisted in cases where there was an absence of mentoring and it also assisted participants with overcoming some developmental challenges, like time spent on them by line, lack of structure, not receiving enough responsibility etc. As with classroom learning, the black females also mentioned that applying knowledge from standard material was sometimes difficult. Some significant quotes include:

[BF] "It does help a lot. What I'm saying is that, most of the things that we go there and ask them, we can always go to the files and find the information there."

[BF] "Um, I, ok, the manuals. The manuals that we have been getting, they really help a lot. It gave me a line about what should I look at."

[BM] "The coursework also helped me a lot because it assisted me in identifying where I lost money."

The preceding statement is an example of how the black males felt that standardised training material gave practical solutions to business problems. Data therefore suggest training material as being instrumental in addressing developmental needs. They also stated, however, that the standard learning material does not sufficiently address all issues pertaining to people management development needs. Some stated that the content of the learning material assisted with their growth, but does not elaborate on whether this growth is as a manager or as a leader. 
Responses from the white males on training material were mixed. Some participants indicate that the standardised training material aided in their development, but one participant also mentioned that the standard learning material (especially assignments) is repetitive, wastes time and does not sufficiently prepare one for assessments. The group agreed with this statement but data still suggest that even though this might be the case, it does not, according to the majority of the white males deem the standardised training material as being without value. These findings are substantiated with the following statements:

[WM] "(Facilitator) Do you feel that the content facilitates that necessary growth during the training period? (Respondent) I think it makes it possible, because if I'm in a three week or four week time period in a certain department I've got to learn how to manage that department."

[WM] "The biggest thing on the content is that it does not match up to the assessment. That is my biggest concern. It takes you hours and hours to finish the assignments, but its duplication."

Some of the white females also agreed that formal assignments from the standardised training material are a waste of time due to the fact that they do not get properly evaluated. However, this is not evidence against the utility of training material, but rather an indication of the programme not being properly managed or material being under-utilised. Others in the white female group stated that they have found standardised training material to be useful, but only if combined with proper coaching. Some mixed responses include:

[WF] "Well, it's given me a lot of knowledge on every department and all that."

[WF] “Um, for our region, I would say that our files weren't used in our region, and it doesn't really help. No-one even thinks about it. We would do it, but it doesn't actually help. It's time wasting."

\subsection{5 c) Experience of on-the-job training (OJT)}

In terms of programme content, OJT emerged as a dominant theme, however, the four groups did not reflect on in in the same manner. Of the four groups, based on frequency of responses, theme occurrence for OJT was the highest amongst the white females.

The white female group agreed, with the exception of one participant, that OJT was a more beneficial learning experience than formalised classroom training. This was further enhanced when trainee managers were involved in line management activities, and even 
receives additional management responsibility of their own. Some illustrative responses were as follows:

[WF] "...I think doing the hands-on job is better than reading, because if you are reading it tells you how to do it, but when you do it you know that you can actually do it..."

[WF] "When I was training, to be straight honest, I learnt more in the store where I was training. This is because they were including me in everything that was happening..."

[WF] "OJT we get a lot of, that's quite fine."

[WF] "I grew the most the day I got appointed at the end of last year. Like E said, when you relieve a manager, you learn more when you are in that position."

The white female group also mentioned that the formal learning material and classroom training does not adequately prepare one for assessments and that the assessment is more geared towards learning that has taken place in OJT.

Data from the white male group echoed the sentiments of the white females in the sense that they also feel that OJT offers a more beneficial learning experience than that of classroom learning. The white male group goes so far as to say that a lot of the standard learning material is redundant and that they learn more from OJT and coaching. These findings were drawn from responses like:

[WM] "In-store training. I learnt more from on-the-job training than from the assignments."

[WM] "I think the company is wasting a lot of money on the manuals, giving each and everyone a manual. They can rather apply it into a much more compact branch manual and say it's an overview, which gives you guidelines."

The black males indicated that they grew from OJT, but there was not clarity on whether this growth was as a manager or as a leader. They mentioned that in this component of the programme, you get exposed to long working hours and you are under real pressure - just like you would be in the actual position. The participants in the black male group stated that OJT aided in the development of managing people and they have, as a result, experienced growth. This was inferred from the statements below, amongst others: 
[BM] "The skill that I grew in most is to function well under pressure. On this program, you get exposed to working long hours, and you are under real pressure, you are required to work under those circumstances. So now I know I can work as a manager and handle that pressure. Working in the store shows you how it will be as a manager one day."

[BM] "Store inspections for every day helped a lot."

The idea that classroom learning is a superior learning experience than OJT also came out in the black female group, like it did in the white female group. In the black female group, however, more participants agreed on this. They mention that while engaged in OJT, mentoring was lacking. The data therefore points towards classroom learning not necessarily having more utility than OJT, but was experienced as such due to the group's higher need for support. The black females, like the black males, indicated that they feel OJT is the best method of learning how to manage subordinates. Some responses on this finding included the following:

[BF] "(Facilitator) What impact has OJT had on your development? (Respondent) I think it's very good. I think that it will balance you."

[BF] "With me, um, the OJT is there the classroom training is marvellous, the mentoring is lacking, we are not mentored enough."

Many responses pertaining to OJT related to responsibility received during the training period. These responses relate to responsibility generally associated with a departmental/assistant manager. In all cases this responsibility is more than would normally be assigned to a programme participant, and has certain consequences associated with it. All four groups mention receiving additional responsibility at some point during their enrolment in the programme.

The black females did not discuss this topic in detail. One participant did however mention that once when she transitioned from one department to another she had a feeling of authority. This new level of authority aided in her development. This opinion was not disputed by other members of the focus group. From this one may ascertain that it is not actual authority which aided in the participant's development, but merely the perception thereof.

[BF] "The branch I was working in I felt more like I was a staff member because of the things I was doing there. Burt since I moved to another 
branch I feel like I am in charge. I feel like I've developed enough to be a manager."

Among the black males it was indicated that receiving additional management responsibility addressed development needs and as a result assisted in the participant's growth. Especially in the case where a participant would be required to act on behalf of the departmental manager. It was also mentioned by the black males, however, that receiving additional responsibility would sometimes contradict the development need for more time, as acting on behalf of a line manager would require a disruption in the participant's structured training plan. There was also a concern about receiving responsibility when the candidate does not yet feel confident enough to receive it. Responses included:

[BM] "My manager has to use me to control his merchandisers. They take instructions from me instead as from him."

[BM] "So there I could feel the responsibility was given to myself and there I can say that I have grown."

[BM] "For me the pressure was too much. As I said I'm relieving as a line manager, but I also still have to finish my training. That's too much pressure."

[WM] "I spoke to some of the guys who's recently been appointed. They can tell you the same, that responsibility and accountability starts when you get appointed. While you are in the programme you are not responsible."

[WM] "I agree with $K$. They throw you into the deep end and you have to swim. You have no choice."

[WM] "(Facilitator) So are you saying that the larger amounts of pressure forces you to develop as a manager? (Respondent) Yes, that and the increased responsibility."

From the listed quotes as well as others, it is inferred that the white males also expressed the opinion that increased responsibility promotes development, as it increases pressure and therefore forces the candidate to learn quicker and apply learning quicker. The group agreed that development either after appointment (as one of line management), or acting on behalf of line during the programme, is enhanced due to the increased pressure to do so. One concern among the white males, however, was subordinate resistance. They explain that some staff members did not want to accept authority until the participant has been officially appointed. The white females (like the black females) did not elaborate much on 
this topic, but also mentioned that receiving additional management responsibility has promoted their development. The group states that "hands-on" training and acting on behalf of a line manager is a far superior learning experience than any other.

\subsection{5 d) Content/Assessment mismatch}

With the exception of a few responses leaning towards a correlation between the content of the formal training material and the content of assessments, the majority of respondents indicated that the programme is insufficient in preparing one for assessment. This, however, could be due to poor management of the programme, deficiencies in the programme or inconsistent assessments. All four groups discuss occurrences of what they perceive to be a mismatch between the content of the programme and eventual assessment(s).

The black females indicated an expectation to be assessed directly on information contained in some piece of standardised training material (file, manual, DVD, etc.). It was mentioned that assessment questions are based more on general knowledge which should have been picked up during OJT or some other activity, rather than one of the formal sessions (once again supporting the inference on the group's high need for structure). The following statement supports this finding:

[BF] "When you go for an assessment, most of the questions they will ask you are general questions. They don't ask you questions from the file."

[BM] "I personally feel that you are not assessed on the content of the material. I mean how else will you be signed off on a module and go to senior personnel to be assessed for appointed and then you fail, even if the work is supposed to be the same. Why? It's almost impossible and irrational."

Among the black males, there to, was a definite experience of a mismatch between assessments and what the candidate experiences during the programme, as indicated by the preceding quote. One proposed reason is that the content of the standardised material is not detailed enough and participants are then left to the mercy of OJT and mentoring, which is not always consistent throughout branches and coaches. There was also a suggestion that the content/assessment mismatch may be the result of a subsequent content/practice mismatch.

Data from the white male group point towards irregular assessments by stating that detailed coverage of coursework does not fully prepare one for an assessment. The white males also mentioned duplication in the content, without any real benefit. 
Like the black females, the white females also indicated an expectation for assessments to be directly linked to standard material content and not programme content in general (including OJT and mentoring sessions for example), agreeing that there is a general mismatch between programme content and assessments. The white females, however, also suggest poor management of their programme as one of the principal causes of the mismatch between programme content and assessment. Some illustrative quotes on these findings are:

[WM] "No, what I found is that a lot of stuff that you are trained in, detailed stuff, you won't find in your file. Then you do your assessment and you are being assessed on something totally different."

[WF] "Even when you write a test, nothing is even in the test or in general there. The files are really only the basics."

\subsection{5 e) Content/Practice mismatch}

As mentioned in the previous section, the black male group suggested that a misalignment between course content and assessments to be one of the factors causing a misalignment between training and practice. Although this opinion was not shared across all groups, all four did indicate a perception of content/practice mismatch. "Content" in this instance refers to standardised material like DVD's, course modules and training manuals, but does not refer to coaching, mentoring or OJT.

Half of the black male group stated that they have difficulty implementing newly acquired knowledge in their immediate work environment. Suggested reasons for this is that in many cases the learning material only covers basics and is not detailed enough, and also the fact that not all branches operate in exactly the same way. This made applying standardised procedures difficult at times. The black males agreed that standardised content (especially classroom learning) provides a good guideline, but nothing more.

The black females, on the other hand, only stated that a content/practice mismatch is mainly due to some of the standardised material not covering all the necessary information. Supporting these finding are illustrative quotes such as the following:

[BM] "I want to add to what $E$ and $C$ has said, because if you look at, I have the one manual and it only gives the basics, and it does not give you the details of what is happening." 
[WM] "(Facilitator) How has the content of the programme assisted you with dealing with challenges? (Respondent) Nothing."

One member, of the white male group, stated that the content of standardised material does not assist with problem solving or filling in knowledge gaps in the absence of a coach, but does not elaborate on it. The rest of the group did not dispute this position.

In the white female group a statement was made that, although knowledge and skill from classroom learning could sometimes assist with problem solving, applying that knowledge is not always possible. It was not elaborated in detail why this is, but one reason that was proposed was time constraints. Supporting statements from the female groups for these findings include:

[WF] "Ya, it's not like we have the time to go and sit and go through the material again and to say, ok now I'm going to do this, but if the class was interesting I will remember it."

[BF] "Um, for some of the ladies who has not went to admin yet, do not understand me when I say, the Admin file does not cover everything. Maybe some of the theory, like the cash office theory, but not that when you have to sit and capture your admin report, or your fruit \& veg recon. Most of the things the admin does every day, they are not in there." 


\subsubsection{Experience with fellow participants}

There was a general consensus among the black females that more coaching and support is necessary for certain components of the programme; partially because of the sheer volume of some components of the programme. They also stated that the nature of some of the components makes it difficult to complete the section in the prescribed time, especially with the level of coaching available. Some of the black female participants did, however, mention that classroom learning and interactions with fellow participants addressed the need for support to a certain extent. Support was also sought from other employees and not necessarily only fellow participants. Quotes supporting the finding that interactions with fellow participants supported participants from the black female group include:

[BF] "I don't want to say I'm slow, but some of the other trainees know things more than I do. They pick up information better than I do, so sometimes I just feel like I don't know. I do get support from the other trainee."

[BF] “We have to help each other. It doesn't matter whether you are a trainee or if you are an assistant manager, or if you are the branch manager, sometimes you need help."

[BF] "In our store, we as trainees participate and help each other with whatever kind of job or task."

The black males shared the sentiment of the black females in that they feel the coaching they were supposed to have received from line management was lacking. The group felt that they do communicate when the need assistance, but does not always receive it. In other cases, they may have received guidance on a specific task, but when it came to applying or practicing their skill, they were not afforded the opportunity to do so. Similarly to the black females the black males also received support from fellow participants in cases where formal coaching and/or mentoring was lacking. Supporting this finding are the following statements:

[BM] "...I will agree as well. If we see like someone is not coping, we try to help that person to build to the same level as the rest of us. So that why you won't see a difference because we are always helping each other to build the same level."

[BM] "There are too much trainees so you can like help each other. At the store where I was working previously, I was the only trainee there." 
The participants in the white male group were also of the opinion that the support from fellow participants replaces the support the need from assigned coaches. One participant mentions (to which the group agrees) that he feels most trainees perform on the same level as a result of the amount of support from fellow participants. Some, however, mentioned that senior personnel (non-branch) spend time on them when they do make branch visits, however this does not happen on a regular or consistent basis since the frequency of branch visits is dictated by operational requirements and not employee development needs.

[WM] "Our regional manager is very strict with the trainees. He wants to know how you are doing, what's your progress and stuff like that."

[WM] "In our stores you don't get that support from your managers, so the trainees are training each other."

Some of the white females mentioned that the level of support during the training period was not what it should have been; however after appointment members of the management team became much more supportive. The group proposed operational pressures as the main reason for this. Evidence of these occurrences is outline in the following quotes:

[WF] "There just isn't enough time. Not even to get to your own work, other than help the trainee."

[WF] "When we come together for a training session we hear this trainee is working like this and that trainee is working like that. Not all the branches is the same, so you learn more from each other."

The white females responded to these statements by saying that they have come to realise, through interactions at training session where they are all together, that the programme is not being managed the same way in all branches. This was followed by a general consensus that, because of this situation, programme participants need to learn from each other. 


\subsubsection{Perceptions of growth during the programme}

\subsection{7 a) Personal and professional growth}

When discussing growth, the focus group facilitator attempted to elicit responses on participant perceptions of professional growth. All four groups mentioned growth at some level. This professional growth was then subcategorised into growth as a leader and growth as a manager. From the available data it was not always clear whether the participant perceived his/her own growth as being growth as a leader or growth as a manager. The facilitator did not define nor clarify the two terms (manager/leader) in order to avoid possible data corruption. In this section, responses are reported on which suggest growth during the programme, but does not elaborate on whether the growth is as a manager or as a leader. Illustrative statements from the black female group were:

[BF] "I can say that I have grown, because firstly, I have seen the importance of leading by example as a manager."

[BF] "I find the content helped me develop, because as I say, most of the time, there is no time, or managers are busy and stuff, so when I consult my file..."

The black females mostly mentioned technical skills development, like that of operating a computer, although there was also mention of the more "soft skills" also being developed. An interesting comment by one of the participants, however, was that she "learnt the importance of leading by example, like a manager". This statement makes it difficult to ascertain if she perceives her growth to have been as a manager or as a leader. Remarks on growth from the two male groups were positive in general, as in the following quotes:

[BM] "...all of the training sessions that I have attended so far has helped me..."

[BM] "The skill that I grew in most is to function well under pressure."

[WM] "I agree with $K$. They throw you into the deep end and you have to swim. You have no choice."

[WM] "My sales manager was on leave for two weeks and I learned from that."

The black males all agreed that they experienced growth during the programme. Their discussion implies that this growth was the result of structure provided by facilitated classroom training, the support from fellow participants as well as additional responsibility 
received during OJT. The white males also mentioned the fact that additional pressure, resulting from increased management responsibility, forced them to develop.

[WF] "I grew the most the day I got appointed at the end of last year. Like $E$ said, when you relieve a manager, you learn more when you are in that position."

[WF] "The most of the knowledge I got when I started, was from my fellow trainees when I started who already worked in the department for 2 or 3 or 4 months before I started."

From the two preceding quotes, it is inferred that, like the two male groups, the white female group also expressed the opinion that receiving additional management responsibility during the programme contributed significantly to their perceived growth. According to this group, growth was also facilitated by support from fellow participants, OJT and interactions with colleagues, as well as inclusion into daily management activities.

\subsection{7 b) Growth as a manager}

Some of the data specifically points towards the group perceiving growth to have been as a manager during enrolment in the programme. All four groups discussed perceived growth as a manager.

In the black female group all the participants, apart from one individual, felt that they have grown as managers. One, however, viewed growing as a manager as negative when compared to being a leader. This is because it seems that her perception of a manager is one who does not consult or communicate with staff.

Consensus among the black males was that they've also grown as managers, specifying that receiving responsibility assisted with this growth. Some illustrative examples from the data gathered from the black male and black female groups include:

[BF] "I feel that I have grown as a manager now, but I still need to improve myself."

[BF] “...ever since I started with the program, I grew as a manager."

[BM] "...someone can just come in and give guidance and show them then they can come and fix those problems. It helped me grow as a manager, because as a manger you should know how to use the system..." 
[WM] "You have to manage the systems, you have to manage the people. I haven't been here long, but I'm getting into that - to manage every aspect of the company. If you don't manage properly, then the wheels come off."

The feeling among white males was also that they have grown as managers, as opposed to leaders. One participant, however, proposed that management and leadership are not mutually exclusive, but rather that they are interlinked. One other participant agreed with that statement, but then also explained (from his perspective) that most management development takes place when you are appointed or if you receive additional management responsibility, and not on the normal day-to-day programme activities. The white females did not elaborate on this topic, but most indicated that they feel like they've grown as managers, as indicated in the statement below:

[WF] “Um, I feel more like a management...”

\subsection{7 c) Growth as a leader}

Very few responses pointed towards perceived growth as a leader. The theme only occurred in the white male and white female groups. In the white male group, the only instance was when one participant indicated that he felt leadership and management is interlinked. He did not, however, elaborate on whether or not he has grown significantly as a leader. More than half of the white female group indicated that they have grown as leaders during their enrolment in the programme.

[WM] "I would say management and leadership goes hand in hand because you have to manage your department but also lead your team."

[WF] "I had an answer for everything he asked. So I think it's also a little bit of management, but more leadership." 


\subsubsection{Results from data sampled from exit documentation}

\subsection{8 a) Introduction}

As part of increasing the validity of the study, a sample of exit documentation was drawn, in order to triangulate this data with data gathered in the focus groups. A random sample of candidate names, voluntarily exiting from the programme, was drawn from SAP and their exit documentation extracted from personnel files (as indicated in Table 11). Voluntary implies that all terminations from the programme resulting from misconduct, death, GROUP

NUMBER OF CANDIDATES' DOCUMENTS

\begin{tabular}{|r|c|}
\multicolumn{1}{|c}{ GROUP } & $\begin{array}{c}\text { NUMBER OF } \\
\text { CANDIDATES' } \\
\text { DOCUMENTS }\end{array}$ \\
\hline BLACK FEMALES & 8 \\
\hline WHITE FEMALES & 6 \\
\hline BLACK MALES & 9 \\
\hline WHITE MALES & 10 \\
\hline TOTAL & 33 \\
\hline
\end{tabular}

Table 11: Exit documentation information disability, or any other cause other than resignations have been excluded from the sample. The sample was drawn for a period of four year pre-dating the date of the focus group data collection sessions.

The organisation makes use of a standardised exit interview. However, this standard format was not used, or not submitted in all the cases of the random sample. Therefore, the term "exit documentation" is used throughout this section. Exit documentation includes standard exit interviews, resignation letters and management reports. Also note that exiting form the programme also implies leaving the organisation. In the case of all of these candidates, employment by the organisation was dependant on the successful completion of the programme. Due to confidentiality restraints, the raw documentation is not included as part of this document, but only a summary of responses per group.

\subsection{8 b) White Males}

\begin{tabular}{|l|r|c|}
\multicolumn{2}{c}{ DIMENSION } & $\begin{array}{r}\text { NUMBER OF } \\
\text { CANDIDATES }\end{array}$ \\
\hline \multirow{2}{*}{ Notice period } & Provided notice period & 9 \\
\cline { 2 - 3 } & Resigned with immediate effect & 1 \\
\hline \multirow{3}{*}{ Reason for exit } & Better opportunities elsewhere & 5 \\
\cline { 2 - 3 } & Undisclosed personal reasons & 2 \\
\cline { 2 - 3 } & Perceived unfair treatment & 1 \\
\cline { 2 - 3 } & Lack of growth opportunities & 0 \\
\hline \multirow{2}{*}{ General } & No reason & 2 \\
\cline { 2 - 4 } & Resignation overall positive & 7 \\
\hline
\end{tabular}

Table 12: Summary of exit documentation data for white males 
From the sample of exit documentation that was drawn, most of the candidates in the white male group provided notice before leaving the programme. All of these notice periods were the minimum as per their contractual agreement. From the white male group, only one candidate resigned from the programme with immediate effect. From the white male group, half left the programme because of a better opportunity with a different organisation, two provided no reason, two cited personal circumstances, and only one mentioned that they felt they had to leave the organisation because of unfair treatment. A summary of the responses are tabulated in Table 12.

The majority of the documentation the candidates supplied to inform the company of their resignation was positive. In some cases the candidate comes across as genuinely regretting having to leave. Most thanked the organisation for the opportunities afforded to them and wished their branch and line manager the best for the future.

\subsection{8 c) White Females}

\begin{tabular}{|r|r|c|}
\multicolumn{2}{c}{ DIMENSION } & $\begin{array}{r}\text { NUMBER OF } \\
\text { CANDIDATES }\end{array}$ \\
\hline \multirow{2}{*}{ Notice period } & Provided notice period & 2 \\
\cline { 2 - 3 } & Resigned with immediate effect & 2 \\
\hline \multirow{3}{*}{ Reason for exit } & Better opportunities elsewhere & 2 \\
\cline { 2 - 3 } & Undisclosed personal reasons & 1 \\
\cline { 2 - 3 } & Perceived unfair treatment & 1 \\
\cline { 2 - 3 } & Lack of growth opportunities & 0 \\
\hline \multirow{2}{*}{ General } & No reason & 2 \\
\cline { 2 - 3 } & Resignation overall positive & 2 \\
\hline
\end{tabular}

Table 13: Summary of exit documentation data for white females

Among the white females some candidates provided a notice period before exiting from the programme, some left with immediate effect and from some of the documentation it could not be established whether or not the candidate provided a notice period. What distinguished this segment of the exit documentation most from the other three segments is that it was significantly more neutrally toned than the rest, i.e. what needed to be said was said and no active stance was taken. In two cases, however, the resignation letter was positive in tone and indicated that the only reason for leaving the programme was because of a better opportunity elsewhere. The candidates didn't seem to have a real opinion of the organisation or programme. Some left because of better opportunities elsewhere, some left 
providing no reason and in one instance the candidate mentioned leaving the programme due to unfair treatment. A summary of the responses is tabulated in Table 13.

\subsection{8 d) Black Females}

\begin{tabular}{|l|r|c|}
\multicolumn{2}{c}{ DIMENSION } & $\begin{array}{c}\text { NUMBER OF } \\
\text { CANDIDATES }\end{array}$ \\
\hline \multirow{2}{*}{ Notice period } & Provided notice period & 1 \\
\cline { 2 - 3 } & Resigned with immediate effect & 7 \\
\hline \multirow{3}{*}{ Reason for exit } & Better opportunities elsewhere & 3 \\
\cline { 2 - 3 } & Undisclosed personal reasons & 1 \\
\cline { 2 - 3 } & Perceived unfair treatment & 0 \\
\cline { 2 - 3 } & Lack of growth opportunities & 1 \\
\hline \multirow{2}{*}{ General } & No reason & 4 \\
\cline { 2 - 3 } & Resignation overall positive & 3 \\
\hline
\end{tabular}

Table 14: Summary of exit documentation data for black females

In the sample of exit documentation drawn for black females exiting the programme prematurely, the most prominent response is that of leaving with immediate effect. With the exception of one candidate, all the black females from the sample exited with immediate effect. Of these, only three mentioned that they are leaving because of a better opportunity elsewhere, four provided no reason, one cited personal circumstances and one mentioned that her reason for leaving as a lack of opportunities for growth. This was the only group in which a candidate mentioned lack of growth opportunities as a reason for leaving, which is interesting as she was enrolled in the development programme when she entered the organisation. A third of the candidates' responses were positive.

Although there was no explicit mention of unfair treatment or that being the reason of prematurely exiting the programme, in some instances the emotion during the resignations was not clear. The letter will start with the fact that she regrets having to leave, but then also speaks unkindly of one or two individuals she had contact with during her time in the programme. A summary of the responses in the exit documentation of black females are tabulated in Table 14. 


\subsection{8 e) Black Males}

\begin{tabular}{|l|r|c|}
\multicolumn{2}{c}{ DIMENSION } & $\begin{array}{r}\text { NUMBER OF } \\
\text { CANDIDATES }\end{array}$ \\
\hline \multirow{2}{*}{ Notice period } & Provided notice period & 6 \\
\cline { 2 - 3 } & Resigned with immediate effect & 3 \\
\hline \multirow{3}{*}{ Reason for exit } & Better opportunities elsewhere & 1 \\
\cline { 2 - 3 } & Undisclosed personal reasons & 1 \\
\cline { 2 - 3 } & Perceived unfair treatment & 1 \\
\cline { 2 - 3 } & Lack of growth opportunities & 0 \\
\hline \multirow{2}{*}{ General } & No reason & 6 \\
\cline { 2 - 3 } & Resignation overall positive & 5 \\
\hline
\end{tabular}

Table 15: Summary of exit documentation data for black males

Like the other male group, the sample of the exit documentation for the black males indicated a notice period before officially exiting from the programme. What stood out the most from this group was the fact that most did not provide a reason for leaving. One cited better opportunities, one candidate mentioned personal reasons, one candidate mentioned unfair treatment and one candidate mentioned leaving to study full time. From more than half of these responses there was an overall positive tone, where they mentioned that they regret having to leave the company and also wish management the best for the future. A summary of the responses for the black male segment of the sample is tabulated in Table 15. 


\subsection{Discussion}

\subsubsection{Introduction}

In this section, dominant themes in the findings from the focus group data are discussed. The discussion is anchored in existing leadership development models as discussed in the literature review, and also explains evident themes, and linkages between themes, grounded in existing leadership development theory pertaining to gender and race issues. By examining dominant themes and keeping in consideration existing research, the following main research questions will attempted to be answered:

- How do participants belonging to different race and gender groups experience the Retail Group's leadership development programme (LDP)?

- Do participants from different gender and race backgrounds feel that their race and gender affect their experiences in a retail group's LDP?

- Are there differences in how different race and gender groups evaluate the content of the programme?

- Do participants from different gender and race backgrounds feel that the programme addresses their developmental needs?

- Are there differences in how different race and gender groups experience peer interactions within the LDP?

- Are there differences in how different race and gender groups experience developmental support within the LDP?

The discussion is supported by statistics on code occurrence as well as graphic depictions of code linkages. As noted in the previous chapters, all code statistics and code network graphics were set up and derived from Atlas.ti. The discussion focuses on race and gender group experiences in and of the programme. Other organisational influences and experiences may be mentioned for contextualisation purposes, but will not be discussed in detail.

\subsubsection{Existing Theoretical Models of Leadership}

\subsection{2 a) The WICS Model}

As part of the literature review, the programme interrogated in this research was positioned as a legitimate leadership development programme (LDP) from the theoretical framework of leadership development as proposed by Sternberg (2003). The proposition was that said programme can be classified as a LDP as the design incorporates all four dimensions of Sternberg's (2003) model, namely wisdom, intelligence, creativity and 
synthesis. During the literature review, this positioning was done from a design perspective. It was explained that the way in which the programme is designed, and based on its intent, all four dimensions are indeed covered. This section will now discuss the level at which each participant race and gender group experienced the programme, which was the main research question. It will attempt to discuss whether or not implementation of the programme succeeds in achieving programme intent, and if race and group experiences differ in terms of programme implementation.

\subsection{2 a.i Intelligence}

The programme intends to provide participants with foundational knowledge and an opportunity to apply new knowledge. The black males indicated that they expected to gain knowledge during their programme and that the knowledge transfer was expected to transpire from interaction with experienced mentors. The black males suggested, however, that in cases where the level of knowledge transfer was less than expected, that they experienced it as a result of professional jealousy and the fear of competition. That said, the black male group also mention that, although standardised training material did not meet all their developmental needs, classroom learning provided structure during the programme and that classroom learning contributed to their learning. This group also mentions that learning new skills was complicated by the fact that practices are not always consistent across branches. This made relying on new information, as credible, problematic for the black male group.

The black females were of the opinion that proper knowledge transfer did not occur because of poor management of the programme, as well as perceived lack of knowledge among some assigned coaches. They do, however, mention that classroom learning and standard learning material provided structure and assistance with overcoming some challenges during the programme, for example coaches not providing them with information. On the other hand, the black females also state that in some cases the learning material did not correspond with business practice.

Some of the white males were of the opinion that their coaches were not sufficiently equipped to train them. They also mention that some of their training session facilitators did not meet their expectation in terms of competence. Like the black females, the white males also experienced difficulty in getting access to the information they needed. The group did not raise any significant opinions about classroom learning, but some mentioned that they felt the standard learning material, especially the workplace assignments to be a lot of duplication. The white males also indicate that their need for solving problems was not 
addressed mainly due to the fact that they did not receive coaching on how to identify problems or any suggestions on what corrective measured to take.

Some of the white females indicated that they needed more depth and detail during their training period. The proposed reason for a lack of depth and detail was that of poor management of the programme. The group agreed that classroom sessions served a necessary foundation in that it provides a knowledge base, provides structure and also seemed to be the white females' preferred mode of learning. The group also indicated that learning material was of good quality, but that it was not properly used by coaches (or in some cases not used at all), as a result of operational pressures. The white females, like the white males, also mentioned that problem solving skills was not developed to a satisfactory level. The proposed cause was that the training material does not address this type of skill. The white female group did mention that assessments addressed this topic, but that the coursework did not fully prepare candidates in terms of problem solving skills.

All together the data suggested that the programme does not fully succeed in addressing the "intelligence" component of leadership development. Being able to critically comment on content is an indication that the programme's selection process is successful in sourcing individuals with the required level of cognitive ability. However, some participants were of the opinion that access to all the necessary information was not in place. The proposed reason (from participants) for this situation was different across the race and gender groups. The black males indicated possible professional jealousy, the white males cited lack of competence and both female groups suggested poor management as the cause of insufficient knowledge transfer from coach(es) to programme participant. Another significant deficit on the "intelligence" dimension of the programme is that of application. In order for intelligence to develop, new knowledge must be subsequently applied. Data suggested that this was not always possible due to operational pressures as well as differences between practice and programme content. The data also suggest that participants' ability to recognise, recall, evaluate and judge information is not optimally developed due to poor management of the application of new learning.

\subsection{2 a.ii Creativity}

Developing creativity is aimed at fostering innovation and creative problem solving. The programme is designed to develop creative management thinking through mentoring and inclusion in everyday management activities. The black males stated that a need for more time to work through all the content, as well as a content/practice mismatch arising from perceived improper management of their programme - a situation which got seemingly worse as participants alternated between branches. The black male group also stated that 
they were at times confused as to how they are progressing, and what section of the work to cover, after the prior section has been successfully concluded. It therefore came as no surprise that the black male group indicated the highest need for structure during the programme. Interestingly though the black males could not elaborate on exactly what type of structure it is that they require. The group, however, feels that their need for structure during the programme, is/was not an inherent development need, but arose as a result of the way in which their programmes were managed. This stance is supported by the fact that the group did not indicate an expectation for structure, but later in the discussion the need for structure emerged as a theme of discussion. The perceived poor management of the programme was also implied in stating that applying new skills was problematic and that access to resources was limited.

Had creative thinking been developed to the desired level or to the level as intended by the programme's design, the black male group would have been able to propose solutions to stated challenges. During the discussion, problems and challenges were merely stated from a "victim" type of mindset, without any indication of possible solutions arising from it. This could either imply that the group lacks the inherent ability to creatively solve problems, or it could be that the challenges were not suited to their level of development, or lastly, it could mean that there was not sufficient engagement with management or that mentoring did not take place in an effort to develop creativity.

Like in the case with the black males, the black females also cited improper management of their programme, but here it was perceived to be as a result of favouritism. The theme of structure also emerged amongst the black females, but in their case it was not only a developmental need, but also an expectation of the programme. Not meeting the expectation for structure from the group's perspective could possibly be a reason for the aforementioned assumption that favouritism exists among assigned coaches. They also indicated that they expected signed coaches to provide them with a sense of structure during the programme. The black females also stated that their need for structure became higher, as confusion about what was expected from them became more, due to a lack of interaction with coaches. Subsequently it was suggested from the black female group that, in cases where coaching was absent or access to resources was problematic, that they received support, and learnt, from fellow participants.

In addition to indicating a high need for structure, like the black males, the white males indicated the highest need for proper management of the programme. The group proposes the reason for this being that the sequence in which learning activities takes place is not promoting development. The group agreed that structure during the programme was expected to come from superiors. The white male group was of the opinion that structure and proper management would assist their progression through the programme. There was 
also mention of access to resources as being problematic. The white males also stated that their development was aided by fellow participants, in cases where their coaches could not provide them with what they needed.

Learning from each other and mutual participant support is indicative of creative thinking. However, emphasis on a lack of proper management of the programme, as well as a distinct need for structure, may also indicate that the group does not feel in control of their development, which may be indicative of a strong internal locus of control (Sterbin \& Rakow, 1996). From this one may deduce that the mentoring process which is supposed to foster the development of creative thinking, is flawed in the sense that it does not accomplish what it sets out to in some of the groups, that the optimal level of mentoring is not taking place in some groups, or that the white male group simply does not have the inherent ability to think creatively and can therefore not be developed on this dimension of leadership.

The white females were the only group who indicated an expectation, and not only a developmental need, for the proper management of their programme. They could, however, not define what they meant by proper management. The group then further commented on this by saying that their expectation for proper management was not met, mainly due to the fact that standard learning material was not utilized properly. This situation was then further exacerbated by the fact that the programme was managed differently across branches where participants are placed, as well as operational pressures negatively impacting on access to resources for learning purposes. The eventual result from this situation was also that the participants started learning from each other, as opposed to learning from their designated coaches.

For the white female group, learning from each other and mutual participant support is indicative of creative thinking. This may or may not be as a result of programme influences. However, emphasis on a lack of proper management, as well as the need for structure (when referring to branches managing the training programme differently), may also indicate that the white females do not feel in control of their own development. This could mean that the mentoring process is deficient in the sense that it does not accomplish what it sets out to achieve in some groups, that the optimal level of mentoring did not take place for some groups, or that the white females does not have the inherent ability to think creatively in management situations and can therefore not be developed on this dimension of leadership.

\subsection{2 a.iii Wisdom}

According to the WICS model (Sternberg, 2003), leadership should be developed, in part, by promoting exceptional understanding, judgement and communication, competence, interpersonal skills, and social modesty. The instructional design requires these 
components to be addressed through experienced mentoring. With the exception of one participant in the white female group stating that she received exceptional mentoring, there was no evidence of a trend in any of the groups that this development effort took place as it should have. In all four of the groups interviewed, there was an expression for the need of mentoring from experienced individuals. What was interesting to note, however, was that insufficient mentoring was attributed by to different causes by different groups.

From the black male group's responses it may be said that "exceptional understanding" and "judgement" was not fully developed as some interaction where clarity on concepts was sought from participants were left unexplained. The group was of the opinion that only a portion of individuals assigned to provide mentoring was able to do so. The group proposed inadequate communication as one of the possible causes for this. From this group's opinion it might be possible that the "communication" component of the "wisdom" dimension was not optimally addressed. The other possibility, although unlikely, might be that the group members' communication skills might already be at the right level and that the deficit only exists with assigned mentors. Current mentoring practices also indicate no evidence of the promotion of "social modesty". If anything, it seemed to have allowed a personal self-view which could be labelled arrogance.

Some participants in the black male group believe that instances of perceived inadequate mentoring might be due to professional jealousy. Some mention that some of their assigned mentors can either not assist them or does not have much to offer them in the way of development. As a result, the black males mention that they need more time to complete the programme. So, although the group mentioned a technical skills development need to have been addressed, this need for more time may be an indication that the "competence" level of the wisdom dimension was not fully reached.

The black females also mentioned instances of "inability to assist" coupled with limited access to resources, but not as much as the black males. Nor did the black females suggest professional jealousy as a possible cause problematic access to resources. The black females were of the opinion that increased inclusion into everyday management activities would have had a significantly beneficial impact on their development. This inclusion, however, did not occur due to operational pressures (as stated by the group). The group was of the opinion that "teaching while doing" was not possible due to time and other constraints. The black females also indicated an expectation for structure and a strong need for guidance, which may be an indication that the development of "exceptional judgement" is not being addressed. Like the black males, the black females also indicated the need for more time to complete the programme. This may also be signalling the optimal competence level not being attained. 
Both white male and white female groups expressed a great expectation for coaching and mentoring. They did not, however, elaborate in great length how and why this would influence development. This expression of an expectation, for mentoring (and coaching), without mention of how this development need was addressed, may be an indication that some of the "wisdom" factors was not fully developed among white females and white males. It is proposed that this is only the case with the white females, since the white male group, interestingly, also mentioned the concept of professional jealousy, but not from management (like the black males) but from fellow participants and that this changed over time. Comparing the two white groups, in considering technical skills development, only the white male group stated that development needs were met. Not enough evidence was presented by the white female group to ascertain if they perceived development on technical skills to be of any significance. It is therefore suggested that there was some form of development since the occurrence of "professional jealousy" was said to dissipate over time (for the white males). This hypothesis is strengthened by the fact that the white male group attributed this change in relationships to better communication - another level in the "wisdom" dimension. In addition, with regards to the two white groups, it is suggested that the white female group did experience growth on the "communication" and "interpersonal skills" sub-dimensions of "wisdom", since they mention a quite high level of resistance from subordinates, which also dissipated over time (like in the case of the perceived professional jealousy with the white males) and that they now have very good work relationships with their subordinates. Earlier in the discussion it was mentioned that the black males attributed poor mentoring to improper communication. If the white males expressed a perception of "professional jealousy" between fellow participants dissipating over time due to improved communication, this may serve as support for the assertion that the black males were not able to communicate properly with their mentors. As the frequency of interactions with mentors are significantly less than interactions among participants, it could imply that without an active attempt (from mentor and mentee) to improve communication, this may impact negatively on the entire development process for the black males, if one considers their experience of "professional jealousy" from assigned coaches and mentors.

The data suggest that there are differences in how the "wisdom" dimension was addressed across groups. Based on responses on various expectations and how development needs were met (among other responses), across all four groups, Table 16 is a summary of perceived development that occurred on the "wisdom" dimension of the WICS (Sternberg, 2003) model. 


\begin{tabular}{|r|c|c|c|c|}
\hline & BM & BF & WM & WF \\
\hline UNDERSTANDING & $x$ & $x$ & $x$ & $x$ \\
\hline JUDGEMENT & $x$ & $x$ & $\checkmark$ & $\checkmark$ \\
\hline COMMUNICATION & $x$ & $x$ & $\checkmark$ & evidence \\
\hline COMPETENCE & $\checkmark$ & $\checkmark$ & $\checkmark$ & $\checkmark$ \\
\hline INTERPERSONAL & Not enough & Not enough & & evidence \\
evidence & $x$ & Not enough & Not enough \\
evidence & Not enough \\
\end{tabular}

Table 16: Summary of development on Wisdom dimension of WICS (Sternberg, 2003) Model

\subsection{2 a.iv Synthesis}

The final dimension of the leadership development programme according to the WICS model (Sternberg, 2003) is that of synthesis. The various programme interventions should facilitate a synthesis of new knowledge and skill into coherent leadership behaviours which influence subordinate behaviour towards organisational goals. The data suggest that participants experienced the most growth as a result of the synthesis of new skills, as opposed to growth occurring and enabling the participant to subsequently synthesise new skills and knowledge. The most significant obstacle was perceived to be that of operational pressures which hinder the application of newly acquired knowledge and skill.

The black males stated that OJT significantly contributed to their development. They propose receiving responsibility as the reason for this occurring. That said, they also stated that applying classroom learning was difficult due to the hypothetical nature of classroom scenarios. During OJT, however, the participants mentioned that they received management responsibility and had to deal with the consequences of their actions, which are assumed to have led to synthesis. There was also an indication of resistance from subordinates when asked to respond to the accepting of additional management responsibility. This could be due to a need for mentoring not being met, resulting in a subsequent difficulty with synthesising new knowledge and skill. This then, in turn, could result in the inability to exhibit desired leadership behaviours to influence subordinates.

The responses of the black females in this respect were similar to the black males in the sense that they perceived their growth to have occurred as a result of being forced to synthesise new knowledge and skill; and the black females also indicated difficulty with applying theoretical knowledge in a real life operational setting. The group, although acknowledging the value of OJT, also stated that they would have preferred more mentoring 
during this process, instead of merely being left to deal with the consequences of their own actions in their respective management positions.

The white males took a stronger position than the other groups in that they feel OJT to be a far superior learning experience than that of classroom learning. Two participants even stated that classroom training and formal learning material to be redundant in some cases, with which there was not any disagreement. The white male group did not indicate any objection to accepting responsibility during the training period and stated that this additional responsibility resulted in significant growth. The group mentioned the need for developing problem solving skills, but did not indicate to what extent receiving OJT responsibility has influenced this skill.

The white females noted that OJT was a more beneficial learning experience than that of classroom learning, but also that the OJT experience was enhanced if it involved inclusion into management activities (which did not always happen). Application of classroom learning also seemed to be problematic for the white females, although they do not elaborate why. The group did mention, however, that even though OJT is a beneficial learning experience, they did encounter difficulty with subordinates accepting their responsibility which hinders their ability to practice management skills. The group also state that OJT develops the problem solving skills assessments test, but that learning material does not prepare one for it.

There is consistency across groups regarding the benefit of OJT as well as the fact that OJT in itself promotes synthesis. There was, however, a difference between the males and the females regarding the need for supervision. All four groups agreed that receiving management responsibility in itself aided growth during the programme, but the two female groups indicated that they still prefer a certain level of supervision. This could imply that the females aren't able to fully synthesise information and therefore feel that they need continued support (further support for the assertion that poor mentoring leads to the inability to synthesise new knowledge and skills for black females), or it could also mean that the females have a more conservative approach to their actions and feel that accepting full management responsibilities is too much during the training period. There also seem to be a discrepancy between what the classroom learning aims to achieve and what happens in OJT. Classroom learning seems to be too standardised and too theoretical. To such an extent that in some instances it is hard to implement. Classroom learning, OJT and assessment practices also seem to be out of sync. Participants mentioned that the one does not necessarily assist or complement the other. 


\subsection{2 b) Gibson et al (2006) framework for studying leadership}

The model for studying organisational leadership, as proposed by Gibson et al (2006), suggests that a leader's traits, leadership behaviour and situational variables culminate in the leader's outputs. Although Stogdill (1948) has found that there are no evidence from which one would be able to distinguish between leader traits and non-leader traits, the trait perspective has resurfaced in contemporary leadership theory; specifically that of charismatic and transformational leadership (Yukl, 2010). The programme acknowledges that leadership as well as management are skills which can be developed by a sequence of planned interventions, but also assumes that certain inherent traits would increase the probability $^{2}$ of successful programme completion. Traits that are considered for the participant to gain access to the programme are basic characteristics like literacy and numeracy skills, basic problem solving as well as a competency framework comprising of the following competencies ${ }^{3}$ :

- Deciding and initiating action

- Leading and supervising

- Planning and organising

- Delivering results and meeting customer expectations

- Following instructions and procedures

- Coping with pressures and setbacks

- Analysing, relating and networking

- Achieving personal work goals and objectives

- Entrepreneurial and commercial thinking

- Applying expertise and technology

- Presenting and communicating information

Screening tests and a competency based interview would determine the level at which the candidate exhibits these competencies and allow the person access to the programme. This does not assume that possession of these traits is a guarantee of desirable future leadership behaviour, but it assumes higher probability of the ability to develop skills necessary for this desired behaviour.

The selection process, since it is most participants' first encounter with the organisation on a professional level, may have played a role in shaping expectations of the programme ${ }^{4}$. It will not affect personality and aptitude as such, since these factors remain by and large constant, but it may have an effect on the participants' motivation through the shaping of expectations. Participant expectations will therefore be used to investigate the possibility of

\footnotetext{
${ }^{2}$ Increased probability of successful completion is based on recruitment and selection principles and is an assumption of the selection process. The selection process comprises of various tools which aims to determine the extent to which the candidate exhibits predetermined competencies.

${ }^{3}$ Due to confidentiality constraints, the competency anchors and behavioural descriptions could not be included.

${ }^{4}$ Refer to background in Chapter 1 for a summary of the sourcing process.
} 
differential motivation to work for the organisation in general, act in a leadership position and to complete the programme.

Although the black females did discuss the developmental need for proper management of their programme, they did not express an expectation before or at the beginning of the programme. They also did not express the expectation for teamwork, to develop communication skills, interact with customers during the programme, or to learn technical skills. The black females also did not explicitly mention an expectation for "leadership from superiors", but from some responses it is inferred that an expectation for leadership from superiors is associated with an expectation for coaching and mentoring. The expectation for bilateral communication, structure and the transfer of knowledge is also presumed to be a part of the expectation for coaching and mentoring, but these expectations were mentioned by the group. Figure 13 earlier in Chapter 4 is a graphic depiction of the black female group's expectations of the programme.

Among the expectations of the black females, was one of a formal corporate-like work environment as well as what was described by the two black groups, as an "office job" ${ }^{5}$. The expectation of an "office job" seems contradictory with the expectation of practical learning in a retail store environment. The group explained that they expected both, but with an emphasis on administrative work. The group agreed that the expectation was not to be involved in hands-on activities in all departments of the operational unit. Based on their perceptions of the organisation (as a large international company), the black females in particular expected a working environment that is stereotypically corporate (formal, and for the lack of a better expression "tight-laced"). It would also seem, from responses, that the initial contact, i.e. the recruitment process, supported this perception. In addition to a distorted perception of the working environment and nature of the position, the black females also indicated an expectation that the duration of the programme would be much shorter. The black females acknowledged the necessity of a training period, but expected to complete it in a shorter amount of time. These expectations, if not met, may have a negative impact on the participant's motivational levels to complete the programme and perform the role for which the programme prepares participants. Participants may feel that this organisation is not right for them, since it is not what they perceived their career path to be. Another expectation, which could also influence the development process negatively if not taken into account, is that coaching and mentoring. An ill deserved dissatisfaction with the programme could result from unrealistic expectations in terms of coaching and mentoring during the programme.

\footnotetext{
${ }^{5}$ The expectation of an "office job" and "formal work environment" was differentiated from each other, since some groups expected a more "corporate" or "formal" type of environment, but not necessarily working in an office for the majority of the day.
} 
Among the black females there was an expression for the expectation of not only coaching and mentoring, but also that mentors should provide the participants with a sense of structure, supply participants with guidelines and guidance, assistance even during busy times and transfer knowledge in a supportive manner. The resentment for this expectation not being met during the programme was clear in the response of one participant who mentions that she had to "learn most of the jobs herself". Although the expectation for coaching as well as mentoring during a development programme can be generally considered as a reasonable expectation, it would seem that the black females expected contact sessions and guidance which is unrealistic when considering operational pressures and the structure of the organisation. There is, however, also the possibility that coaching at branch level is not in line with the intent of the programme's design. In other words, some individuals assigned to act as a coach may not be fulfilling their duties; but this cannot be determined, from the primary data alone, since the data was only collected from one party's perspective. Nevertheless, incorporating controls to align coaching and mentoring expectations and/or further probing into this matter specifically, coaching and mentoring practices could be a valuable addition to the programme as far as participant motivation is concerned.

The expectation of structure, if not taken into account, could also impact negatively on motivation during the programme. This notion is supported by the black females indicating reduced engagement as a result of confusion about priorities and sequence of activities. Although also mentioned in the other groups, one participant expresses concern for the fact that she didn't know where to focus her attention, and that spending excess time on the wrong areas may waste time. Since this programme has a set time period, it is understandable that this may lead to anxiety and stress. Ensuring adherence to a certain expected structure could possibly promote motivation (Hollyforde \& Whiddett, 2003), as it allows the participant the opportunity to gauge her own progress. What should also be considered is that the experience of a certain structure may differ. For example, the black females mentioned that they did not receive the desired sense of structure from coaches as they had expected, but that standardised training material and classroom sessions provided them with a sense of structure, whereas the white males did not have their expectation for structure met, nor did training material or classroom sessions provide them with a sense of structure.

The black males did not express an expectation of learning technical skills, proper management or teamwork. They also did not explicitly mention an expectation of "leadership from superiors", but from other responses it is supposed that an expectation of leadership from superiors is associated with an expectation of coaching and mentoring. Figure 16, in earlier in Chapter 4, is a graphic depiction of all the expectations the black 
males had of the programme. Like the black females, the black males also indicated an expectation of a formal work environment and as they called it, an "office type of job". The expectation of practical learning was also mentioned, but only briefly. The black males went on to say that their expectation of the enrolment period was that it would be a brief "crash course" and that you would go straight into managing after that. From their responses it would seem that the way in which the positions are advertised played a significant role in creating this expectation. According to the participants the job advertisements do not state that the organisation is recruiting trainee managers, and that they applied because they assumed the role would be as a full-fledged manager from the start of employment. The participants did not elaborate on how they felt about this situation. The possibility does, however, exist that an individual who is expecting to enrol in a development programme before they are considered for the position applied for, believing that they can successfully complete it and sees the value in both the development programme and subsequent appointment, would be more motivated to successfully complete the programme (Hollyforde \& Whiddett, 2003). Expectations about being enrolled in this LDP should have been corrected during the initial contact phase to avoid this type of situation. From the black males' responses, there is no evidence of such an intervention.

Responses also indicate an expectation from black males of a work environment which is conducive to open and bilateral communication. What is important here is to determine what exactly constitutes open communication according to the participants' perception. An expectation for open and frank communication with one's mentor or coach is a relevant and legitimate expectation from a participant in a LDP, but from the responses, it would seem that the black males' expectation regarding communication may have been somewhat unrealistic and out of sync with the structure of the organisation as well as the programme. They mentioned wanting to have a say in how they are trained, voicing opinions on operational issues and being allowed to be innovative. Considering how the business and programme is structured, these expectations are quite unrealistic. The scope of knowledge which needs to be obtained in the short amount of time available does not allow for unique deviations. If this happens, the participant may not finish the programme in time, or not cover all the work with the required amount of depth. Due to the unionised nature of the industry, management cannot be seen as anything but unified. If all members of management start voicing different opinions about operational issues, it creates a situation where diverse opinions and ideas could be misinterpreted and snowball into a labour issue. And lastly, although the creativity dimension of the WICS model (Sternberg, 2003) favours innovation, this should only culminate into management action close to the end of after successful completion of the programme. If the desire to be innovative is granted to the programme participant too early in his career, it could be detrimental to the individual as well 
as the organisation, since this innovation should be grounded in a solid knowledge base. Nevertheless, this expectation not being met, or adjusted, may impact on individuals' motivation to complete the programme (or stay with the organisation), and the experience of the expectation possibly not being met should be considered by the programme.

In terms of coaching and support, compared to the other groups, the black males did not mention a high expectation thereof; nor did they discuss at length an expectation for knowledge transfer. Although the possibility still exists that this expectation, like others, could be unrealistic. Possible evidence of this is one participant mentioning that he expected a "one-on-one" with his coach, to correct him where he goes wrong during the programme. The other participants agreed with this statement and added some aspects of the programme they are also dissatisfied with. Introducing structures to determine how coaching and mentoring is experienced and how this relates to expectations (before and during the programme) may prove valuable in managing possible dissatisfaction with the programme.

Figure 14, in earlier in Chapter 4, is a graphic depiction of all expectations discussed by the white male group. The white males did not mention an expectation for proper programme management, the learning of technical and communication skills, or customer interaction; Although, apart from customer interaction, they did indicate a developmental need for these perceived aspects of the programme. A possible reason for this could be the fact that the expectation was met and that the members of the group did not feel it necessary to express the expectation. In addition to this, the white males did not expect the programme and management positions in general to be office based, like the black males and females did. This might be due the fact that a portion of the group of white males have worked in retail before which made their expectations more realistic. Similarly to the other groups, the expectation for leadership from superiors is assumed to be associated with the expectation for coaching and mentoring.

In terms of the white male group's expectation of coaching and mentoring and knowledge transfer, the overall impression was dissatisfaction. This dissatisfaction could subsequently impact on motivation to act in a leadership role or to complete this leadership development programme. There is, however, the possibility that the dissatisfaction experienced by the white males, could be due to distorted expectations of the expected coaching and mentoring they would receive during the programme, like in the case of the black males. Participants in the white male group indicate that they expected not only highly experienced individuals to mentor them during the programme, but that they expected personal attention and one-onone sessions in this regard. There was also mention of a dedicated person to manage the training process on branch level and one of applying classroom learning immediately and directly in-branch. These are all expectations that are unrealistic when considering that 
experienced mentors assigned to programme participants have immense operational pressures in addition to their developmental obligations and that branches differ in some processes (due to customer requirements).

A built in gauge to determine the nature of the coaching or mentoring experienced could possible identify these misaligned expectations and also enable stakeholders to correct improper coaching and mentoring practices. An interesting opinion was also mentioned in the white males' group about knowledge transfer and that of interactions between participants. It was said that the possibility of positive interactions could make a participant bias into accepting knowledge from a fellow participant without consideration for its correctness. In an instance where the participant feels dissatisfied with the coaching he receives he might sought out the assistance of a fellow participant, be supplied with incorrect information and then perform poorly and not understand why - once again possibly impacting on motivation to continue with the programme.

The white males state that the prescribed time period for the training programme was communicated with them upon entry into the programme. Some of them, however, mention that they expected to finish earlier, and some also mention that they have extended their initially agreed upon time period without the anticipation of such an extension. The main concern around this, it would seem, was that of time wastage. The group indicated that they expected a sense of structure to have come from superiors, and that in instances where this was not the case, they felt that they were focusing time and effort on areas of the business that they did not have to. Considering that the white males were the group indicating the highest expectation for structure during the programme, not considering how they experience the structure of the programme could, according to achievement theory, prove detrimental to their motivation to complete the programme (Hollyforde \& Whiddett, 2003) as this may be an indication of perceived loss of control of their process.

The white males were the only group who expressed an expectation for teamwork. The black females briefly mention that they do not think the organisation encourages it, but it was not articulated as an expectation or developmental need. The expectation of a strong support structure is evident from the white male's expression of an expectation for structure and teamwork. This could also be one of the causes of an expectation for contact sessions with experienced mentors. If participants' expectations of the original support structure were not met (and from the nature of the responses as well as the nature of the expectations we can assume it was not met) the participants could have constructed a possible alternative to their original support structure, i.e. high levels of time spent with mentors. Continuous failure to address expectations, especially expectations which are intended to make the participant feel safe and secure, could possibly impact on the motivation to continue in the programme. 
The white female group did not express an expectation for a formal work environment teamwork a short enrolment period or to acquire communication skills (as indicated in Figure 15 earlier in Chapter 4). The group also did not expect an "office job", nor did they mention bilateral communication as an expectation. Bilateral communication, however, is assumed to be associated with an expectation for coaching and mentoring, which the white females did express an expectation for. The expectation of knowledge transfer is also assumed to be part of the expectation for coaching and mentoring, whereas coaching and mentoring is assumed to also have led to an expectation for structure during the programme.

The main theme which came out among white females around the concept of structure within the programme is that of guidance and assistance. The white females indicated that they expected their assigned coaches and mentors to provide them with a sense of structure and process and to assist in cases where they needed it. One participant mentioned (without opposition from the rest of the group) that in order for her to have felt that there was structure, she would have needed to get consistent feedback on her own performance from her coach, another mentions that there was significant repetition of tasks. The impression was given that this repetitive nature of tasks is contra acting existing efforts to maintain structure, i.e., repeating tasks excessively leads to the deviation from the participant's training plan, resulting in a loss of structure.

Of all the groups, the white females seemed to have expected the most from coaches and mentors, especially with regards to structure, guidance and support. The group mentioned several expectations from coaches and mentors, like that of inclusion in everyday activities, the opportunity to practice new skills under supervision, as well as continuous feedback. These are all reasonable expectations from a participant in a development programme, however, the undertone and the choice of words makes these responses interesting. Some of the white females mentioned that they expected "to be trained", possibly indicating a passive approach to the learning process. There was also significant mention of receiving "help" during the learning process. By no means does this prove that the white females was sitting and waiting in anticipation to be developed, but if coaches (or other stakeholders) considered their group level/personal experiences of the coaching and mentoring interventions, it might have illuminated dissatisfaction, and correct expectations that are unrealistic, or correct coaching practices that are counter-productive (as some participants also claim that their development is not being managed in accordance with their expectation). In this regard, coaches and mentors should be asking themselves if their intervention during the programme is motivating the participants to complete the programme or not. From the white females' responses about their own experience in this regard there is no evidence that this is taking place. 
The white females were the only group who expressed an expectation of acquiring technical skills, although the other groups did mention it as a developmental need. There was a strong indication among the group to be actively involved. They do however state that the expectation was that the practical learning and the technical skills would merely be complementary to management skills. The group expected the latter to be learnt though inclusion onto daily management activities, with the subsequent practicing of new skills under supervision. Not being able to implement new skills, or practice it in an environment that is considered by the group as being safe (i.e. under supervision), might discourage the acquisition of new skills or the willingness to put new knowledge into practice. Should the coach or mentor have considered this experience, it may serve as a positive means of encouragement and reassurance. Taking this experience into account could also serve as a means of tweaking task giving to ensure that the focus is adjusted correctly, for example making sure that the correct proportional time is spent on technical skills training in relation to management and leadership skills training.

The general impression across all four groups was that the majority of expectations were not met. Major criticism of the programme in this regard, is not necessarily the perception that expectation was not met, but a lack of structures which would enable stakeholders to identify and manage these expectations. One of the key themes was that of coaching and mentoring. Coaching and mentoring has very distinct definitions in the literature, but the groups seemed to use the terms interchangeably. They were not corrected on what each means. What was interesting though, was that not each group's expectation of the coaching and support is the same. The black females indicated the expectation to not be involved in staff duties, but to be involved in "corporate" management and to receive high levels of attention from coaches and mentors. The white females, however, also expected coaching and support and to gain guidance and support from it, but also a large expectation of being actively involved in business operations. Similar to the white females, the white males also indicated a large expectation for personal attention and being able to apply new knowledge and skill. The black males however, did not discuss in detail the nature of their expectation of coaching and support in this programme, nor did they discuss expectations regarding the nature of activities during the programme. What is also interesting to note was the fact that all the groups made mention of some form of support, but the white males and the white females indicated this expectation very strongly compared to the two black groups. This occurrence could be the result of various influences. It could be due to differences in race and gender between white participants (the majority being male) and black coaches (majority being male), it could possibly be due to poor orientation and acclimatization to company culture, or, since this was indicated by both white groups, it could be indicative of inherent socialized way of viewing the world from a "white" perspective. The white males 
indicated the expectation of a support structure originating from fellow participants (teamwork) and white females expecting this support to come from coaches.

These differences, not in expectations, but in the nature of the expectation supports the proposition that the programme needs to have built into it a structure that allows for ascertaining what participant expectations are before and during the programme, since expectations may also change over time. Herein lays a great deficit in the programme. Although induction is done, expectations are not discussed in depth, nor are expectations that may arise during the programme elicited and discussed with the relevant mentors. Discrepancies in terms of participant expectations and eventual experiences could negatively influence motivation and subsequently impact the programme's ability to develop desired behaviours. Like in the case of the expectation for coaching or structure, the programme should have a built in mechanism which can determine the nature of the expectation (since not all groups expect the same "type" of coaching or structure) and correct where expectations may be unrealistic, as well as incorporate formalised feedback sessions which can determine if expectations are met throughout the programme.

According to Achievement-, Expectancy- and Goal-Setting Theory, expectations and perceptions of the nature of a future outcome shape motivation (Hollyforde \& Whiddett, 2003), and motivation, in turn, drives behaviour. The failure to incorporate expectation management could therefore have an effect on developing desired leadership behaviours as well as the retention of talent. The model for studying leadership as proposed by Gibson et al (2006), state leader behaviour as the next dimension to consider. When discussing this component of the model, it is assumed that expectations have been managed and that the participants are motivated to continue in the programme and act in a leadership role. It will therefore only be discussed how the perception of developmental needs being met and those not being met could possibly impact on the development of desired leadership behaviours.

The literature proposes that in order for an individual to be successful as a leader there must be a balance between task- and person orientation, a balance between consideration for persons and focus on structure, as well as the ability to create transactional relationships between outputs and returns and initiate transformation. If the assumption is that leader behaviours can be developed (Sinclair, 2009), then it stands to reason that development interventions should incorporate individual development needs. As part of an attempt to identify differential group experiences, those developmental needs candidates perceived to have been met and those perceived to not have been met need to be discussed. It should be noted at this point, that during discussions, various developmental needs were mentioned, but not all of them were indicated as being met or not. Some development 
needs were also indicated as being met as well as not being been, inter and intra-group. In all of these cases, only the main themes and trends have been included in the discussion.

Based on frequency of responses, the main theme within the concept of developmental needs, was that of the experience that the programme was not being managed properly and that coaching was not up to standard and lastly, that mentoring was insufficient and in some cases absent. The four groups all discussed these topics, but from different viewpoints.

Considering developmental needs experienced as met and those as not met, the black females' responses were significantly more about coaching and support, than other facets of the programme. Emotive words like "confused" and "uncertain" may indicate that either the branch of support during the programme was not appropriate to the black females' specific needs, or merely absent. Among the black females there seemed to be a constant reference back to interactions with people. They would make statements about a component of the programme or its application and then refer back to the human interaction element. For example, one participant mentioned that OJT gives good exposure to business processes, but that she would have preferred more coaching during the training intervention. There is a definite indication from the black females that they feel estranged from the individuals responsible for providing them with learning coaching and support. In fact, a majority of the coaches are male (of which the majority are black males), whereas the majority of individuals assigned to act as mentors are white males. The research by David Thomas on mentoring across race may be applicable to this case of coaching experience of the black females. Thomas (1989) reported that the black women in his study were reluctant to establish a mentoring relationship with white men in their organisations. More recent research (Blake, 1999; Mahwah, 1999) on the mentoring experiences of professional black women also point to tensions and distance in relationships of white males.

The black females also mentioned difficulty with the development of their assertiveness. If coaching and mentoring is absent, like the group suggests, this may be the cause of difficulty in developing skills associated with assertiveness. However, if coaching is merely incompatible with the black females' specific developmental needs, that may be the result of a lack of assertiveness, as the programme participants cannot voice their dissatisfaction and specific needs to the coach or mentor.

Among the black males, the focus was more the management of the developmental programme than on interactions with various stakeholders. There was an overwhelming indication that what was experienced as poor coaching and mentoring was as a result of the poor management of the programme which, according to respondents, sprung forth from coaches' lack in ability to act as such. In some cases, participants also attribute their own poor performance in the programme to poor coaching. This may be due to coaching being insufficient, or not tweaked to suit the group's specific needs. The general impression 
around this theme is that the group of black males seem to have some sort of sense of entitlement. The impression was given that the group expected the assigned coaches to perform some sort of "service" to them. There was not much mention from the group that their own endeavours are met with no support, but rather that not much is done "for them".

Like the black males, the white males' responses regarding development needs mostly revolved around the concept of the programme being poorly managed. There were multiple responses indicating "misuse" of programme participants. "Misuse" in this instance referring to involvement in activities supporting solely operational needs instead of developmental needs. However, where the black males' responses indicated a perception of incompetence among coaches; the white males referred to poor management of the programme and improper coaching as being the result of "misuse". The white males did not provide convincing responses that would indicate a perception of coaches being ill-equipped to assist them with development. The white males continue to point out that in cases where they did not receive developmental support from coaches that this role was taken over by fellow participants.

With the white females, the responses regarding developmental needs being met and those experienced as not being met were quite diverse. This may be due to the size of the group. The programme has generally a lot less white females, than black females, or black and white males. It is possible that stronger themes may have emerged, should the group have been larger. Nonetheless, some key ideas will be highlighted. What made the white females' responses different from other groups was that their major concern was that they experienced the mix between technical skills development and management skills development to be unbalanced. Like with the black females, the white females also indicated problems with developing their assertiveness. The group did not furnish convincing reasons for this, however, some did mention that their levels of assertiveness did improve as they progressed through the programme, unlike the black females who still (even post-programme) have issues in terms of their assertiveness.

According to the model for studying leadership proposed by Gibson (2006) et al., followers' needs, task structure, position power, leader-follower trust and group readiness also need to be considered. Since "programme content" and "treatment during the programme" may be considered as situational variables affecting leadership development, these themes will be discussed to illustrate the four groups' experience of the situation in which development took place. "Programme content" refers to responses on classroom learning, standardised training material and OJT. "Treatment during the programme" refers to treatment from fellow participants, superiors, as well as subordinates.

Of the various learning delivery approaches, the black females seemed to favour classroom learning and standardised material. The group indicated that OJT is valuable as 
well, but also stated that the mentoring component is missing for them. Focus on structure and support may be indicative of a general external locus of control (Sterbin \& Rakow, 1996) in the group. This inference is supported by the statement that one develops more in a management-relief position when you "receive" authority. This indicates towards the need for another party to "grant authority" in a given context, rather than endeavouring to "take authority". This is also further supported by the mention of both staff and customers not recognising black females as authority figures, and accepting it as the status quo instead of taking action against such behaviour in others. Other research has documented the challenges to authority experienced by black females in management positions (e.g. see Bell \& Nkomo, 2001).

The black males' commented on classroom learning and standardised learning material to be helpful in overcoming challenge, but that its application in the workplace is difficult may point to various flaws in the programme. Firstly, it could be because there is a definite discrepancy between what is taught and what is practiced. It could also be as a result of poor coaching, and not allowing participants to practice what has been learnt. Lastly, it is suggested that it could be because differential experiences have not been taken into account, i.e. how the black males experience new skills and knowledge. On the surface what is happening post-training intervention might seem different to what is happening in practice, but could in actual fact be linked. This link, however, may not have been recognised due to the inability of the learning programme to take into account differential experience, if such differences exist. Like the black females, the black males also spoke about the benefits of receiving additional management responsibility, but their main concern was that is disrupted the original training process. This being a main concern comes as no surprise, since the black males mentioned as one of their main expectations to be immediately appointed in a management role, and not train first for a 12-month period. Considering these expectations and their situational variables, the probability of said situational variables impacting negatively on development outcomes might increase. In addition to this, what was interesting to note among the black males, is that all four groups mentioned the possibility of professional jealousy among fellow participants, but the black males were the only group to indicated a suspicion that some negative experiences during the programme could be due to professional jealousy from management, and specifically management assigned to act as coaches.

The white males were the only group with an overtly negative opinion of both classroom learning and standardised learning material, although OJT experiences were mentioned to have been beneficial to their learning experience. There was a strong indication of frustration, in the sense that the participants felt their time was being poorly spent and wasted on repetition. A possible cause of this might be that some of the white males have 
previous retail management experience, more so than in the other three groups. There was also an indication towards an internal locus of control. This statement is made based on the emphasis the group placed on pressure in the workplace, and how this pressure is beneficial to development. When compared to the black female group, which emphasised the lack of support during OJT, the white males state that when faced with additional management responsibility (e.g. in a relief position), you have no choice but to adapt and to survive. The statement that captures this sentiment the best was:

"You get thrown into deep end and you either have to sink or swim..."

What was interesting to note in this case, however, was the fact that even though it seemed like the white males had a more generally aggressive approach to authority and asserting it, they also mention resistance from subordinates like in the case of the black females. They mention that their authority sometimes only get accepted after being appointed as assistant managers. In this sense their experience is similar to that of the black females who seem to wait to be "given authority".

In terms of content, what stood out among the white females' was their opinion that the learning material is of a good standard, but that it is being underutilised, by the custodians of the programme. They also mentioned that classroom learning is a necessary foundation but is not sufficient to cover all the necessary developmental needs by itself. This once again points towards improper management of the programme, although the group does not explicitly mention it as such (apart from expressing concern for material utilisation). Considering situational variables in general, what was distinctive of the white females' responses, was that they clearly indicate a change in the nature in which subordinates interact with them as time went by. The other groups seem to wait for some type of "authority" to be bestowed upon them, whereas the white females seem to indicate that, when they got to know people, relationships improved. This may be the cause of the white females favouring OJT since this provides them with an opportunity to interact with subordinates and develop better working relationships.

The last component in the model proposed by Gibson (2006) et al, is that of effective results, or outcomes. For this, the themes of "content/assessment mismatch", "growth" and "own behaviour affecting outcome" will be discussed. Note that "growth" refers to participants' experience of personal and professional growth and both a manager and leader. Two prominent cross-group similarities where noted in terms of the theme of growth. The two male groups clearly indicated that they perceived increased pressure (especially pressure resulting from acting in a relief-management position) to have contributed 
significantly to their growth. In addition to this, the two white groups where the only two groups who mentioned growth as leaders.

The black females were clearly left out within these prominent responses. They did, however, mention a perception that they grew during the programme, but not in line with aforementioned themes. When discussing programme outcomes they mention situations where assessment questions are asked which does not come directly from their training material, and that their programme in general is being managed out of sync with the assessment process. This could be due to poor preparation for assessment on the assigned coach's side, or it could be further justification for the earlier proposition that the black females have an external locus of control.

Among the four groups, the group who discussed the idea of a misalignment between programme content and assessments was the black males. The group also echoed the sentiments of the black females, in the sense that assessments are not in line with standardised training material. However, in addition to this, the black males expressed an overwhelming realisation of self-awareness, in that your own behaviour has an impact on outcomes. They expressed an appreciation for cultural differences and value systems and how their own behaviour impacts on how those cultural and value system.

Responses from the white males with regards to outcomes during- and after the programme, were very much similar to the black males, in the sense that they also felt the material and assessments were out of synch and that the standardised assignments were a lot of duplication. However, what was unique to the white male group was a much more dominant and aggressive approach. As proposed earlier in this discussion, this may be indicative of a strong internal locus of control, or possibly merely residual behaviours acquired from previous retail management experience. The white males also expressed a sense of self-awareness and the knowledge that one's own behaviour impact on outcomes. Another comment that stood out among the white males was that, in order to learn, you need to be "open to experiences" and not wait for the learning to take place "for you"; Yet another justification for the proposition that the white males have a strong internal locus of control.

The white females' responses on outcomes (derived from responses within various themes), as mentioned earlier, seemed as if it was from an "outsider perspective", but not so much so that it was indicative of an external locus of control. When asked how they feel their own behaviour affects outcome, it was discussed from the viewpoint of other managers' behaviour. It was noted that current practices in dealing with people did not yield positive results, but they did not mention much in terms of their own behaviour influencing outcomes. In addition to raising concern about available learning resources not being properly managed and utilised, they also mention that most of their outcomes on assessments, being it positive or negative, were directly related to learning experiences during OJT. 
Apart from the two models for studying leadership, which were used for this discussion, a great body of knowledge also exists on how different identities may lead to differential experiences within a developmental programme. The next section will discuss the collected data based on said literature.

\subsubsection{Identity as a possible determinant of differential experiences}

In summary, the previous discussion points to some important differences in how the different groups experienced and interpreted the LDP, but it is also important to discuss what might generally account for such differences. In this section, existing literature on how different identities may shape differential experiences within a LDP, is compared to the results of the findings of the present study. Differential experiences between groups, as well as cross-group similarities will be highlighted based on the concept of intersectionality.

Existing literature (Ospina \& Foldy, 2009; Booysen \& Nkomo, 2010) suggest that various different identity characteristics in individuals (like in the case of this study, the person's race and gender) converge and should be studied together, instead of in isolation, this convergence impacts significantly on how the individual experiences an event (like that of a development intervention). Evidence of this was found in the data, where the two race groups' responses would differ across gender, or the two gender groups' responses would differ across race. A summary of some examples are included in Table 17.

\begin{tabular}{|c|c|c|c|c|}
\hline & BF & $\mathbf{B M}$ & WM & WF \\
\hline $\begin{array}{r}\text { Problems associated } \\
\text { with access to } \\
\text { resources }\end{array}$ & $\begin{array}{l}\text { Suggested poor } \\
\text { management of the } \\
\text { training process. }\end{array}$ & $\begin{array}{l}\text { Suggested professional } \\
\text { jealousy on the part of } \\
\text { the coach/mentor. }\end{array}$ & $\begin{array}{l}\text { Suggested lack of } \\
\text { competence to act the } \\
\text { role of coach. }\end{array}$ & $\begin{array}{l}\text { Suggested poor } \\
\text { management of the } \\
\text { training process. }\end{array}$ \\
\hline $\begin{array}{r}\text { Experience of } \\
\text { structure during the } \\
\text { programme }\end{array}$ & $\begin{array}{l}\text { Expectation of structure } \\
\text { during the programme } \\
\text { was not met due to } \\
\text { perceived favouritism. }\end{array}$ & $\begin{array}{l}\text { Suggests need for } \\
\text { structure arose from } \\
\text { poor management of } \\
\text { their learning process. }\end{array}$ & $\begin{array}{l}\text { Emphasis of a lack of } \\
\text { structure during the } \\
\text { programme may be } \\
\text { indicative of a feeling of } \\
\text { not being in control. }\end{array}$ & $\begin{array}{l}\text { Suggests a lack of } \\
\text { structure during the } \\
\text { programme resulting } \\
\text { from underutilization of } \\
\text { standardised learning } \\
\text { material. }\end{array}$ \\
\hline $\begin{array}{r}\text { Experience of } \\
\text { mentoring during the } \\
\text { programme }\end{array}$ & $\begin{array}{l}\text { Operational pressures } \\
\text { resulted in insufficient } \\
\text { mentoring/coaching } \\
\text { sessions. }\end{array}$ & $\begin{array}{l}\text { Inadequate } \\
\text { communication lead to } \\
\text { poor mentoring }\end{array}$ & $\mathrm{N} / \mathrm{A}$ & $\mathrm{N} / \mathrm{A}$ \\
\hline $\begin{array}{r}\text { Experience of } \\
\text { interaction with } \\
\text { standardised learning } \\
\text { material }\end{array}$ & $\begin{array}{l}\text { Generally value adding } \\
\text { and helpful in } \\
\text { overcoming challenges. }\end{array}$ & $\begin{array}{l}\text { Does not sufficiently } \\
\text { address developmental } \\
\text { needs. }\end{array}$ & $\begin{array}{l}\text { Duplication in } \\
\text { assignments and does } \\
\text { not align with testing in } \\
\text { assessments. }\end{array}$ & $\begin{array}{l}\text { Material is useful but is } \\
\text { being underutilized. }\end{array}$ \\
\hline $\begin{array}{r}\text { Synthesis of new } \\
\text { knowledge and skills } \\
\text { (OJT) }\end{array}$ & $\begin{array}{l}\text { OJT contributed to } \\
\text { development but would } \\
\text { have preferred more } \\
\text { mentor involvement. }\end{array}$ & $\begin{array}{l}\text { OJT contributed } \\
\text { significantly to } \\
\text { development. }\end{array}$ & $\begin{array}{l}\text { OJT contributed } \\
\text { significantly to } \\
\text { development. }\end{array}$ & $\begin{array}{l}\text { OJT experienced as } \\
\text { beneficial learning } \\
\text { experience, but } \\
\text { encountered resistance } \\
\text { from subordinates, } \\
\text { which negatively } \\
\text { impacted on the } \\
\text { application of new skills. }\end{array}$ \\
\hline
\end{tabular}

Table 17: Diverging factors of identity influencing experience 
The information contained in Table 17, clearly outlines that even though there may be a few similarities across genders or across races, there must be some influence that develops prominent themes within group, while discussing the same topic, so different. A suggestion for this is the support of the assertion that identity factors converge to influence perceptions and personal (and in this case group-) experiences.

From a positive perspective, there is some research (Ohlott, 2002; Debebe, 2011) that suggests that making use of single identity groups and tailored learning practices are conducive to bringing about better leadership transformation. From a more negative perspective, Chatman (2010) proposes possible distrust between participants as well as participants and coaches. Chatman (2010) suggests that differing psychological conditions, coupled with the minority group factor, questions regarding authenticity in feedback may arise. At face value, across the four groups, there was evidence to the contrary. Males indicated getting along better with females and vice versa, as well as white participants indicate better working relationships black participants. However, further probing did yield some support for Chatman's (2010) position. The black males attributes various negative experiences in their programme to professional jealousy on the part their assigned coaches and mentors. The white males, on the other hand, mentioned that they experienced professional jealousy from fellow participants as well as some racial tension. As indicated in Figure 17. Interestingly though, no conflict or tension seem to have emerged between different gender groups, like aforementioned racial tension.

Figure 17: Code occurrences across groups

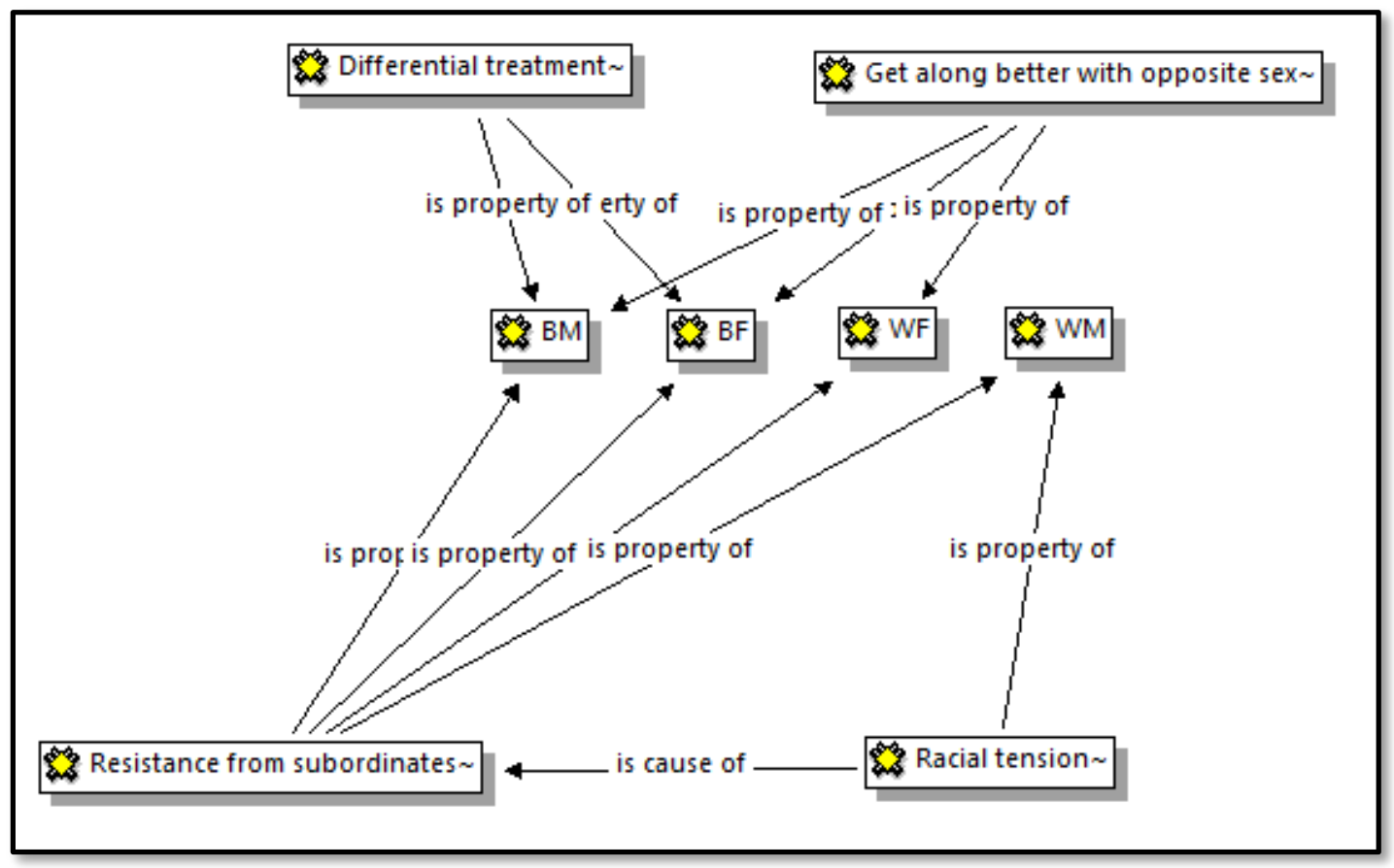

Atlas.ti mindmap of code occurrence relating to possible differential experiences between groups 
Certain tensions between groups support the premise that a development environment needs to be perceived as being "safe" in order for candidates to open themselves up to new experiences in an attempt to reach their full potential (Ohlott, 2002; Locander \& Luechauer, 2005; Ospina \& Foldy, 2009; Chatman, 2010; Debebe, 2011). There was some evidence that there were differing experiences across groups in terms of how the learning environment was experienced. The black males seemed to feel threatened to a certain extent, in the sense that they did not receive proper access to all available learning aids due to professional jealousy from assigned coaches and mentors, and perceived this as differential treatment, compared to other groups (see Figure 17). The theme of poor communication between participant and coach also emerged quite strongly in the black male group. Evidence gathered from the white males, however, seemed to indicate a need for control over their learning process, and an inability of the programme and stakeholders to offer them that autonomy and control. Notwithstanding this and some other dissatisfaction with the programme and expectations not being met, the white males seemed to be more comfortable with the learning environment and the organizational structure and culture in general. The white males took strong positions on the quality of certain components of the learning process and there was no serious objection to the acceptance of more responsibility and openness to new experiences. With the two female groups, however, there was a lot more emphasis on guidance and support than from the two male groups. There was also a reluctance to accept additional responsibility. Both female groups also expressed difficulty with developing assertiveness as well as resistance from subordinates. Although resistance from subordinates was mentioned in the males groups as well (see Figure 17), it did not seem to be as prominent a theme as with the females. This may be justification for single identity development from a standpoint that the females' need for self-preservation is inhibiting the development of their full potential and in a mixed LDP setting they may be reluctant to raise their insecurities around the difficulty of being assertive.

It would therefore seem that there is support in the data for the premise that females face more challenges than their male counterparts when places in leadership positions (April \& Torun, 2006; Fauconnier \& Mathur-Helm, 2008; Eagly \& Carli, 2007; Heilmann, 2011). These include gender stereotyping, exclusion from networks and challenges to authority. The black females indicated an experience of a blatant challenge to their authority based on their race and gender. When asked if they felt that black females are seldom accepted as authority figures they agreed. Interestingly, the white females also mentioned resistance from subordinates, as previously mentioned, but goes on to say that these relationships with subordinates improved over time. Even so, this type of behaviour was not indicated from the females to occur between groups of participants. In fact, the two females groups indicated that inter-gender relationships with fellow participant were very good and in fact quite 
supportive but perhaps not enough for the females to raise issues that may have been interpreted in a stereotypical fashion. This contention needs to be tested further.

All of the assertions mentioned in this discussion were based solely on existing literature and responses collected from the focus groups. In an effort to justify certain assumptions and build a stronger case for inferences, the primary data was also compared to secondary data derived from exit documentation. A discussion on this comparison follows.

\subsection{Quality of data}

Due to the qualitative nature of this study, no statistical techniques can be used to ensure reliability and validity. Specifically, attention should be paid to trustworthiness of data, credibility, transparency of methods, and confirmability (Klenke, 2008). The following was taken into account to ensure quality research:

\subsubsection{Trustworthiness and Credibility}

Firstly, focus group moderator bias was considered. Bias may have occurred when the person leading the focus group discussion imposes their own beliefs and frame of reference on the participant. Trust and credibility was established by acknowledging personal shortcomings and beliefs, and by ensuring that data are recorded as it was intended. During the focus groups, responses were paraphrased and summarised to confirm understanding. This practice then also addressed the concept of participant bias, where the individual may have a pre-conceived idea of the agenda of the researcher and subsequently provide untrue/skewed responses.

An added benefit of the researcher's current position within the organisation is the knowledge base on the phenomenon at hand. Knowledge on leadership development (especially issues relating to gender and race) were properly researched from the literature. Researcher's appearance, location of the focus groups and opening comments was aimed at establishing rapport and open communication. The intent was for the participants to feel involved in a transparent, professional, safe, value adding experience.

This research dealt with various cultural issues, and participants from different backgrounds. The mode of recording data was taken into consideration, since some participants may have felt uncomfortable with being recorded (written notes and audio recordings). During the opening conversation it was made clear that notes will be merely for the recording of information and that no judgements or decisions will be made, through this, on the researcher's part. Notes were therefore taken openly and available for participant perusal. This also strengthened trustworthiness of information as the participants were able 
to correct the researcher if something was recorded differently than it was intended. Also, the researcher was careful to verify views of the group before moving on to newer topics.

According to Creswell (2009), to ensure accuracy of findings, validity must be established. In addition to aforementioned considerations, trustworthiness and credibility from a qualitative standpoint was ensured by means of the following techniques (Creswell, 2009):

- Member checking. This procedure involves checking findings against the perspectives of the original participants for accuracy of inferences.

- Also presenting negative findings. Presenting findings that are contrary to established themes adds to trustworthiness and may indicate a need for further research.

- External auditing. Presenting finding to an external party that is not familiar with the project or participants may provide an objective assessment of the project outcomes.

- Triangulation. Data from secondary sources, including statistics from SAP and qualitative data from exit interviews (content analysis), was compared to findings to determine congruence and coherent justification for themes. (See Table 1 in Chapter 1 for SAP statistics).

\subsubsection{Triangulation}

In this section, an effort is made to triangulate the findings from the focus groups with exit interview data collected by the organisation. Firstly, it should be noted that triangulation of data was complicated by the fact that the focus groups and the data from exit documentation were not aligned in terms of response probing. The secondary data, in the form of exit documentation, was sampled from an existing business process outside that of the research project and was therefore not structured in accordance with the research design. Secondly, triangulation was further complicated as a result of the data from the exit documentation sample not being standardised. The secondary data sample contains a mix of exit interviews, resignation letters and notes from counselling sessions (See section 4.1.8 for details). Nevertheless, there was still qualitative data available, which was used for the purpose of triangulating findings from the primary source, i.e. focus groups.

Sampled exit documentation from the white female group yielded support for some findings. It is proposed that, based on responses, the white female group developed the "communication" and "interpersonal skills" sections of the "wisdom" component of the WICS (Sternberg, 2003) model. The general positive tone of resignation letters and the mention of positive relationships support this finding. 
One element that differentiated the exit data for white females from, especially the male groups was that it did not have a specific stance about the programme or the organisation. This mild and positive tone might be support for the finding that this group experienced difficulty developing their assertiveness, more so than the male groups, even though they received the same training. This general "mild" tone also supports the postulation that the white females approached the programme from an "outsider's perspective". In their dealings with superiors and subordinates, the females were asked to comment on their experience of their own behaviour on certain outcomes. They commented that they do experience one's own behaviour to have an effect on the outcomes of situations, in particular how other people treat you, but they discussed it from how others' own behaviour impacted the situation, as opposed to how participant behaviour affects participant outcomes. In other words, viewing behavioural "cause and effect", not from their own experience, but from the behaviour of others.

One characteristic that stood out from the sampled secondary data for the white males was that the largest majority of the candidates provided a notice period. It is proposed that this is indicative of two findings of the group. Firstly it may indicate that a certain level of professionalism was developed during their tenure in the programme (business competence), or it may be indicative of positive relationships that was established during the training period (communication and interpersonal skill development), but it is not possible to be conclusive about either proposition.

Mentioning regret for leaving and that they have learnt a great deal during the programme is in line with the findings that the white males indicate a strong stance that OJT was a superior learning experience (the majority of programme delivery is OJT), and also supports the finding that synthesis took place, in accordance with the WICS model (Sternberg, 2003). Half of the sampled secondary data indicate participants from the white male group exiting the programme prematurely to pursue better opportunities. This may be indicative of the significant impact expectations like "short enrolment period" and "formal work environment" has on retention of participants and their willingness to complete the programme. It therefore supports the premise that the programme insufficiently deals with unmet or unrealistic expectations on the participant's part.

The black male group's secondary data was challenging to triangulate with the findings from the primary data. There were not a lot of convergent themes. At most, it could be argued that the fact that a majority resigned with immediate effect, and half of them providing no reason for exiting the programme prematurely, could be an indication of some disillusionment or dissatisfaction. Frequent mentioning of an experience of poor management of the programme within the black male group, supports this premise. 
Dissatisfaction with the programme may also be the case with the black females, since a distinguishing factor in their secondary data was that most of them resigned with immediate effect. This argument is supported by the fact that most of the black females did not mention resigning to pursue better opportunities, like in the other groups. This may support the premise (from the literature) that black females are at a double disadvantage, since the group discussed experiencing resistance from subordinates, a significant amount of unmet expectations and difficulty developing assertiveness. This also possibly adds support to the notion that special attention needs to be given to certain individuals and how they experience the programme.

In sum, the secondary data in some respects converges with dominant themes identified in the primary data. However, these convergences are at best tentative and future investigations should be designed to ensure alignment between primary research data collection and the exit interview structure.

\subsubsection{Transparency of methods and Confirmability}

In addition to issues of validity, outlined and addressed in the previous section, procedures were put in place to ensure reliability of reporting on data analysis. Reliability was established by means of the following (Creswell, 2009):

- Checking data for obvious mistakes. Transcripts and notes will be checked for any mistakes that may have been made during transcription.

- Adherence to coding schemes. There will be strict adherence to coding themes to ensure that there isn't a shift in meaning between coding.

- Intercoder agreement. This is also known as cross-checking, which involves agreement between what defines a specific coding process/procedure. Similar codes were also integrated into each other by means of axial coding, and reported on as such in the "results" section.

In addition to these measures, to increase confirmability and transparency, the coded data was submitted to a colleague with a Masters degree in Industrial Psychology who perused the data and checked it for consistency across the coding for the various groups. She also examined content against codes to determine validity of themes coded. There were no significant discrepancies found. 


\section{CHAPTER 5: Conclusion and recommendations}

\subsection{Conclusion}

At face value, there seems to be convergence across all groups in terms of major themes. The groups seem to have very similar concerns and discussed many of the same topics. However, within each theme there were quite a few differentiations in terms of how the groups viewed a particular concept or issue pertaining to the development programme.

The study set out to gain insight into several research questions about participant experience during a leadership development programme. Firstly, it was considered whether or not different gender and race groups experienced the content of the programme differently. There were similarities across black groups in terms of the experience of material being aligned with business practice. The fact that the two white groups do not discuss this, but in fact experiencing standardised learning as being duplication and repetition, could indicate that the black groups had difficulty assimilating new knowledge or the application thereof, and therefore attributing it to inconsistency or lack of appropriate opportunities for application.

Another cross-group trend that emerged was between the two male groups. As part of the programme, participants occasionally have to take on management responsibilities. The two male groups did not seem to be averse to this practice, and in fact, the white males seem to welcome it. The female groups, however, expressed great concern for the lack of support during this process. This came as no surprise since both female groups also expressed concern in terms of developing assertiveness. Where the white males took on a very strict approach to exerting their authority and black males a more collaborative approach (but none the less assumed an authoritative position), the white females expressed difficulty in striking a balance between being friendly and being strict. The black females seem to be at the biggest disadvantage when regarding taking on authoritative roles.

The ability to develop assertiveness seems to be at the core of many of the experiences discussed during the focus group. This is proposed as a possible explanation of why the two female groups had a strong concern for support when receiving additional management responsibility, why they experienced difficulty overcoming resistance from subordinates and why they in some instances attributed poor performance to a lack of frequent interaction with coaches and mentors. Findings from the triangulation with secondary data can also be proposed as support for this postulation, when taking into account that the majority of black females who exited the programme prematurely did so with immediate effect and without citing leaving to pursue better opportunities as the reason for the resignation. 
Another possible reason could simply be poor management of the development programme, at coach level. Another research question was concerned with participant experience of developmental support and if there was a difference between groups. There was consensus across groups that coaching, mentoring and general development support was insufficient. However, what also emerged was differing views on why development support was of this nature. One concern among the black females, was that improper support was intentional and as a result of favouritism, which points towards support for the idea that the black females felt helpless to a certain extent and unable to control their learning environment.

Both male groups discussed their experience of "professional jealousy". However, in the case of the white males, this was not indicated as a possible cause of inadequate developmental support. The black males, like the black females, also proposed that poor developmental support was intentional, but in their case as a result of said professional jealousy and the fear of the participant becoming competition for the coach him- or herself. The white males merely cited a lack of knowledge to act as coach as the most prominent reason for poor support. It was interesting to note among the white females, however, the fact that it almost seemed like they did not want to blame the coaches for their poor experience of the coaching.

In terms of peer interactions across groups, which was another research question, some interesting themes emerged. The results suggest that inter-gender group interactions were experienced as more positive than intra-gender group interactions. The common theme within intra-gender group interactions was that of jealousy. The white males mention that this dissipated over time, but the females did not. The group who seemed to interact the best with other groups was the black males. This echoes the premise that they also follow a more collaborative approach where authority over subordinates is concerned. Inter-race interactions experienced as less than favourable, was only indicated in the two white groups. The white males and females mentioned experiencing some exclusion based on racial groups, however, the males indicated that this got better as the participants got to know each other better. The white females did not. Based on the aforementioned differences in interactions across groups of participants, as well as participants mentioning an experience of differential treatment from superiors and subordinates, it can be argued that all four groups did experience the programme differently to a certain extent, based on their gender and/or race.

Lastly, the research set out to determine if there were differences in how the programme addressed each group's developmental needs. It has already been discussed that the two female groups experienced difficulty is developing their assertiveness. Apart from that, only experienced mentoring emerged as a theme across the two black groups. The other 
development needs not addressed, was mentioned by all four groups. Considering other inferred factors of development that was not met, based on the WICS model (Sternberg, 2003) it would appear that the participants in the black male and black female groups had difficulty establishing relationships with all the relevant stakeholders necessary for effective development.

The findings from this research justify the use of an intersectional approach when investigating the experiences of a diverse group of people within the same context. The data clearly indicate that converging identities impact on experience and that focusing on one single aspect of a person or group's identity and then generalising those findings to the population may yield incorrect information. However, the results from this study did not identify major differences which would justify interventions such as single identity development (i.e. that is separate leadership development programmes for each group). Identified differences in experiences does not, for example, provide enough evidence to explain the major differences in success rates across groups as indicated in Table 1 . It is suggested that overarching organisational and macro influences may also have a significant impact on these indicators, and not merely the subjective experience of the programme. The data do suggest that attention should be paid to training coaches and mentors to sensitise them to particular development challenges that may be peculiar to a particular group. For example, attention should be paid to how to support the women in developing confidence to be assertive and how to deal with resistance to their authority. Focus areas for improvement and areas of further inquiry have been identified and should be considered if the organisation wishes to optimise its investment into this programme. The last section outlines suggested areas of further academic research, as well as suggestions for the specific programme. 


\subsection{Recommendations}

In this section, recommendations are made for further research as well as practical recommendations for improving the programme. This was done by considering limitations of the current research.

\subsubsection{Recommendations for further research}

- A significant limitation to the current study is the generalisability of findings. To to the small nature of the sample and since all respondents were selected from one organisation, this study needs to be repeated in different settings.

- Further focus groups should be conducted, with the same stratified sample, with less structure to encourage more open-ended answers. The semi-structured focus groups conducted for this study may have encouraged similar answers across groups and therefore not clearly illuminating real subjective group experiences.

- Further research should probe into the differential experiences already identified. These may include addressing such questions as:

- Why are there better relationships across gender groups, instead of within gender groups?

- Why do only whites experience racial cliquing?

- Why do black males have a more collaborate style in terms of their interaction with fellow participants as well as subordinates?

- What changed in the relationship between white males and black males for them to mention that professional jealousy dissipated over time?

- How can leadership development programmes assist women with obtaining confidence in their ability to be appropriately assertive?

- Are there unique leadership development challenges experienced by black women?

- Further inquiry should contain larger groups. Small group size, especially for the white females in the present study, may have contributed to a lack of dominant themes across groups.

- Differing views within a particular group may have contributed to a lack in dominant themes. It is therefore suggested that further enquiry should not only stratify groups according to gender and race, but also according to progress in the programme. 
Participants at the same level may yield more coherent responses per group than a group of mixed-tenure participants.

- A pre-and post-programme research design should be utilised to better ascertain the impact of the leadership development programme on the different groups. The current study was not able to measure pre-programme knowledge in respect to some of the content of the development programme. This limitation restricted the possibility of fully examining the extent to which the programme met the developmental needs of the different groups.

\subsubsection{Recommendations for programme improvement}

- Data suggests that the programme does not fully develop the "Intelligence" component of leadership development, as proposed by the WICS model (Sternberg, 2003). This could be due to poor integration of new knowledge acquisition with workplace experience, or poor management of the programme. Careful attention should be given to the alignment of standardised training material with business practice, the consistent delivery thereof, and the proper management of the learning process.

- Problems associated with overcoming challenges indicate a lack of proper development on the "Creativity" dimension of the WICS model (Sternberg, 2003). It is suggested that challenges should be tailored to be more appropriate to development level and be managed as such. Existing gauges, in the form of formative assessments, should be managed properly, or adjusted, to ensure that challenges during the programme are appropriate for the development level.

- Poor development on the wisdom component could indicate poor management of the application component of new knowledge. In addition to ensuring that programme content is aligned with business practice, opportunities for the application of new skills should be monitored more closely to ensure proper, communication-, interpersonaland social skills, as well as superior understanding and judgement associated with the management role the participants are being prepared for is developed.

- The results suggest that OJT is being experienced as the superior delivery method across all four groups. Coaching during the process, however, seems to be insufficient in some cases. Careful attention should also be given to consistency across branches where OJT is done, in order to maintain training standards and 
overarching business standards. Coaching preparation and readiness should also be monitored and controlled on a consistent basis.

- Un-met expectations seem to have a major impact on participants from all four groups. It is recommended that expectations are clarified properly in the beginning of the programme; by all stakeholders and that these expectations should be consistently managed. Unrealistic expectations should be corrected in order to reduce the likelihood of it impacting negatively on the participant's development. 


\section{List of references}

April, K. \& Torun, E. (2006). Individual control (locus of control): Implications for business managers. Journal for Convergence, 7(1), 1-4.

Avolio, B.J., Avey, J.B. \& Quisenberry, D. (2010). Estimating return on leadership development investment. Leadership Quarterly, 21, 633-644.

April, K. \& Shockley, M. (2007). Diversity - New Realities in a Changing World. Basingstoke, Hampshire: Palgrave MacMillian.

Bell, E. \& Nkomo, S.M. (2001). Our separate ways: Black and white women and the struggle for professional identity. Boston: Harvard Business School Press.

Blake, S. (1999). At the crossroads of race and gender: Lessons from the mentoring experiences of professional Black women. Chapter in Mentoring dilemmas: Developmental relationships within multicultural organisations. Lawrence Erlbaum Associates: New Jersey.

Booysen, L.A.E. \& Nkomo, S.M. (2010). Gender role stereotypes and requisite management characteristics: The case of South Africa. Gender in Management: An International Journal, 25(4), 1754-2413.

Bradbury-Jones, C., Sambrook, S. \& Irvine, F. (2009). The phenomenological focus group: an oxymoron? Journal of Advanced Nursing, 663-671.

Burman, E. (2004). From difference to intersectionality: challenges and resources. European Journal of Psychotherapy, Counseling \& Health, 6(4), 293-308.

Bush, E. (2005). Gender: a factor in leadership development programs. Corrections Today, 67(6), 118-119.

BWASA Census (2010). Downloaded form:

http://www.bwasa.co.za/Census/2010CensusResults/tabid/14708/Default.aspx on [10-11-2010].

Chatman, J.A. (2010). Norms in mixed sex and mixed race work groups. The Academy of Management Annals, 4(1), 447-484. 
Conner, J.O. (2009). Student engagement in an independent research project: The influence of cohort culture. Journal of Advanced Academics, 21(1), 8-38.

Creswell, J.W. (2009). Research design, qualitative, quantitative and mixed method approaches ( $3^{\text {rd }}$ ed.). Los Angeles: Sage.

Davis, L.E., Galinsky, M.J. \& Schopler, J.H. (1995). RAP: A Framework for leadership of multiracial groups. Social Work, 40(2), 155-165.

Day, D.V. (2001). Leadership development: A review in context. Leadership Quarterly 11(4), 581-613.

Debebe, G. (2011). Creating a safe environment for women's leadership transformation. Journal of Management Education, 20(10), 1-34.

Employment Equity Report (2009). Downloaded from http://www.pmg.org.za/node/17863 on [10-11-2010].

Employment Equity Report (2011). Downloaded from http://www.labour.gov.za/documents /annual-reports/Commission\%20for\%20Employment\%20Equity\%20Report/20102011/commission-for-employment-equity-report-2010-2011 on [20-09-2011].

Eagly, A.H. \& Carli, L.L. (2007). Women and the labyrinth of leadership. Harvard Business Review, pp. 63-71.

Fauconnier, A. \& Mathur-Helm, B. (2008). Black economic empowerment in the South African mining industry: A case study of Exxaro Limited. South African Journal of Business Management, 39(4), 1-14.

Gibson, J.L., Ivancevich, J.M., Donnelly, J.H. \& Konopaske, R. (2006). Organizations: Behavior structure, processes (12 ${ }^{\text {th }}$ ed.). New York: McGraw-Hill.

Henze, B. (2004). Scientific definition in rhetorical formations: race as "permanent variety" in James Cowles Prichard's ethnology. Rhetoric Review, 2(4), 311-31. 
Heilman, M.E. (2001). Descriptions and prescriptions: How gender stereotypes prevent women's ascent up the organisational ladder. Journal of Social Issues, 57(4), 657674.

Hofstee, E. (2006). Contructing a good dissertation. EPE: Sandton.

Hollyforde, S. \& Whiddett, S. (2003). The Motivation Handbook. CIPD Enterprises: London.

Igbaria, M. \& Wormley, W.M. (1992). Organizational experiences and career success of MIS professionals and managers: An examination of race differences. MIS Quarterly, 16(4), 507-529.

Jones, J.R., Ni, J. \& Wilson, D.C. (2009). Comparative effects of race/ethnicity and employee engagement on withdrawal behaviour. Journal of Managerial Issues, 21(2), 195-215.

Killian, C.M., Hukai, D. \& McCarty, C.E. (2005). Building diversity in the pipeline to corporate leadership. Journal of Management Development, 24(2), 155-168.

Klenke, K. (2008). Qualitative research in the study of leadership. Bingley: Emerald Group.

Leedy, P.D. \& Ormrod, J.E. (2005). Practical research: planning and design. (8 ${ }^{\text {th }}$ ed.). Upper Saddle River: Pearson.

Locander, W.B. \& Luechauer, D.L. (2005, September/October). The leadership equation. Marketing Management, pp. 42-44.

Lunsford, L.G. (2011). Psychology of mentoring: The case of talented college students. Journal of Advanced Academics, 22(3), 474-498.

Lyons, D., McArthur, C. \& De Vries, K. (2007). Gender's unspoken role in leadership evaluations. Human Resource Planning, 30(3), 24-32.

Marckwardt, A.H., Cassidy, F.G. \& McMillan, J.G. (1998). Webster comprehensive dictionary. Ferguson: Chicago.

Maree, K. (2010). First steps in research. Pretoria: Van Schaik. 
McCall, L. (2005). The complexity of intersectionality. Journal of Women in Culture and Society, Spring, pp. 1771-1800.

Nkomo, S. M. (1992). The Emperor Has No Clothes: Rewriting Race in the Study of Organizations. Academy of Management Review 1 17, 487-513.

Ohlott, P.J. (2002, November). Myths versus realities of single identity development. Training and Development, pp.33-37.

Ospina, S. \& Foldy, E. (2009). A critical review of race and ethnicity in the leadership literature: Surfacing context, power and the collective dimensions of leadership. The Leadership Quarterly, 20, 876-896.

Ratele, K. \& Duncan, N. (2003). Social psychology: Identities and relationships. Lansdowne: UCT Press.

Riviere, D. (2005). Identities and intersectionalities: Performance, power and the possibilities for multicultural education, research in drama education. The Journal of Applied Theatre and Performance, 10(3), 341-354.

Rusch, E.A. (2004). Gender and race in leadership preparation: A constrained discourse. Educational Administration Quarterly, 40(14), 14-46.

Saunders, M., Lewis, P. \& Thornhill, A. (2009). Research methods for business students $\left(5^{\text {th }}\right.$ ed.). London: Prentice-Hall.

Sinclair, A. (2009). Seducing leadership: Stories of leadership development. Gender, Work and Organization, 16(2), 266-284.

Schmidt, F.L. \& Hunter, J.E. (1998). The validity and utility of selection methods in personnel psychology: Practical and theoretical implications of 85 years of research findings. Psychological Bulletin, 124, 262-274.

Sternbin, A. \& Rakow, E. (1996). Self-Esteem, Locus of Control, and Student Achievement. Paper presented at the Annual Mid-South Educational Research Association. Tuscaloosa, AL. 
Sternberg, R.J. (2003). WICS: A model of leadership in organisations. Academy of Management Learning and Education, 2(4), 386-401.

Stogdill, R. M. (1948). Personal Factors Associated with Leadership: A Survey of the Literature. Journal of Applied Psychology, pp. 35-71.

Swanepoel, B., Erasmus, B., Van-Wyk, M. \& Schenk, H. (2007). South African human resource management ( $3^{\text {rd }}$ ed.). Lansdowne: Juta.

Taie, E.S. (2011). Coaching as an approach to enhance performance. The Journal for Quality \& Participation, April, 34-38.

Thomas, A. (2008). Focus groups in qualitative research: culturally sensitive methodology for the Arabian Gulf? International Journal of Research \& Method in Education 31(1), 77-88.

Thomas, D.A. (1989). Mentoring and irrationality: The role of racial taboos. Human Resource Management, 28(2), 279.

Trochim, W.M.K. (2001). The research methods knowledge base $\left(2^{\text {nd }}\right.$ ed.). Cincinnati: Atomicdogpublishing.

Valentine, G. (2007). Theorising and researching intersectionality: A challenge for feminist geography. The Professional Geographer, 59(1), 10-21.

Yukl, G. (2010). Leadership in organizations. New Jersey: Pearson.

Zhang, X. \& Bartol, K.M. (2010). Linking empowering leadership and employee creativity: The influence of psychological empowerment, intrinsic motivation, and creative process engagement. Academy of Management Journal, 53(1), 107-128. 


\section{Annexure}

\section{Supporting documents}

\section{D0C.01: Executive summary}

\section{INTRODUCTION}

This document outlines a proposed study which, if approved, will be conducted in an operational division of a retail group in South Africa. The study is primarily for academic purposes but also intends to add value by gaining insight into why a differential success/dropout rate between racial and gender groups exist in a specific development programme. What follows is a description of the situation that prompted the need for the enquiry, the nature of the research project and possible benefits of pursuing the study.

\section{NEED FOR ENQUIRY}

High staff turnover is a common phenomenon in the retail industry. High staff turnover is associated with the problem of the loss of skills and knowledge which is especially detrimental to the organisation at a management level. Managers take time to be developed and subsequently cost the organisation a lot of money to employ. If they leave the organisation, they depart with their skills and knowledge, often directly into the employment of the competition. This weakens the organisation's competitive position, while strengthening the competition's competitive position.

According to Neely (2009), it is important to recognise that participant perceptions influence the design of a development program. This should be the case as gender and race are interdependent, interactive and play a significant role in giving meaning to social experiences (Bell \& Nkomo, 2001); Booysen \& Nkomo, 2010. As race and gender give subjective meaning to the social experience, it will invariably also influence behaviour (Ospina \& Foldy, 2009). The specific behaviour concerned here is the successful completion or, premature exit, from the programme. Statistics were drawn from SAP to compare premature terminations from the programme against enrolments per group, as well as the average duration in the programme per group (statistics contained in Table 1). Using these statistics and working on an average of 6 months for each individual who exits without completing the programme an annual investment, including the salary, travel, meal and material costs, of $R$ 744027 was wasted as no management talent was retained. 


\begin{tabular}{|c|c|c|c|c|c|c|c|c|c|c|}
\hline GROUP & \multicolumn{2}{|c|}{ BLACK MEN } & \multicolumn{2}{|c|}{ WHITE MEN } & \multicolumn{2}{|c|}{ BLACK WOMEN } & \multicolumn{2}{|c|}{ WHITE WOMEN } & \multicolumn{2}{c|}{ TOTAL } \\
\hline $\begin{array}{c}\text { NUMBER OF } \\
\text { ENROLMENTS* }\end{array}$ & 137 & $38.59 \%^{\dagger}$ & 55 & $15.49 \%^{\dagger}$ & 137 & $38.59 \%^{\dagger}$ & 26 & $7.32 \%^{\dagger}$ & 355 & $100 \%$ \\
\hline TERMINATIONS $^{* *}$ & 26 & $18.97 \%^{\ddagger}$ & 32 & $58.18 \%^{\ddagger}$ & 21 & $15.32 \%^{\ddagger}$ & 16 & $61.53 \%^{\ddagger}$ & 95 & $26.76 \%$ \\
\hline $\begin{array}{c}\text { AVERAGE } \\
\text { DURATION } \\
\text { (months) }^{*}\end{array}$ & \multicolumn{2}{|c|}{13.99} & 12.54 & 15.62 & & 14.70 & 14.21 \\
\hline
\end{tabular}

Table 1: Summary of differential programme outcomes over the last four years

† Expressed as a percentage of total number of enrolments.

$\mp$ Expressed as a percentage of stratum enrolments.

* All these figures exclude trainee managers who are currently still active in the program. Prescribed duration is 12 months.

** Terminations exclude terminations due to death.

\section{PROPOSED RESEARCH}

Due to the significant differences between groups and the overall cost implication of individuals not completing the program, the proposed research aims to uncover the factors that result in unique group experiences that influence the premature exiting from the program. The research project will investigate the experiences in focus group discussion format. 40 participants (trainee managers) will be required to take part - 10 from each group. Each focus group session will require half a day and will be conducted when operations can most afford the absence of these individuals.

\section{OUTCOMES AND BENEFITS}

An understanding of what factors in group experience influence the premature exiting from the development programme will provide a foundation for the creation of practical guidelines in leadership skills development in a diverse setting. This knowledge of participant experience may include:

- Deficits in the programme that applies to all groups

- Deficits in the programme to address unique group developmental needs

- Inappropriate learning delivery methods

This information would then be used for academic purposes (omitting the organisation's name) but also in adapting the programme in an effort address unique developmental needs of the organisation. 
DOC.02: Research Authorisation From

\begin{tabular}{|c|c|c|c|}
\hline \multicolumn{4}{|c|}{ AUTHORISATION TO CONDUCT ACADEMIC RESEARCH } \\
\hline $\begin{array}{r}\text { Research } \\
\text { Site }\end{array}$ & & Date & \\
\hline Researcher & Clifford Pierre Lewis & $\begin{array}{r}\text { Supervision } \\
\text { Institution }\end{array}$ & University of Pretoria \\
\hline \multirow{2}{*}{\multicolumn{4}{|c|}{$\begin{array}{l}\text { I hereby authorise access to the researcher, for the purposes of academic research, to } \\
\text { company resources related to the topic under investigation. I acknowledge that an executive } \\
\text { summary of the research has been provided to me and that I agree with its objectives. } \\
\text { I am also aware that if at any time I feel the research is damaging the resources, image or } \\
\text { employees of my organisation, that I am under no obligation to have the research continue, } \\
\text { and that I may terminate the project. }\end{array}$}} \\
\hline & & & \\
\hline \multicolumn{4}{|c|}{$\begin{array}{l}\text { Resources include: } \\
\text { - The time of selected participants of a focus group } \\
\text { - Organisational statistics from SAP } \\
\text { - Access to the contents of the development programme } \\
\text { - Information contained in exit interviews } \\
\text { - Training venues }\end{array}$} \\
\hline Name & & Position & \\
\hline Signature & & Date & \\
\hline
\end{tabular}




\section{DOC.03: Letter of Invitation}

UNIVERSITEIT VAN PRETORIA

UNIVERSITY OF PRETORIA

YUNIBESITHI YA PRETORIA

Faculty of Economic and Management Sciences

Department of Human Resource Management

\section{Invitation for participation in an academic research study}

\section{A RACE AND GENDER GROUP ANALYSIS OF PARTICIPANT EXPERIENCES IN A LEADERSHIP DEVELOPMENT PROGRAMME IN A SOUTH AFRICAN RETAIL ENVIRONMENT}

Research conducted by:

Mr. C.P. Lewis (10336584)

Cell: 0824494511

Dear Respondent

You are invited to participate in an academic research study conducted by Clifford Lewis, Masters Student from the Department of Human Resource Management at the University of Pretoria.

The purpose of the study is to gain insight into unique experiences of participants from diverse background who are enrolled in the same development programme. Please note the following:

- This study involves an anonymous focus group. Your name will not appear on the notes and/or transcripts and the answers you give will be treated as strictly confidential. You cannot be identified in person based on the answers you give.

- Your participation in this study is very important to us. You may, however, choose not to participate and you may also stop participating at any time without any negative consequences.

- The results of the study will be used for academic purposes and may be published in an academic journal. The results will also be used to improve the current development program. We will provide you with a summary of our findings on request.

- This session will be combined with a training session and therefore qualifies for the same procedure as any other company training session, with regards to scheduling, travelling etc.

The focus group session will be on Friday 11 February 2011, and will start promptly at

08:00. The session will take place at

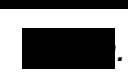

Tick the appropriate box at the bottom of this form and fax to

for the attention of

to indicate that you have read and understand the information provided above.

"I accept the invitation to take part in the research project."

"I DO NOT accept the invitation to take part in the research project."

Employee number: 
DOC.04: Question Schedule

\begin{tabular}{|c|c|}
\hline TOPIC OF INTEREST & POSSIBLE OPEN-ENDED QUESTION \\
\hline Expectations upon entering the programme & $\begin{array}{l}\text { What were your expectations about the } \\
\text { programme when you started? } \\
\text { - What did you expect to learn? }\end{array}$ \\
\hline Perceptions of development needs & $\begin{array}{l}\text { What areas, if any, of your skills upon } \\
\text { entering the programme did you feel you } \\
\text { needed the most training and } \\
\text { development? }\end{array}$ \\
\hline Relevance of content during programme & $\begin{array}{l}\text { During this time, do you feel that you } \\
\text { have grown as a manager or as a } \\
\text { leader? Explain why you choose the } \\
\text { word manager over leader or visa versa. } \\
\text { If you feel that you have not developed } \\
\text { much as either, elaborate. } \\
\text { Which component of the programme } \\
\text { contributed the most to you feeling like } \\
\text { you described in the previous question? } \\
\text { When you think about your experiences } \\
\text { in this program, what have been your } \\
\text { greatest areas of growth and } \\
\text { development? }\end{array}$ \\
\hline Structure of programme & $\begin{array}{l}\text { How have you experienced the structure } \\
\text { of the programme? (Consider the } \\
\text { sequence of the modules and the various } \\
\text { delivery methods.) }\end{array}$ \\
\hline Experience with fellow participants & $\begin{array}{l}\text { - How would you describe your interactions } \\
\text { you're your fellow participants? } \\
\text { - Do you feel you perform better or worse } \\
\text { than your colleagues who are on the } \\
\text { same programme? Why is that? }\end{array}$ \\
\hline Treatment during programme & $\begin{array}{l}\text { - How were you treated during } \\
\text { programme? } \\
\text { Do you feel the programme addresses } \\
\text { your developmental needs? }\end{array}$ \\
\hline
\end{tabular}


DOC.05: Informed Consent Form

UNIVERSITEIT VAN PRETORIA

UNIVERSITY OF PRETORIA

YUNIBESITHI YA PRETORIA

Faculty of Economic and Management Sciences

Department of Human Resource Management

Invitation for participation in an academic research study

\section{A RACE AND GENDER GROUP ANALYSIS OF PARTICIPANT EXPERIENCES IN A LEADERSHIP DEVELOPMENT PROGRAMME IN A SOUTH AFRICAN RETAIL ENVIRONMENT}

Research conducted by:

Mr. C.P. Lewis (10336584)

Cell: 0824494511

This document serves as proof of informed consent for the participation in an academic research study conducted by Clifford Lewis, Masters Student from the Department of Human Resource Management at the University of Pretoria.

- I understand that the purpose of the study is to gain insight into unique experiences of participants from diverse background who are enrolled in the same development programme.

- I understand that this study involves an anonymous focus group and that my name will not appear on the questionnaire and the answers given will be treated as strictly confidential. I understand that I cannot be identified in person based on the answers I give.

- I understanding that I may choose not to participate and you may also stop participating at any time without any negative consequences.

- I understand that I will not receive incentive or remuneration for my participation in this study.

- I understand that the results of the study will be used for academic purposes as well as program improvement and may be published in an academic journal.

I hereby sign this form to indicate that:

- I have read and understand the information provided above.

- I give my consent to participate in the study on a voluntary basis. 


\section{Codes and Definitions}

\begin{tabular}{|c|c|c|}
\hline CODE & GROUNDED & DEFINITION \\
\hline Access to resources & 13 & $\begin{array}{l}\text { "Access to resources" refers to comments made by participants that indicate to what extent they were } \\
\text { granted time and permission to use resources in an effort to gain knowledge or practice skills. This } \\
\text { includes access as well as a lack of access. "Resources" include access to physical assets, or } \\
\text { knowledge resources that may aid in participant development. }\end{array}$ \\
\hline Alienation & 7 & $\begin{array}{l}\text { Statements in this code refer to expressions of perceived exclusion. These exclusions may be from } \\
\text { groups of participants, social work groups, or the management team in general. }\end{array}$ \\
\hline Content not useful & 8 & $\begin{array}{l}\text { Responses in this code indicate that the participant did not find the content useful, timeous or } \\
\text { applicable. }\end{array}$ \\
\hline Content/assessment correlation & 3 & $\begin{array}{l}\text { Responses in this code indicate that the participant experienced assessments to be correlated to the } \\
\text { content of the programme. }\end{array}$ \\
\hline Content/assessment mismatch & 16 & $\begin{array}{l}\text { This code contains responses indicating that the individual or group feels the content of the } \\
\text { programme to be insufficiently in preparing the participant for assessment. This may be due to poor } \\
\text { management of the programme, deficiencies in the program or inconsistent assessments. }\end{array}$ \\
\hline Content/practice mismatch & 11 & $\begin{array}{l}\text { This code includes responses indicating that the individual or group perceives the content of the } \\
\text { program to be different or inconsistent with what is required by the actual job. }\end{array}$ \\
\hline Development need: Admin & 7 & $\begin{array}{l}\text { The responses indicated a perception in the individual or group of a development need on the } \\
\text { administrative side of the business. }\end{array}$ \\
\hline $\begin{array}{l}\text { Development need: Assertiveness/Strong } \\
\text { character }\end{array}$ & 15 & $\begin{array}{l}\text { Responses in this code indicate that the candidate or group needed to develop their assertiveness or } \\
\text { their character to be able to comply with the demands of the job. }\end{array}$ \\
\hline Development need: Coaching and support & 48 & $\begin{array}{l}\text { These responses indicated a perception in the individual or group of a need to receive coaching and } \\
\text { support in order to be successful on the program. }\end{array}$ \\
\hline Development need: Communication skills & 3 & $\begin{array}{l}\text { Responses in this code indicate that the individual or group has as a developmental need that of } \\
\text { developing communication skills. }\end{array}$ \\
\hline Development need: Experienced mentoring & 23 & $\begin{array}{l}\text { These responses indicated that the individual or group requires expert mentoring as a developmental } \\
\text { need. This expertise is linked to the mentor's level of knowledge and experience. }\end{array}$ \\
\hline
\end{tabular}




\begin{tabular}{|c|c|c|}
\hline Development need: People management skills & 22 & $\begin{array}{l}\text { These responses indicated the perception of the individual or group to develop skills pertaining to } \\
\text { people management. These skills may include assertiveness, managing conflict, problem solving, } \\
\text { managing perceptions, instruction giving or feedback. }\end{array}$ \\
\hline Development need: Practical learning & 7 & Responses in this code are indicative of the need to develop by experiences in practical learning. \\
\hline Development need: Problem solving & 3 & $\begin{array}{l}\text { Responses in this code indicate that the participant or group feels they need to develop problem } \\
\text { solving skills. }\end{array}$ \\
\hline Development need: Proper management & 22 & $\begin{array}{l}\text { These responses indicated that the individual or group has as a developmental need, the proper and } \\
\text { systematic management of the program. This means that there should be minimal deviation from the } \\
\text { standardised structure or set development plan. }\end{array}$ \\
\hline Development need: Structure & 24 & $\begin{array}{l}\text { These responses indicated that the individual or group requires adherence to a set structure of } \\
\text { learning as a development need. }\end{array}$ \\
\hline Development need: Technical skills & 22 & $\begin{array}{l}\text { These responses indicated that the individual perceives development on technical skills as a need. } \\
\text { These technical skills involves learning the proper use of systems, processes and assets of the } \\
\text { business. }\end{array}$ \\
\hline Development need: Time & 11 & $\begin{array}{l}\text { These responses indicated that the individual or group has as a developmental need a longer period } \\
\text { of time to complete all components of the training as perceived to be expected of them. }\end{array}$ \\
\hline Development needs met & 35 & $\begin{array}{l}\text { These responses indicated that a developmental needs of an individual or group has been met during } \\
\text { the programme. }\end{array}$ \\
\hline Development needs not met & 65 & $\begin{array}{l}\text { These responses indicated that the individual or group has expressed a developmental need, which } \\
\text { was subsequently not met during the programme. }\end{array}$ \\
\hline Development not aligned with career path & 3 & $\begin{array}{l}\text { In this code candidates or groups indicate that they don't feel their training and development is } \\
\text { assisting their career aspirations. This may include "wasting time" on development on areas in which } \\
\text { the candidate does not choose to work, or development into a different career direction that the } \\
\text { preferred direction of the candidate. }\end{array}$ \\
\hline Deviates from program & 6 & $\begin{array}{l}\text { These responses indicate that there has been a deviation from the participant's planned development } \\
\text { activities. Due to the flexible nature of the programme, each participant has a unique development } \\
\text { plan based on the circumstances of the business unit they are assigned to. Development should take } \\
\text { place in accordance to this plan to ensure timeous completion. As one would gather from some }\end{array}$ \\
\hline
\end{tabular}




\begin{tabular}{|c|c|c|}
\hline & & responses during the focus group, this was not always the case. \\
\hline Differential treatment & 11 & $\begin{array}{l}\text { Responses in this code indicate the perception of differential treatment on the part of the participant, } \\
\text { compared to the treatment of other participants. "Treatment" includes treatment from management, } \\
\text { staff and or fellow participants. }\end{array}$ \\
\hline Equal treatment & 10 & $\begin{array}{l}\text { Responses occurring in this code refer to instances where the participant perceived his or her } \\
\text { treatment to be equal to that of other participants. "Treatment" includes treatment from management, } \\
\text { staff and or fellow participants. }\end{array}$ \\
\hline Expectation: Bilateral communication & 11 & $\begin{array}{l}\text { Responses in this code indicate that the individual or group expected two-way open communication. } \\
\text { This communication is related to all stakeholders involved in the development of the candidate and } \\
\text { also includes a desire on the candidate's part for self-expression. }\end{array}$ \\
\hline Expectation: Coaching and mentoring & 51 & $\begin{array}{l}\text { These responses indicated that the individual or group expected to receive coaching and/or mentoring } \\
\text { from more senior personnel than themselves. Coaching refers to support, assistance or guidance with } \\
\text { tasks, whereas mentoring refers to highly experienced individuals sharing experience. }\end{array}$ \\
\hline Expectation: Customer interaction & 3 & $\begin{array}{l}\text { These responses indicated that the individual or group expected a significant amount of customer } \\
\text { interaction. }\end{array}$ \\
\hline Expectation: Formal work environment & 6 & $\begin{array}{l}\text { These responses indicated that the individual or group expected a formal business work environment. } \\
\text { This work environment relates to physical environment, use of language, typical tasks and general } \\
\text { conduct. }\end{array}$ \\
\hline Expectation: Knowledge transfer & 29 & $\begin{array}{l}\text { These responses indicated that the individual or group expected experiences individuals to share } \\
\text { knowledge. }\end{array}$ \\
\hline Expectation: Leadership from superiors & 1 & $\begin{array}{l}\text { Responses grouped into this code indicate that the individual or group expected leadership from } \\
\text { superiors. }\end{array}$ \\
\hline Expectation: Office Job & 12 & These responses indicated that the inidvidual or group expected the position to involve mostly "office \\
\hline
\end{tabular}




\begin{tabular}{|c|c|c|}
\hline & & $\begin{array}{l}\text { based" activities. This may also include an expectation of what is generally regarded as typical "office } \\
\text { hours". }\end{array}$ \\
\hline Expectation: Practical learning & 16 & $\begin{array}{l}\text { These responses indicated that the individual or group expected to receive practical OJT during } \\
\text { enrolment in the program. }\end{array}$ \\
\hline Expectation: Proper management & 4 & $\begin{array}{l}\text { These responses indicated that the individual or group had as an expectation, the proper and } \\
\text { systematic management of the program. This means that there should be minimal deviation from the } \\
\text { standardised structure. }\end{array}$ \\
\hline Expectation: Short enrolment period & 13 & $\begin{array}{l}\text { These responses indicated that the individual or group expected to be enrolled in the program for } \\
\text { shorter than the standard training period. }\end{array}$ \\
\hline Expectation: Structure & 21 & $\begin{array}{l}\text { These responses indicated that the individual or group expected structure. This structure may relate } \\
\text { to duties assigned, information supplied, sequence of tasks or timing of learning activities. }\end{array}$ \\
\hline Expectation: Teamwork & 3 & $\begin{array}{l}\text { In this code, statements indicate that the participant expected some form of teamwork with either } \\
\text { fellow participants, other members of management, or staff members. }\end{array}$ \\
\hline Growth as a leader & 4 & $\begin{array}{l}\text { These responses indicate that the participant felt he or she developed into a leader during the } \\
\text { programme. }\end{array}$ \\
\hline Growth & 22 & $\begin{array}{l}\text { When discussing growth during the focus groups, the researcher attempted to elicit responses on } \\
\text { participant perceptions of professional growth. This professional growth was then subcategorised into } \\
\text { growth as a leader and growth as a manager. Most responses did not make it clear on whether the } \\
\text { participant perceived his/her own growth as being growth as a leader or growth as a manager. In } \\
\text { these responses, the participant or group suggest growth during the program, but does not elaborate } \\
\text { on whether the growth is as a manager or as a leader. }\end{array}$ \\
\hline Growth as a manager & 16 & These responses indicate that the individual or group perceives to have grown as a manager during \\
\hline
\end{tabular}




\begin{tabular}{|c|c|c|}
\hline & & enrolment in the programme. \\
\hline On-the-job training & 26 & $\begin{array}{l}\text { These responses indicate that the individual or group mentioned on-the-job training (OJT). OJT } \\
\text { includes all learning resulting from interactions with the work environment, with or without supervision. }\end{array}$ \\
\hline Perform poorer & 3 & $\begin{array}{l}\text { A response in this code is an indication of a perception of performing poorer, relative to other } \\
\text { programme participants. }\end{array}$ \\
\hline Positive interactions & 37 & $\begin{array}{l}\text { Positive interactions were mentioned by all four groups. Responses in this code imply positive } \\
\text { interaction between programme participant and other stakeholders in the organisation. Positive } \\
\text { interaction can be between participant and management, participant and staff, or between fellow } \\
\text { participants. }\end{array}$ \\
\hline Professional jealousy & 13 & $\begin{array}{l}\text { These responses imply a perception, on the respondent's part, that negative behaviour on a } \\
\text { colleague's part is due to professional jealousy. Professional jealousy refers to feelings of contempt } \\
\text { towards another person, based on the other person's level of success, relative to your own. }\end{array}$ \\
\hline Received responsibility & 21 & $\begin{array}{l}\text { These responses indicate that the individual received additional management responsibility during the } \\
\text { programme. This relates to responsibility generally associated with a departmental assistant } \\
\text { manager (assistant to the branch manager). In all cases this responsibility is more than would } \\
\text { normally be assigned to a trainee manager, and has certain consequences associated with it. }\end{array}$ \\
\hline Resistance from subordinates & 18 & $\begin{array}{l}\text { These responses indicate that the participant experienced difficulty with staff members following } \\
\text { instructions and accepting authority, whilst the participant was still enrolled in the programme. }\end{array}$ \\
\hline Training material & 13 & $\begin{array}{l}\text { Responses in this code indicate a mention by the candidate and group regarding training material. } \\
\text { Standardised training material includes program files, classroom training manuals, and educational } \\
\text { DVD's. }\end{array}$ \\
\hline
\end{tabular}


A Race And Gender Group Analysis Of Participant Experiences In A Leadership Development Programme In A South African Retail Environment

Value adding classroom learning

These responses indicate that the individual or group perceives classroom training sessions to be value adding to the learning process. 


\section{Summary Grids}

\begin{tabular}{|c|c|c|c|}
\hline \multicolumn{4}{|c|}{ Developmental need not met } \\
\hline ED & 48 & DENSITY & 14 \\
\hline BF & BM & WM & WF \\
\hline $\begin{array}{l}\text { Need: Structure, } \\
\text { M: The candidate indicates here that she does } \\
\text { not know what she should be doing/ } \\
\text { Need: Admin, } \\
\text { M: In this statement the candidate that some } \\
\text { technical development needs where not met } \\
\text { due to insufficient learning/ } \\
\text { Need: Proper management, } \\
\text { Q: For example, I am now on the front end } \\
\text { and I am just about to go to the cash office. In } \\
\text { the next month I have to write a test on } \\
\text { groceries and I've never trained on groceries, } \\
\text { Q: Honestly speaking I do love the system a } \\
\text { lot. I don't think that there is a problem with } \\
\text { the program, I do believe that there are } \\
\text { problems individually in our branches/ } \\
\text { Need: Experienced mentoring, } \\
\text { M(x3): In this statement the candidate } \\
\text { explains that she experiences classroom } \\
\text { sessions to be very rewarding, as well as OJT, } \\
\text { but that the mentoring was lacking, } \\
\text { M: In this statement the candidate explains } \\
\text { that a lack of access to resources may be due }\end{array}$ & $\begin{array}{l}\text { Need: Experienced mentoring, } \\
\text { Q: but now the person doesn't know the } \\
\text { information. Then in anycase it becomes } \\
\text { more difficult for you, } \\
\text { Q: if you go with a question to ask that person, } \\
\text { they don't know how to answer the question, } \\
\text { but they know how to do it practically, } \\
\text { Q: Ok, so who else also feels that the person } \\
\text { coaching you has the competence to do the } \\
\text { job but the find it hard to transfer that } \\
\text { knowledge? - Yes, } \\
\text { M: This statement indicates that experienced } \\
\text { mentoring was not met as a development } \\
\text { need, which also may have led to a mismatch } \\
\text { between the content of training and the } \\
\text { content of the assessment, } \\
\text { M: This statement indicates that the candidate } \\
\text { experiences mentoring form some individuals } \\
\text { but not from all his mentors/ } \\
\text { Need: People Mgt Skills } \\
\text { Q: Now you come to soft skills. Many of us, in } \\
\text { fact I can say most of us, have to be able to } \\
\text { conduct an enquiry, but not even one of us } \\
\text { has had the chance to conduct a disciplinary } \\
\text { enquiry. So while we are expected to do that, }\end{array}$ & $\begin{array}{l}\text { Need: Structure, } \\
\text { M: The candidate indicates here that he } \\
\text { experienced a lot of training and content to not } \\
\text { be generalizable to all branches in which he } \\
\text { worked. He indicated a development need for } \\
\text { structure and consistency/ } \\
\text { Need: Proper Management, } \\
\text { Q: I've been an assistant for } 8 \text { months now. } \\
\text { I've only been for two training sessions in a } \\
\text { classroom situation, } \\
\text { Q: I think a lot of the info is in the file, but you } \\
\text { don't really have time, } \\
\text { Q: I'm not happy with the sequence of the } \\
\text { departments, because one day they need you } \\
\text { in a stocktake and one day they need you in } \\
\text { the deli and you can't finish something, } \\
\text { M: The candidate indicates here that you } \\
\text { could go into the task/activity with the best } \\
\text { attitude, but if you are not managed properly, } \\
\text { you will not benefit, } \\
\text { Q: When you are being used for something } \\
\text { totally different for what you are here for. Like } \\
\text { with the } 2 \text { revamps, } \\
\text { Q: Yes, absolutely, but it depends on what you } \\
\text { do. So the application of you in the revamp. }\end{array}$ & $\begin{array}{l}\text { Need: Coaching and support+ time, } \\
\text { Q: I like went to my service } \\
\text { department manager and told her that I } \\
\text { wanted to do the recon and she } \\
\text { just told me that she was busy, } \\
\text { Q: A lot of times I've gone to my managers } \\
\text { and said, this is what l've noticed, } \\
\text { please explain it to me or help me, only to } \\
\text { hear that they don't have time, } \\
\text { M: The participant indicates here that a } \\
\text { possible reason for the lack of coaching the } \\
\text { operational pressures and time constraints } \\
\text { Q: We don't have the support from our } \\
\text { managers, } \\
\text { Q: If the managers then don't have time to } \\
\text { train you, why don't they put someone there to } \\
\text { train you?/ } \\
\text { Need: Proper management, } \\
\text { M: In this statement, the candidate indicates } \\
\text { that the available material was not utilised } \\
\text { properly, and that in doing assignments and } \\
\text { following set structures was experienced a s a } \\
\text { waste of time, } \\
\text { M: The participant indicates here that there is } \\
\text { too much manual work that is being done and }\end{array}$ \\
\hline
\end{tabular}




\section{Developmental need not met}

\section{GROUNDED}

\section{BF}

to managers not knowing what e-learning or some other resources are,/

\section{Need: Coaching and support,}

Q: When you are training in your specific departments, do you feel you are getting sufficient mentoring from the assistant manager? - No,

$M(x 3)$ : Here the participant explains that the need for support was not met due to the way in which the coach supports the participant during the programme. The participant says that the coaching approach is not developmental, but counter-productive,

Q: Once or twice I've told a line manager mam, or sir, there is a problem in your department, how can we go about fixing it. Then they will say 'I care less, do whatever you want'. Then the next day when the branch manager asks the problem here, what did you do about this problem? Then the line manager looks at me and asks 'did you fix it?'/

Need: Assertiveness,

M: Here the candidate indicates that she realises that the job requires her to be more assertive, but she does not know how to

48

|

we

BN

Need: Coaching and support,

Q: In the store level they don't have time to do

these things, but in anycase if someone can just come in and give guidance and show them then they can come and fix those problems,

M: The participant indicates here that his poor performance is partially due to a lack of support from fellow trainees,

M: The participant indicates here that he sometimes do not get coaching and support/

Need: Time,

M: The participant indicates here that receiving additional responsibility contradicted the development need for sufficient time.

Need: Training material,

M: The candidate indicates that the learning material does not sufficiently address all issues pertaining to people management skills needs/

Need: Admin,

M: The participant explains here that the need

\section{DENSITY}

14

You are not playing a manager's role if you are doing the work and the merchandiser is sitting

\section{Need: Coaching and support,}

M: The participant indicates here that he feels most trainees perform on the same level because of the amount of support fellow participants have to give to each other in the absence of coaching and support,

Q: That's because mangers don't always help as they should but I don't think it's because they don't want to, I just don't think they have the time,

M: The candidates explain that in quite a few cases they are being "misused" for certain operational functions,

Q: In our stores you don't get that support from your managers, so the trainees are training each other/

\section{Need: People Mgt Skills}

Q: Within the first week I realised that I was doing the work myself, instead of giving instructions/

Need: Training material,

tasks/

Need: People Mgt Skills+Assertiveness

Q: It's more like I'm your friend rather than me being the manager and you being the staff member

Q: Yes, definitely. I think that is my main issue at the moment. I can't be strict and say 'listen, you WILL do it' 


\begin{tabular}{|c|c|c|c|}
\hline \multicolumn{4}{|c|}{ Developmental need not met } \\
\hline GROUNDED & 48 & DENSITY & 14 \\
\hline BF & BM & WM & WF \\
\hline $\begin{array}{l}\text { develop that, } \\
\text { Q: I am too soft/ } \\
\text { Need: People Mgt Skills } \\
\text { Q: I feel I still lack some skill on how to handle } \\
\text { situation. How to handle difficult situation, } \\
\text { without fighting with them, } \\
\text { M: In this statement the candidate indicates an } \\
\text { inability to establish balance between firmness } \\
\text { and friendliness, } \\
\text { Q: Yes like, I need to know how to react } \\
\text { correctly and professionally, } \\
\text { Q: Hmm, I have a problem with disciplining the } \\
\text { staff./ } \\
\text { Need: Time, } \\
\text { Q: I feel like I need more time/ }\end{array}$ & $\begin{array}{l}\text { for more admin skills was not developed/ } \\
\text { Need: Structure } \\
\mathrm{Q}(\times 3) \text { : The manager will decide you are } \\
\text { going to another module without fully } \\
\text { completing one of the modules/ } \\
\text { Need: Proper mgt, } \\
\text { M: The participant states here that sometimes } \\
\text { their program is properly managed and } \\
\text { sometimes it is not. In cases where the } \\
\text { program is not properly managed, it results in } \\
\text { a content/practice mismatch because the } \\
\text { branch does not operate in accordance with } \\
\text { set company standard structures and } \\
\text { procedures, } \\
\text { M: The participant expresses an opinion that } \\
\text { in some cases he feels he is not being } \\
\text { managed properly because he is being } \\
\text { assigned to task that is, in his opinion, not } \\
\text { related to his training/ }\end{array}$ & $\begin{array}{l}\text { Q: That is my biggest concern. It takes you } \\
\text { hours and hours to finish the assignments, but } \\
\text { its duplication that you are doing. } \\
\text { Q: How has the content of the program } \\
\text { assisted you with dealing with these } \\
\text { challenges? - Nothing }\end{array}$ & \\
\hline
\end{tabular}




\section{Developmental need met}

\section{GROUNDED}

\section{BF}

\section{Need Practical learning,}

$\mathrm{M}$ : This statement indicates that the candidate needed practical interaction with the environment to develop. This need was met,

M: The participant indicates here that she feels that currently the OTJ is very valuable as it offers a practical foundation/

\section{Need: People Mgt Skills}

Q: I was very shy, I could not talk in front of people, but then now, I am able to give instructions. Mainly because of the "Managing people for profit" course/

Need: Assertiveness

M: Here the candidate indicates that she realises that the job requires her to be more assertive, but she also indicates that this vocational development has impacted negatively on her personal life/

Need: Technical skills,

Q: When I came into the store, I remember it was before I started working in the deli, I did not know how to cook. Until I started working in the deli. I didn't even know how to bake. But I know how to ice a cake now,
24

DENSITY

Need: Technical skills,

Q: The technical skills and the way and the

training has been structured, is structured in a

way for you to become a technical person with the primal focus,

Need: Classroom learning,

M: In this section the participant indicates that Need: Coaching and support,

development needs were met through $M$ : The participant indicates here that he gets classroom learning

M: It gives me like a guideline as what I have

to do at the branch level/

Need: Responsibility,

M: This statement indicates that the candidate feels being afforded increased responsibility, meets developmental needs/

\section{Need: Training material}

$\mathrm{M}$ : The candidate indicates that the content of the training material addresses developmenta needs/

Need: People Mgt Skills

M: Here the candidate indicates that OJT aided in the development need of managing people was addressed and has, as a result,

Need: Structure+

Need: Proper Management,

Q: My branch manager sat with me and divided us up into different sections and worked out a program for me according to the roll-out/

a lot of support on his development from senior management,

M: The candidate explains here that he has received good treatment and support from seniors and fellow participants,

Q: Our regional manager is very strict with the trainees. He wants to know how you are doing, what's your progress and stuff like that, Q: I had the experience of my regional actually coming in and took me in for a day and trained me himself,

Q: Your on-the-job and your mentoring is where you learn the most/

Need: Assertiveness/Strong character

$Q(x 2)$ : I agree with $G$. In the beginning I was

the same. I would always ask please

can you do this, now I'm telling them/

Need: Experienced mentoring,

M: Here the candidate indicates that the interactions and observation of various managers made her grow into the person she is today/

Need: Coaching and support,

M: This participant indicates that she has received the necessary development she needed from her coach, as well as access to resources

Q: So you are getting a lot of guidance? -

Q: They were including me in everything that was happening,

M: The participant indicates here that training material is useful, but coaching and support is still necessary to make for a sensible learning experience/

\section{Need: Structure,}

M: In this statement the candidate indicates that classroom learning has been beneficial in the sense that it provided structure and opportunity to reflect on learning/

Need: People Mgt Skills 


\begin{tabular}{|c|c|c|c|}
\hline \multicolumn{4}{|c|}{ Developmental need met } \\
\hline GROUNDED & 24 & DENSITY & 15 \\
\hline BF & BM & WM & $\overline{~ W F}$ \\
\hline $\begin{array}{l}\text { Q: I never had a computer at home, but right } \\
\text { now, I'm a computer wizz/ } \\
\text { Need: Coaching and support, } \\
\mathrm{M}(\times 3) \text { : In this statement the participant } \\
\text { indicates that interactions with fellow } \\
\text { participants addressed the need for support/ }\end{array}$ & $\begin{array}{l}\text { grown, } \\
\text { M: The candidate indicates that people } \\
\text { management skills was developed to such an } \\
\text { extent that he can manage his people better } \\
\text { than the branch manager, and therefore } \\
\text { received more responsibility./ } \\
\text { Need: Knowledge Transfer } \\
\text { Q: Yes, ya ok, its different for because my eh, } \\
\text { I'm getting like the right information if I ask a } \\
\text { branch manager but when you ask the next } \\
\text { level or maybe different manager you are not } \\
\text { getting, its like you are not on the same page/ } \\
\text { Need: Coaching and support, } \\
\text { M: In this statement the participant indicates } \\
\text { that the need for support was met by fellow } \\
\text { participants/ }\end{array}$ & $\begin{array}{l}\text { Need: People Mgt Skills } \\
\text { M: The candidate indicates here that he felt he } \\
\text { had management responsibilities, even from } \\
\text { the beginning of the programme and that he } \\
\text { had to manage people/ } \\
\text { Need: Technical Skills+Admin, } \\
\text { Q: When you do work are interacting with the } \\
\text { content of the course, which component would } \\
\text { you say is the most beneficial or most value } \\
\text { adding? - I would say it's the reports on the } \\
\text { system - Admin - Front end \& Cash Office/ }\end{array}$ & $\begin{array}{l}\text { Q: for instance now, that lady will greet me, } \\
\text { she will do something if I ask her to }\end{array}$ \\
\hline
\end{tabular}




\begin{tabular}{|c|c|c|c|}
\hline \multicolumn{4}{|c|}{ Developmental need: Coaching and support } \\
\hline GROUNDED & 47 & DENSITY & 8 \\
\hline BF & 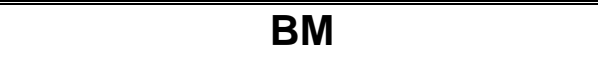 & WM & WF \\
\hline $\begin{array}{l}\text { M: In this statement the candidate indicates } \\
\text { that more coaching and support is necessary } \\
\text { for certain components of the program. In this } \\
\text { instance because of the sheer volume of } \\
\text { some components. } \\
\text { M: In this response the candidate indicates } \\
\text { the need for support and more time due to the } \\
\text { nature of some sections of the programme. } \\
\text { M: Here the participant explains that } \\
\text { classroom learning addressed the need for } \\
\text { support in the program. } \\
\text { Q: When you are training in your specific } \\
\text { departments, do you feel you are getting } \\
\text { sufficient mentoring from the assistant } \\
\text { manager? - No. } \\
M(x 3) \text { : Here the participant explains that the } \\
\text { need for support was not met due to the way } \\
\text { in which the coach supports the participant } \\
\text { during the programme. The participant says } \\
\text { that the coaching approach is not } \\
\text { developmental, but counter-productive. } \\
M(\times 3) \text { In this statement the participant }\end{array}$ & $\begin{array}{l}\text { Q: I need assistance, someone who can } \\
\text { coach me. } \\
\text { Q: if someone can just come in and give } \\
\text { guidance and show them then they can come } \\
\text { and fix those problems. } \\
\text { M: This statement indicates that the } \\
\text { participant did not receive support when } \\
\text { needed. } \\
\text { M: The participant indicates that in some } \\
\text { instances guidance and support is provided, } \\
\text { but that they are not always able to apply and } \\
\text { practice skills in the workplace. } \\
\text { Q: Some of the mentors, instead of like } \\
\text { mentoring you and showing you what to do, } \\
\text { they, because of lack of knowledge or lack of } \\
\text { competence, they will just deviate from } \\
\text { talking. } \\
\text { M: The participant indicates here that his poor } \\
\text { performance is partially due to a lack of } \\
\text { support from fellow trainees. } \\
\text { M: The participant indicates here that he has }\end{array}$ & $\begin{array}{l}\text { Q: In our stores you don't get that support } \\
\text { from your managers, so the trainees are } \\
\text { training each other. } \\
\text { M: The candidate experiences the learning } \\
\text { material as being redundant and says that } \\
\text { one learns more from OJT and coaching. } \\
\text { Q: I think you will accomplish more, with a } \\
\text { dedicated training manager in each branch, } \\
\text { that will take you through the certain steps, } \\
\text { giving you more, what's it, management skills } \\
\text { Q: I'm not happy with the sequence of the } \\
\text { departments, because one day they need you } \\
\text { in a stocktake and one day they need you in } \\
\text { the deli and you can't finish something. } \\
\text { M: The participant indicates here that he feels } \\
\text { most trainees perform on the same level } \\
\text { because of the amount of support fellow } \\
\text { participants have to give to each other in the } \\
\text { absence of coaching and support. } \\
\text { M: The participant indicates here that he gets } \\
\text { a lot of support on his development from } \\
\text { senior management. }\end{array}$ & $\begin{array}{l}\text { Q: We don't have the support from our } \\
\text { managers. } \\
\text { M: In this statement the candidate indicates } \\
\text { that she does not get coaching and support, } \\
\text { however, after appointment, when you are } \\
\text { seen as "one of the managers" this support } \\
\text { becomes better. } \\
\text { M: The participant indicates here that the } \\
\text { development need for coaching and support } \\
\text { was not met. } \\
\text { M: The participant indicates here that training } \\
\text { material is useful, but coaching and support is } \\
\text { still necessary to make for a sensible learning } \\
\text { experience. } \\
\text { Q: A lot of times I've gone to my managers } \\
\text { and said, this is what I've noticed, please } \\
\text { explain it to me or help me, only to hear that } \\
\text { they don't have time. } \\
\text { M: This participant indicates that she has } \\
\text { received the necessary development she } \\
\text { needed from her coach, as well as access to } \\
\text { resources. }\end{array}$ \\
\hline
\end{tabular}




\begin{tabular}{|c|c|c|c|}
\hline \multicolumn{4}{|c|}{ Developmental need: Coaching and support } \\
\hline GROUNDED & 47 & DENSITY & 8 \\
\hline BF & BM & WM & WF \\
\hline $\begin{array}{l}\text { indicates that interactions with fellow } \\
\text { participants addressed the need for support. } \\
\text { Q: Do you feel it is necessary to have that } \\
\text { support structure in order to be successful as } \\
\text { a trainee? - Yes I do. } \\
\text { Q: Yes because they might help you with stuff } \\
\text { which you have not picked up while you were } \\
\text { still training. } \\
\text { M: Here the participant explains that support } \\
\text { is not only necessary between trainees, but } \\
\text { between everyone in the store. } \\
\text { Q: I don't want to say I'm slow, but some of } \\
\text { the other trainees know things more than I do. } \\
\text { They pick up information better than I do, so } \\
\text { sometimes I just feel like I don't know. I do get } \\
\text { support from the other trainee. } \\
\text { Q: Sometimes when they ask me questions } \\
\text { I'm like 'oh my word I don't know that'. } \\
\text { Sometimes I just tell myself maybe it's } \\
\text { because they've been longer in this thing than } \\
\text { I have. }\end{array}$ & $\begin{array}{l}\text { recently been moved to a branch where he } \\
\text { receives support from fellow trainees and this } \\
\text { has assisted with growth. } \\
\text { M: In this statement the participant indicates } \\
\text { that the need for support was met by fellow } \\
\text { participants. } \\
\text { Q: I just wanted to say, um, it's not a case of, } \\
\text { eh, others being better than others. I think it's } \\
\text { just a case of, how good are you in } \\
\text { interpreting the information that you got from } \\
\text { training. Some are good at one thing and } \\
\text { some are not. } \\
\text { Q: I will agree as well. If we see like someone } \\
\text { is not coping, we try to help that person to } \\
\text { build to the same level as the rest of us. So } \\
\text { that why you wont see a difference because } \\
\text { we are always helping each other to build the } \\
\text { same level. }\end{array}$ & $\begin{array}{l}\text { M: The candidate indicates support from } \\
\text { senior personnel. } \\
\text { Q: Apart from a few isolated incidents I would } \\
\text { say the overall treatment is good. This } \\
\text { management team, especially the branch } \\
\text { manager has gone out of his way to assist } \\
\text { you. } \\
\text { Q: I agree with A. Management was very } \\
\text { supportive. I was included in all the } \\
\text { management meetings. They leaded me, they } \\
\text { showed me. }\end{array}$ & $\begin{array}{l}\text { M: The participant indicates here that a } \\
\text { possible reason for the lack of coaching the } \\
\text { operational pressures and time constraints. } \\
\text { Q: If the managers then don't have time to } \\
\text { train you, why don't they put someone there to } \\
\text { train you? } \\
\text { Q: When we come together for a training } \\
\text { session we hear this trainee is working like } \\
\text { this and that trainee is working like that. Not } \\
\text { all the branches is the same, so you learn } \\
\text { more from each other. }\end{array}$ \\
\hline
\end{tabular}




\begin{tabular}{|c|c|c|c|}
\hline \multicolumn{4}{|c|}{ Developmental need: Structure } \\
\hline GROUNDED & 24 & DENSITY & 10 \\
\hline BF & BM & WM & WF \\
\hline $\begin{array}{l}\text { M: The candidate indicates here that she does } \\
\text { not know what she should be doing. } \\
\text { Q: Yes, you do get time to read the manual, } \\
\text { and when time comes when you have to be in } \\
\text { charge of that activity that you have to do then } \\
\text { you just go there and apply what the manual } \\
\text { said. } \\
\text { Q: Ok, so the material gives you guidance? - } \\
\text { Yes. } \\
\text { M: In this statement the candidate indicates } \\
\text { that more coaching and support is necessary } \\
\text { for certain components of the program. In this } \\
\text { instance because of the sheer volume of } \\
\text { some components. }\end{array}$ & $\begin{array}{l}\text { M: This discussion indicates that the } \\
\text { increased need for structure results from the } \\
\text { way in which the participant's program is } \\
\text { being managed. } \\
\text { Q: I just need someone to tell me what is } \\
\text { expected of me. } \\
\text { M: In this section, the candidate expresses the } \\
\text { perception that formal classroom learning } \\
\text { addressed developmental needs by providing } \\
\text { structure during the program. } \\
\text { Q: Ok, but that is not part of the program, but } \\
\text { the way your program is managed in the } \\
\text { store? - Yes. } \\
\text { M: The need for more structure arose from } \\
\text { deviations from the original program. } \\
\text { Q: there should be input from the senior } \\
\text { personnel so that when a person starts } \\
\text { training, that they are trained on what they are } \\
\text { going to be asking you. } \\
\text { Q: the manager will decide you are going to } \\
\text { another module without fully completing one of }\end{array}$ & $\begin{array}{l}\text { M: The candidate indicates here that he } \\
\text { experienced a lot of training and content to not } \\
\text { be generalizable to all branches in which he } \\
\text { worked. He indicated a development need for } \\
\text { structure and consistency. } \\
\text { Q: I'm not happy with the sequence of the } \\
\text { departments, because one day they need you } \\
\text { in a stocktake and one day they need you in } \\
\text { the deli and you can't finish something. } \\
\text { Q: Its better to get that overview of the whole } \\
\text { place than to only sit in that one place and to } \\
\text { only get info of what's going on in that one } \\
\text { place and not knowing what's going on in the } \\
\text { other departments. } \\
\text { M: The participants indicate here that they } \\
\text { experience disruptions to their set program as } \\
\text { detrimental to their development. } \\
\text { Q: I just want to add something on that. When } \\
\text { I started out now we had a roll-out plan from } \\
\text { SETA where they told us that we will have to } \\
\text { spend a certain amount of time in a certain } \\
\text { section. }\end{array}$ & $\begin{array}{l}\text { M: In this statement the candidate indicates } \\
\text { that classroom learning has been beneficial in } \\
\text { the sense that it provided structure and } \\
\text { opportunity to reflect on learning. } \\
\text { M: Here the candidate indicates that } \\
\text { classroom learning provided structure. } \\
\text { M: In this statement the participant indicates } \\
\text { that the structure which the classroom training } \\
\text { provided is not always possible to put into } \\
\text { practice due to time constraints. }\end{array}$ \\
\hline
\end{tabular}




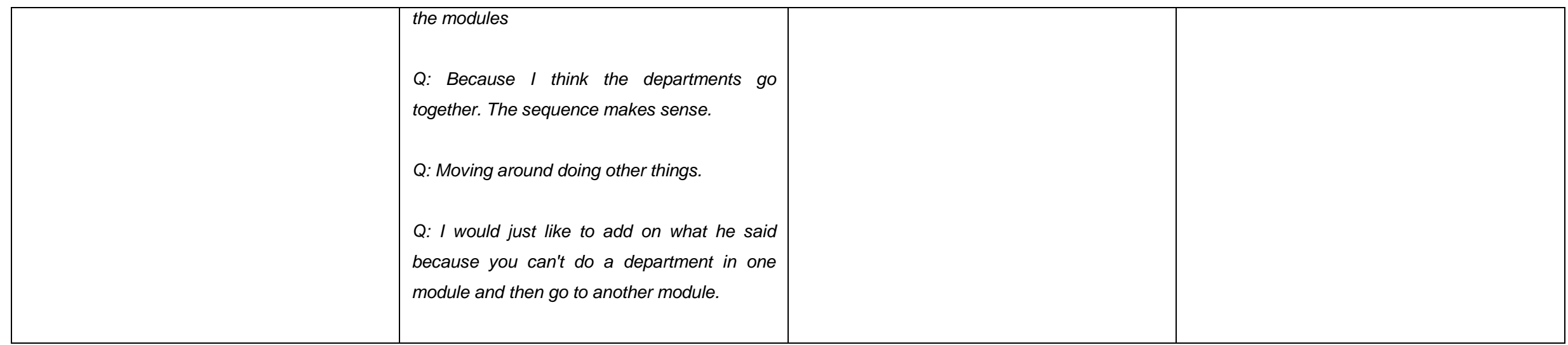

\begin{tabular}{|c|c|c|c|}
\hline \multicolumn{4}{|c|}{ Developmental need: Proper management } \\
\hline GROUNDED & 23 & DENSITY & 12 \\
\hline BF & BM & WM & WF \\
\hline $\begin{array}{l}\text { Q: For example, I am now on the front end } \\
\text { and I am just about to go to the cash office. In } \\
\text { the next month I have to write a test on } \\
\text { groceries and I've never trained on groceries. } \\
\mathrm{M}(\mathrm{x} 2) \text { : Here the participant expresses a } \\
\text { concern about how their programme is } \\
\text { managed and that possible favouritism may } \\
\text { lead to professional jealousy. } \\
\text { Q: Honestly speaking I do love the system a } \\
\text { lot. I don't think that there is a problem with } \\
\text { the program, I do believe that there are } \\
\text { problems individually in our branches. }\end{array}$ & $\begin{array}{l}\text { M: The dialogue in this section indicates that } \\
\text { the development need for more time is not } \\
\text { necessarily isolated and related to the } \\
\text { participant's individual needs, but rather a } \\
\text { product of the way in which the participant's } \\
\text { program is being managed. } \\
\text { M: The participant states here that } \\
\text { sometimes their program is properly } \\
\text { managed and sometimes it is not. In cases } \\
\text { where the program is not properly managed, } \\
\text { it results in a content/practice mismatch } \\
\text { because the branch does not operate in } \\
\text { accordance with set company standard } \\
\text { structures and procedures. }\end{array}$ & $\begin{array}{l}\text { Q: I think a lot of the info is in the file, but you } \\
\text { don't really have time. } \\
\text { Q: I'm not happy with the sequence of the } \\
\text { departments, because one day they need } \\
\text { you in a stocktake and one day they need } \\
\text { you in the deli and you can't finish something. } \\
\text { M: The candidate indicates here that you } \\
\text { could go into the task/activity with the best } \\
\text { attitude, but if you are not managed properly, } \\
\text { you will not benefit. } \\
\text { Q: I just want to add something on that. } \\
\text { When I started out now we had a roll-out plan }\end{array}$ & $\begin{array}{l}\text { Q: When I was training, to be straight honest, } \\
\text { I learnt more in the store where I was training. } \\
\text { This is because they were including me in } \\
\text { everything that was happening. } \\
\text { Q: Um, for our region, I would say that our } \\
\text { files weren't used in our region, and it doesn't } \\
\text { really help. No-one even thinks about it. We } \\
\text { would do it, but it doesn't actually help. It's } \\
\text { time wasting. } \\
\text { M: The participant indicates here that there is } \\
\text { too much manual work that is being done and } \\
\text { they feel they are wasting time on menial } \\
\text { tasks. }\end{array}$ \\
\hline
\end{tabular}




\begin{tabular}{|c|c|c|c|}
\hline \multicolumn{4}{|c|}{ Developmental need: Proper management } \\
\hline GROUNDED & 23 & DENSITY & 12 \\
\hline BF & BM & WM & WF \\
\hline $\begin{array}{l}\text { Q: I also think it might be implementation that } \\
\text { needs some work. }\end{array}$ & $\begin{array}{l}\text { Q: I would say, I don't have a complaint about } \\
\text { how management treats me. Um, like, } \\
\text { actually I am very happy in the store. I feel at } \\
\text { home. Unlike when we went to the other } \\
\text { store where we were treated like a highly } \\
\text { paid shelf packer. } \\
\text { M: The participant expresses an opinion that } \\
\text { in some cases he feels he is not being } \\
\text { managed properly because he is being } \\
\text { assigned to task that is, in his opinion, not } \\
\text { related to his training. }\end{array}$ & $\begin{array}{l}\text { from SETA where they told us that we will } \\
\text { have to spend a certain amount of time in a } \\
\text { certain section. } \\
\text { Q: Another concerning point for me is how it } \\
\text { is possible that a person can slip through the } \\
\text { system with so less, I will use myself as an } \\
\text { example, I've been an assistant for } 8 \text { months } \\
\text { now. I've only been for two training sessions } \\
\text { in a classroom situation. } \\
\text { Q: If I could just add, like, because some } \\
\text { trainees that have been } 10 \text { months in the } \\
\text { company, then there comes new trainees } \\
\text { who get sent for training. Why can't they } \\
\text { rather send me then I can get the training, } \\
\text { then at a later stage they can send the other } \\
\text { trainees. } \\
\text { Q: When you are being used for something } \\
\text { totally different for what you are here for. Like } \\
\text { with the } 2 \text { revamps. } \\
\text { Q: Yes, absolutely, but it depends on what } \\
\text { you do. So the application of you in the } \\
\text { revamp. You are not playing a manager's role } \\
\text { if you are doing the work and the }\end{array}$ & \\
\hline
\end{tabular}




\begin{tabular}{|c|c|c|c|}
\hline \multicolumn{4}{|c|}{ Developmental need: Proper management } \\
\hline GROUNDED & 23 & DENSITY & 12 \\
\hline BF & $\overline{B M}$ & WM & WF \\
\hline & & $\begin{array}{l}\text { merchandiser is sitting. } \\
\text { M: The candidates explain that in quite a few } \\
\text { cases they are being "misused" for certain } \\
\text { operational functions. }\end{array}$ & \\
\hline
\end{tabular}

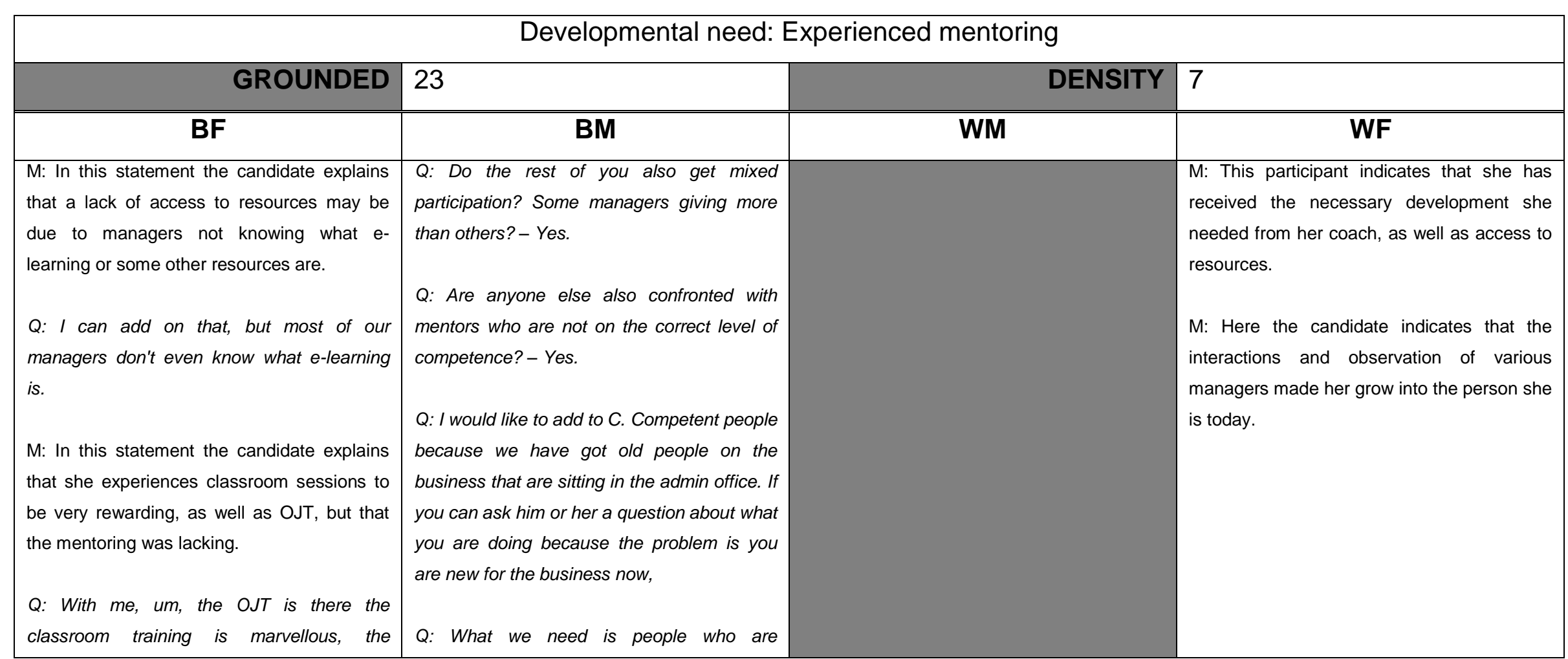




\begin{tabular}{|c|c|c|c|}
\hline \multicolumn{4}{|c|}{ Developmental need: Experienced mentoring } \\
\hline GROUNDED & 23 & DENSITY & 7 \\
\hline BF & BM & WM & $\overline{\text { WF }}$ \\
\hline $\begin{array}{l}\text { mentoring is lacking, we are not mentored } \\
\text { enough. The e-learning, what I can tell you is } \\
\text { that we don't have time to sit there ever. } \\
\text { Q: Management, isn't it something we are } \\
\text { supposed to learn from our managers? I can } \\
\text { understand why we have to have receiving, } \\
\text { groceries, non food, fresh foods, but now, the } \\
\text { management skills isn't it something we must } \\
\text { learn by observing or be taught by our } \\
\text { manager's in the store? In fact, it has to be a } \\
\text { mentoring module. }\end{array}$ & $\begin{array}{l}\text { equipped enough to provide the training. } \\
\text { M: The participant expresses here that the } \\
\text { development need for mentoring was not met } \\
\text { because of a lack of communication. } \\
\text { Q: My experience on the job training, eh, like } \\
\text { some of the department, like eh, maybe you } \\
\text { training at the till points some of the people } \\
\text { like who are training you, they don't know } \\
\text { what they are talking about. Some questions } \\
\text { that you ask you don't get straight answers. } \\
\text { Like K said, they can demonstrate, but they } \\
\text { cannot explain why they are doing this. } \\
\text { M: This statement indicates that the } \\
\text { candidate experiences mentoring form some } \\
\text { individuals but not from all his mentors. } \\
\text { Q: But if you put the person in the right } \\
\text { department then they know this is what I am } \\
\text { going to do until I am finished. That is the } \\
\text { reason I wanted to highlight it, because I've } \\
\text { seen it. We are trainees and we } \\
\text { communicate and we can see, eish, the } \\
\text { person is a bit confused }\end{array}$ & . & \\
\hline
\end{tabular}




\begin{tabular}{|c|c|c|c|}
\hline \multicolumn{4}{|c|}{ Developmental need: Experienced mentoring } \\
\hline GROUNDED & 23 & DENSITY & 7 \\
\hline BF & BM & WM & WF \\
\hline & $\begin{array}{l}\text { Q: some of the people like who are training } \\
\text { you, they don't know what they are talking } \\
\text { about. } \\
\text { Q: For me it goes back to the mentor, } \\
\text { because they know I'm a trainee and that I'm } \\
\text { in the store. There are certain things that I } \\
\text { get involved in when I get appointed } \\
\text { M: This statement indicates that the } \\
\text { candidate perceives a lack of mentoring } \\
\text { being as a result of professional jealousy. }\end{array}$ & & \\
\hline
\end{tabular}

\begin{tabular}{|c|c|c|c|}
\hline \multicolumn{4}{|c|}{ Developmental need: Technical skills } \\
\hline GROUNDED & 22 & DENSITY & 5 \\
\hline BF & BM & WM & WF \\
\hline $\begin{array}{l}\text { Q: When I came into the store, I remember it } \\
\text { was before I started working in the deli, I did } \\
\text { not know how to cook. Until I started working } \\
\text { in the deli. I didn't even know how to bake. } \\
\text { But I know how to ice a cake now } \\
\text { Q: Well, at some point you will be getting } \\
\text { information, you need your reports from }\end{array}$ & $\begin{array}{l}\text { Q: because you have to check on the reports } \\
\text { to be able to manage the various processes. } \\
\text { Q: Ya I think the both go hand and hand } \\
\text { whereby, let's say he has produced those } \\
\text { good, you can't manage him if you don't } \\
\text { even know the recipe. }\end{array}$ & $\begin{array}{l}\text { Q: When you do work are interacting with the } \\
\text { content of the course, which component } \\
\text { would you say is the most beneficial or most } \\
\text { value adding? - I would say it's the reports on } \\
\text { the system. } \\
\text { Q: So the rest of you then felt you needed } \\
\text { more development on technical skills? - Yes }\end{array}$ & \\
\hline
\end{tabular}




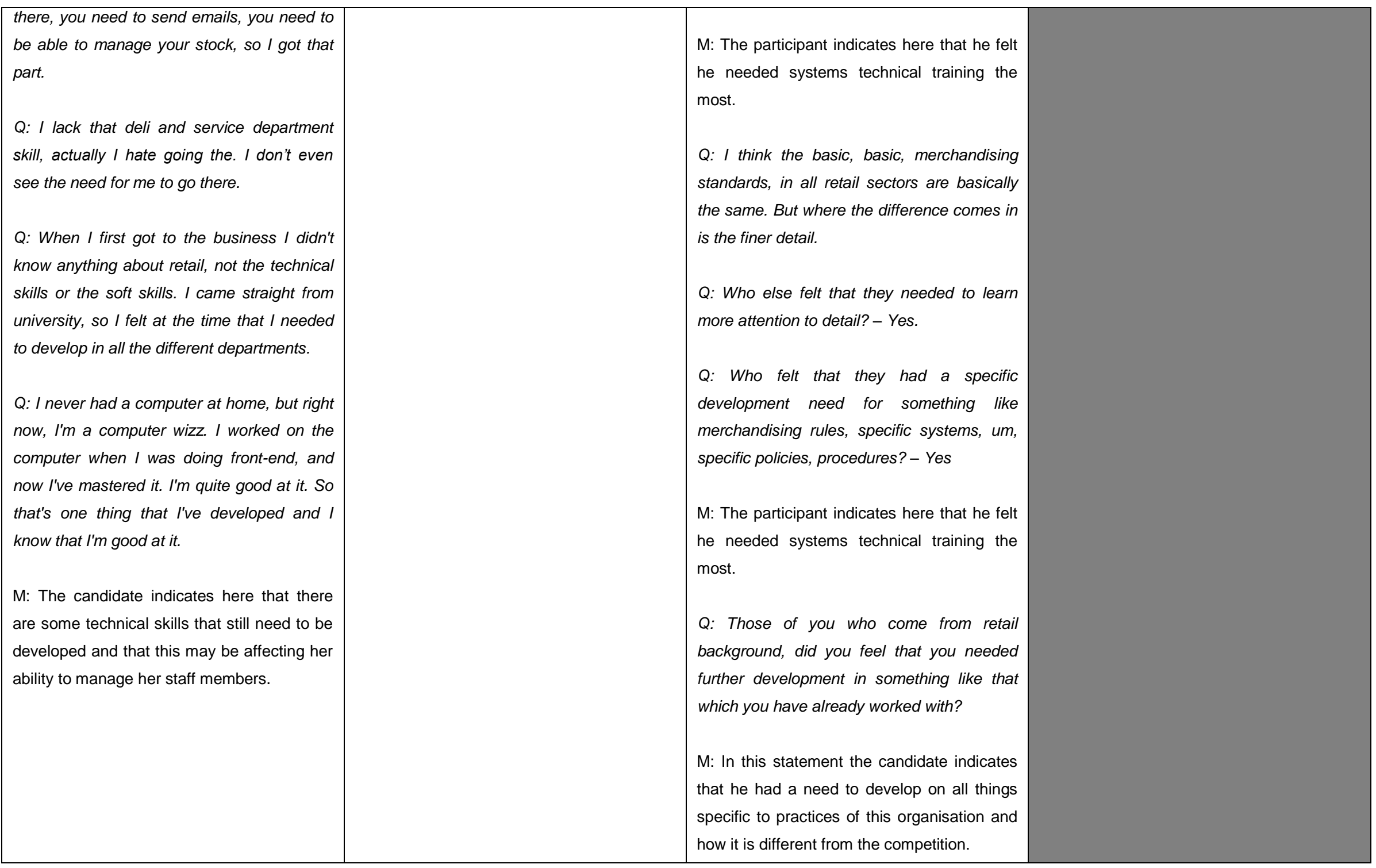




\begin{tabular}{|c|c|c|c|}
\hline \multicolumn{4}{|c|}{ Developmental need: People management skills } \\
\hline GROUNDED & 21 & DENSITY & 8 \\
\hline BF & BM & WM & WF \\
\hline $\begin{array}{l}\text { Q: I feel I still lack some skill on how to } \\
\text { handle situation. How to handle difficult } \\
\text { situation, without fighting with them. I still } \\
\text { need to learn people management skills. } \\
\text { M: In this statement the candidate indicates } \\
\text { an inability to establish balance between } \\
\text { firmness and friendliness. } \\
\text { Q: Yes like, I need to know how to react } \\
\text { correctly and professionally. } \\
\text { Q: Hmm, I have a problem with disciplining } \\
\text { the staff. } \\
\text { Q: Because I'm too soft. } \\
\text { M: The candidate indicates here that there } \\
\text { are some technical skills that still need to be } \\
\text { developed and that this may be affecting her } \\
\text { ability to manage her staff members. } \\
\text { Q: I was very shy, I could not talk in front of } \\
\text { people, but then now, I am able to give } \\
\text { instructions. Mainly because of the } \\
\text { "Managing people for profit" course. }\end{array}$ & $\begin{array}{l}\text { M: People will be in a good mood, even if I } \\
\text { give them an instruction. } \\
\text { Q: He the candidate indicates that OJT aided } \\
\text { in the development need of managing } \\
\text { people was addressed and has, as a result, } \\
\text { grown. } \\
\text { M: The candidate indicates that the learning } \\
\text { material does not sufficiently address all } \\
\text { issues pertaining to people management } \\
\text { skills needs. }\end{array}$ & $\begin{array}{l}\text { Q: Within the first week I realised that I was } \\
\text { doing the work myself, instead of giving } \\
\text { instructions. } \\
\text { Q: Ok so what skill is that? Delegation? - } \\
\text { Yes } \\
\text { Q: So you wanted to learn how to manage } \\
\text { instead of doing the work yourself? - Yes } \\
\text { Q: So when you talk about skills } \\
\text { development, do you feel you had more of a } \\
\text { development need on soft management } \\
\text { skills or technical skills? - Soft Skills } \\
\text { M: The candidate indicates here that he felt } \\
\text { he had management responsibilities, even } \\
\text { from the beginning of the programme and } \\
\text { that he had to manage people. }\end{array}$ & $\begin{array}{l}\text { Q: Managing people and, uh, especially for } \\
\text { me bakery and deli skills. } \\
\text { Q: Ok, so technical skills as well as soft skills } \\
\text { like working with people and giving } \\
\text { instructions, delegating. Would you agree? - } \\
\text { Ya } \\
\text { Q: To work with your staff members. } \\
\text { Q: It's more like I'm your friend rather than } \\
\text { me being the manager and you being the } \\
\text { staff member. } \\
\text { Q: Well ya, at the time, because it was still } \\
\text { really early in my program. }\end{array}$ \\
\hline
\end{tabular}




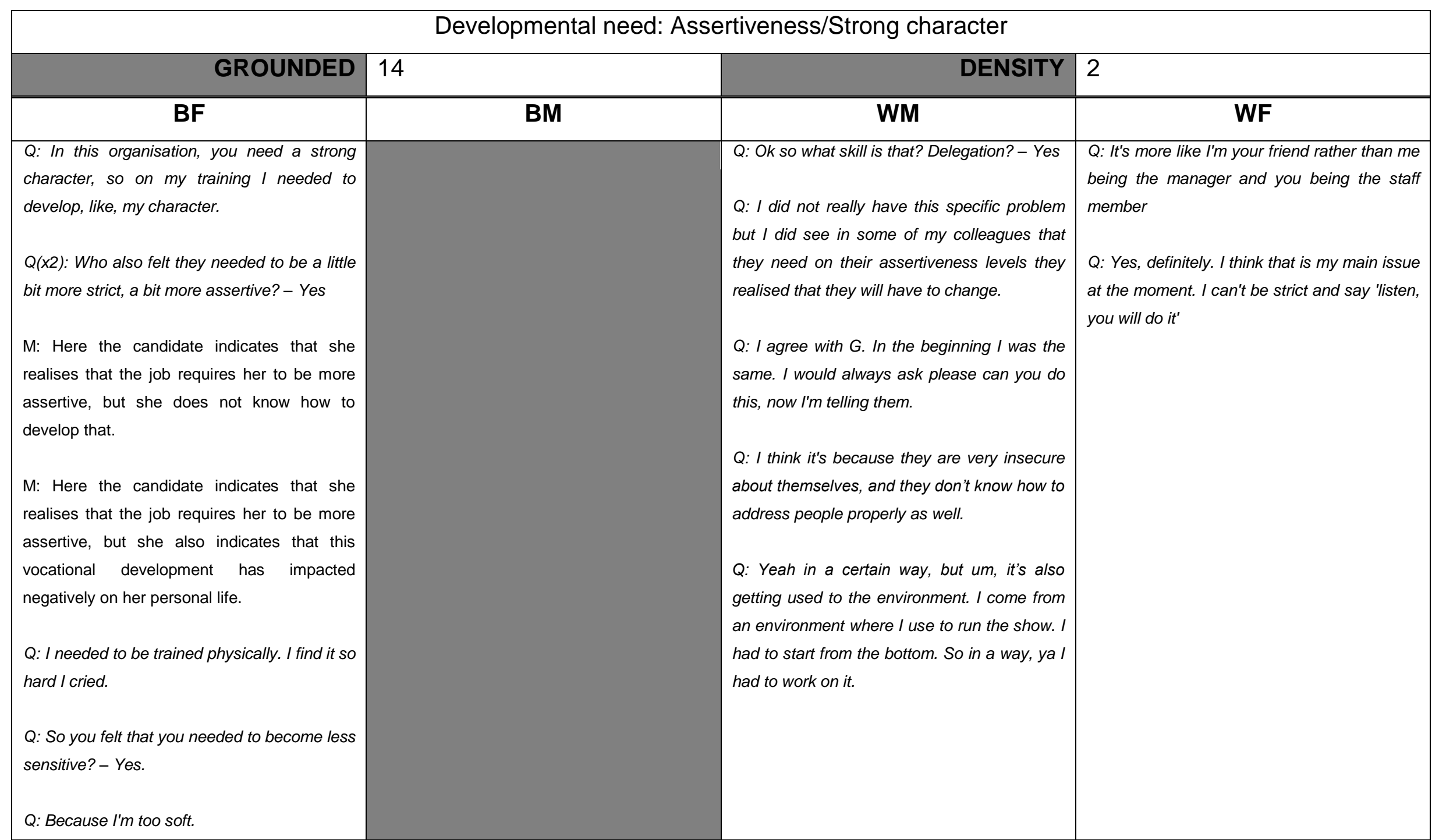




\begin{tabular}{|c|c|c|c|}
\hline \multicolumn{4}{|c|}{ Developmental need: Time } \\
\hline GROUNDED & 11 & DENSITY & 6 \\
\hline BF & BM & WM & WF \\
\hline $\begin{array}{l}\text { Q: I feel like I need more time, } \\
\text { Q: I also like the programs, but maybe they } \\
\text { should also look at duration and appointment, } \\
\text { staying inside the stipulated time period. }\end{array}$ & $\begin{array}{l}\text { Q: My concern is that I do get all the skills but } \\
\text { it's the timeframe. } \\
\text { Q: Does anyone else also feel that more time } \\
\text { is a part of your development needs? - Yes } \\
\text { we do. } \\
\text { Q: .As I said I'm relieving as a line manager, } \\
\text { but I also still have to finish my training. } \\
\text { Q: I would like say maybe } 4 \text { months on some } \\
\text { of the modules because they are the most } \\
\text { crucial parts. }\end{array}$ & & $\begin{array}{l}\text { M: The participant indicates here that a } \\
\text { possible reason for the lack of coaching the } \\
\text { operational pressures and time constraints. } \\
\text { Q: I would say in the service departments, } \\
\text { because in the admin and in the } \\
\text { management, they don't really have time to } \\
\text { train someone. } \\
\text { Q: I would say fresh foods, because most of } \\
\text { the time you will spend the because it's four } \\
\text { departments. } \\
\text { M: In this statement the participant indicates } \\
\text { that the structure which the classroom training } \\
\text { provided is not always possible to put into } \\
\text { practice due to time constraints. }\end{array}$ \\
\hline
\end{tabular}

\begin{tabular}{|c|l|l|l|}
\hline \multicolumn{2}{|c|}{ GROUNDED } & 7 & Developmental need: Admin \\
\hline BF & BM & DENSITY & WM \\
\hline \hline $\begin{array}{l}\text { Q: I never had a computer at home, but right } \\
\text { now, I'm a computer wizz. I worked on the } \\
\text { computer when I was doing front-end, and } \\
\text { now I've mastered it. I'm quite good at it. So }\end{array}$ & $\begin{array}{l}\text { Q: Which of your skills, if any, upon entering } \\
\text { training and development? - I think Admin. }\end{array}$ & $\begin{array}{l}\text { Q: When you do work and are interacting with } \\
\text { the content of the course, which component } \\
\text { would you say is the most beneficial or most } \\
\text { value adding? - I would say it's the reports on }\end{array}$ \\
\hline
\end{tabular}




\begin{tabular}{|c|c|c|c|}
\hline \multicolumn{4}{|c|}{ Developmental need: Admin } \\
\hline GROUNDED & 7 & DENSITY & 4 \\
\hline BF & BM & WM & WF \\
\hline $\begin{array}{l}\text { that's one thing that I've developed and I } \\
\text { know that I'm good at it. } \\
\text { Q; Um, for some of the ladies who has not } \\
\text { went to admin yet, do not understand me } \\
\text { when I say, the Admin file does not cover } \\
\text { everything. Maybe some of the theory, like the } \\
\text { cash office theory, but not that when you have } \\
\text { to sit and capture your admin report, or your } \\
\text { fruit \& veg recon. Most of the things the admin } \\
\text { does every day, they are not in there. } \\
\text { M: In this statement the candidate that some } \\
\text { technical development needs were not met } \\
\text { due to insufficient learning. }\end{array}$ & $\begin{array}{l}\text { Q: I need development on admin. } \\
\text { M: The participant explains here that the need } \\
\text { for more admin skills was not developed. }\end{array}$ & $\begin{array}{l}\text { the system; Admin; Can you just "unpack" } \\
\text { admin a bit for me? - Front end, cash office. }\end{array}$ & \\
\hline
\end{tabular}

\begin{tabular}{|l|l|l|l|}
\hline \multicolumn{1}{|c|}{ GROUNDED } & Developmental need: Practical learning \\
\hline \hline \multicolumn{1}{|c|}{ BF } & BM & 1 \\
\hline $\begin{array}{l}\text { Q: you still need to do things practically. } \\
\text { M: In this statement the candidate indicates } \\
\text { that the content of learning material is } \\
\text { beneficial, but only if it can be subsequently } \\
\text { applied. }\end{array}$ & & $\begin{array}{l}\text { Q: I think maybe disruptions are good, } \\
\text { because when you eventually get top that } \\
\text { department, then you already know whats } \\
\text { going on then you can complete it in a faster } \\
\text { time. }\end{array}$ \\
\hline
\end{tabular}




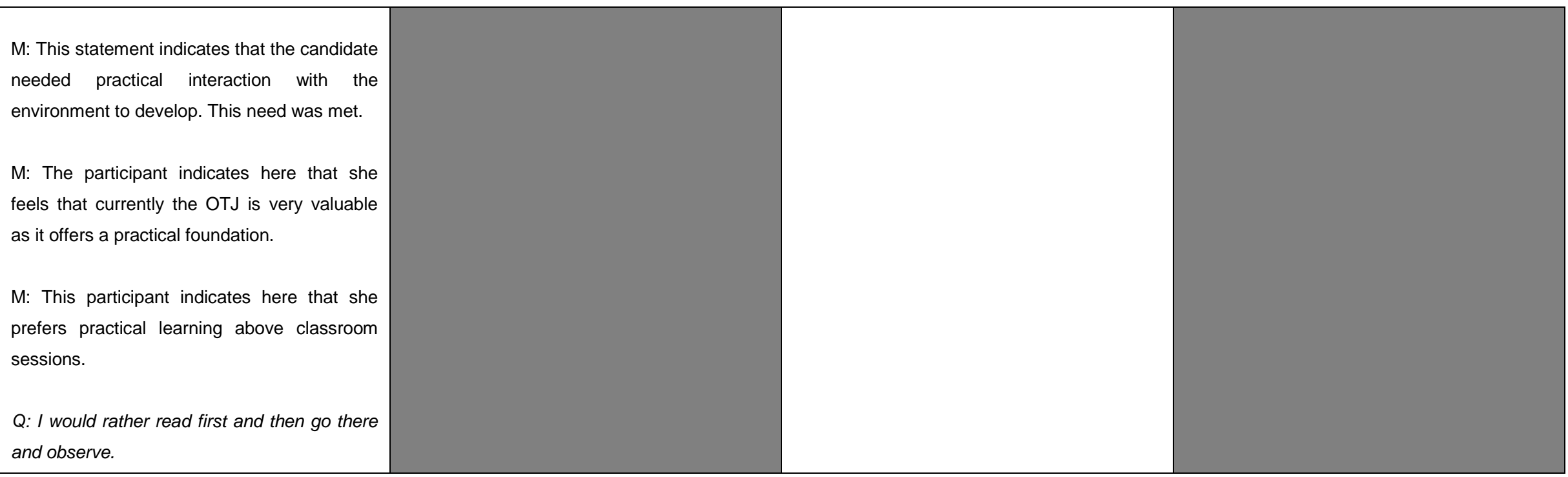

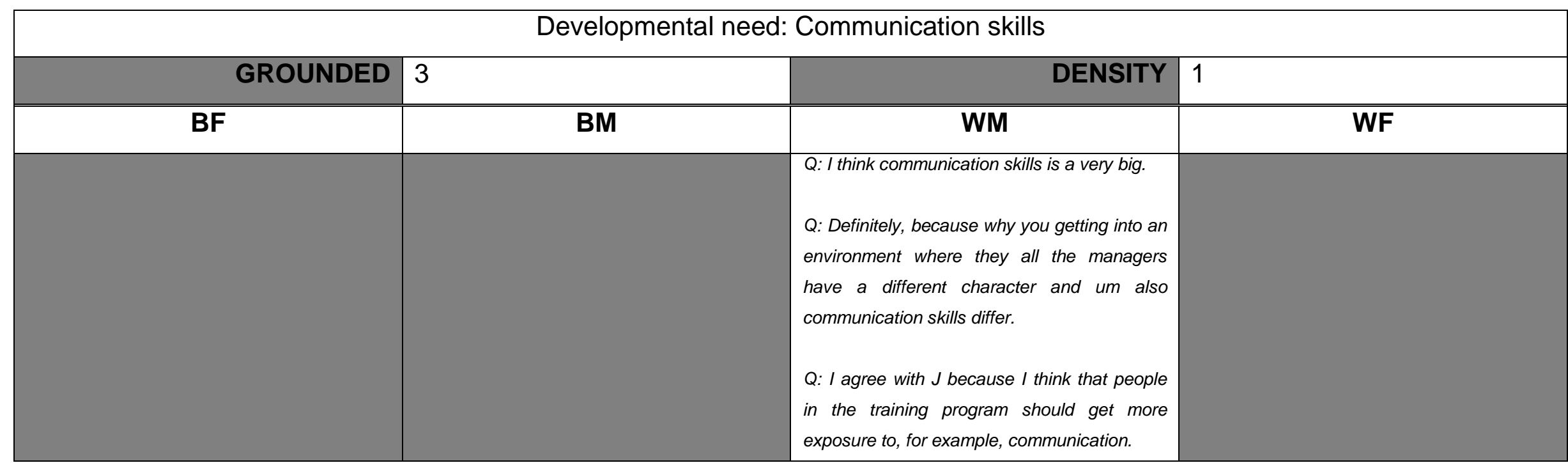




\begin{tabular}{|c|c|c|c|}
\hline \multicolumn{4}{|c|}{ Developmental need: Problem solving } \\
\hline GROUNDED & 3 & DENSITY & 3 \\
\hline BF & BM & WM & WF \\
\hline & & $\begin{array}{l}\text { Q: You've got to learn how to pick up } \\
\text { problems and obviously rectify them. }\end{array}$ & $\begin{array}{l}\text { Q: Ya, um, also like, thinking on your feet. } \\
\text { Q: Can you sort it out if there is a problem, } \\
\text { how the place is going, everything } \\
\text { M: In this statement the participant explains } \\
\text { that she feels assessment is based on } \\
\text { demonstration of management competence } \\
\text { and not content. There is also an indication } \\
\text { that she feels the content does not } \\
\text { adequately prepare or lead to this } \\
\text { competence. }\end{array}$ \\
\hline
\end{tabular}

\begin{tabular}{|c|c|c|c|}
\hline \multicolumn{4}{|c|}{ Expectation: Coaching and mentoring } \\
\hline GROUNDED & 50 & DENSITY & 8 \\
\hline BF & BM & WM & WF \\
\hline $\begin{array}{l}\text { M: The participant indicates here that she } \\
\text { expected the mentor to provide structure to } \\
\text { the training process. } \\
\text { Q: I was also expecting that we are going to } \\
\text { have a one-on-one with the person who is } \\
\text { going to be training you. } \\
\text { Q: No, only a select few, because most of the }\end{array}$ & $\begin{array}{l}\text { Q: there must be someone who sits down with } \\
\text { you and corrects you on that issue }\end{array}$ & $\begin{array}{l}\text { Q: I was expecting to learn, you know, from } \\
\text { these guys that's been around, you know, for } \\
\text { 10, 15, } 20 \text { years, and the first } 2 / 3 \text { weeks was } \\
\text { extremely difficult. } \\
\text { M: In this statement the participant indicates } \\
\text { the expected to receive time and attention } \\
\text { from more senior individuals in order to be } \\
\text { able to grow. }\end{array}$ & $\begin{array}{l}\text { Q: When I started I thought the training } \\
\text { manager told me I was going to be trained. } \\
\text { Q: Ya. But I'm not being trained. If I don't go } \\
\text { and ask, what is this, what are we doing about } \\
\text { this - I have to pull everything - people are } \\
\text { supposed to train me. } \\
\text { Q: Yes, because I thought there will be }\end{array}$ \\
\hline
\end{tabular}




\begin{tabular}{|c|c|c|c|}
\hline \multicolumn{4}{|c|}{ Expectation: Coaching and mentoring } \\
\hline GROUNDED & 50 & DENSITY & 8 \\
\hline BF & BM & WM & WF \\
\hline $\begin{array}{l}\text { jobs I had to go learn myself. } \\
\text { M: Here the participant indicates that there } \\
\text { was not proper communication with some of } \\
\text { the individuals who was supposed to train her. } \\
\text { She also indicates that there wasn't proper } \\
\text { knowledge transfer. The one might be the } \\
\text { cause of the other. This also indicates and } \\
\text { expectation of some form of coaching and /or } \\
\text { mentoring. } \\
\text { M: The participants indicate here that they } \\
\text { expected competence from those training } \\
\text { them and that that competence should be } \\
\text { transferred in a supportive manner. } \\
\text { Q: I expected that she is my manager, she is } \\
\text { my mentor. If I ask for info, she must answer } \\
\text { me now. I know that they are busy. } \\
\text { Q: Yes I can say that I expected managers to } \\
\text { participate, to assist us in many things. } \\
\text { Q: I expected, um, the managers to give us } \\
\text { time. They don't give us time and attention. } \\
\text { Q: I didn't need them to work for me, but I }\end{array}$ & & $\begin{array}{l}\text { Q: Or they don't have time for us. How I find it } \\
\text { was that the first } 2 \text { or } 3 \text { weeks like B was } \\
\text { saying, if you were better introduced to the } \\
\text { whole setup for like me for example, I'm } \\
\text { finished with my frame, but I never had } \\
\text { induction while I'm here. } \\
\text { Q: It's my first week here and I think I'm } \\
\text { working with the right kind of people that will } \\
\text { help me through the hard times and try to } \\
\text { make it easier for me. } \\
\text { Q: Where I made the biggest mistake is that I } \\
\text { thought I was going to be spoonfed. } \\
\text { Q: Yes but I at least expected a one on one } \\
\text { with a departmental manager. } \\
\text { Q: I expected like, in the department, there } \\
\text { should be a dedicated training manager } \\
\text { M: The participant explains here that he } \\
\text { expected more guidance and structure as he } \\
\text { expects to wander in the wrong direction and } \\
\text { waste time without it. }\end{array}$ & $\begin{array}{l}\text { somebody do guide me and to help me. } \\
\text { M(x2): Here the candidate indicates that the } \\
\text { specific coaching expectation was that of } \\
\text { support. } \\
\text { M: In this statement the candidate indicates } \\
\text { that she would have felt more comfortable if } \\
\text { her assigned coach monitored her progress } \\
\text { more closely. } \\
\text { Q: No, I just thought that a coach would be } \\
\text { more actively involved than what there was. } \\
\text { Q: No, I just assumed that's how it would be. } \\
\text { Q: They're supposed to support you. } \\
\text { M: In this statement the specific coaching that } \\
\text { comes out is guidance. } \\
\text { M: The candidate indicates here that she } \\
\text { expected inclusion into demonstrations during } \\
\text { practical learning. } \\
\text { expected inclusion into demonstrations during }\end{array}$ \\
\hline
\end{tabular}




\begin{tabular}{|c|c|c|c|}
\hline \multicolumn{4}{|c|}{ Expectation: Coaching and mentoring } \\
\hline GROUNDED & 50 & DENSITY & 8 \\
\hline BF & BM & WM & WF \\
\hline $\begin{array}{l}\text { wanted to learn. I was the one asking } \\
\text { questions, I'm the one going there pushing. } \\
\text { Please help, please help, please help. But } \\
\text { now I expected less, at least less from them, } \\
\text { so as I ask something, at least they must } \\
\text { answer me. } \\
\text { M: The participant indicates that the mentor or } \\
\text { coach assigned to her did not have the } \\
\text { necessary knowledge. } \\
\text { Q: I think it's because they don't want to help } \\
\text { us. I think they have time, but they are just not } \\
\text { interested in helping us } \\
\text { Q: So once again the theme of guidance and } \\
\text { having guidelines? - Yes }\end{array}$ & & $\begin{array}{l}\text { Q: That they will assist you with problems, } \\
\text { M: In this statement the participant indicates } \\
\text { that he expected a high level of competence } \\
\text { from superiors, coupled with guidance and } \\
\text { support from those superiors during the } \\
\text { training process. } \\
\text { M: The participant indicates here that he } \\
\text { expected some form of guidance. Either in the } \\
\text { form of coaching, or some set structure to } \\
\text { work from. } \\
\text { Q: So are you saying that the management } \\
\text { team created an expectation of support, which } \\
\text { was then not met? - Yes. }\end{array}$ & $\begin{array}{l}\text { practical learning. } \\
\text { Q: Ya, my think is like, if you don't know } \\
\text { something exists, you can't ask a question. So } \\
\text { you have to go ask a manager about } \\
\text { something or find out about something, but } \\
\text { how can you find out information about what } \\
\text { you know nothing about? } \\
\text { Q: That's what I have got a problem with. I'm } \\
\text { supposed to train in receiving but I've heard } \\
\text { enough of people telling me I'm supposed to } \\
\text { be taught by the back admin manager. } \\
\text { Q: Yes. I'm double checking at the moment, } \\
\text { but that is not all that receiving is about. So } \\
\text { I'm not actually learning anything about } \\
\text { receiving. } \\
\text { Q: Well, um, me having to run the department } \\
\text { or having to be with the manager and see } \\
\text { what she does so that when I go to my branch } \\
\text { I know that this is what I should do. } \\
\text { Q: I expected the help to be there, } \\
\text { a They want trainees in the store, but to do }\end{array}$ \\
\hline
\end{tabular}




\begin{tabular}{|c|c|c|c|}
\hline \multicolumn{4}{|c|}{ Expectation: Coaching and mentoring } \\
\hline GROUNDED & 50 & DENSITY & 8 \\
\hline BF & $\overline{\mathrm{BM}}$ & WM & WF \\
\hline
\end{tabular}

\begin{tabular}{|c|c|c|c|}
\hline \multicolumn{4}{|c|}{ Expectation: Knowledge transfer } \\
\hline GROUNDED & 29 & DENSITY & 6 \\
\hline BF & BM & WM & WF \\
\hline $\begin{array}{l}\text { M: Here the participant indicates that there } \\
\text { was not proper communication with some of } \\
\text { the individuals who was supposed to train } \\
\text { her. She also indicates that there wasn't } \\
\text { proper knowledge transfer. The one might be } \\
\text { the cause of the other. This also indicates and } \\
\text { expectation of some form of coaching and /or } \\
\text { mentoring. }\end{array}$ & $\begin{array}{l}\text { Q: we will be getting experience from people } \\
\text { who has that previous experience in terms of } \\
\text { the FMCG } \\
\text { M: The participant indicates that knowledge } \\
\text { transfer did not occur because of suspected } \\
\text { professional jealousy. }\end{array}$ & $\begin{array}{l}\text { Q: Not that I'm saying I didn't get sufficient } \\
\text { information, but at the end of the day it } \\
\text { actually took me } 3 \text { weeks to find my feet, to } \\
\text { find out that this is actually what it is. } \\
\text { Q: So you had no knowledge of the } \\
\text { organisation or of a stocktake?-Yes. }\end{array}$ & $\begin{array}{l}\text { Q: Well I thought there would be a lot more } \\
\text { information about the department itself. Like, } \\
\text { um, information about management and also, } \\
\text { say fruit and veg for example, they've got a lot } \\
\text { of information, but there is still a lot of } \\
\text { information, like for example the recons that } \\
\text { you have to do, it's not in there at all. }\end{array}$ \\
\hline
\end{tabular}




\begin{tabular}{|c|c|c|c|}
\hline \multicolumn{4}{|c|}{ Expectation: Knowledge transfer } \\
\hline GROUNDED & 29 & DENSITY & 6 \\
\hline BF & BM & WM & WF \\
\hline $\begin{array}{l}\text { M: The participants indicate here that they } \\
\text { expected competence from those training } \\
\text { them and that that competence should be } \\
\text { transferred in a supportive manner. } \\
\text { Q: I expected to get more knowledge, more } \\
\text { competence, more info from the manager } \\
\text { M: The participant indicates that the mentor or } \\
\text { coach assigned to her did not have the } \\
\text { necessary knowledge. } \\
\text { Q: Always we have to find out information } \\
\text { from them, but then, at the end of the day, } \\
\text { there are certain things that you don't even } \\
\text { know about, not even slightly aware of, that } \\
\text { person, because, she or he knows about it, } \\
\text { they should come to you with the information } \\
\text { and tell you, because you are not aware of it. } \\
\text { M: Here the participant indicates that she is } \\
\text { not convinced that the mentor/coach } \\
\text { possesses all the necessary knowledge and } \\
\text { competence for training someone else. }\end{array}$ & $\begin{array}{l}\text { Q: Yes, ya ok, its different for because my eh, } \\
\text { I'm getting like the right information if I ask a } \\
\text { branch manager but when you ask the next } \\
\text { level or maybe different manager you are not } \\
\text { getting, it's like you are not on the same page. }\end{array}$ & $\begin{array}{l}\text { Q: At some point you have to say, listen if you } \\
\text { are not going to step up and get information } \\
\text { you are going to sit. And to get information } \\
\text { isn't always that easy to obtain certain things } \\
\text { Q: Oh, I was just expecting more, how can I } \\
\text { say, cleverness. } \\
\text { M: In this statement the participant indicates } \\
\text { that he expected a high level of competence } \\
\text { from superiors, coupled with guidance and } \\
\text { support from those superiors during the } \\
\text { training process. } \\
\text { Q: Things that are repeated and repeated } \\
\text { without daily inspections, for argument sake, } \\
\text { this should be like this, health and safety, } \\
\text { production, hygiene, whatever the case might } \\
\text { be with the running of the company, you are } \\
\text { learning that when you are appointed } \\
\text { somewhere, this is not how you should be } \\
\text { doing it. }\end{array}$ & $\begin{array}{l}\text { Q: That's what I have got a problem with. I'm } \\
\text { supposed to train in receiving but I've heard } \\
\text { enough of people telling me I'm supposed to } \\
\text { be taught by the back admin manager. } \\
\text { Q: Yes. I'm double checking at the moment, } \\
\text { but that is not all that receiving is about. So } \\
\text { I'm not actually learning anything about } \\
\text { receiving. } \\
\text { Q: Well, um, me having to run the department } \\
\text { or having to be with the manager and see } \\
\text { what she does so that when I go to my branch } \\
\text { I know that this is what I should do. } \\
\text { Q: When I'm with my manager in that } \\
\text { department I follow them to see how they } \\
\text { handle situations. } \\
\text { Q: Ya, I mean if I do waste three times, for } \\
\text { three different departments, I think I know } \\
\text { how to do waste. Why do I need to continue } \\
\text { to do waste all the time? It is the work of the } \\
\text { manager in that department, actually, to } \\
\text { appoint someone or to do it themselves. }\end{array}$ \\
\hline
\end{tabular}




\begin{tabular}{|c|c|c|c|}
\hline \multicolumn{4}{|c|}{ Expectation: Knowledge transfer } \\
\hline GROUNDED & 29 & DENSITY & 6 \\
\hline BF & BM & WM & WF \\
\hline & & $\begin{array}{l}\text { Q: They also told us that you will not be } \\
\text { spoonfed. But now you go to them and ask a } \\
\text { question then they tell you again that they are } \\
\text { not going to spoonfeed you, so how does that } \\
\text { work? } \\
\text { Q: Sometimes you may even find that with } \\
\text { your knowledge that you have gained in the } \\
\text { store you have more knowledge than the } \\
\text { facilitator } \\
\text { M: The participant explains here that positive } \\
\text { interactions is good in terms of support, but } \\
\text { this may also lead to incorrect knowledge } \\
\text { transfer. }\end{array}$ & \\
\hline
\end{tabular}

\begin{tabular}{|c|c|c|c|}
\hline \multicolumn{4}{|c|}{ Expectation: Structure } \\
\hline GROUNDED & 21 & DENSITY & 8 \\
\hline BF & BM & WM & WF \\
\hline $\begin{array}{l}\text { M: The participant indicates here that she } \\
\text { expected the mentor to provide structure to } \\
\text { the training process. } \\
\text { Q: OK, so you expected support from the }\end{array}$ & $\begin{array}{l}\text { Q: They want the company standard, but we } \\
\text { will never know, because the shops are } \\
\text { different } \\
\text { Q: So were expecting a little bit more }\end{array}$ & $\begin{array}{l}\text { M: In this statement the participant indicates } \\
\text { the expected to receive time and attention } \\
\text { from more senior individuals in order to be } \\
\text { able to grow. }\end{array}$ & $\begin{array}{l}\text { Q: I thought there will be somebody do guide } \\
\text { me and to help me } \\
\text { M: In this statement the candidate indicates } \\
\text { that she would have felt more comfortable if }\end{array}$ \\
\hline
\end{tabular}




\begin{tabular}{|c|c|c|c|}
\hline \multicolumn{4}{|c|}{ Expectation: Structure } \\
\hline GROUNDED & 21 & DENSITY & 8 \\
\hline BF & BM & WM & WF \\
\hline $\begin{array}{l}\text { beginning and more information? - Yes } \\
\text { Q: I thought I knew a lot, but when I started } \\
\text { this whole thing it was like ok, which part do I } \\
\text { target? Do I target the management part, or } \\
\text { do I start at the bottom or do like where do I } \\
\text { really go? No one showed me the route to go } \\
\text { so that I could get as much information as I } \\
\text { needed. } \\
\text { M: Here the candidate explains that the } \\
\text { training material provided structure as it gave } \\
\text { an indication where to focus and what } \\
\text { questions to ask. }\end{array}$ & $\begin{array}{l}\text { standard? A little bit more structure? A little bit } \\
\text { more guidance; is that correct? - Yes } \\
\text { Q: When I started my training, they didn't tell } \\
\text { me that you are going to start somewhere and } \\
\text { then go somewhere else. }\end{array}$ & $\begin{array}{l}\text { Q: I was fortunate enough to start on the } \\
\text { Monday and went for induction on the } \\
\text { Wednesday. And for me that came out of a } \\
\text { non-retail environment, it was an eye-opener } \\
\text { to say "this is what the company is about", } \\
\text { "this is what's expected of me". I stepped } \\
\text { down from there and I immediately fell into } \\
\text { the system and I said ok, this is where I'm } \\
\text { starting. I got my program and I saw this is } \\
\text { where I had to go. } \\
\text { M: In this statement the candidate indicates } \\
\text { that he would have preferred more guidance } \\
\text { in terms of what is expected of him. } \\
\text { Q: We are training in an environment where } \\
\text { people are running a business and they don't } \\
\text { have the time always to come and sit with you } \\
\text { to say listen this and this and this because } \\
\text { they have other matters to attend to. } \\
\text { M: The participant explains here that he } \\
\text { expected more guidance and structure as he } \\
\text { expects to wander in the wrong direction and } \\
\text { waste time without it. } \\
\text { Q: You see because see now you start with a }\end{array}$ & $\begin{array}{l}\text { her assigned coach monitored her progress } \\
\text { more closely. } \\
\text { Q: Ya, I mean if I do waste three times, for } \\
\text { three different departments, I think I know } \\
\text { how to do waste. Why do I need to continue } \\
\text { to do waste all the time? It is the work of the } \\
\text { manager in that department, actually, to } \\
\text { appoint someone or to do it themselves. } \\
\text { M: This statement gives an indication that the } \\
\text { candidate required structure and guidance, } \\
\text { and received that through positive } \\
\text { interactions. }\end{array}$ \\
\hline
\end{tabular}




\begin{tabular}{|c|c|l|l|}
\hline \multicolumn{2}{|c|}{ GROUNDED } & 21 & Expectation: Structure \\
\hline \hline BF & & WM & $\begin{array}{l}\text { department and it has certain steps, a - z, but } \\
\text { now you with stupidity instead of starting with } \\
\text { a, you are starting with } j . \text { The whole picture is } \\
\text { not coming together so it takes you longer to } \\
\text { get the whole picture. }\end{array}$ \\
\hline & $\begin{array}{l}\text { M: The participant indicates here that he } \\
\text { expected some form of guidance. Either in the } \\
\text { form of coaching, or some set structure to } \\
\text { work from. }\end{array}$ \\
\hline
\end{tabular}

\begin{tabular}{|c|c|c|c|}
\hline \multicolumn{4}{|c|}{ Expectation: People management/Generic management skills } \\
\hline GROUNDED & 20 & DENSITY & 6 \\
\hline BF & BM & WM & WF \\
\hline $\begin{array}{l}\text { Q: What I expected from this, as the position } \\
\text { stipulated, I expected to be a manger. When I } \\
\text { get to a store I expected to be trained as a } \\
\text { manager } \\
\text { Q: and then after you can learn the soft stuff. } \\
\text { That's what I expected. } \\
\text { M: In these statements the candidate } \\
\text { indicates an appreciation for being technically } \\
\text { competent before going over into generic }\end{array}$ & $\begin{array}{l}\text { Q: Leadership skills like communicating with } \\
\text { staff and being assertive } \\
\text { Q: management skills, like how to operate on } \\
\text { the floor, problem solving, how to make a plan } \\
\text { if something happened, quickly in the stores } \\
\text { Q: I was also thinking I you could use your } \\
\text { mind, not only like things whereby now they } \\
\text { tell you how you do it like this }\end{array}$ & $\begin{array}{l}\text { Q: Within the first week I realised that I was } \\
\text { doing the work myself, instead of giving } \\
\text { instructions. } \\
\text { M: The participant indicates here that he } \\
\text { expected to learn how to manage. }\end{array}$ & $\begin{array}{l}\text { Q: I expected to learn more about managing } \\
\text { instead fo doing the job itself. } \\
\text { Q: I expected to learn about how to handle } \\
\text { the people } \\
\text { Q: So you expected the technical skills like for } \\
\text { example how to bake a bread, but then also } \\
\text { how to manage the person that bakes the } \\
\text { bread. - Yes. }\end{array}$ \\
\hline
\end{tabular}




\begin{tabular}{|c|c|c|c|}
\hline \multicolumn{4}{|c|}{ Expectation: People management/Generic management skills } \\
\hline GROUNDED & 20 & DENSITY & 6 \\
\hline BF & BM & WM & WF \\
\hline $\begin{array}{l}\text { management. } \\
\text { Q: and ten after you can learn the soft stuff. } \\
\text { That's what I expected. }\end{array}$ & $\begin{array}{l}\text { M: The candidate indicates that people } \\
\text { management skills was developed to such an } \\
\text { extent that he can manage his people better } \\
\text { than the branch manager, and therefore } \\
\text { received more responsibility. }\end{array}$ & & $\begin{array}{l}\text { Q: But sometimes, especially in my branch it's } \\
\text { not always possible to see what he is doing. } \\
\text { Everyone is Tswana so I don't know how to } \\
\text { handle the people. }\end{array}$ \\
\hline $\begin{array}{l}\text { M: The participant indicates here that she } \\
\text { expected the soft and technical skills to } \\
\text { complement each other. }\end{array}$ & & & $\begin{array}{l}\text { Q: I would have liked to have a little team of } \\
\text { my own. A group of } 4 / 5 \text { people that I could } \\
\text { have managed for ascertain period of time to } \\
\text { also further my management skills. }\end{array}$ \\
\hline $\begin{array}{l}\text { M: This statement also indicates that the } \\
\text { participant is concerned that there is not a } \\
\text { good balance between practical (technical) } \\
\text { and management training. }\end{array}$ & & & $\begin{array}{l}\text { Q; Ya, you learn a lot from the program, but } \\
\text { the physical management part, you don't } \\
\text { actually learn. }\end{array}$ \\
\hline $\begin{array}{l}\text { Q: I expected to, you know, the training } \\
\text { program is saying 'trainee manager', so what I } \\
\text { expected is how to be a manager. }\end{array}$ & & & \\
\hline $\begin{array}{l}\text { Q: How to be a manager, how to control } \\
\text { people }\end{array}$ & & & \\
\hline
\end{tabular}




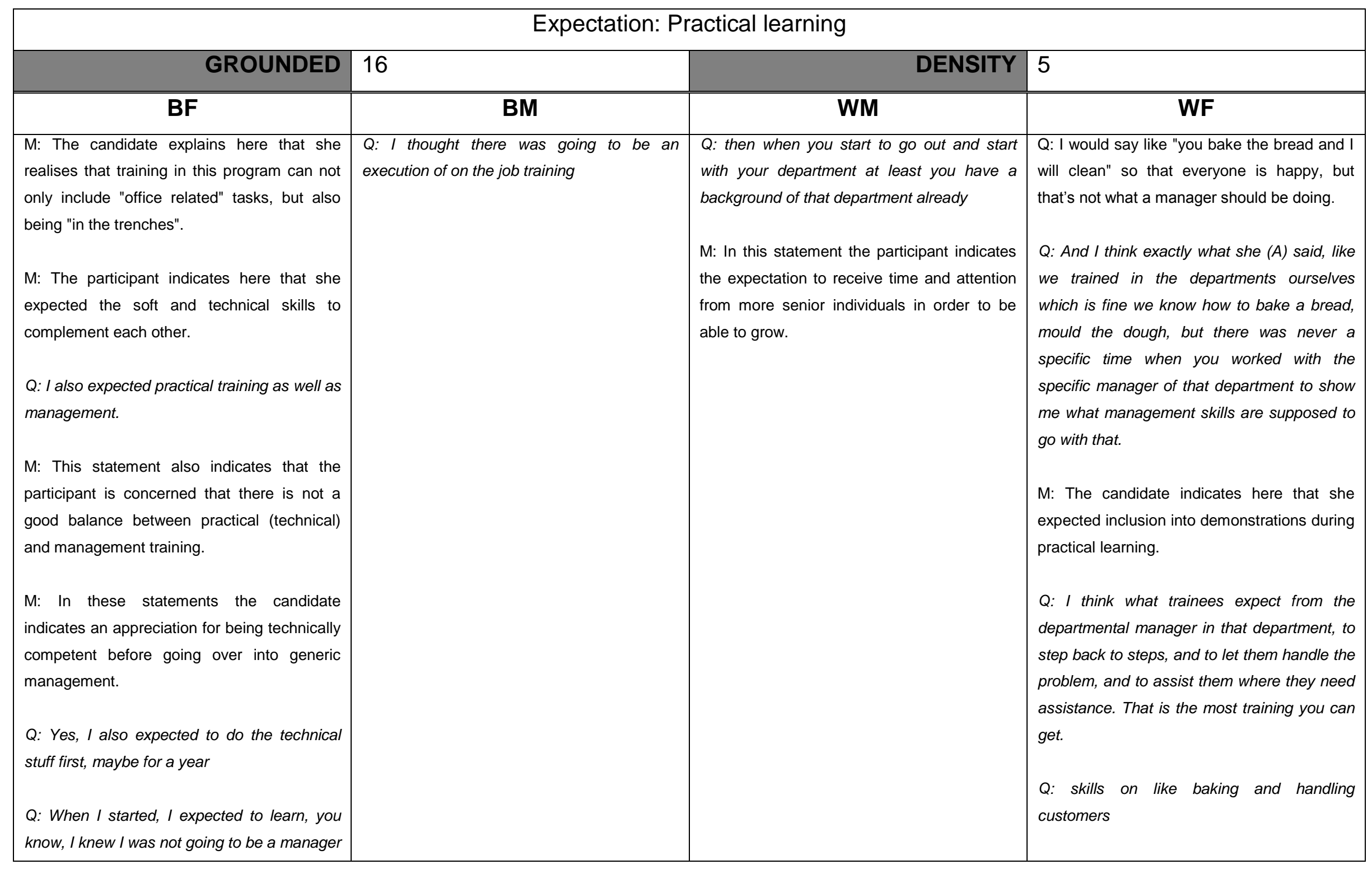




\begin{tabular}{|l|l|l|l|}
\hline \multicolumn{1}{|c|}{ GROUNDED } & 16 & & Dxpectation: Practical learning \\
\hline BF & & DENSITY & WM \\
\hline $\begin{array}{l}\text { at the get-go, you know, I expected to learn } \\
\text { first and then become a manager. }\end{array}$ & & & WF \\
$\begin{array}{l}\text { Q: I expected to know the technical skills first, } \\
\text { you know, then after that, you know, you have } \\
\text { to learn the management skills. But I didn't } \\
\text { expect to be on the technical part all the time. }\end{array}$ & & & \\
\hline
\end{tabular}

\begin{tabular}{|c|c|c|c|}
\hline \multicolumn{4}{|c|}{ Expectation: Short enrolment period } \\
\hline GROUNDED & 13 & DENSITY & 3 \\
\hline BF & BM & WM & WF \\
\hline $\begin{array}{l}\text { Q: So you didn't expect to be a manager from } \\
\text { the get-go, but you expected it to come } \\
\text { sooner? - Yes }\end{array}$ & $\begin{array}{l}\text { Q: When they advertise, they don't say we } \\
\text { are looking for trainee manager, they say we } \\
\text { are looking for branch managers, admin } \\
\text { managers, sales managers and service } \\
\text { department managers is the one the most } \\
\text { used to, so it makes us to expect more such } \\
\text { a things. } \\
\text { Q: I thought I was going to train for like } 6 \\
\text { months or less } \\
\text { Q: I thought I was going to train for like } 6 \\
\text { months or less - Yes }\end{array}$ & $\begin{array}{l}\text { Q: Anyone else also feel that way and that } \\
\text { you have extended your training } \\
\text { period? - Yes } \\
\text { Q: Where I made the biggest mistake is that I } \\
\text { thought I was going to be spoonfed. By that } \\
\text { though my training was delayed by some } \\
\text { time and then I just changed my mindset } \\
\text { whereby I basically just excluded them from } \\
\text { my training and just kept on doing my own } \\
\text { thing. } \\
\text { Q: Well, my expectations were to start and } \\
\text { finish as soon as possible. The thing is to }\end{array}$ & \\
\hline
\end{tabular}




\begin{tabular}{|c|c|c|c|}
\hline \multicolumn{4}{|c|}{ Expectation: Short enrolment period } \\
\hline GROUNDED & 13 & DENSITY & 3 \\
\hline BF & BM & WM & WF \\
\hline & $\begin{array}{l}\text { Q: I was also expecting that when you are } \\
\text { done with your training you will eventually be } \\
\text { appointed. } \\
\text { Q: You didn't expect a whole } 12 \text { month } \\
\text { program? - No } \\
\text { Q: Basically I thought it was going to be a } 6 \\
\text { months training } \\
\text { Q: ... train for maybe a month or less... } \\
\text { Q: When I applied, I applied for a sales } \\
\text { manager, but only to find out that I was going } \\
\text { to be a trainee for } 12 \text { months. }\end{array}$ & $\begin{array}{l}\text { finish as soon as possible so that you can go } \\
\text { and start to work. } \\
\text { Q: Ok, so was your specific timeframe } \\
\text { communicated to you in the beginning? - Yes }\end{array}$ & \\
\hline
\end{tabular}




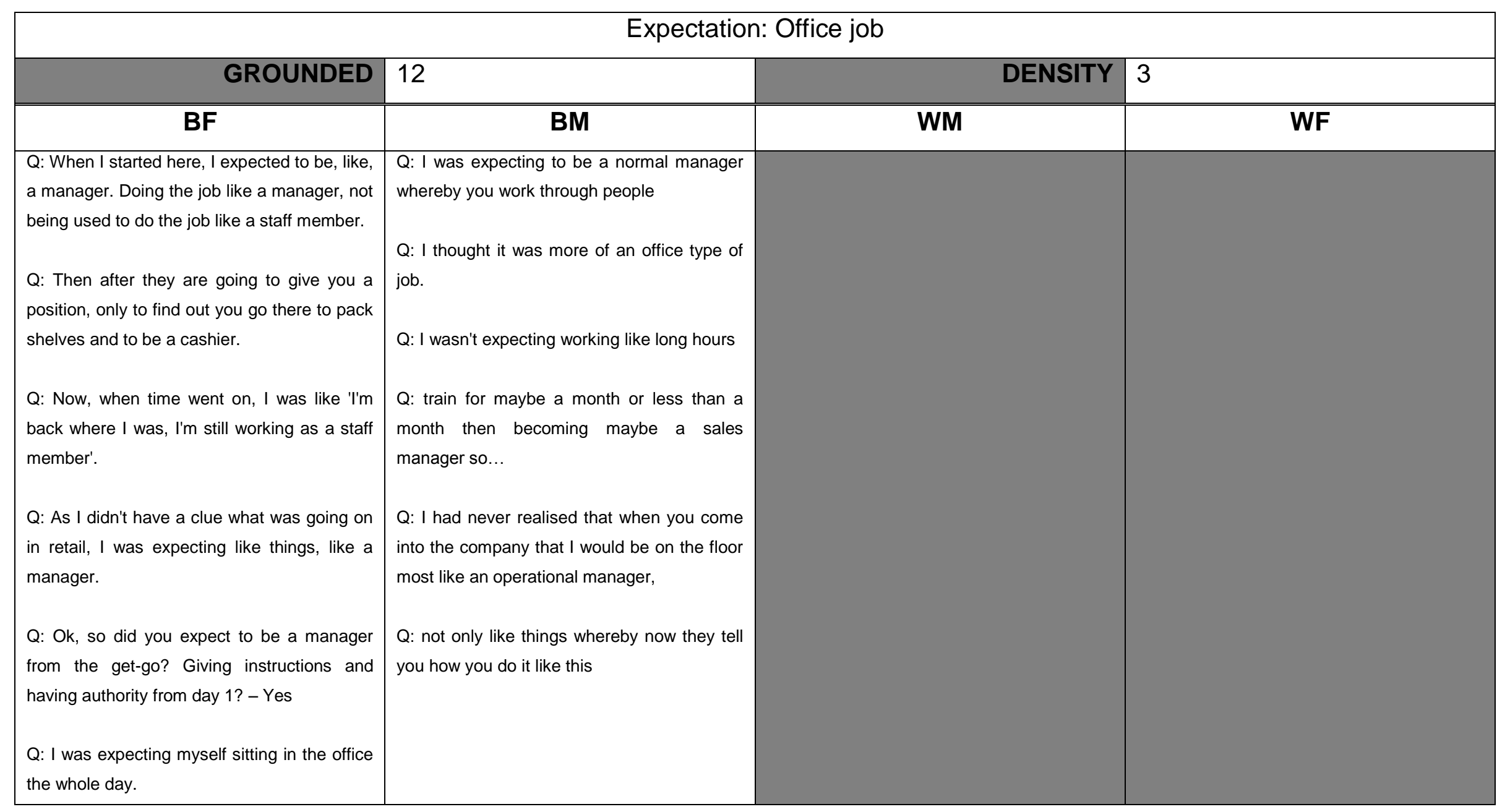




\begin{tabular}{|c|c|c|c|}
\hline \multicolumn{4}{|c|}{ Expectation: Bilateral communication } \\
\hline GROUNDED & 11 & DENSITY & 4 \\
\hline BF & BM & WM & WF \\
\hline $\begin{array}{l}\text { Q: Then you ask, can you help me with this } \\
\text { then they say, no I'm busy. } \\
\text { Q: I can help her achieve her task whatever } \\
\text { she is doing. But now they are too busy, they } \\
\text { can't assist you with this, whatever they are } \\
\text { doing then, you know. } \\
\text { M: The candidate indicates here that she } \\
\text { feels if there was better communication } \\
\text { between the trainees and management there } \\
\text { would be better coaching and trainees will } \\
\text { also be able to assist management with their } \\
\text { tasks. } \\
\text { M: Here the participant indicates that there } \\
\text { was not proper communication with some of } \\
\text { the individuals who was supposed to train } \\
\text { her. She also indicates that there wasn't } \\
\text { proper knowledge transfer. The one might be } \\
\text { the cause of the other. This also indicates } \\
\text { and expectation of some form of coaching } \\
\text { and /or mentoring. }\end{array}$ & $\begin{array}{l}\text { Q: The branch manager they've got this, I } \\
\text { don't know if it is their style or what like in } \\
\text { anycase if you want to show him something, } \\
\text { he doesn't want to listen to your opinion. He } \\
\text { just wants to do the work he does. } \\
\text { Q: I was expecting to be in an environment } \\
\text { whereby I could voice my opinion or that I } \\
\text { could say something that I want to say } \\
\text { Q: So you expected to have more say in } \\
\text { what is taught and how it is taught. Being } \\
\text { able to give input? - Yes } \\
\text { Q; if they could give you a chance in order to } \\
\text { whereby to express your opinion } \\
\text { Q: I was expecting open communication with } \\
\text { superiors. }\end{array}$ & $\begin{array}{l}\text { Q: The flagship. It's an eye-opener to realise } \\
\text { that behind the scene its actually not going } \\
\text { that well. It's a matter of communication and } \\
\text { it's a matter of } \\
\text { incompetence }\end{array}$ & \\
\hline
\end{tabular}




\begin{tabular}{|c|c|c|c|}
\hline \multicolumn{4}{|c|}{ Expectation: Formal work environment } \\
\hline GROUNDED & 6 & DENSITY & 3 \\
\hline BF & BM & WM & WF \\
\hline $\begin{array}{l}\text { Q: Now, when time went on, I was like 'I'm } \\
\text { back where I was, I'm still working as a staff } \\
\text { member'. }\end{array}$ & $\begin{array}{l}\text { Q; I did not expect the content of the } \\
\text { language. The language that is being used. } \\
\text { The swearing } \\
\text { Q: I expected a more professional } \\
\text { environment, } \\
\text { Q: So you expected to communicate } \\
\text { professionally with staff? - Yes } \\
\text { Q: In other companies admin training is done } \\
\text { at head office }\end{array}$ & $\begin{array}{l}\text { Q: My first experience in the organisation, is } \\
\text { that I had this big expectation that it is a } \\
\text { proper environment }\end{array}$ & \\
\hline
\end{tabular}

\begin{tabular}{|c|c|c|c|}
\hline \multicolumn{4}{|c|}{ Expectation: Proper management } \\
\hline GROUNDED & 4 & DENSITY & 3 \\
\hline BF & BM & WM & WF \\
\hline & & & $\begin{array}{l}\text { Q: Ok, so would you say you expected bettel } \\
\text { management of your program? - Yes } \\
\text { Q: Ya, I mean if I do waste three times, for } \\
\text { three different departments, I think I know } \\
\text { how to do waste. Why do I need to continue } \\
\text { to do waste all the time? It is the work of the } \\
\text { manager in that department, actually, to } \\
\text { appoint someone or to do it themselves. }\end{array}$ \\
\hline
\end{tabular}




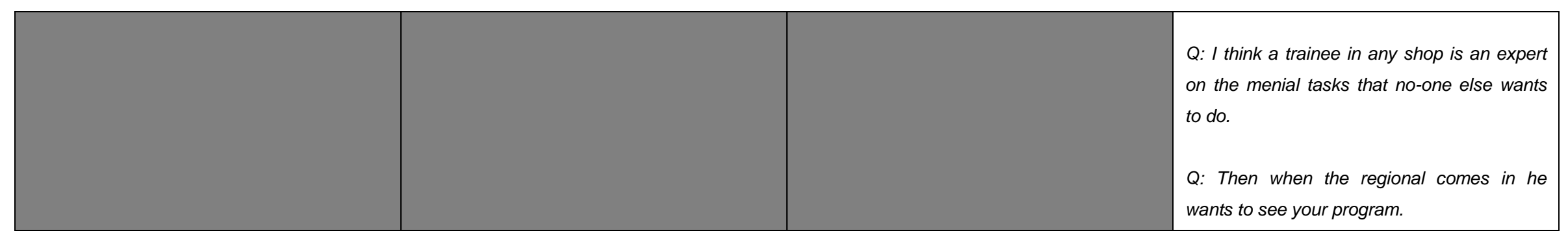

\begin{tabular}{|c|c|c|c|}
\hline \multicolumn{4}{|c|}{ Expectation: Teamwork } \\
\hline GROUNDED & 3 & DENSITY & 1 \\
\hline BF & $\overline{B M}$ & WM & WF \\
\hline & & $\begin{array}{l}\text { Q: I expected more teamwork. } \\
\text { Q: Definitely, because it is also, when you get } \\
\text { appointed, you get thrown into } \\
\text { the deep end, teamwork isn't always that } \\
\text { great because of race and all } \\
\text { that, } \\
\text { Q: I'm happy with the level of teamwork. }\end{array}$ & \\
\hline
\end{tabular}




\begin{tabular}{|c|l|c|l|}
\hline \multicolumn{5}{|c|}{ Expectation: Customer interaction } \\
\hline GROUNDED & 3 & \multicolumn{1}{|c|}{ DENSITY } & 2 \\
\hline BF & \multicolumn{1}{|c|}{ BM } & \multicolumn{1}{|c|}{ WF } \\
\hline & $\begin{array}{l}\text { Q: Since we are dealing with staff I was } \\
\text { expecting more of like customer interaction; I } \\
\text { also agree }\end{array}$ & handling customers \\
\hline
\end{tabular}

\begin{tabular}{|c|l|c|c|}
\hline \multicolumn{5}{|c|}{ Expectation: Communication skills } \\
\hline GROUNDED & 2 & DENSITY & 1 \\
\hline BF & \multicolumn{1}{|c|}{ BM } & WM & WF \\
\hline & Q: When I communicate with my staff & & \\
& Q: skills like communicating with staff & & \\
\hline
\end{tabular}

\begin{tabular}{|c|c|c|c|}
\hline \multicolumn{4}{|c|}{ Expectation: Technical skills training } \\
\hline GROUNDED & 2 & DENSITY & 1 \\
\hline BF & $\overline{B M}$ & WM & $\overline{\text { WF }}$ \\
\hline & & & $\begin{array}{l}\text { Q: So you expected the technical skills like for } \\
\text { example how to bake bread, but then also } \\
\text { how to manage the person that bakes the } \\
\text { bread. - Yes } \\
\text { Q: Yes. I'm double checking at the moment, } \\
\text { but that is not all that receiving is about. So } \\
\text { I'm not actually learning anything about } \\
\text { receiving. }\end{array}$ \\
\hline
\end{tabular}




\begin{tabular}{|c|c|c|c|}
\hline \multicolumn{5}{|c|}{ Expectation: Leadership from superiors } \\
\hline GROUNDED & 1 & \multicolumn{1}{c|}{ DENSITY } & \multicolumn{1}{c|}{ WM } \\
\hline BF & BM & $\begin{array}{l}\text { Q: I expected more leadership from the } \\
\text { managers above. }\end{array}$ & WF \\
\hline & &
\end{tabular}

\begin{tabular}{|c|c|c|c|}
\hline \multicolumn{4}{|c|}{ Positive interactions } \\
\hline GROUNDED & 37 & DENSITY & 10 \\
\hline BF & BM & WM & WF \\
\hline $\begin{array}{l}\text { Q: I don't want to say I'm slow, but some of } \\
\text { the other trainees know things more than I do. } \\
\text { They pick up information better than I do, so } \\
\text { sometimes I just feel like I don't know. I do get } \\
\text { support from the other trainee, } \\
\text { M: Here the participant explains that support } \\
\text { is not only necessary between trainees, but } \\
\text { between everyone in the store. } \\
\text { M: The candidate mentions that there is } \\
\text { positive interaction, but only on personal } \\
\text { level. She states that teamwork is not } \\
\text { encouraged. } \\
M(x 3) \text { : In this statement the participant } \\
\text { indicates that interactions with fellow } \\
\text { participants addressed the need for support. }\end{array}$ & $\begin{array}{l}\text { Q: My experience with ladies is no problem } \\
\text { because as I would say like almost always I } \\
\text { was surrounded by trainee ladies, because } \\
\text { like I was the only guy in the store of the } \\
\text { trainees. So when it is time to eat, I don't like } \\
\text { eating alone, but later I would just see them } \\
\text { as my friends like guys. We would do things } \\
\text { together. } \\
\text { Q: Even in our store, we are treated like } \\
\text { brothers and sisters. } \\
\text { Q: Yes, we agree. }\end{array}$ & $\begin{array}{l}\text { M: The candidate indicates here that } \\
\text { subordinates only comply when they officially } \\
\text { get authority and is seen as an appointed } \\
\text { manager. } \\
\text { Q: I was fortunate enough to follow in my } \\
\text { esteemed colleague's footsteps. } \\
\text { Q: Ya, A and B, and some of the other guys. I } \\
\text { came in here, they took me in and did a little } \\
\text { induction, then as I went through my } \\
\text { departments they said this is how it works, } \\
\text { this is what they want. } \\
\text { M: The participant indicates here that he feels } \\
\text { that they are treated well overall, and that } \\
\text { they receive equal treatment. In some cases, } \\
\text { however, they are told not to ask certain } \\
\text { questions, and just to comply. }\end{array}$ & $\begin{array}{l}\text { Q: I agree with B, but like, I don't think we do } \\
\text { better or worse than the fellow trainees, } \\
\text { because I think it balances out. Say we are } \\
\text { both in the service department for instance } \\
\text { and I had a question that I asked which that } \\
\text { person didn't think about, but they are with } \\
\text { me when I ask the question, then they are } \\
\text { also learning, and vice versa. } \\
\text { M: This statement gives an indication that the } \\
\text { candidate required structure and guidance, } \\
\text { and received that through positive } \\
\text { interactions. } \\
\text { M: The participant indicates here that some } \\
\text { staff members do co-operate, but others } \\
\text { don't. The reason she provides is that she } \\
\text { feels the staff sees her as someone who will } \\
\text { not be sticking around. }\end{array}$ \\
\hline
\end{tabular}




\begin{tabular}{|c|c|c|c|}
\hline \multicolumn{4}{|c|}{ Positive interactions } \\
\hline GROUNDED & 37 & DENSITY & 10 \\
\hline BF & BM & WM & WF \\
\hline $\begin{array}{l}\text { Q: Yes because they might help you with stuff } \\
\text { which you have not picked up while you were } \\
\text { still training, }\end{array}$ & & $\begin{array}{l}\text { M: The candidate explains here that he has } \\
\text { received good treatment and support from } \\
\text { seniors and fellow participants. } \\
\text { Q: Well overall treatment has been good so } \\
\text { far. } \\
\text { M: The candidate explains here that he has } \\
\text { received good treatment and support from } \\
\text { seniors and fellow participants. } \\
\text { Q: It comes from different sides, from } 2 \\
\text { different sides. Sometime you get some of the } \\
\text { managers who will be like that and then some } \\
\text { who are not. So I don't want to make a } \\
\text { generalization. You don't feel like that } \\
\text { because it doesn't come from all sides. } \\
\text { Q: I don't think it's a case of spoiling; it's just } \\
\text { carrying on that protective thing and helping } \\
\text { each other on. } \\
\text { M: The participant explains here that positive } \\
\text { interactions is good in terms of support, but } \\
\text { this may also lead to incorrect knowledge } \\
\text { transfer. }\end{array}$ & $\begin{array}{l}\text { Q: I didn't have fellow trainees when I was } \\
\text { training but I was successful in the program } \\
\text { because I was included in the management } \\
\text { group. I was part of management. } \\
\text { M: In this statement the participant indicates } \\
\text { that she genrally feels included but that there } \\
\text { is still an element of racial clicking. } \\
\text { Q: We in the training group are more like a } \\
\text { team rather than an individual we are each } \\
\text { other we trainee each other rather than, like } \\
\text { the trainer in that department. They know } \\
\text { what you go through and they know what } \\
\text { you're struggling with so it's easy to relate to } \\
\text { each other. } \\
\text { Q: I think we just got to know each other from } \\
\text { working together so many hours. } \\
\text { M: In this statement the candidate indicates } \\
\text { that she experiences positive interactions with } \\
\text { subordinates as a manager, rather than as a } \\
\text { leader. }\end{array}$ \\
\hline
\end{tabular}




\begin{tabular}{|c|c|c|c|}
\hline \multicolumn{4}{|c|}{ Positive interactions } \\
\hline GROUNDED & 37 & DENSITY & 10 \\
\hline BF & BM & WM & WF \\
\hline & & $\begin{array}{l}\text { M: In this statement the candidate indicates } \\
\text { that he got better co-operation with fellow } \\
\text { participants of a different race. }\end{array}$ & $\begin{array}{l}\text { Ya } \\
\text { M: In this statement the participant indicates } \\
\text { that positive interaction with fellow } \\
\text { participants is necessary for successful } \\
\text { completion. The reason she provides is that is } \\
\text { serves as a good substitute for senior } \\
\text { coaching. } \\
\text { M: The participant indicates here that positive } \\
\text { interactions with fellow participants will still be } \\
\text { beneficial, even if coaching and mentoring } \\
\text { occurs at an optimum level. } \\
\text { Q: In a way - I started out as a receiving } \\
\text { admin clerk - and I grew from there, by } \\
\text { learning how to work with the people and how } \\
\text { to give the respect they need, to give you the } \\
\text { respect and that is how they build me up } \\
\text { Q: I also agree with them, because when I } \\
\text { started all the other trainees would go and } \\
\text { write tests and report back to you and tell you } \\
\text { have to know this, you have to know this, } \\
\text { make sure you know all about this, you must } \\
\text { know it all by heart. }\end{array}$ \\
\hline
\end{tabular}




\begin{tabular}{|c|c|c|c|}
\hline \multicolumn{4}{|c|}{ Positive interactions } \\
\hline GROUNDED & 37 & DENSITY & 10 \\
\hline BF & BM & WM & $\overline{\text { WF }}$ \\
\hline & & & $\begin{array}{l}\text { M: The participant indicates here that some } \\
\text { staff members do co-operate, but others } \\
\text { don't. } \\
\text { M: Here the participant explains that she } \\
\text { learnt more from fellow participants. }\end{array}$ \\
\hline
\end{tabular}

\begin{tabular}{|c|c|c|c|}
\hline \multicolumn{4}{|c|}{ On-the-job training } \\
\hline GROUNDED & 26 & DENSITY & 10 \\
\hline BF & BM & WM & WF \\
\hline $\begin{array}{l}\text { M: The participant indicates here that she } \\
\text { feels that currently the OTJ is very valuable as } \\
\text { it offers a practical foundation. } \\
\text { Q: What impact has OJT had on your } \\
\text { development? - On the job learning is the } \\
\text { best way to learn how to manage staff. } \\
\mathrm{M}(\times 3) \text { : In this statement the candidate } \\
\text { explains that she experiences classroom } \\
\text { sessions to be very rewarding, as well as OJT, } \\
\text { but that the mentoring was lacking. }\end{array}$ & $\begin{array}{l}\text { M: This statement indicates that the candidate } \\
\text { grew from OJT, but there was not clarity on } \\
\text { whether this growth was as a manager or } \\
\text { leader. } \\
\text { M: He the candidate indicates that OJT aided } \\
\text { in the development need of managing people } \\
\text { was addressed and has, as a result, grown. } \\
\text { Q: On this program, you get exposed to } \\
\text { working long hours, and you are under real } \\
\text { pressure, you are required to work under } \\
\text { those circumstances. } \\
\text { Q: in-store training and interacting with }\end{array}$ & $\begin{array}{l}\text { M: The participant indicates here that OJT was } \\
\text { more beneficial than formalised "academic" } \\
\text { exercises. } \\
\text { M: The candidate indicates here that } \\
\text { disruptions to set program may be beneficial, } \\
\text { depending on your own attitude and approach. } \\
\text { Q: In-store training. I learnt more from on-the- } \\
\text { job training than from the assignments. } \\
\text { M: The candidate experiences the learning } \\
\text { material as being redundant and says that one } \\
\text { learns more from OJT and coaching. }\end{array}$ & $\begin{array}{l}\text { M: The participant indicates here that } \\
\text { classroom learning was more beneficial to her } \\
\text { than the OJT. } \\
\text { M: In this statement the participant explains } \\
\text { that she feels assessment is based on } \\
\text { demonstration of management competence } \\
\text { and not content. There is also an indication } \\
\text { that she feels the content does not adequately } \\
\text { prepare or lead to this competence. } \\
\text { Q: I think doing the hands-on job is better than } \\
\text { reading, because if you are reading it tells you } \\
\text { how to do it, but when you do it you know that } \\
\text { you can actually do it. }\end{array}$ \\
\hline
\end{tabular}




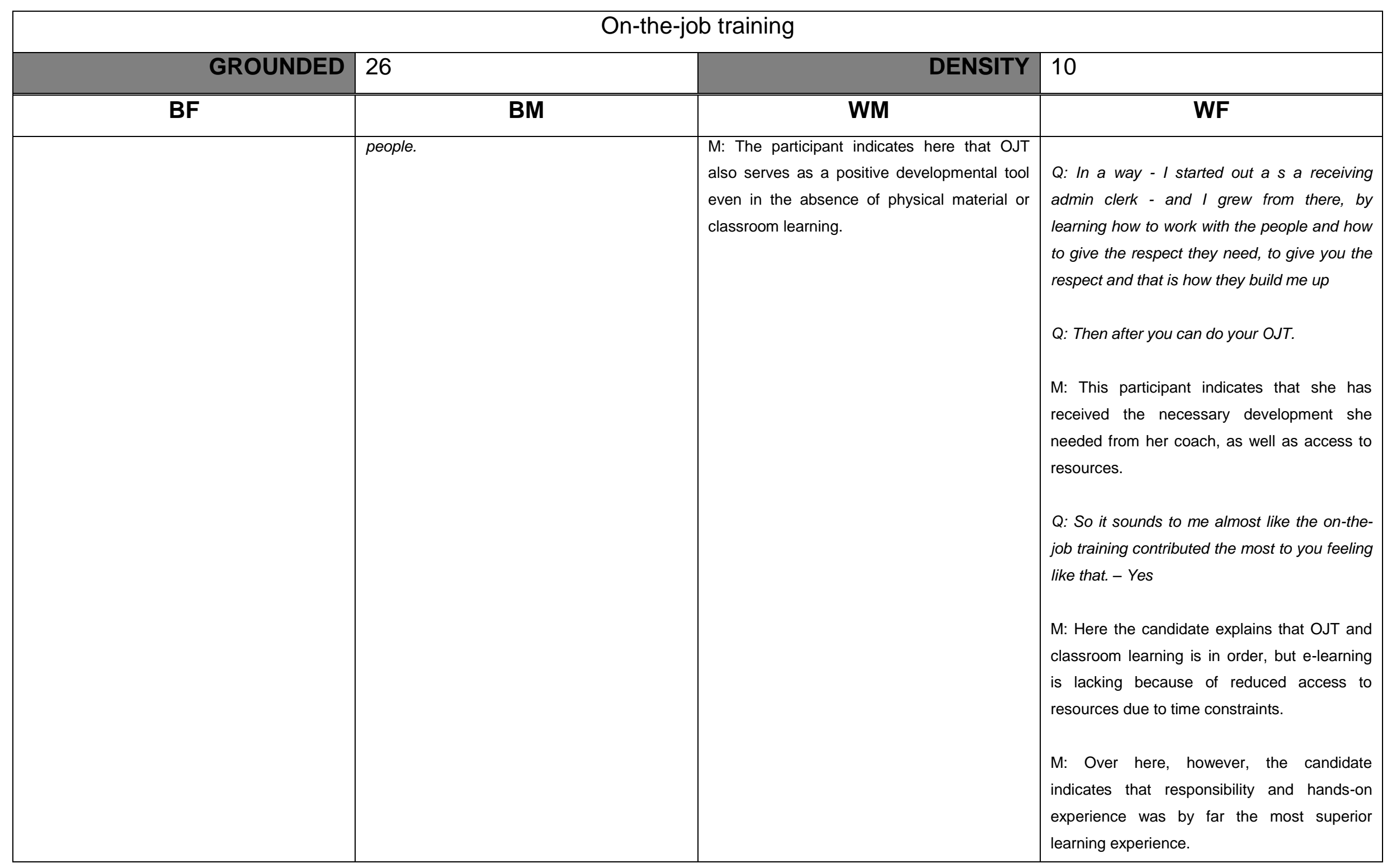




\begin{tabular}{|c|c|c|c|}
\hline \multicolumn{4}{|c|}{ On-the-job training } \\
\hline GROUNDED & 26 & DENSITY & 10 \\
\hline BF & BM & WM & $\overline{\text { WF }}$ \\
\hline & & & $\begin{array}{l}\text { Q: When I was training, to be straight honest, I } \\
\text { learnt more in the store where I was training. } \\
\text { This is because they were including me in } \\
\text { everything that was happening }\end{array}$ \\
\hline
\end{tabular}

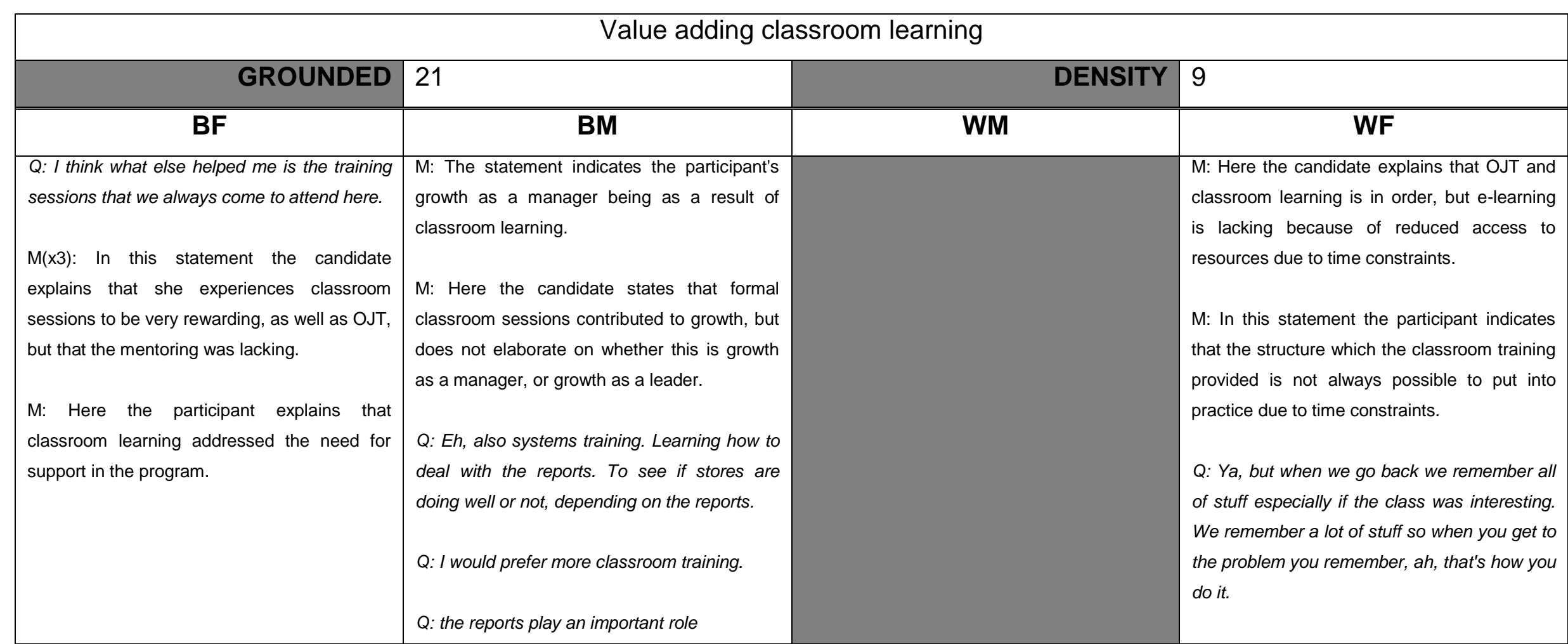




\begin{tabular}{|c|c|c|c|}
\hline \multicolumn{4}{|c|}{ Value adding classroom learning } \\
\hline GROUNDED & 21 & DENSITY & 9 \\
\hline BF & BM & WM & WF \\
\hline & $\begin{array}{l}\text { M: In this section, the candidate expresses the } \\
\text { perception that formal classroom learning } \\
\text { addressed developmental needs by providing } \\
\text { structure during the program. } \\
\text { M: In this section the participant indicates that } \\
\text { development needs were met through } \\
\text { classroom learning. } \\
\text { M: The candidate indicates here the } \\
\text { classroom learning has contributed to growth, } \\
\text { but however, was not always aligned with } \\
\text { what is going on in practice. The participant } \\
\text { was also not always able to apply the newly } \\
\text { acquired knowledge. }\end{array}$ & & $\begin{array}{l}\text { Q: So classroom sessions are a necessary } \\
\text { basis? - Yes } \\
\text { M: The participant explains here that in some } \\
\text { instances where coaching and support was } \\
\text { lacking, classroom learning provided some } \\
\text { structure in its absence. } \\
\text { M: In this statement the candidate indicates } \\
\text { that classroom learning has been beneficial in } \\
\text { the sense that it provided structure and } \\
\text { opportunity to reflect on learning. } \\
\text { M: The participant indicate here that } \\
\text { classroom learning was more beneficial to her } \\
\text { than the OJT. } \\
\text { M: Here the candidate indicates that } \\
\text { classroom learning provided structure. }\end{array}$ \\
\hline
\end{tabular}




\begin{tabular}{|c|c|c|c|}
\hline \multicolumn{4}{|c|}{ Training material } \\
\hline GROUNDED & 12 & DENSITY & 7 \\
\hline BF & BM & WM & WF \\
\hline $\begin{array}{l}\text { M: In this statement the candidate indicates } \\
\text { that the training material helped her a lot in } \\
\text { overcoming some challenges during the } \\
\text { training process. } \\
\text { M: The candidate explains here that the } \\
\text { training material assisted with development. } \\
\text { M: In this statement the candidate indicates } \\
\text { that the content of learning material is } \\
\text { beneficial, but only if it can be subsequently } \\
\text { applied. } \\
\text { Q: the manuals I got at the training, they } \\
\text { helped me a lot. } \\
\text { M: In this statement the candidate indicates } \\
\text { that the training material assisted when there } \\
\text { was no coach/mentor to assist. }\end{array}$ & $\begin{array}{l}\text { M: The candidate indicates that the learning } \\
\text { material does not sufficiently address all } \\
\text { issues pertaining to people management skills } \\
\text { needs. } \\
\text { M: The candidate expresses in this section } \\
\text { that the content of the learning material } \\
\text { assisted with his growth/development, but } \\
\text { does not elaborate on whether this growth is } \\
\text { as a manager or as a leader. } \\
\text { M: The candidate indicates that the content of } \\
\text { the training material addresses developmental } \\
\text { needs. }\end{array}$ & $\begin{array}{l}\text { M: The candidate indicates here that the } \\
\text { content of the program assisted with growth. } \\
\text { Q: The biggest thing on the content is that it } \\
\text { does not match up to the assessment. That is } \\
\text { my biggest concern. It takes you hours and } \\
\text { hours to finish the assignments, but its } \\
\text { duplication that you are doing. Most of the } \\
\text { stuff they ask you is stuff that's on the system. } \\
\text { Now you must go complete an assignment } \\
\text { that takes you two hours, just because } \\
\text { somebody wants you to do it but nobody is } \\
\text { checking it, so why must you do it? } \\
\text { M: The candidate indicates here that he } \\
\text { experiences the content to be a lot of } \\
\text { duplication. }\end{array}$ & $\begin{array}{l}\text { M: The participant indicates here that training } \\
\text { material is useful, but coaching and support is } \\
\text { still necessary to make for a sensible learning } \\
\text { experience. } \\
\text { M: Here the candidate explains that the } \\
\text { content of the training material has provided } \\
\text { her with information she needed to grow into } \\
\text { the role of leader. } \\
\text { M: In this statement, the candidate indicates } \\
\text { that the available material was not utilised } \\
\text { properly, and that in doing assignments and } \\
\text { following set structures was experienced a s a } \\
\text { waste of time. }\end{array}$ \\
\hline
\end{tabular}




\begin{tabular}{|c|c|c|c|}
\hline \multicolumn{4}{|c|}{ Growth } \\
\hline GROUNDED & 22 & DENSITY & 11 \\
\hline BF & BM & WM & WF \\
\hline $\begin{array}{l}\text { Q: I can say, um, my skills. I can say, now, my } \\
\text { admin skills, you know. My PC skills, my } \\
\text { admin skills, my manage skills. It has } \\
\text { developed a lot. The contents has had an } \\
\text { impact on that development. } \\
\text { Q: I can say that I have grown, because firstly, } \\
\text { I have seen the importance of leading by } \\
\text { example as a manager. } \\
\text { Q: I was very shy, I could not talk in front of } \\
\text { people, but then now, I am able to give } \\
\text { instructions. Mainly because of the "Managing } \\
\text { people for profit" course. } \\
\text { M: In this statement the candidate indicates } \\
\text { that the training material assisted when there } \\
\text { was no coach/mentor to assist. }\end{array}$ & $\begin{array}{l}\text { M: Here the candidate states that formal } \\
\text { classroom sessions contributed to growth, but } \\
\text { does not elaborate on whether this is growth } \\
\text { as a manager, or growth as a leader. } \\
\text { M: In this section, the candidate expresses the } \\
\text { perception that formal classroom learning } \\
\text { addressed developmental needs by providing } \\
\text { structure during the program. } \\
\text { M: This statement indicates that the candidate } \\
\text { grew from OJT, but there was not clarity on } \\
\text { whether this growth was as a manager of } \\
\text { leader. } \\
\text { Q: Ya, where I've like grew } \\
\text { M: The participant indicates here that he has } \\
\text { recently been moved to a branch where he } \\
\text { receives support from fellow trainees and this } \\
\text { has assisted with growth. } \\
\text { M: The candidate expresses in this section } \\
\text { that being given responsibility assisted with } \\
\text { his growth/development, but does not } \\
\text { elaborate on whether this growth is as a } \\
\text { manager or as a leader. }\end{array}$ & $\begin{array}{l}\text { Q: So are you saying that the larger amounts } \\
\text { of pressure force you to develop as a } \\
\text { manager? - Yes, that and the increased } \\
\text { responsibilities. } \\
\text { Q: My sales manager was on leave for two } \\
\text { weeks and I learned from that. } \\
\text { Q: I agree with K. They throw you into the } \\
\text { deep end and you have to swim. You have no } \\
\text { choice. } \\
\text { M: The candidate indicates here that the } \\
\text { content of the program assisted with growth. }\end{array}$ & $\begin{array}{l}\text { M: Here the participant explains that she } \\
\text { learnt more from fellow participants. } \\
\text { M: Over here, however, the candidate } \\
\text { indicates that responsibility and hands-on } \\
\text { experience was by far the most superior } \\
\text { learning experience. } \\
\text { Q: In a way - I started out a s a receiving } \\
\text { admin clerk - and I grew from there, by } \\
\text { learning how to work with the people and how } \\
\text { to give the respect they need, to give you the } \\
\text { respect and that is how they build me up } \\
\text { M: Here the candidate indicates that the } \\
\text { interactions and observation of various } \\
\text { managers made her grow into the person she } \\
\text { is today. }\end{array}$ \\
\hline
\end{tabular}




\begin{tabular}{|c|l|c|c|}
\hline \multicolumn{5}{|c|}{ Growth } & DENSITY & 11 \\
\hline GROUNDED & 22 & WM & \\
\hline BF & BM & & \\
\hline & Q: The skill that / grew in most & & \\
\hline
\end{tabular}

\begin{tabular}{|c|c|c|c|}
\hline \multicolumn{4}{|c|}{ Grown as a manager } \\
\hline GROUNDED & 16 & DENSITY & 9 \\
\hline BF & BM & WM & WF \\
\hline
\end{tabular}




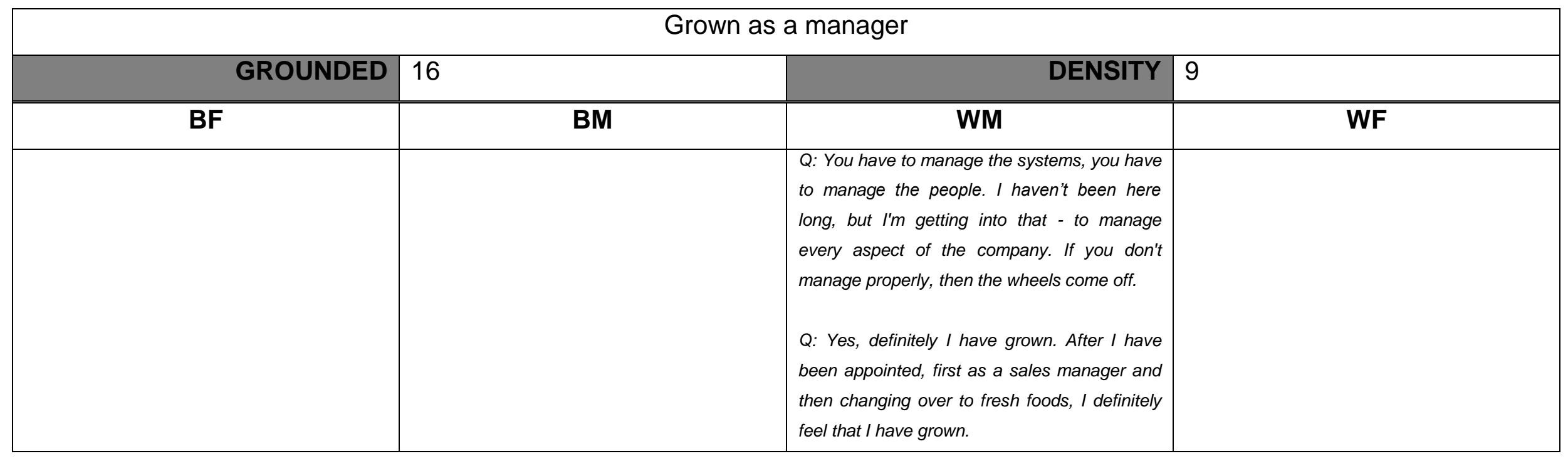

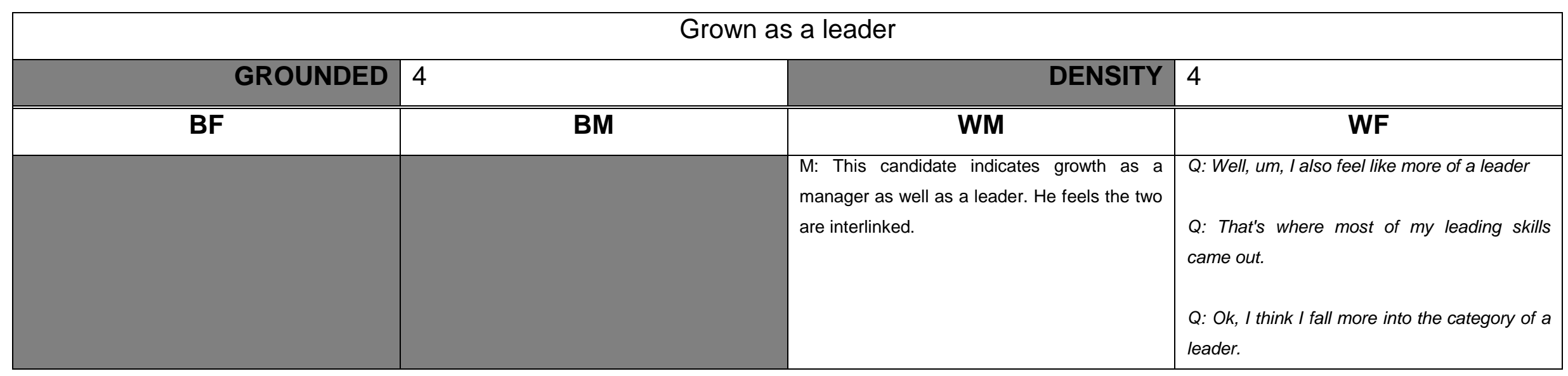




\begin{tabular}{|c|c|c|c|}
\hline \multicolumn{4}{|c|}{ Own behaviour affects outcome } \\
\hline GROUNDED & 22 & DENSITY & 6 \\
\hline BF & BM & WM & WF \\
\hline & $\begin{array}{l}\text { Q: I think it's the manner of giving instruction. } \\
\text { Each person has their own way of giving } \\
\text { instruction, so the language that they are } \\
\text { using, that is where the problem comes. } \\
\text { Sometimes, maybe the way they approach } \\
\text { those old ladies, that is the problem (x2) } \\
\text { Q: There is something you have to understand } \\
\text { about black people. It depends on sometimes } \\
\text { if they liked you the first time they saw you. If } \\
\text { you've got } 5 \text { trainees in the store, they won't } \\
\text { like all of us. If they don't like you from the } \\
\text { beginning, they will say 'you are not even the } \\
\text { age of my first born so why are you telling me } \\
\text { what to do'. But if you speak polite to them } \\
\text { they will do what you tell them to do. } \\
\text { Q: To be on my experience somebody to give } \\
\text { you respect, actually we don't just demand } \\
\text { respect form the staff, and we earn the } \\
\text { respect from the staff, by respecting them. } \\
\text { Q: Do you therefore feel that your treatment } \\
\text { as a trainee greatly depends on your own } \\
\text { attitude? - Yes (x11) }\end{array}$ & $\begin{array}{l}\text { Q: If I can just add to what E said. We did } \\
\text { experience with some of the trainees we } \\
\text { worked with is that attitude was a big problem. } \\
\text { The trainees' attitudes towards other trainees. } \\
\text { You make difficult for yourself, because that is } \\
\text { the people who is going to help you in the } \\
\text { future, so that can be like career suicide also. } \\
\text { Q: I don't agree with what } H \text { is saying. It also } \\
\text { depends on how you stamp down your } \\
\text { authority because you don't really have that } \\
\text { big authority. Also, I agree it will depend from } \\
\text { different people if how you, um, approach the } \\
\text { people or get information } \\
\text { Q: Do the rest of you feel that that is a } \\
\text { legitimate assumption to make - that if a } \\
\text { manager or controller who is supposed to } \\
\text { share knowledge with you do not like you that } \\
\text { they might be reluctant to... - Yes (x3) } \\
\text { M: The candidate indicates here that you } \\
\text { could go into the task/activity with the best } \\
\text { attitude, but if you are not managed properly, } \\
\text { you will not benefit. } \\
\text { Q: I do agree with what } K \text { said. If you come }\end{array}$ & $\begin{array}{l}\text { Q: In a way - I started out a s a receiving } \\
\text { admin clerk - and I grew from there, by } \\
\text { learning how to work with the people and how } \\
\text { to give the respect they need, to give you the } \\
\text { respect and that is how they build me up } \\
\text { Q: I agree with her in the sense that you never } \\
\text { get recognised for the things you do right. It's } \\
\text { always just like 'you didn't do this, you didn't } \\
\text { do that'. So it's demotivating and I think that } \\
\text { counts for staff members as well. } \\
\text { Q: What I learnt in my program, is respect. If } \\
\text { you don't respect your colleagues, they will not } \\
\text { respect you. But as a management, respect } \\
\text { can go that far } \\
\text { Q: I think if you have a quite bossy attitude } \\
\text { they will tell you they want to do it their way, } \\
\text { but if you ask them nicely and lead by } \\
\text { example they will get used to your way. } \\
\text { Q: In general, in our company we have a really } \\
\text { bad way of speaking to our staff. You won't } \\
\text { get co-operation that way, you will lose all your } \\
\text { staff that way. }\end{array}$ \\
\hline
\end{tabular}




\begin{tabular}{|c|c|c|c|}
\hline \multicolumn{4}{|c|}{ Own behaviour affects outcome } \\
\hline GROUNDED & 22 & DENSITY & 6 \\
\hline BF & (BM & WM & WF \\
\hline & & $\begin{array}{l}\text { here with a cocky attitude, if you come here, } \\
\text { how can I say, if you come here with an } \\
\text { attitude that "I am here to learn and it's your } \\
\text { job to learn me so stick to it", then it's career } \\
\text { suicide. } \\
\text { Q: I think about your attitude as well. How you } \\
\text { treat them as well. } \\
\text { Q: If you shout at your staff all day, what } \\
\text { respect will they have for you? } \\
\text { Q: I think a big part of the way you are being } \\
\text { treated is the first impression you make, } \\
\text { because I always say first impressions last } \\
\text { forever, so if you give a bad first impression to } \\
\text { someone you don't know you're not going to } \\
\text { get treated very well because you don't like } \\
\text { the guy from the beginning. } \\
\text { Q: Ok, that's an interesting approach. Who } \\
\text { would agree that your own behaviour affects } \\
\text { your treatment? - Me (x4) } \\
\text { M: The candidate indicates here that } \\
\text { disruptions to set program may be beneficial, } \\
\text { depending on your own attitude and approach. }\end{array}$ & \\
\hline
\end{tabular}




\begin{tabular}{|c|c|c|c|c|}
\hline \multicolumn{2}{|c|}{ GROUNDED } & 22 & Own behaviour affects outcome & WM \\
\hline \hline BF & & DM & $\begin{array}{l}\text { M: This candidate explains here that he } \\
\text { experienced resistance from staff as a result } \\
\text { of a poor attitude. }\end{array}$ & $\begin{array}{l}\text { Q: Definitely ya, but I think most of the people } \\
\text { see that as a waste of their time. I don't think } \\
\text { they actually open themselves up to grow from } \\
\text { that experience. }\end{array}$ \\
\hline
\end{tabular}

\begin{tabular}{|c|c|c|c|}
\hline \multicolumn{4}{|c|}{ Received responsibility } \\
\hline GROUNDED & 21 & DENSITY & 10 \\
\hline BF & BM & WM & $\overline{\text { WF }}$ \\
\hline $\begin{array}{l}\text { Q: The branch I was working in I felt more like } \\
\text { I was a staff member because of the things I } \\
\text { was doing there. But since I moved to another } \\
\text { branch I feel like I am in charge. I feel like I've } \\
\text { developed enough to be a manager. }\end{array}$ & $\begin{array}{l}\text { M: The participant indicates here that } \\
\text { receiving additional responsibility contradicted } \\
\text { the development need for sufficient time. } \\
\text { M: This statement indicates that receiving } \\
\text { responsibility assisted with the participant's } \\
\text { growth as a manager. } \\
\text { Q: I have been given an opportunity as well } \\
\text { M: The candidate expresses in this section } \\
\text { that being given responsibility assisted with }\end{array}$ & $\begin{array}{l}\text { M: The candidate indicates here that he felt he } \\
\text { had management responsibilities, even from } \\
\text { the beginning of the programme and that he } \\
\text { had to manage people. } \\
\text { Q: I think you grow as a manager when you } \\
\text { get appointed, because the gap is very big } \\
\text { between trainee and being a manager. As } \\
\text { soon as you are appointed as manager you } \\
\text { get thrown into the deep side and you have to } \\
\text { manage' you have to pedal. }\end{array}$ & $\begin{array}{l}\text { Q: Well ya, you had to make sure certain } \\
\text { things were done and inspect on if it } \\
\text { was done correct, } \\
\text { M: Over here, however, the candidate } \\
\text { indicates that responsibility and hands-on } \\
\text { experience was by far the most superior } \\
\text { learning experience. } \\
\text { Q: Well, um, me having to run the department } \\
\text { or having to be with the manager and see } \\
\text { what she does so that when I go to my branch }\end{array}$ \\
\hline
\end{tabular}




\begin{tabular}{|c|c|c|c|}
\hline \multicolumn{4}{|c|}{ Received responsibility } \\
\hline GROUNDED & 21 & DENSITY & 10 \\
\hline BF & BM & WM & $\overline{\text { WF }}$ \\
\hline & $\begin{array}{l}\text { his growth/development, but does not } \\
\text { elaborate on whether this growth is as a } \\
\text { manager or as a leader. } \\
\text { Q: because maybe you got that instruction } \\
\text { from the branch manager for so and so to do } \\
\text { 1, 2, 3. } \\
\text { M: The candidate indicates that people } \\
\text { management skills was developed to such an } \\
\text { extent that he can manage his people better } \\
\text { than the branch manager, and therefore } \\
\text { received more responsibility. } \\
\text { M: This statement indicates that the candidate } \\
\text { feels being afforded increased responsibility, } \\
\text { meets developmental needs. } \\
\text { M: The candidate expresses concern here for } \\
\text { receiving responsibility for something he is not } \\
\text { fully prepared for yet. }\end{array}$ & $\begin{array}{l}\text { Q: I agree with K. They throw you into the } \\
\text { deep end and you have to swim. You have no } \\
\text { choice. } \\
\text { Q: My sales manager was on leave for two } \\
\text { weeks and I learned from that. } \\
\text { Q: I think why you grow as a manager when } \\
\text { you get appointed, is because you need } \\
\text { responsibility } \\
\text { M: The candidate indicates here that } \\
\text { subordinates only comply when they officially } \\
\text { get authority and is seen as an appointed } \\
\text { manager. } \\
\text { Q: So are you saying that the larger amounts } \\
\text { of pressure forces you to develop as a } \\
\text { manager? - Yes } \\
\text { Q: I spoke to some of the guys who's recently } \\
\text { been appointed. They can tell you the same, } \\
\text { that responsibility and accountability starts } \\
\text { when you get appointed. While you are in the } \\
\text { program you are not responsible. }\end{array}$ & $\begin{array}{l}\text { I know that this is what I should do. } \\
\text { M: In this statement the participant indicates } \\
\text { that she has grown from being assigned more } \\
\text { responsibility. }\end{array}$ \\
\hline
\end{tabular}




\begin{tabular}{|c|c|c|c|}
\hline \multicolumn{4}{|c|}{ Resistance from subordinates } \\
\hline GROUNDED & 18 & DENSITY & 9 \\
\hline BF & BM & WM & WF \\
\hline $\begin{array}{l}\text { Q: To add on C, yes we work very fine, but it's } \\
\text { about the staff and the customers. Sometimes } \\
\text { when a customer comes to you and explains a } \\
\text { problem then they say they want to talk to a } \\
\text { manager, and I say I am the manager and } \\
\text { when the white trainee manager walks past, } \\
\text { then they will explain to them. Even the staff. } \\
\text { Q: Do you feel that there is a perception } \\
\text { among some people that black females do not } \\
\text { have authority? - Yes (x6) } \\
\text { Q: I was telling this other girl, you are working } \\
\text { in the deli, please stop touching yourself, go } \\
\text { wash your hands. Then they will come back } \\
\text { and do it again and they will say I have a } \\
\text { problem with them. } \\
\text { M: The candidate explains that resistance } \\
\text { from staff may be due to a large age } \\
\text { difference. }\end{array}$ & $\begin{array}{l}\text { Q: What I experience in most of our stores is } \\
\text { maybe when you are giving another person an } \\
\text { instruction, because maybe you got that } \\
\text { instruction from the branch manager for so } \\
\text { and so to do 1, 2, 3. So when you tell that } \\
\text { person what to do, then they tell you, that } \\
\text { person how good is she or he and how long } \\
\text { has he or she been with the company so that } \\
\text { is the problem that we are facing. } \\
\text { Q: I've been told some things and when } \\
\text { coming to staff that are like the same age as } \\
\text { me, when I give instructions then they say oh } \\
\text { well you are just a trainee. } \\
\text { Q: If, like I said, if you have people working for } \\
\text { the company for the last } 25 \text { years, like for } \\
\text { instance the big stores, they will question } \\
\text { some things. }\end{array}$ & $\begin{array}{l}\text { M: The participant indicates here that he } \\
\text { experiences resistance from subordinates as } \\
\text { a result of racial tension. } \\
\text { M: The candidate indicates here that } \\
\text { subordinates only comply when they officially } \\
\text { get authority and is seen as an appointed } \\
\text { manager. } \\
\text { M: This candidate explains here that he } \\
\text { experienced resistance from staff as a result } \\
\text { of a poor attitude. }\end{array}$ & $\begin{array}{l}\text { Q: Yes, definitely. I think that is my main issue } \\
\text { at the moment. I can't be strict and say 'listen, } \\
\text { you WILL do it'. } \\
\text { M: The participant indicates here that some } \\
\text { staff members do co-operate, but others don't. } \\
\text { Q: Well ya, at the time, because it was still } \\
\text { really early in my program. } \\
\text { Q: I agree with her in the sense that you never } \\
\text { get recognised for the things you do right. It's } \\
\text { always just like 'you didn't do this, you didn't } \\
\text { do that'. So it's demotivating and I think that } \\
\text { counts for staff members as well. } \\
\text { Q: Staff members in a way are really harder in } \\
\text { a way because they don't listen to you. } \\
\text { M: The participant indicates here that some } \\
\text { staff members do co-operate, but others don't. } \\
\text { The reason she provides is that she feels the } \\
\text { staff sees her as someone who will not be } \\
\text { sticking around. } \\
\text { Q: In general, in our company we have a } \\
\text { really bad way of speaking to our staff. You }\end{array}$ \\
\hline
\end{tabular}




\begin{tabular}{|l|l|l|l|l|l|l}
\hline & won't get co-operation that way, you will lose \\
all your staff that way.
\end{tabular}

\begin{tabular}{|c|c|c|c|}
\hline \multicolumn{4}{|c|}{ Content/assessment mismatch } \\
\hline GROUNDED & 15 & DENSITY & 9 \\
\hline BF & BM & WM & WF \\
\hline
\end{tabular}




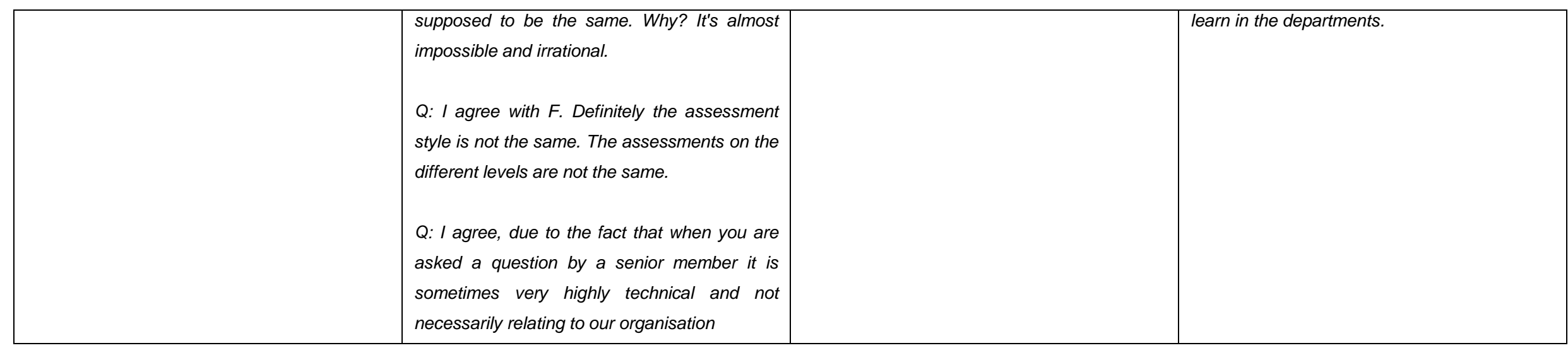

\begin{tabular}{|l|l|l|l|}
\hline \multicolumn{1}{|c|}{ GROUNDED } & 3 & Content/assessment correlation \\
\hline \hline \multicolumn{1}{|c|}{ BF } & BM & DENSITY & WM \\
\hline $\begin{array}{l}\text { Q: I've been for final assessment, but I } \\
\text { disagree because the assessor was asking me } \\
\text { stuff that I learnt in the store. }\end{array}$ & & WF \\
$\begin{array}{l}\text { Q: I say between the two there is a connection } \\
\text { Q: I've only been for formative assessment } \\
\text { and it's also not different from what I've } \\
\text { learned. }\end{array}$ & & \\
\hline
\end{tabular}




\begin{tabular}{|c|c|c|c|}
\hline \multicolumn{4}{|c|}{ Content/practice mismatch } \\
\hline GROUNDED & 10 & DENSITY & 5 \\
\hline BF & BM & WM & WF \\
\hline $\begin{array}{l}\text { Q: Um, for some of the ladies who have not } \\
\text { went to admin yet, do not understand me } \\
\text { when I say, the Admin file does not cover } \\
\text { everything (x5). }\end{array}$ & $\begin{array}{l}\text { Q: So when we try to implement, the branch } \\
\text { manager will say that it depends on the } \\
\text { branches. } \\
\text { Q: but what is happening is it is not happening } \\
\text { in the stores } \\
\text { Q: say you are training in the one department, } \\
\text { some of the stuff that you get in the manual, } \\
\text { it's not the stuff you get when you go to the } \\
\text { branch. } \\
\text { Q: I want to add to what E and C has said, } \\
\text { because if you look at, I have the one manual } \\
\text { and it only gives the basics, and it does not } \\
\text { give you the details of what is happening. } \\
\text { M: The candidate indicates here the } \\
\text { classroom learning has contributed to growth, } \\
\text { but however, was not always aligned with } \\
\text { what is going on in practice. The participant } \\
\text { was also not always able to apply the newly } \\
\text { acquired knowledge. } \\
\text { Q: Who else experiences a difference in what } \\
\text { is taught in class to what happens in the } \\
\text { branch? - Yes (x5) }\end{array}$ & $\begin{array}{l}\text { Q: How has the content of the program } \\
\text { assisted you with dealing with these } \\
\text { challenges? } \\
\text { Q: So for example, if a manager does not want } \\
\text { to assist you, you can't go and find that } \\
\text { information in your file? - No }\end{array}$ & $\begin{array}{l}\text { Q: Ya, it's not like we have the time to go and } \\
\text { sit and go through the material again and to } \\
\text { say, ok now I'm going to do this, but if the } \\
\text { class was interesting / will remember it. } \\
\text { M: In this statement the participant indicates } \\
\text { that the structure which the classroom training } \\
\text { provided is not always possible to put into } \\
\text { practice due to time constraints. }\end{array}$ \\
\hline
\end{tabular}




\begin{tabular}{|c|c|c|c|}
\hline \multicolumn{4}{|c|}{ Content/practice mismatch } \\
\hline GROUNDED & 10 & DENSITY & 5 \\
\hline BF & BM & WM & WF \\
\hline & $\begin{array}{l}\text { Q: So you get good guidelines, you get good } \\
\text { information, but you have a problem with } \\
\text { implementation? - Yes } \\
\text { M: The participant states here that sometimes } \\
\text { their program is properly managed and } \\
\text { sometimes it is not. In cases where the } \\
\text { programme is not properly managed, it results } \\
\text { in a content/practice mismatch because the } \\
\text { branch does not operate in accordance with } \\
\text { set company standard structures and } \\
\text { procedures. }\end{array}$ & & \\
\hline
\end{tabular}

\begin{tabular}{|l|l|l|l|}
\hline \multicolumn{2}{|c|}{ GROUNDED } & 13 & \\
\hline \multicolumn{1}{|c|}{ BF } & \multicolumn{1}{|c|}{ Access to resources } \\
\hline $\begin{array}{l}\text { M: In this statement the candidate explains } \\
\text { that she has a problem with access to } \\
\text { resources, especially e-learning resources. }\end{array}$ & $\begin{array}{l}\text { Q: One problem. Normally sometimes it } \\
\text { requires a password. So, we as trainees, we } \\
\text { don't have passwords. And sometimes they } \\
\text { don't want to give }\end{array}$ & WM & $\begin{array}{l}\text { M: The candidate explains that access to } \\
\text { resources is a problem because the resources } \\
\text { is used for both operations and training. }\end{array}$ \\
$\begin{array}{l}\text { Q: I can add on that, but most of our } \\
\text { managers don't even know what e-learning is. }\end{array}$ & $\begin{array}{l}\text { M: The candidate expresses concern here for } \\
\text { receiving responsibility for something he is not } \\
\text { fully prepared for yet. }\end{array}$ & $\begin{array}{l}\text { M: Here the candidate explains that OJT and } \\
\text { classroom learning is in order, but e-learning } \\
\text { is lacking because of reduced access to } \\
\text { resources due to time constraints. }\end{array}$ \\
\hline
\end{tabular}




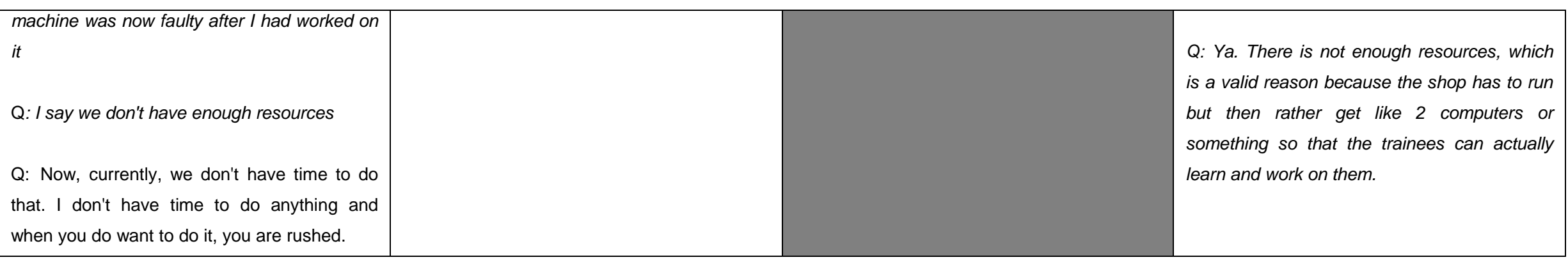

\begin{tabular}{|c|c|c|c|}
\hline \multicolumn{4}{|c|}{ Professional jealousy } \\
\hline GROUNDED & 13 & DENSITY & 8 \\
\hline BF & BM & WM & $\overline{\text { WF }}$ \\
\hline $\begin{array}{l}\text { M: Here the participant expresses a concern } \\
\text { about how their programme is managed and } \\
\text { that possible favouritism may lead to } \\
\text { professional jealousy (x2). } \\
\text { Q: I just feel than men, they can open up to } \\
\text { me. I can ask questions and you know we can } \\
\text { communicate better, but now with women I } \\
\text { don't know we have this thing where we are } \\
\text { looking at each other like no, she thinks she is } \\
\text { better. }\end{array}$ & $\begin{array}{l}\text { M: This statement indicates that the candidate } \\
\text { perceives a lack of mentoring being as a result } \\
\text { of professional jealousy. } \\
\text { Q: Ok, who else feels there is professional } \\
\text { jealousy? - Yes ( } x 11) \\
\text { M: The participant indicates that knowledge } \\
\text { transfer did not occur because of suspected } \\
\text { professional jealousy. }\end{array}$ & $\begin{array}{l}\text { Q: I also when I started felt that there is a lot of } \\
\text { professional jealousy, but your fellow trainees } \\
\text { they help you. When I started I was running up } \\
\text { and down like somebody that doesn't know } \\
\text { what to do, but I was guided by certain people. } \\
\text { Q: I think it's professional jealousy or } \\
\text { something like that. It's like I told you, after a } \\
\text { while, you start to know them and you are } \\
\text { more accepted }(x 3) \text {. }\end{array}$ & $\begin{array}{l}\text { Q: The girls are very jealous, I don't know why. } \\
\text { M: In this statement it would seem that the } \\
\text { participant experiences negative interaction } \\
\text { from same-gender participants as a result of } \\
\text { professional jealousy. } \\
\text { Q: One branch talks to the regional, the } \\
\text { regional talks to the other branch to sort it out } \\
\text { and then there is conflict because this branch } \\
\text { is talking about that branch and that branch is } \\
\text { talking about this branch. } \\
\text { Q: The guys will also come to you and assist } \\
\text { you. The ladies it's not like they won't help } \\
\text { you, if you ask them, but they won't come to } \\
\text { you. They guys will come out of their own. }\end{array}$ \\
\hline
\end{tabular}




\begin{tabular}{|c|c|c|c|}
\hline \multicolumn{4}{|c|}{ Differential treatment } \\
\hline GROUNDED & 11 & DENSITY & 3 \\
\hline BF & BM & WM & WF \\
\hline $\begin{array}{l}\text { M: The candidate explains here that she } \\
\text { perceives resistance from staff to be due to } \\
\text { her race and gender. } \\
\text { M: Here the candidate explains that some } \\
\text { managers would treat her fairly and } \\
\text { communicate. Others will not. } \\
\text { M: In this statement the candidate expresses a } \\
\text { concern for possible nepotism (x2). } \\
\text { Q: I feel that in this organisation that the title } \\
\text { trainee manager, when ever they feel like it } \\
\text { you are a trainee manager, only, whenever it } \\
\text { suits them, whenever they know you have to } \\
\text { cover a certain space, you are a manager - } \\
\text { they cancel the trainee. }\end{array}$ & $\begin{array}{l}\text { Q: Now, my concern is, this guy he is always } \\
\text { in the branch with the branch manager, now } \\
\text { he doesn't do anything, he is always with the } \\
\text { branch manager. And now, the branch } \\
\text { manager is telling the guy that he must tell us } \\
\text { what to do. I mean, is that fair in that way? } \\
\text { Q: I know what he is talking about. I have } \\
\text { experienced it, and I am not the only person } \\
\text { who has experienced the same scenario he is } \\
\text { talking about. } \\
\text { Q: Ok, eh, on my side, I'm with F there. I'm the } \\
\text { only black person training with a white. With } \\
\text { the other trainees we are ok, but the problem } \\
\text { comes to the branch level. Because there are } \\
\text { some of the people who are favoured by the } \\
\text { branch manager } \\
\text { Q: Yes, I have experienced that, but in } \\
\text { different manner, not necessarily when I give } \\
\text { an instruction. In a way of that they have that } \\
\text { mentality that if I should say, white people are } \\
\text { still superior to black people } \\
\text { M: The participant indicates here that he } \\
\text { receives differential treatment from staff. His }\end{array}$ & $\begin{array}{l}\text { M: The participant indicates here that he } \\
\text { experiences resistance from subordinates as a } \\
\text { result of racial tension. } \\
\text { Q: Sometimes you are the only one from a } \\
\text { certain race group and then you might get } \\
\text { excluded from the group. } \\
\text { Q: Not even only staff, managers as well. I had } \\
\text { a problem in one of the departments where I } \\
\text { was training, where I would go to the sales } \\
\text { manager, uh, and you go past the specific } \\
\text { question about a really important point then } \\
\text { they can't answer you and she or he says they } \\
\text { don't have time or go and find out. ( } x 5 \text { ) } \\
\text { M: In this statement the candidate indicates } \\
\text { that he experienced a certain amount of } \\
\text { exclusion based on racial differences. }\end{array}$ & \\
\hline
\end{tabular}




\begin{tabular}{|c|c|c|c|}
\hline \multicolumn{4}{|c|}{ Differential treatment } \\
\hline GROUNDED & 11 & DENSITY & 3 \\
\hline BF & BM & WM & WF \\
\hline
\end{tabular}

\begin{tabular}{|c|c|c|c|}
\hline \multicolumn{4}{|c|}{ Equal treatment } \\
\hline GROUNDED & 10 & DENSITY & 4 \\
\hline BF & BM & WM & WF \\
\hline $\begin{array}{l}\text { Q: Treatment by managers I can say is more } \\
\text { or less fair } \\
\text { Q: I've even experience treatment like an } \\
\text { outsider in the store I am in. } \\
\text { Q: Sometimes with some of the line managers } \\
\text { they remind us 'you guys train lekker'. I don't } \\
\text { like it when say 'you are training very nice'. }\end{array}$ & $\begin{array}{l}\text { Q: My experience for me, having white and } \\
\text { blacks, I wouldn't say there is a problem } \\
\text { because our branch manager treats us the } \\
\text { same } \\
\text { Q: Who else experienced fair treatment } \\
\text { irrespective of race or gender? - Yes ( } x 7) \text {. } \\
\text { Q: I was talking about a previous situation just } \\
\text { now. It was a once off. In fact, that situation } \\
\text { was when we went to another store to go help. } \\
\text { I had that experience, but not in my current } \\
\text { store. } \\
\text { M: This statement indicates that the }\end{array}$ & $\begin{array}{l}\text { M: The participant indicates here that he feels } \\
\text { that they are treated well overall, and that they } \\
\text { receive equal treatment. In some cases, } \\
\text { however, they are told not to ask certain } \\
\text { questions, and just to comply (x2). } \\
\text { Q: Well overall treatment has been good so } \\
\text { far. }\end{array}$ & \\
\hline
\end{tabular}




\begin{tabular}{|c|c|c|c|}
\hline \multicolumn{4}{|c|}{ Equal treatment } \\
\hline GROUNDED & 10 & DENSITY & 4 \\
\hline BF & BM & WM & WF \\
\hline & $\begin{array}{l}\text { participant feels that his normal mentors treats } \\
\text { him fairly, but when assigned to a special } \\
\text { assignment those managers sometimes } \\
\text { mistreat. } \\
\text { Q: The treatment is fine. } \\
\text { Q: I think treatment of the managers is fair to } \\
\text { me because if you are a manager, if you are } \\
\text { going to teach either person you must know } \\
\text { exactly how to pack a shelf. }\end{array}$ & & \\
\hline
\end{tabular}

\begin{tabular}{|c|c|c|c|}
\hline \multicolumn{4}{|c|}{ Get along better with opposite sex } \\
\hline GROUNDED & 10 & DENSITY & 5 \\
\hline BF & BM & WM & WF \\
\hline
\end{tabular}




$\begin{aligned} & \text { Q: I also feel that way. I see it with the other } \\ & \text { trainees, but with the managers it is a different } \\ & \text { story. With managers it isn't a problem, but }\end{aligned}$
$\begin{aligned} & \text { with trainees it is better if you work with } \\ & \text { someone from the opposite gender. }\end{aligned}$

\begin{tabular}{|c|c|c|c|}
\hline \multicolumn{4}{|c|}{ Content not useful } \\
\hline GROUNDED & 8 & DENSITY & 2 \\
\hline BF & BM & WM & WF \\
\hline & & $\begin{array}{l}\text { Q: How has the content of the program } \\
\text { assisted you with dealing with challenges? - } \\
\text { Nothing (x2) } \\
\text { Q: No, what I found is that a lot of stuff that } \\
\text { you are trained in, detailed stuff, you won't find } \\
\text { in your file. Then you do your assessment and } \\
\text { you are being assessed on something totally } \\
\text { different. } \\
\text { M: The candidate indicates here that he } \\
\text { experiences the content to be a lot of } \\
\text { duplication (x5). } \\
\text { M: The candidate experiences the learning } \\
\text { material as being redundant and says that one } \\
\text { learns more from OJT and coaching. }\end{array}$ & \\
\hline
\end{tabular}




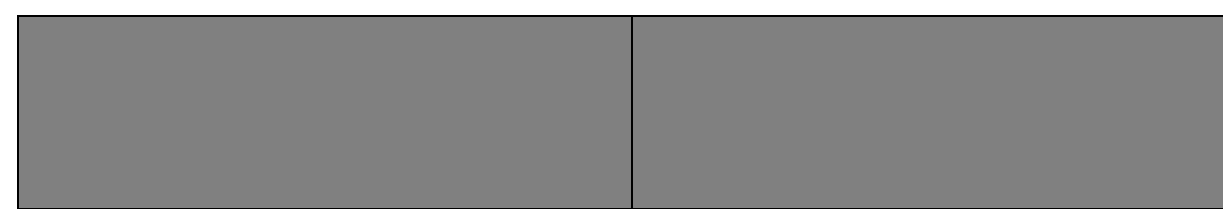

Q: I can say that say for instance you are a

year a trainee manager, then you get on a

classroom session and that training session

don't help you at all.

\begin{tabular}{|c|c|c|c|}
\hline \multicolumn{4}{|c|}{ Alienation } \\
\hline GROUNDED & 7 & DENSITY & 3 \\
\hline BF & BM & WM & WF \\
\hline & & $\begin{array}{l}\text { Q: I think it's only in the beginning when you } \\
\text { are not familiar with the people, but when you } \\
\text { start to know your fellow trainees it's going } \\
\text { much better. It's just in the beginning when } \\
\text { people are afraid to share. } \\
\text { M: In this statement the candidate indicates } \\
\text { that he experienced a certain amount of } \\
\text { exclusion based on racial differences. }\end{array}$ & $\begin{array}{l}\text { M: The participant explains here that alienation } \\
\text { took place due to her close association with } \\
\text { management. } \\
\text { M: In this statement the participant indicates } \\
\text { alienation as a result of racial differences. } \\
\text { M: In this statement the participant indicates } \\
\text { that racial cliques did form, but did not last. } \\
\text { M: In this statement the participant indicates } \\
\text { that she generally feels included but that there } \\
\text { is still an element of racial cliquing. } \\
\text { M: The participant indicates experiences of } \\
\text { racial cliquing. }\end{array}$ \\
\hline
\end{tabular}




\begin{tabular}{|c|c|c|c|}
\hline \multicolumn{4}{|c|}{ Racial tension } \\
\hline GROUNDED & 4 & DENSITY & 2 \\
\hline BF & BM & WM & WF \\
\hline
\end{tabular}

